\title{
DEVELOPMENT OF SUSTAINABLE CONCRETE BRIDGE DECK SLAB SYSTEMS USING CORROSION-RESISTANT GFRP BARS
}

\author{
by \\ Imad Eldin Ahmed Eisa Khalafalla \\ Bachelor of Science in Civil Engineering, University of Khartoum, Sudan, 1994 \\ Master of Applied Science in Civil Engineering, Ryerson University, Toronto, 2009
}

\author{
A Dissertation \\ presented to Ryerson University \\ in partial fulfillment of the \\ requirements for the degree of \\ Doctor of Philosophy \\ in the program of \\ Civil Engineering
}

Toronto, Ontario, Canada, 2014

CImad Eldin Khalafalla 2014 


\section{AUTHOR'S DECLARATION}

I hereby declare that I am the sole author of this dissertation. This is a true copy of the dissertation, including any required final revisions, as accepted by my examiners.

I authorize Ryerson University to lend this dissertation to other institutions or individuals for the purpose of scholarly research

I further authorize Ryerson University to reproduce this dissertation by photocopying or by other means, in total or in part, at the request of other institutions or individuals for the purpose of scholarly research.

I understand that my dissertation may be made electronically available to the public. 


\section{Development of Sustainable Concrete Bridge Deck Slab Systems using Corrosion-Resistant GFRP Bars}

by Imad Eldin Ahmed Eisa Khalafalla

Ryerson University - Civil Engineering

Toronto, Ontario, Canada, 2014

\section{ABSTRACT}

This research investigates the use of glass fiber reinforced polymer (GFRP) bars to reinforce the bridge deck slabs as well as jointed precast bridge deck slab in prefabricated bulb-tee pretensioned bridge girders. The experimental program included two phases. In phase (I), six precast slab joint details between flanges of precast bulb-tee girders were developed incorporating GFRP bars with straight ends, L-shaped ends and headed ends, embedded in a closure strip filled with non-shrink cement grout or ultra-high-performance concrete (UHPC). A total of 11 actual-size specimens representing the one-way slab system with the proposed joint details, in addition to 5 cast-in-place control specimens, were built and tested to failure to examine the structural adequacy of the proposed joint details. Based on the results from Phase (I), the best joint was selected for further tests in Phase (II) to examine its fatigue life and ultimate load carrying capacity under vehicular wheel loading. A total of 8 actual-size, GFRPreinforced, 3500x2500x200 mm concrete deck slabs were designed for this purpose according to CHBDC specifications. Ultimate strength, fatigue behavior and fatigue life of the GFRPreinforced deck slabs were investigated using different schemes of fatigue loading, namely: accelerated variable amplitude fatigue loading and constant amplitude fatigue loading. Overall, the experimental results indicated that GFRP-reinforced deck slabs showed high fatigue performance. A new prediction model for fatigue life of the GFRP-reinforced deck slabs was developed. The failure mode of the tested composite slabs was punching shear. Correlation 
between the experimental findings and the prediction models for punching shear resistance available in the literature showed that the prediction models by CSA S806-12 (2012) and ElGamal et al. (2005) can accurately predict the punching shear capacity of the cast-in-place and precast jointed bridge deck slabs reinforced with GFRP bars. In addition, the average observed mid-depth punching shear perimeter for the cast-in-place deck slabs and the precast jointed deck slabs were measured to be $1.25 \mathrm{~d}$ and $1.33 \mathrm{~d}$ away from the sides of the loaded area , respectively, which are more than twice the corresponding distance specified in ACI 440.1R-06 and CSA S806-12 for calculating the critical punching shear perimeter. 


\section{ACKNOWLEDGEMENTS}

The author wishes to express his deep appreciation to his advisor Dr. K. Sennah, for his constant support and valuable supervision during the development of this research. Dr. Sennah devoted his time and effort to make this study a success. His most helpful guidance is greatly appreciated. This research was supported by Ontario Centres of Excellence (OCE) Collaborative Research Program, Schoeck Canada Inc., V-Rod Canada Inc. and Ontario Ministry of Transportation (MTO). The inkind contributions of Lafarge North America Inc., Euclid Chemical Company and Pultrall Inc. are greatly appreciated. The financial support through Ryerson University Graduate Scholarship and teaching and research assistantship, Ontario Graduate Scholarship (OGS), Cement Association of Canada Scholarship and Canadian Precast/Prestressed Concrete Institute (CPCI) Student Scholarship are greatly appreciated. Many thanks to Mr. Nidal Jaalouk and other technical staff at Ryerson University structures laboratory for their assistance during the construction and testing of specimens. Also, the author is very grateful to his father, mother, wife, sons and daughter for their great support and encouragement during the course of this study. 


\section{TABLE OF CONTENTS}

AUTHOR'S DECLARATION................................................................................................... ii

ABSTRACT ................................................................................................................................................... iii

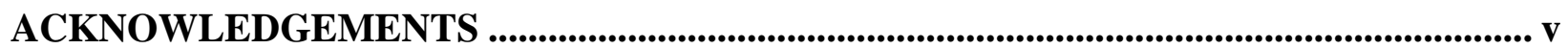

TABLE OF CONTENTS .............................................................................................................. vi

LIST OF TABLES .................................................................................................................................. ix

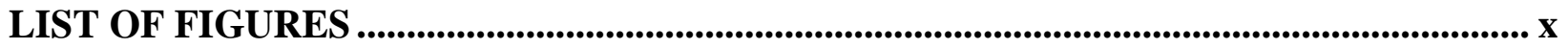

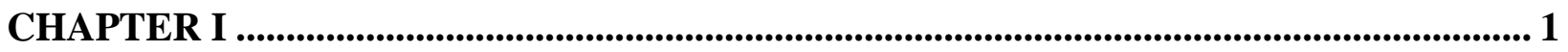

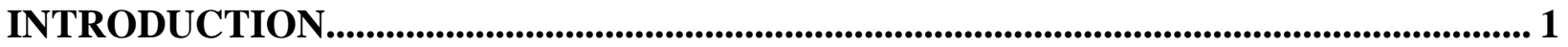

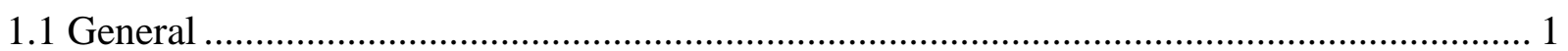

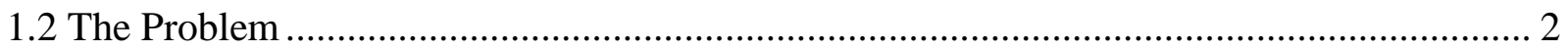

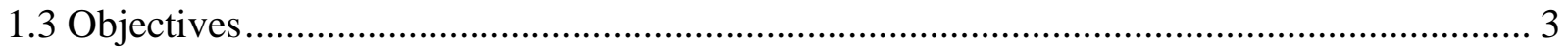

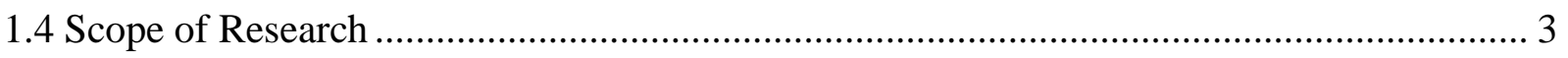

1.5 Contents and Arrangement of The Thesis ..................................................................... 5

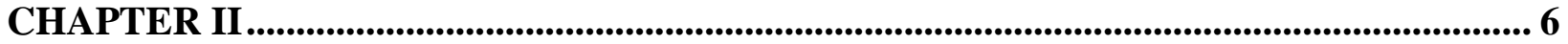

LITERATURE REVIEW ...................................................................................................... 6

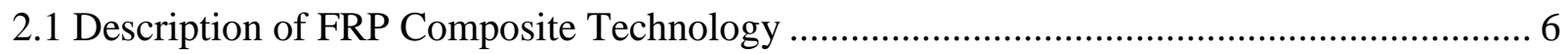

2.2 Durability of GFRP Bars in Concrete ……………........................................................ 8

2.3 Concrete Deck Slabs under Static and Fatigue Loading ................................................... 11

2.4 Bridge Deck Slab Reinforced with GFRP Bars ........................................................... 14

2.5 Prefabricated Bridge Elements and Connection Technology .............................................. 18

2.6 Anchorage of Steel-Headed Bars to Concrete................................................................... 23

2.7 Punching Shear of FRP-Reinforced Slabs ..................................................................... 26

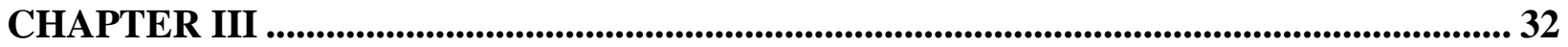

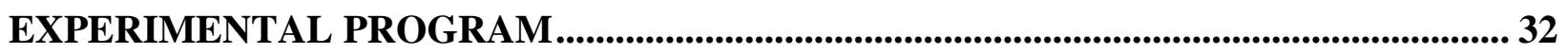

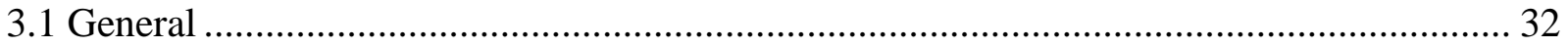

3.2 Proposed Bulb-Tee Girder Connection Details using GFRP Bars...................................... 32

3.3 Phase I: Static Ultimate Load Tests on Simply-Supported Deck Slab Strips ...................... 37

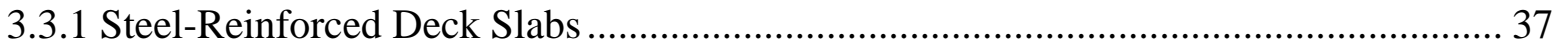

3.3.2 Ribbed-Surface GFRP-Reinforced Deck Slabs ....................................................... 37 
3.3.3 Sand-Coated GFRP-Reinforced Deck Slabs ................................................... 42

3.4 Phase II: Static Ultimate Load Tests and Fatigue Load Tests on Internally .................... 45

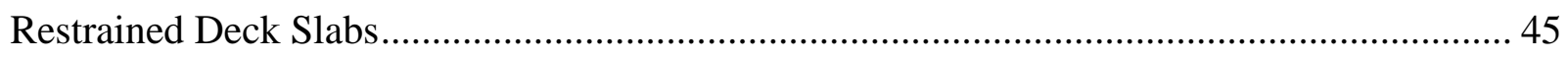

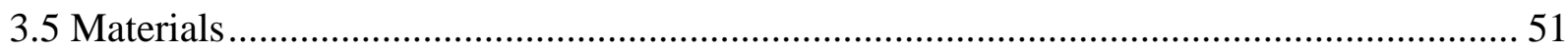

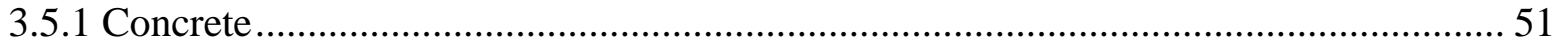

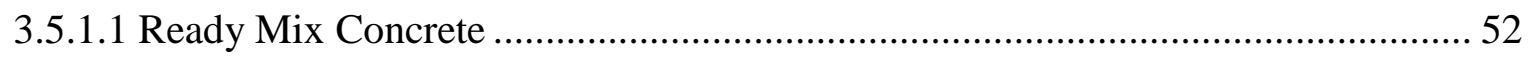

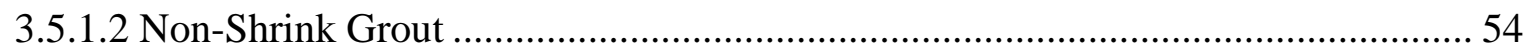

3.5.1.3 Ultra-High-Performance Concrete............................................................... 54

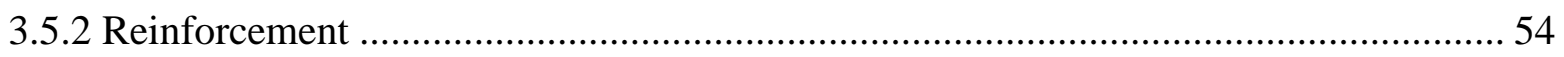

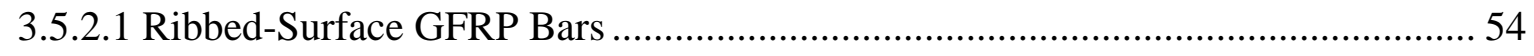

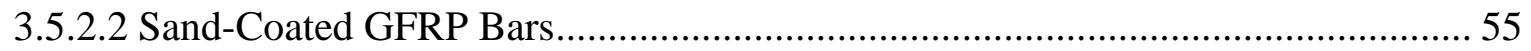

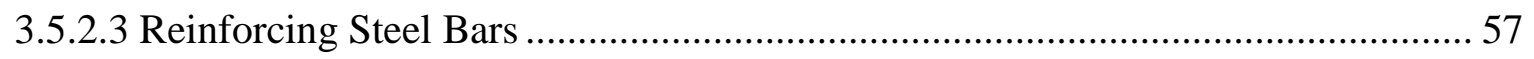

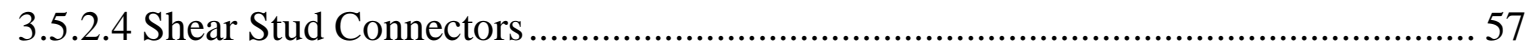

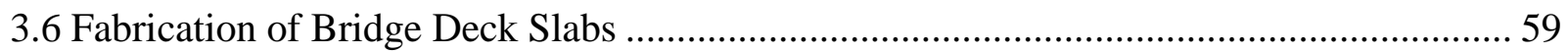

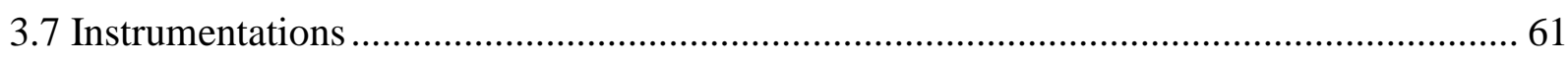

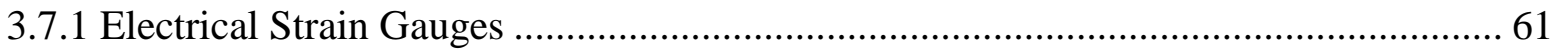

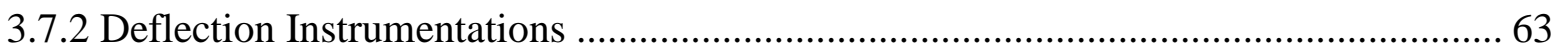

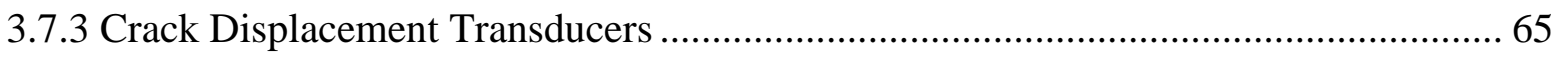

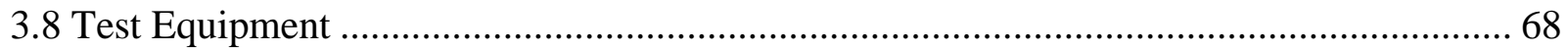

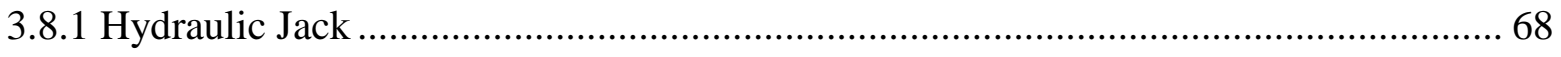

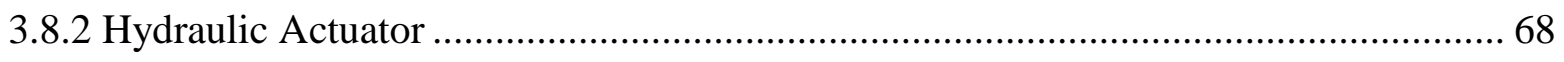

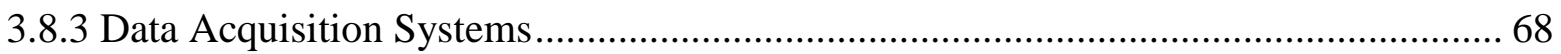

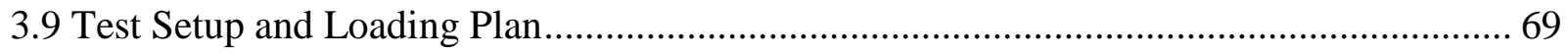

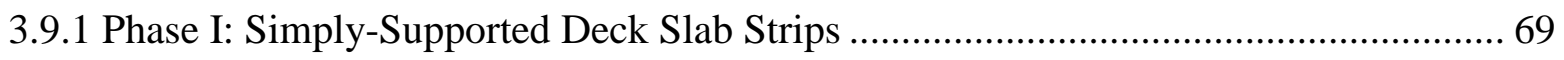

3.9.2 Phase II: Internally Restrained Deck Slabs ........................................................... 71

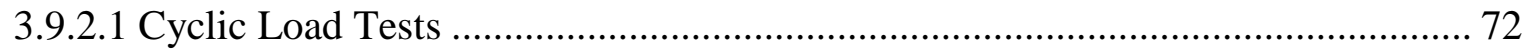

3.9.2.1.1 Accelerated Variable Amplitude Fatigue (VAF) Loading ........................... 72

3.9.2.1.2 Constant Amplitude Fatigue (CAF) Loading ......................................... 73

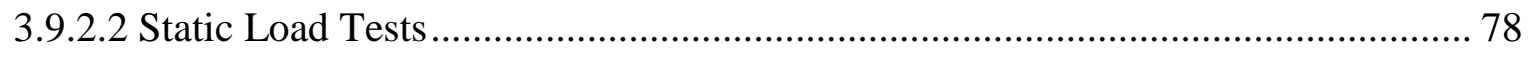

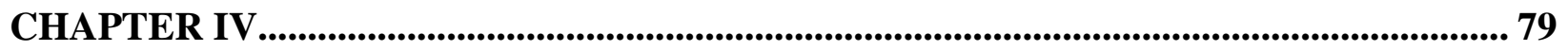

EXPERIMENTAL RESULTS.................................................................................. 79 


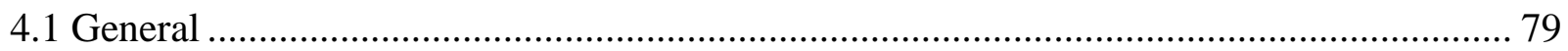

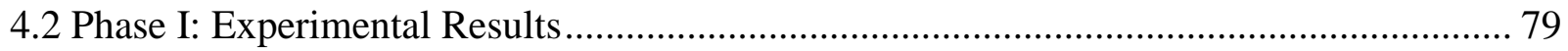

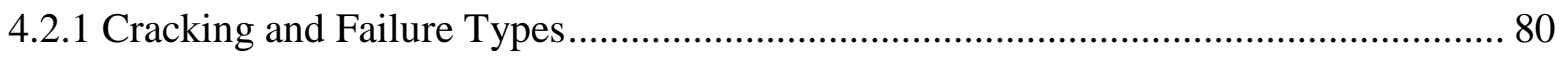

4.2.1.1 Steel-Reinforced Deck Slabs ............................................................................ 80

4.2.1.2 Ribbed-Surface GFRP-Reinforced Deck Slabs ................................................. 80

4.2.1.3 Sand-Coated GFRP-Reinforced Deck Slabs.......................................................... 90

4.2.2 Deflection Patterns ......................................................................................................... 94

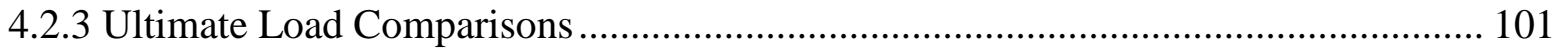

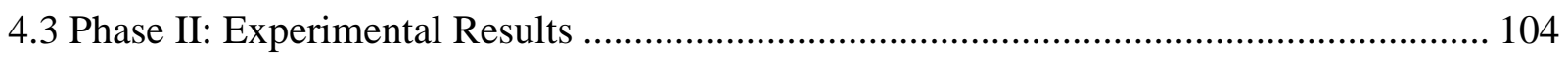

4.3.1 Cracking Patterns and Crack Width ............................................................................. 104

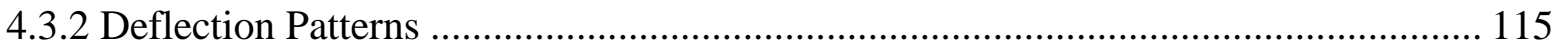

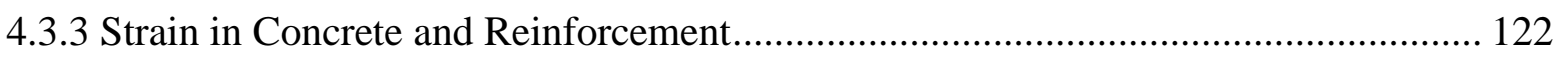

4.3.4 Ultimate Capacity and Failure Type................................................................... 129

4.3.5 Punching Shear Design Formulas................................................................... 132

4.3.6 Life Estimation of Fatigue of GFRP-Reinforced Concrete Deck Slabs ..................... 135

4.3.7 Prediction of Fatigue Life of the Tested GFRP-Reinforced Deck Slabs.................... 137

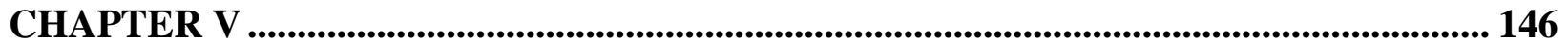

CONCLUSIONS AND RECOMMENDATIONS FOR FUTURE RESEARCH................. 146

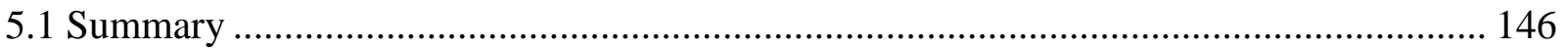

5.1.1 Phase I: Static Tests on Simply-Supported Deck Slab Strips..................................... 146

5.1.2 Phase II: Static and Fatigue Tests on Internally-Restrained Deck Slabs.................... 147

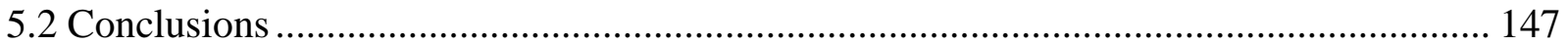

5.3 Recommendations for Future Research ................................................................... 150

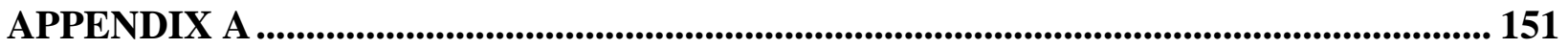

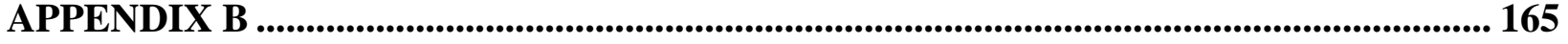

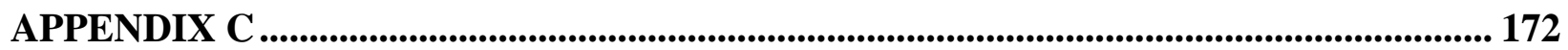

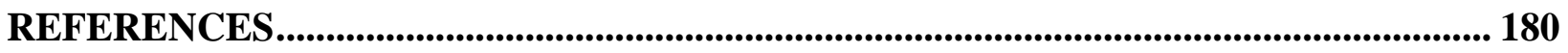




\section{LIST OF TABLES}

Table 3.1 Summary of reinforcement details of the deck slabs in Phase I tested under static load

Table 3.2 Summary of tested slab configurations for phase II 46

Table 3.3 Summary of commercial mechanical properties of the reinforcement used in this research 58

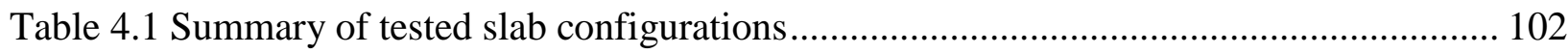

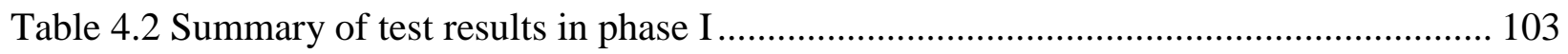

Table 4.3 Typical field-cast concrete and UHPC material properties used in phase II ............... 108

Table 4.4 Summary of test results of phase II ................................................................ 108

Table 4.5 Correlation between the punching shear strength of the tested slabs obtained experimentally and from available equations .......................................................................... 134

Table 4.6 Equivalent number of cycles to failure at constant amplitude fatigue loading for deck

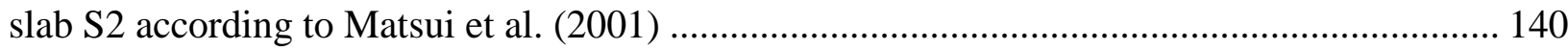

Table 4.7 Equivalent number of cycles to failure at constant amplitude fatigue loading for deck slab S2 according to Mufti et al. (2002) 141

Table 4.8 Equivalent number of cycles to failure at constant amplitude fatigue loading for deck slab S2 according to Memon (2005) 


\section{LIST OF FIGURES}

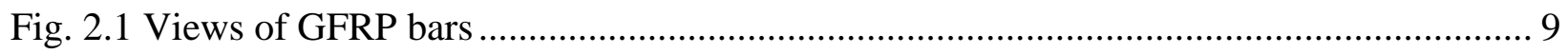

Fig. 2.2 Prefabricated bulb-tee bridge system (Sennah et al., 2004) ............................................ 19

Figure 3.1 Schematic diagrams of the precast bulb-tee girders with the proposed joint details... 35

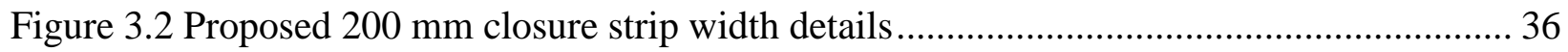

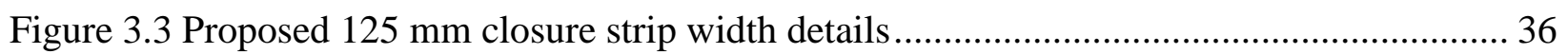

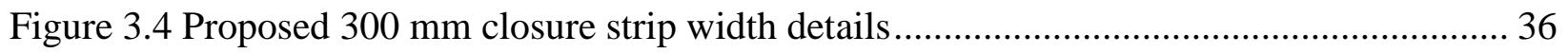

Figure 3.5 Schematic diagram of the test setup of slabs SS0, SS1 and SS2 ……...................... 39

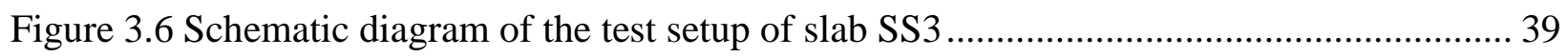

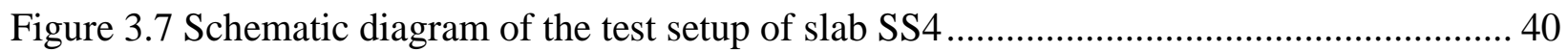

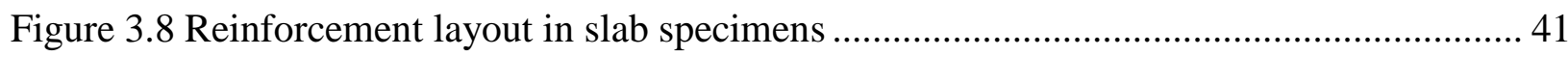

Figure 3.9 Views of closure strips in jointed slabs ................................................................ 42

Figure 3.10 Reinforcement layout in slab specimens reinforced with sand-coated GFRP bars... 44

Figure 3.11 Views of closure strip in jointed slabs reinforced with sand-coated GFRP bars ...... 45

Figure 3.12 Typical schematic diagram of the test setup of the cast-in-place slabs ......................... 47

Figure 3.13 Typical schematic diagram of the test setup of the jointed precast slabs ..................... 47

Figure 3.14 Reinforcement layout for cast-in-place deck slabs................................................. 49

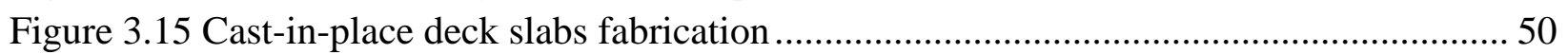

Figure 3.16 Reinforcement layout for the jointed precast deck slabs ......................................... 52

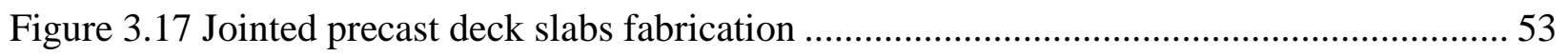

Figure 3.18 Sequence of mixing and placing of UHPC into connection...................................... 56

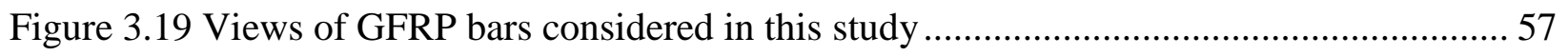

Figure 3.20 View of bolts fixed on the top flanges of the twin-girder system ............................. 59

Figure 3.21 Geometric details of shear pocket and shear studs inside the shear pockets ............ 60

Figure 3.22 Photos during concreting and curing of a precast deck slab .................................. 62

Figure 3.23 Profiles of surfaces at the joints before and after grinding for simply-supported deck

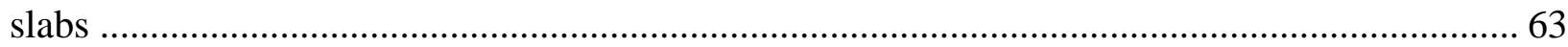

Figure 3.24 Profiles of the surface of the joint before and after grinding for a restrained deck slab

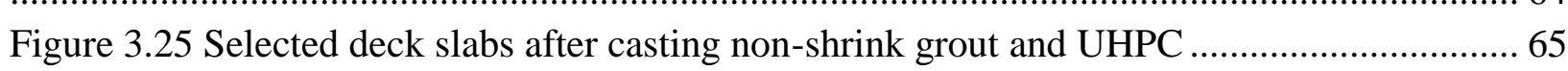

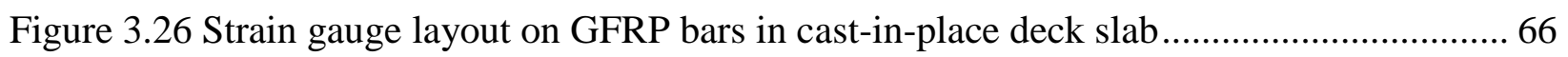

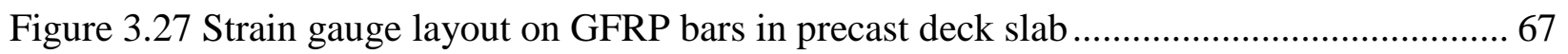

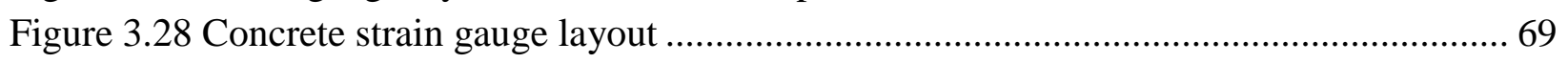

Figure 3.29 Layout of POTs and LVDTs at the underside of the deck slabs .............................. 71

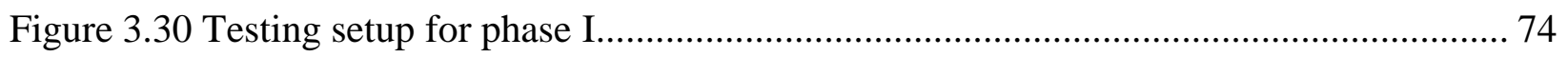

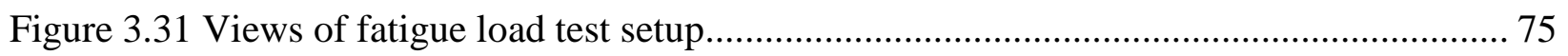

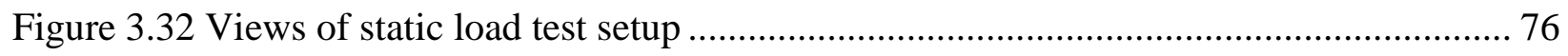

Figure 3.33 Fatigue loading histories considered in this study................................................... 77 


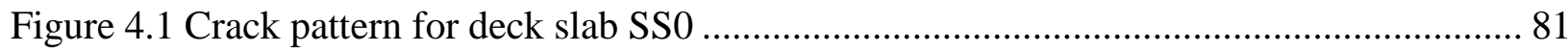

Figure 4.2 Crack pattern for deck slab SS1 .............................................................. 81

Figure 4.3 Crack pattern for deck slab SS2 ….............................................................. 82

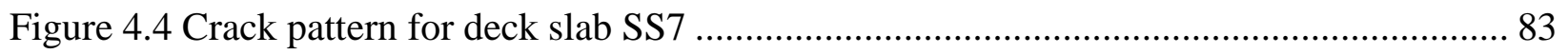

Figure 4.5 Crack pattern for deck slab SS3 .................................................................. 83

Figure 4.6 Crack pattern for deck slab SS4 ..................................................................... 84

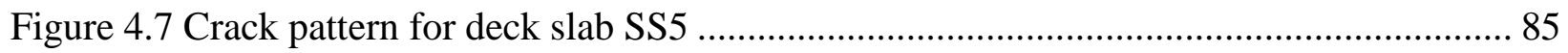

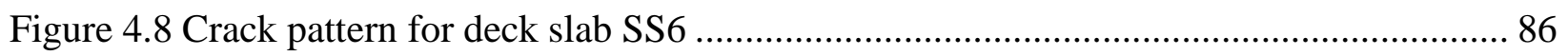

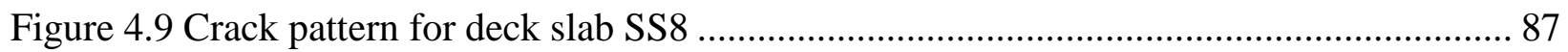

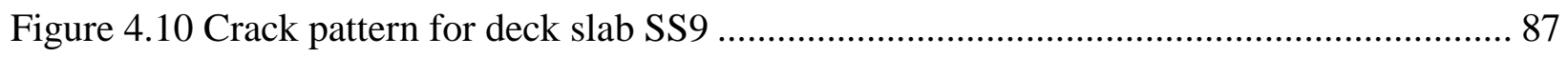

Figure 4.11 Crack pattern for deck slab SS10 ............................................................... 88

Figure 4.12 Selected failure modes in ribbed-surface GFRP-reinforced slabs.......................... 89

Figure 4.13 Crack pattern for deck slab PS1 .................................................................. 90

Figure 4.14 Crack pattern for deck slab PS2 .................................................................... 91

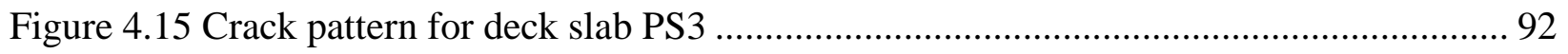

Figure 4.16 Crack pattern for deck slab PS4 ................................................................. 93

Figure 4.17 Crack pattern for deck slab PS5 ....................................................................... 94

Figure 4.18 Selected failure modes in sand-coated GFRP-reinforced slabs............................. 95

Figure 4.19 Load-deflection relationships obtained at mid-span of slabs SS1 through SS6 under

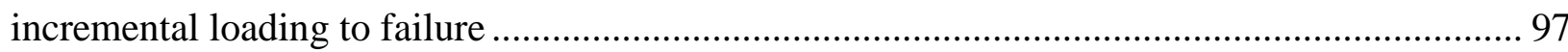

Figure 4.20 Envelopes of the load-deflection relationships obtained at mid-span of slabs SS1

through SS6 subjected to incremental loading to failure ................................................... 98

Figure 4.21 Load-deflection relationships obtained at mid-span of slabs SS0, SS7, SS8, SS9 and

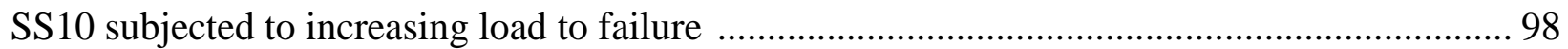

Figure 4.22 Load-deflection relationships obtained at mid-span of slabs PS1 through PS5

subjected to incremental loading to failure ....................................................................... 100

Figure 4.23 Envelopes of the load-deflection relationships obtained at mid-span of slabs SS1,

PS1, PS2, PS3, PS4 and PS5 subjected to incremental loading to failure ............................ 101

Figure 4.24 Crack pattern at failure of deck slab S1...................................................... 105

Figure 4.25 Crack pattern at failure of deck slab S2 ..................................................... 107

Figure 4.26 Crack pattern at failure of deck slab S3 ......................................................... 109

Figure 4.27 Views of punching shear crack pattern and failure of precast jointed slab S4 ....... 111

Figure 4.28 Views of punching shear crack pattern and failure of precast jointed slab S5 ....... 113

Figure 4.29 Views of punching shear crack pattern and failure of precast jointed slab S6....... 114

Figure 4.30 Views of punching shear crack pattern and failure of precast jointed slab S7 ....... 116

Figure 4.31 Views of punching shear crack pattern and failure of precast jointed slab S8....... 117

Figure 4.32 Load-deflection relationships for slabs S1, S3, S4, S6 and S8........................... 119

Figure 4.33 Load-maximum deflection relationships obtained at mid-span of slabs S1, S3, S4, S6

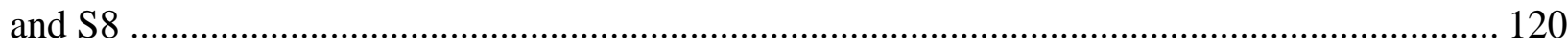


Figure 4.34 Static load-deflection relationships of slabs S3, S4 and S8 after different constantamplitude fatigue loading cycles 124

Figure 4.35 Static load-deflection relationships of S2, S5 and S7 after different variableamplitude fatigue loading steps 125

Figure 4.36 Deflection versus number of load cycles for CAF tested slabs S3, S4 and S8 ....... 126 Figure 4.37 Deflection versus number of load cycles for VAF tested slabs.............................. 126 Figure 4.38 Concrete strain versus number of load cycles for CAF loading of the tested slabs S3, S4 and S8 127

Figure 4.39 Concrete strain versus number of load cycles for VAF loading of the tested slabs S2, S5 and S7 127 Figure 4.40 Bottom GFRP reinforcement strain versus number of load cycles for CAF loading of the tested slabs S3, S4 and S8 129 Figure 4.41 Comparison of failure shapes at the underside of the cast-in-place deck slabs....... 130 Figure 4.42 Comparison of failure shapes at the top surface of the precast slabs S4 through S8

Figure 4.43 Comparison of failure shapes at the underside of the precast slabs S4 through S8 131 Figure 4.44 Views of saw-cut slab segments after punching shear failure for all deck slabs S1 throught $\mathrm{S} 8$ (transverse direction)

Figure 4.45 Views of saw-cut slab segments after punching shear failure for deck slabs, S1 and S2 (longitudinal direction)

Figure 4.46 Equivalent number of load cycles to failure at constant amplitude fatigue loading based on the fatigue prediction model by Matsui et al. (2001) 140

Figure 4.47 Equivalent number of load cycles to failure at constant amplitude fatigue loading based on the fatigue prediction model by Mufti et al. (2002) 141

Figure 4.48 Equivalent number of load cycles to failure at constant amplitude fatigue loading based on the fatigue prediction model by Memon (2005) 142 Figure 4.49 Equivalent number of load cycles to failure at constant amplitude fatigue load based on the developed equation for cast-in-place bridge deck slabs. 144 Figure 4.50 Equivalent number of load cycles to failure at constant amplitude fatigue load based on the developed equation for precast jointed bridge deck slabs ............................................ 145 Figure 4.51 P-N curves for GFRP-reinforced cast-in-place and precast jointed deck slabs....... 145 Figure A.1 Load versus concrete strain of slab SS1 subjected to incremental loading to failure

Figure A.2 Load versus concrete strain of slab SS2 subjected to incremental loading to failure 152

Figure A.3 Load versus concrete strain of slab SS3 subjected to incremental loading to failure 153

Figure A.4 Load versus concrete strain of slab SS4 subjected to incremental loading to failure 
Figure A.5 Load versus concrete strain of slab SS5 subjected to incremental loading to failure

Figure A.6 Load versus concrete strain of slab SS6 subjected to incremental loading to failure

Figure A.7 Envelopes of the Load versus concrete strain of slabs SS1 through SS6 subjected to incremental loading to failure 155

Figure A.8 Load versus concrete strain of slabs SS0, SS7, SS8, SS9 and SS10 subjected to increasing load to failure.

Figure A.9 Load versus concrete strain of slab PS1 subjected to incremental loading to failure 156

Figure A.10 Load versus concrete strain of slab PS2 subjected to incremental loading to failure 156

Figure A.11 Load versus concrete strain of slab PS3 subjected to incremental loading to failure 157

Figure A.12 Load versus concrete strain of slab PS4 subjected to incremental loading to failure 157

Figure A.13 Load versus concrete strain of slab PS5 subjected to incremental loading to failure 158

Figure A.14 Load versus reinforcement strain of slab SS2 subjected to incremental loading to failure 158

Figure A.15 Load versus reinforcement strain of slab SS3 subjected to incremental loading to failure

Figure A.16 Load versus reinforcement strain of slab SS4 subjected to incremental loading to failure

Figure A.17 Load versus reinforcement strain of slab SS5 subjected to incremental loading to failure

Figure A.18 Load versus reinforcement strain of slab SS6 subjected to incremental loading to failure 160

Figure A.19 Envelopes of the Load versus reinforcement strain of slabs SS2 through SS6 subjected to incremental loading to failure 161

Figure A.20 Load versus reinforcement strain of slabs SS7 through SS10 subjected to increasing load to failure 161

Figure A.21 Load versus reinforcement strain of slab PS1 subjected to incremental loading to failure 162

Figure A.22 Load versus reinforcement strain of slab PS2 subjected to incremental loading to failure 162 Figure A.23 Load versus reinforcement strain of slab PS3 subjected to incremental loading to failure 163 Figure A.24 Load versus reinforcement strain of slab PS4 subjected to incremental loading to failure 
Figure A.25 Envelopes of the Load versus reinforcement strain of slabs PS1 through PS4

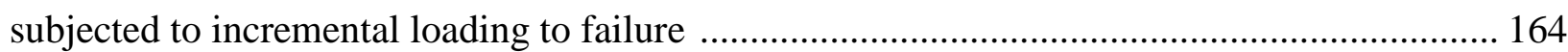

Figure B.1 Typical hysteresis curves of cast-in-place deck slab S2 under VAF loading .......... 166 Figure B.2 Typical hysteresis curves of cast-in-place deck slab S3 under CAF loading .......... 167

Figure B.3 Typical hysteresis curves of precast deck slab S4 under CAF loading ................... 168

Figure B.4 Typical hysteresis curves of precast deck slab S5 under VAF loading ................... 169

Figure B.5 Typical hysteresis curves of precast deck slab S7 under VAF loading .................. 170

Figure B.6 Typical hysteresis curves of precast deck slab S8 under CAF loading .................. 171

Figure C.1 Static load versus maximum concrete strain measured on top surface of slab S2 after different variable-amplitude fatigue loading steps ........................................................ 173

Figure C.2 Static load versus maximum concrete strain measured on top surface of slab S5 after different variable-amplitude fatigue loading steps

Figure C. 3 Static load versus maximum concrete strain measured on top surface of slab S7 after different variable-amplitude fatigue loading steps

Figure C. 4 Static load versus maximum concrete strain measured on top surface of slab S3 after different constant-amplitude fatigue loading cycles

Figure C.5 Static load versus maximum concrete strain measured on top surface of slab S4 after different constant-amplitude fatigue loading cycles

Figure C.6 Static load versus maximum concrete strain measured on top surface of slab S8 after

different constant-amplitude fatigue loading cycles 175

Figure C.7 Static load versus maximum reinforcement strain of slab S3 after different different constant-amplitude fatigue loading cycles 176

Figure C.8 Static load versus maximum reinforcement strain of slab S4 after different different constant-amplitude fatigue loading cycles 176

Figure C.9 Static load versus maximum reinforcement strain of slab S8 after different different constant-amplitude fatigue loading cycles 177

Figure C.10 Static load versus crack width of slab S5 after different variable-amplitude fatigue loading steps. 177

Figure C.11 Static load versus crack width of slab S7 after different variable-amplitude fatigue loading steps. 178

Figure C.12 Static load versus crack width of slab S3 after different constant-amplitude fatigue loading cycles 178 Figure C.13 Static load versus crack width of slab S4 after different constant-amplitude fatigue loading cycles 179 Figure C.14 Static load versus crack width of slab S8 after different constant-amplitude fatigue loading cycles. 179 


\section{CHAPTER I INTRODUCTION}

\subsection{General}

Deterioration of bridge deck slabs due to corrosion of steel reinforcement is a major problem currently facing bridge construction. The environmental effects and the use of de-icing salts in winter times are main factors that may accelerate the corrosion rate in bridge deck slabs, leading to costly and frequent bridge maintenance or replacement. Also the deck slabs are the part of bridge most prone to repeated moving wheel loads specially from heavy trucks, and this may reduce the integrity of the reinforced-concrete deck slab and may significantly reduce the life expectancy of bridge superstructure. The use of glass fiber reinforced polymer (GFRP) bars as internal reinforcement in concrete is considered an excellent solution for the replacement of deteriorated concrete bridge deck slabs, where corrosion of steel reinforcement is of main concern. The GFRP reinforcing bars have many advantages over steel reinforcement, including being resistant to corrosion, of high tensile strength, durable and of lightweight.

According to the Provincial Auditor's report in 2009, more than $70 \%$ of Ontario bridges were built between 1950 and 1980, and these older bridges have an average lifespan of 60 years. Based on Ontario Ministry of Transportation (MTO) assessment as of June 2009, one quarter of the approximately 2,800 provincial bridges were in fair to poor condition and need immediate repair. The MTO estimated that the cost of repairing and rehabilitating bridges in fair or poor condition would be approximately $\$ 2.2$ billion (OAGO, 2009). The Residential and Civil Construction Alliance of Ontario (RCCAO, 2007) published a report on the state of Ontario bridges. The report 
reveals that the integrity of Ontario's municipal bridge infrastructure and public safety are at risk after years of deferred maintenance and irregular inspections. To enhance the public safety and the sustainability of Ontario bridges, RCCAO report stated some recommendations to promote bridge engineering designs that improve the life span expectancy, reduce maintenance costs of bridges and seek accelerated delivery methods to address the mounting infrastructure repair and construction backlog. These recommendations can be achieved by utilizing prefabricated bridge systems made of GFRP-reinforced Deck Bulb-Tee (DBT) girders as explained in the current research.

\subsection{The Problem}

Deterioration of bridge deck slabs due to corrosion of steel reinforcement can be avoided by utilizing a prefabricated bridge system made of GFRP-reinforced Deck Bulb-Tee (DBT) girders. This system not only addresses the steel corrosion problem, but also provides accelerated method for replacing the deteriorated deck slabs. A GFRP-reinforced DBT girder system combines the advantages of the corrosion resistance of GFRP reinforcing bars with the economic benefits of the prefabricated bridge elements. This includes reduction in on-site construction time and labor, design efforts, negative impact on the environment in the vicinity of the site, closure times and inconvenience to the traveling public. Because this is a relatively new technology, the Canadian Highway Bridge Design Code, (CHBDC, 2006), and AASHTO-LRFD Bridge Design Specifications (AASHTO, 2010) do not provide guidance to design prefabricated concrete girder/deck joints made with GFRP bars. Also, there is no enough information available in the literature to design such joints, nor is there test data available to give confidence when designing such joints. Moreover, the literature survey showed limited number of experiments conducted on bridge deck slabs to examine their fatigue and ultimate load carrying capacities under wheel loads. 
In summary, it is important to develop effective precast deck joint in DBT girder systems reinforced with GFRP bars to provide continuity of reinforcement in the closure strips so that load sharing between girders is not compromised.

\subsection{Objectives}

The intent of this research is to contribute to the efficient design of GFRP-reinforced concrete bridge deck slabs by developing experimentally calibrated models capable of predicting accurately their response when subjected to static and fatigue loading. The specific objectives of this research are:

1- Establish the load carrying capacity (i.e. flexural or punching shear capacity) of GFRPreinforced deck slabs, cast-in-place or precast with closure strip and headed-stud field connection, when subjected to truck wheel loads.

2- Examine whether the GFRP-reinforcement ratio for internally-restrained deck slabs recommended by CHBDC Section 16 is adequate for ultimate, serviceability and fatigue limit state designs.

3- Develop empirical expressions for the predication of the ultimate load capacity and fatigue life of bridge deck slabs reinforced with GFRP bars in case of cast-in-place and jointed precast slab in Bulb-Tee girder system.

\subsection{Scope of Research}

In this research, the experimental program was undertaken to investigate the structural behavior of bridge deck slabs under static and fatigue loading. In case of slab-on-girder bridges, deck slab design follows two approaches based on the span-to-depth ratio as well as edge restraint conditions. AASHTO-LRFD design specifications (AASHTO, 2010) consider the design of deck 
slabs as a continuous strip, of $1000 \mathrm{~mm}$ width, supported freely over the main bridge beams. In this case, the load carrying capacity of the slab is based on its bending moment capacity. However, CHBDC specifies an empirical design method of the deck slabs based on punching shear capacity provided that (i) the main beam spacing-to-slab depth ratio is less than 18; (ii) the slab free edges normal to the main beams are stiffened by composite end beams and increase in slab thickness per Clause 8.18.6; and (iii) the deck slab acts compositely with the supporting beams. As an alternative to the empirical method, CHBDC specifies the flexural design method if the above-mentioned conditions are not met to promote punching shear failure. In this proposed research, two phases of the experimental program are considered. Phase I represents the one-way slab action considering the flexural design approach, while Phase II represents the restrained slab over the supporting beams considering punching shear and arching action phenomenon.

In phase I, six precast slab joint details between flanges of precast bulb-tee girders were developed incorporating GFRP bars with straight/L-shaped/headed end, embedded in a closure strip filled with non-shrink cement grout or ultra-high-performance concrete (UHPC). A total of 11 actual-size specimens representing the proposed joint details, in addition to 5 control cast-inplace specimens, were built and tested to-collapse to examine the developed new connection details between precast slab elements incorporating GFRP bars. Each slab had $2500 \mathrm{~mm}$ length, $200 \mathrm{~mm}$ thick and $600 \mathrm{~mm}$ width in the direction of traffic. Further tests were conducted in phase II to examine the fatigue life of the successful control joints under simulated vehicular wheel loading. A total of 8 actual-size, GFRP-reinforced, concrete deck slabs were designed according to CHBDC specifications to perform static and fatigue tests to determine their behavior under CHBDC truck wheel loading. Each slab had $200 \mathrm{~mm}$ thickness, $2500 \mathrm{~mm}$ width and $3500 \mathrm{~mm}$ length in the direction of traffic. Ultimate strength, fatigue behavior and fatigue life of the GFRP 
reinforced deck slabs were investigated using different schemes of cyclic loadings (accelerated variable amplitude cyclic loading as well as constant amplitude cyclic loading followed by loading the slab monotonically to-collapse).

\subsection{Contents and Arrangement of The Thesis}

This thesis consists of five chapters. Chapter II presents a literature review on the description of fiber reinforced polymer (FRP) technology and prefabricated bridge elements and connection technology. Chapter III presents the details of the experimental program of this research. Proposed deck bulb-tee (DBT) girder connection details using GFRP bars, test setup and instrumentation, and test procedure are discussed. Chapter IV presents analysis and discussion of the experimental results as well as the procedure to develop the prediction model for fatigue design of the studied deck slabs and their static load carrying capacities under truck wheel loading. Chapter V consists of summary, conclusions, and recommendations for future research studies. 


\section{CHAPTER II \\ LITERATURE REVIEW}

\subsection{Description of FRP Composite Technology}

Fiber-reinforced polymer (FRP) is an anisotropic two-component composite material consisting of high strength fibers embedded in a polymer matrix. FRP materials offer advantages over conventional isotropic structural materials such as steel. These advantages include high strength, light weight, improved fatigue life and corrosion resistance. The excellent properties of FRP composites are dependent on the two major constituents, namely: the fiber and the matrix. The strength and stiffness of the FRPs are provided by the fibers, whereas the overall material properties depend on the mechanical properties of the matrix, the fiber volume fraction (i.e. the volume of fibers per unit volume of matrix), the fiber cross-sectional area, the orientation of the fibers within the matrix, and the method of manufacturing.

The most common types of FRPs used in structural engineering applications are glass FRP (GFRP), carbon FRP (CFRP) and aramid FRP (AFRP). Because of their relatively low cost, high tensile strength and good chemical resistance, GFRPs are used extensively in structural engineering applications. However, their properties don't match those of CFRPs, such as lower modulus and lower fatigue behavior. There are several types of glass fiber, but the most common types are E-glass, S-glass and quartz. E-glass is the most common and least expensive, providing a good combination of tensile strength of about $3500 \mathrm{MPa}$ and modulus of elasticity of about 70 GPa. S-glass that has tensile strength of about $4500 \mathrm{MPa}$ and a modulus of elasticity of about 87 $\mathrm{GPa}$, is more expensive, but is $28.6 \%$ stronger, than E-glass and retains a greater percentage of its strength at elevated temperatures. Quartz fiber is rather expensive ultrapure silica glass that is 
low-dielectric fiber and is used primarily in electrical applications (Campbell, 2010). Glass fibers are often used in the manufacturing of FRP reinforcing bars and tendons, pultruded FRP structural sections, FRP wraps for seismic upgrade, and filament wound FRP tubes. The commercially available GFRP bars have various types of cross-sectional shapes (i.e. square, round, solid, and hollow) and surface deformation systems (i.e. exterior wound fibers, sand coatings, and ribbedsurface).

Due to the environmental effects and the use of de-icing salts in winter times, many of the North American bridges were badly deteriorated due to corrosion of reinforcing steel and in need of regular maintenance, repair and rehabilitation. Using composites such as FRP-reinforcing bars as internal reinforcement in concrete is a relatively new and exciting application. FRP-reinforcing bars help minimize these problems, primarily because they do not corrode. Furthermore, FRPreinforcing bars exhibit several properties, such as high tensile strength, that make them suitable for use as structural reinforcement (Iyer and Sen, 1991; JSCE, 1992; Neale and Labossiere, 1992; White, 1992; Nanni, 1993; Nanni and Dolan, 1993; Taerwe, 1995; El-Badry, 1996; JSCE, 1997a; Benmokrane and Rahman, 1998; Saadatmanesh and Ehsani, 1998; Dolan et al., 1999; Humar and Razaqpur, 2000; Figueiras et al., 2001; Burgoyne, 2001; Cosenza et al., 2001; Teng, 2001; ACI $440,2006)$.

Because of the linear-elastic behavior of FRP reinforcement until failure, a change in the traditional design philosophy of concrete structures is required to account for the difference between the mechanical behavior of FRP reinforcement and conventional steel reinforcement. A number of codes and design guidelines for the use of FRP reinforcement for concrete structures has recently been established, such as CSA-S806-12 standard for design and construction of 
building structures with fiber reinforced polymers (CSA, 2012), Section 16 of the Canadian Highway Bridge Design Code, CSA/S6-06, on fiber reinforced structures (CHBDC, 2006), ACI 440.1R-06 (ACI, 2006) and AASHTO-LRFD Bridge Design Guide Specifications for GFRPReinforced Concrete Bridge Decks and Traffic Railings (AASHTO, 2009).

Due to their lower cost, GFRP bars are more attractive to bridge deck slab applications than CFRP and AFRP. Given the GFRP's small transverse strength and relatively low modulus of elasticity, the shear strength of GFRP-reinforced deck slab is lower than that for steel-reinforced deck slab. However, this issue is not important since shear strength in deck slabs is provided primarily by concrete. The ribbed-surface profile of the first FRP bar type shown in Fig. 2.1(a), as well as the sand-coated surface of the second FRP bar type shown in Fig. 2.1(b) ensure optimal bond between concrete and the rebar. FRP manufacturers have recently developed a FRP bar with anchor head at the bar ends, shown in Fig. 2.1, to eliminate the unnecessary and expensive use of custom made bar bends. Most recently, these manufacturers conducted pullout tests on selected FRP bars with anchor head to determine their pullout capacity (Pahn, 2008; Ahmed and Benmokrane, 2009).

\subsection{Durability of GFRP Bars in Concrete}

GFRP materials are increasingly being used in structural engineering applications. Since GFRP materials are still relatively new in the civil engineering applications, there are concerns related to the overall durability of these materials, especially as related to their performance when exposed to various environmental conditions under load. The main concern is the degradation of GFRP in the alkaline environment of concrete. A few researchers conducted experiments to examine the durability of GFRP bars in concrete. Most of these experiments were conducted using accelerated 
laboratory tests to simulated concrete pore water solution of high $\mathrm{pH}$ values and at elevated temperatures up to $80^{\circ} \mathrm{C}$. The conclusion of these studies indicated that there is a decrease in the tensile, shear and bond strength of the GFRP bars (Sen et al. 1993; Bank and gentry, 1995; Bank et al. 1998). These results would suggest that GFRP should not be used in direct contact with concrete (Uomoto, 2000). Similar results were reported by Sen et al. 2002, for GFRP bars in a strong alkaline solution and were stressed to $25 \%$ of their failure loads and failed $15-25$ days after stressing.

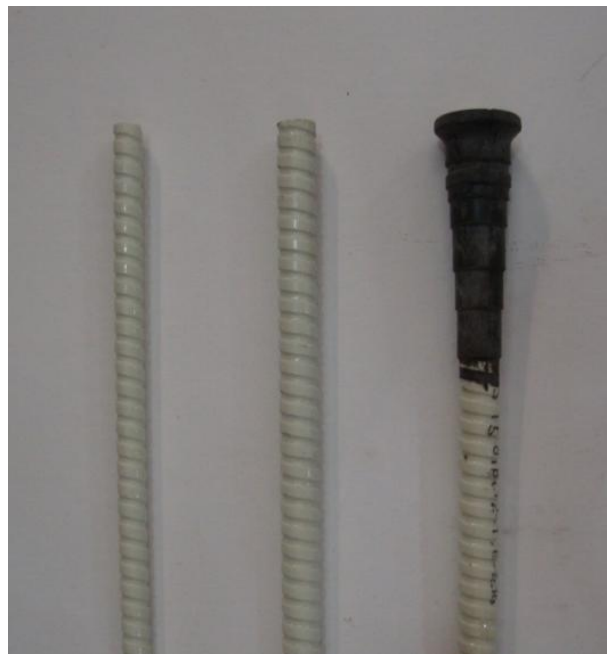

(a) Ribbed-surface GFRP bars

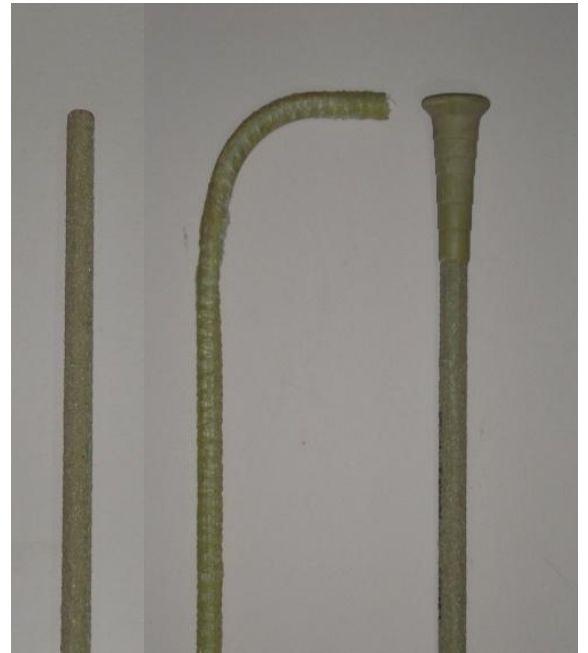

(b) Sand-coated GFRP bars

Figure 2.1 Views of GFRP bars

In contrast, Tomosawa and Nakatsuji (1997) concluded that after 12 months exposure of GFRP composite to alkaline solutions at temperatures between 20 and $30^{\circ} \mathrm{C}$, there had been no mechanical or physical deterioration of the bars. Similar results reported by Clarke and Sheard (1998) for GFRP composite after 2 years of exposure to a tropical climate on a test platform off the Japanese coast. In 2004, Canada Research Network of Centres of Excellence (ISIS Canada), 
conducted an extensive study on GFRP-reinforced concrete structures to examine the durability of GFRP bars in concrete exposed to natural environment for 5-8 years. To perform this task, core samples were taken from five GFRP-reinforced concrete structures from across Canada. Based on the test results, the GFRP bars in concrete did not undergo any damage during the 5-8 years of exposure. Accordingly, CHBDC 2006 has permitted the use of GFRP for both primary reinforcement and prestressing tendons in concrete (Mufti et al., 2005).

The tensile strength and bond properties of GFRP reinforcing bars in concrete have been experimentally examined by many researchers. Benmokrane et al. (2002) investigated the durability of various types of GFRP bars using different resins, fiber types, surface coatings, and manufacturing techniques. The researchers recommended that a GFRP rebar should consist of vinyl ester resin with surface coatings to reduce the imperfections that result from the pultrusion process and to protect the rebar surface at the same time. GFRP bars were found to be adequately durable in alkaline environments with stress levels less than $25 \%$ of the ultimate strength. Malvar (1995) performed bond tests on four different types of GFRP bars embedded in $76.2 \times 101.6 \mathrm{~mm}$ concrete cylinders. He found that small surface deformations of about $5.4 \%$ of the nominal rebar diameter yielded a maximum bond stress of up to five times the concrete tensile strength, similar to what is observed in steel reinforcing bars. However, it was suggested that the rebar deformations be developed during the pultrusion process since the deformations could fail during loading. The bond strength of the GFRP bars was found to be 1.2 to 1.5 times smaller than those of the steel bars, along with larger variations found in the indentation depths which caused larger variations in the bond strength. 
Muruts and Nad (1998) conducted pullout tests on rectangular GFRP bars at four different embedment lengths of 145, 195, 245, and $295 \mathrm{~mm}$, using $152.4 \times 304.8 \mathrm{~mm}$ concrete cylinders. They concluded that the controlling factor in terms of the bond strength appeared to be the resin type rather than the fiber type. Also, it appeared that the tests with the smaller development lengths showed adequate bond strengths whereas the longer embedment length specimens attained their ultimate tensile strength levels before bar pullout. Vijay (1999) carried out an experimental program on two types of pullout tests, namely: the general ACI pullout tests and pullout tests of bundled bars. He used cylinders $152.4 \times 304.8 \mathrm{~mm}$ with a development length of $88.9 \mathrm{~mm}$. Vijay only considered tap water, salt water $(3 \% \mathrm{NaCl})$, and freeze-thaw conditions. No alkaline environment was investigated. For sand-coated bars, the bond stress was found to be $14 \mathrm{MPa}$ with an increase in bond strength of $14 \%$ for bars under tap water at freeze-thaw conditions and a loss of $5.3 \%$ for bars exposed to salt water at room temperature, both for duration of 15 months. This study revealed that GFRP bars exhibited superior bond properties over steel (C-bar and sandcoated bar being $33.5 \%$ and $55.5 \%$ higher, over that of steel, respectively). For the bundled bar investigation, a two bar-bundle, a three bar-bundle, and a four bar-bundle were fastened to the extended bar with a bond length of $63.5 \mathrm{~mm}$ embedded within the concrete. Experimental results indicated a perimeter of a single bar with an equivalent area could be used for calculating the bond strength, which was found to be proportional to the perimeter of the bundled bars.

\subsection{Concrete Deck Slabs under Static and Fatigue Loading}

The deck slabs are the part of bridge most prone to repeated moving wheel loads. The design of concrete deck slabs is governed by long-term fatigue endurance and durability of constituent materials. Previous research on concrete bridge deck slabs subjected to concentrated loads has shown that laterally restrained slabs exhibit strengths higher than those predicted by most design 
codes. This strength enhancement is due to the development of compressive membrane forces or arching action. Arching action is generally developed after cracking of concrete and is mainly dependent on the magnitude of the external restraint. The increase in the arching action can be so significant that punching shear capacity controls the failure of the deck slab (Kuang and Morly, 1992; Mufti et al., 1993; Rankin and Long, 1997; Taylor et al., 2001, Taylor et al., 2007).

The current AASHTO-LRFD design specifications (AASHTO, 2010) consider the design of deck slabs as a continuous strip of $1000 \mathrm{~mm}$ width supported freely over the main bridge beams. In this case, the load carrying capacity of the slab is based on its bending moment capacity. This design approach appears to be over-conservative (Perdikaris and Beim, 1988). However, CHBDC specifies an empirical design method based on punching shear capacity provided that (i) the main beam spacing-to-slab depth ratio is less than 18; (ii) the slab free edges normal to the main beams are stiffened by the end composite beam and increase in slab thickness per Clause 8.18.6; and (iii) the deck slab acts compositely with the supporting beams. As an alternative to the empirical method, CHBDC specifies the flexural design method if the above-mentioned conditions are not met to promote punching shear failure.

A few researchers conducted experiments on bridge deck slabs to examine their fatigue and ultimate load carrying capacity under wheel loads. Sonoda, and Horikawa (1982) carried out experimental program to study the fatigue strength of reinforced concrete slabs under moving loads. Twenty $1 / 3$-scale models of a reinforced concrete bridge deck slab were tested under static loading, fixed point pulsating loading and repetitive moving loads. Test results indicated that moving loads produced more fatigue deterioration than pulsating loads at a fixed point and the influence of transverse reinforcements on the enhancement of fatigue life becomes greater in 
repeated moving loadings than in pulsating loading at a fixed point. Mufti et al. (1993) conducted experimental investigation on fiber reinforced concrete (FRC) deck slabs without internal steel reinforcement. Four 1/2-scale slab-on-girder bridges were tested under concentrated load. Test results demonstrated that FRC deck slab can develop the necessary internal arching system only if the girders top flanges were connected with adequately spaced transverse steel straps.

Kuang and Morley (1992) conducted experimental program to study the punching shear behavior of restrained reinforced concrete slabs. Twelve $1 / 5$-scale reinforced concrete slab specimens were tested under static load. All tested specimens failed in the punching shear mode. The experimental test results indicated that the observed punching shear strengths were higher than the predictions of the yield-line theory and the design provisions of BS 8110 (1997) and ACI-318 (1989), and the enhanced punching strength of the specimens is due to the development of compressive membrane action. Fang et al. (1994) investigated experimentally the behavior of partially restrained slabs under concentrated load. A total of 18 partially restrained reinforced concrete slabs with isotropic reinforcements per OHBDC 1983 were tested under concentrated load. Experimental results showed that all the slabs failed by punching shear due to membrane action.

Perdikaris and Beim, (1988) conducted experimental program to examine the effect of pulsating and moving load on reinforced-concrete bridge deck slabs. Reduced-scale model deck slabs were tested under pulsating and moving loads. All slabs failed due to punching shear. The experimental results demonstrated that moving loads produced more fatigue deterioration than pulsating loads and AASHTO design approach (orthotropic reinforcement ) appear to be over-conservative. Mufti and Newhook (1998) proposed a model for predicting punching shear failure of laterallyrestrained, fiber reinforced concrete (FRC) bridge decks. The proposed model was based on the 
assumption that the stiffness of the bottom transverse reinforcement in concrete deck slabs, rather than its strength, provides the required confinement to develop the arching action and governs the load carrying capacity under concentrated loads.

Khanna et al. (2000) investigated experimentally the effects of reinforcement on the strength of concrete deck slabs. A full-scale model consisted of four segments, each having a different reinforcement pattern, were tested under monotonically increasing loads. All segments failed in the punching shear mode. The experimental results showed that the strength of reinforced concrete deck slabs depends on the stiffness of its bottom transverse reinforcement. Graddy et al. (2002) studied experimentally and analytically the punching-shear behavior of bridge decks under fatigue loading. Full-scale cast-in-place as well as precast prestressed panel specimens were tested under static and pulsating fatigue loads. The effect of membrane compression was considered in predicting the punching-shear capacity of the tested slabs. Based on the experimental results, S-N curves were developed for pulsating fatigue design and assessment. Edalatmanesh and Newhook (2013) carried out experimental program to investigate the fatigue damage in steel-free bridge

deck systems. Two sets of five precast steel-free decks with two different concrete strengths were tested under differing levels of fatigue loading. Based on these test results, S-N curve was proposed for the precast steel-free decks.

\subsection{Bridge Deck Slab Reinforced with GFRP Bars}

Experimental investigations into the behavior of FRP-reinforced deck slabs in general are limited, especially those into the fatigue performance (Kumar and GangaRao, 1998; Rahman et al., 2000; Matsui et al., 2001; EL-Gamal et al., 2005; El-Salakawy et al., 2005; Benmokrane et al., 2006; ElRagaby et al., 2007). Hence, it is necessary to understand the fatigue behavior of such FRP- 
reinforced bridge decks, given the new FRP configurations with the presence of headed stud ends. Fatigue in concrete is a progressive micro-crack initiation and propagation. The mechanism of fatigue in concrete starts with early age micro-cracks in the cement matrix at the interface with aggregates. Under fatigue loading, plain concrete exhibits sharply increasing strains at the beginning within a short period of time, followed by a longer period of steady or slightly increasing strains. With increase in fatigue loading, the concrete matrix turns to be extensively micro-cracked and so strains increase significantly before the slab fails in brittle fracture style. Also, the modulus of elasticity significantly decreases during fatigue loading due to crack formation at the microscopic level (Hwan, 1986; Holman, 1982). Fatigue life in steel bars includes the following phases: (i) crack initiation phase; (ii) steady-state propagation phase; and (iii) brittle fracture of the remaining section. It is understood that corrosion favors crack initiation, leading to lower fatigue life (Tilly and Moss, 1982). Since FRP bars are inherently heterogeneous, a rather complex behavior under fatigue loading results in. Typical damage mechanisms observed under fatigue loading in FRP bars, includes: matrix cracking, fiber-matrix debonding, void growth, and fibre breakage. FRP bar-concrete friction under fatigue loading may result in abrasion of bar surface (Demers, 1998; Adimi et al., 2000; Katz, 2000).

Kumar and GangaRao (1998) carried out experimental program to examine the fatigue response of concrete decks reinforced with sand-coated FRP bars. A total of four concrete deck specimens with varying stringer stiffnesses, composite and non-composite casting, and transverse posttensioning were constructed and tested. All specimens were subjected to a cyclic load at the center with a load range of $169.1 \mathrm{kN}$ and a frequency of $1 \mathrm{~Hz}$. After every 100,000 fatigue cycles, static tests were conducted for a maximum point load of $178 \mathrm{kN}$ to measure the central deck and stringer deflections and strains on the concrete deck and FRP bars. The experimental results 
indicated that: (i) the decks reinforced with FRP bars had a linear variation in stiffness degradation even after 2,000,000 fatigue cycles, thus 2,000,000 fatigue cycles could be conservatively assumed as $80 \%$ of the fatigue life of these decks; (ii) transverse post-tensioning limited the increase of degradation by a factor of five; (iii) a closer stringer spacing may prove to be more acceptable and economical than transverse post-tensioning in arresting crack growth or loss of composite action; and (iv) fatigue failure in concrete decks was influenced by crack formation at the bottom of the deck and it was recommended that the span-to-depth ratios be proportioned such that the extreme fiber tensile stress in the deck is less than $50 \%$ of the modulus of rupture of concrete.

Rahman et al. (2000) studied experimentally the behavior of bridge deck reinforced with carbon FRP grid under service load. A full-scale model of a bridge deck slab reinforced with $0.3 \%$ carbon FRP grid was tested under cyclic load. The slab was pre-cracked and then loaded cyclically in three stages of 4 million cycles each at a frequency of $5 \mathrm{~Hz}$. Test results showed that overall behavior of the slab under the simulated service load is satisfactory and after 4,000,000 cycles, the minimum ultimate load capacity of the deck slab was found to be $534 \mathrm{kN}$. El-Gamal et al. (2005) investigated the punching shear behavior of edge-restrained concrete deck slabs reinforced entirely with GFRP and CFRP bars. Six full-scale deck slabs, $3000 \mathrm{~mm}$ long, $2500 \mathrm{~mm}$ wide and $200 \mathrm{~mm}$ thick, were made fully composite over two steel girders spaced at $2000 \mathrm{~mm}$. All deck slabs were tested to failure under CHBDC vehicular load. Test results indicated that all slabs failed under punching shear with carrying capacities of more than three times the design factored load specified by CHBDC. Also, a new empirical model to predict the punching shear capacity of restrained deck slabs reinforced by FRP reinforcement was proposed. 
El-Salakawy et al. (2005) reported on the design, construction details, and field test results for the Cookshire-Eaton Bridge (Québec, Canada). The bridge was constructed with a total length of $52.08 \mathrm{~m}$ over two equal spans. One span was totally reinforced using GFRP bars, while the other span was reinforced with galvanized steel bars. The bridge was tested for service performance using calibrated truck loads as specified by the CHBDC. Results from the field test indicated that during the first year of service, no cracks were observed in the bridge deck slabs and the deflections of the bridge deck slabs were well below CHBDC allowable limits. Benmokrane et al. (2006) presented design, construction details, and test results for the GFRP-reinforced concrete deck of the Morristown Bridge on Route 100 (Vermont, United States). The bridge was a single span steel girder bridge with integral abutments spanning $43.9 \mathrm{~m}$ and $230 \mathrm{~mm}$ thick concrete deck slab continuous over girders spaced at $2.36 \mathrm{~m}$. The deck slab was reinforced with GFRP bars in two identical layers at the top and the bottom. The bridge was tested for service performance using standard truck loads. The field test results under actual service conditions revealed that GFRP rebar provides very good and promising performance.

El-Ragaby et al. (2007) studied experimentally the fatigue behavior and fatigue life of concrete bridge deck slabs reinforced with GFRP bars. Five full-scale deck slabs were constructed and tested under different schemes of concentrated cyclic loading until failure. In this study, different reinforcement types (steel and GFRP), ratios, and configurations were used. The study showed the superior fatigue performance and longer fatigue life of GFRP-reinforced deck slabs. Klowak et al. (2007) investigated experimentally the static and fatigue behavior of the second-generation steelfree bridge decks. Three segments reinforced with steel, CFRP and GFRP bars were tested under cyclic loads of 222 and $588 \mathrm{kN}$. Test results indicated that all three segments of the bridge deck failed in fatigue under a $588 \mathrm{kN}$ cyclic load and the GFRP reinforcement proved to have the best 
fatigue performance because the modulus of elasticity of the GFRP is much closer to that of concrete.

Liu and Pantelides (2012) investigated experimentally the flexural and shear performance of GFRP-reinforced slabs. Twenty simply-supported slabs of both normal-weight and light-weight concretes were tested. The researchers reported that the modified compression field theory can accurately predict shear strength for GFRP-reinforced slabs.

\subsection{Prefabricated Bridge Elements and Connection Technology}

The use of prefabricated bridge elements and systems (PFBS) is considered an innovative method for accelerating bridge construction and replacement. PFBS are structural elements of a bridge that are built offsite under controlled environment, and include features that could reduce design efforts, negative impact on the environment in the vicinity of the site, lane closure times and inconvenience to the traveling public. PFBS could reduce the on-site construction time and labor by concentrating the construction effort in a fabrication facility rather than at the bridge site, and thus significant economic benefits can be achieved. Aging bridges in North America may require repair, rehabilitation, or replacement. The conventional bridge rehabilitation/replacement system in most situation is very time consuming and expensive. Also, a full-lane closure is very costly specially in large busy urban highways because of the significant economic impact on commercial and industrial activities. Furthermore, issues related to work zone safety and traffic disruptions are also a major concern. As a result, prefabricated bridge technology is seen as a potential solution to many of these issues.

A prefabricated bridge system made of deck bulb-tee (DBT) girders (shown in Fig. 2.2) can be an attractive choice for accelerating bridge construction/replacement. In this system, the concrete 
deck slab is cast with a prestressed girder under controlled conditions at a fabrication facility and then transported to the bridge site. These precast sections are produced in standardized widths of 1.2, 1.8 and $2.4 \mathrm{~m}$ and cover bridge spans up to $36 \mathrm{~m}$. Placed contiguously, these girders provide a ready-made deck, eliminating the need for a closely cast-in-place deck. The DBT girder system requires that longitudinal deck joints be provided to transfer the load between adjacent units. One of the main issues inherent in these prefabricated systems is the presence of cold joints created by the closure pours and their potential impact on the overall deck system behavior. In addition, it is important to develop effective connection details between the prefabricated elements to provide continuity of reinforcement in the closure strips so that load sharing between girders is not compromised.

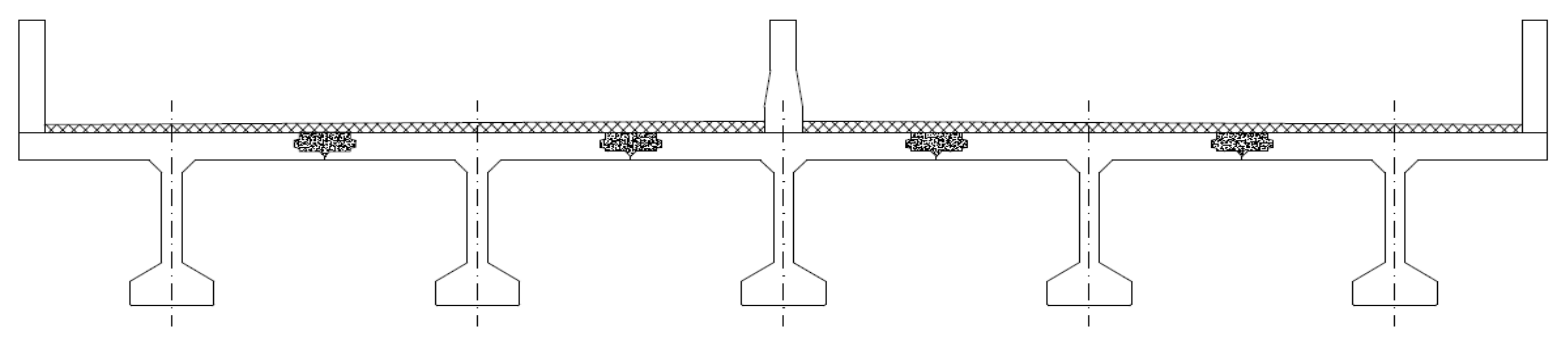

(a) Cross-section

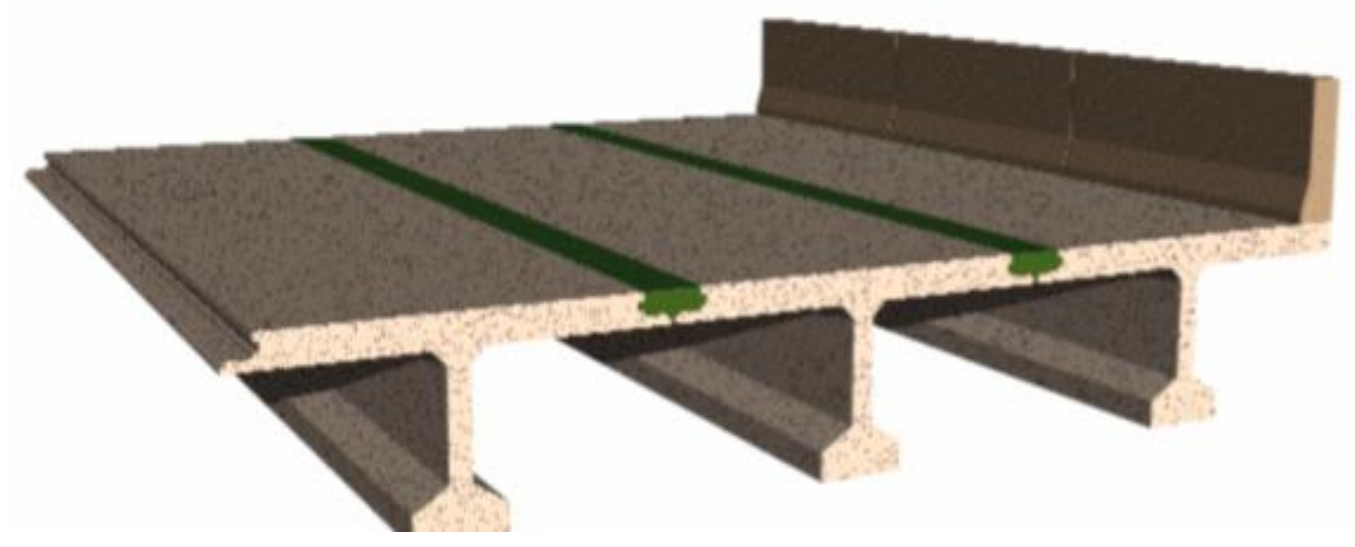

(b) Schematic view

Figure 2.2 Prefabricated bulb-tee bridge system (Sennah et al., 2004) 
Most recently, a few researchers developed and tested to-collapse joint details between flanges of precast bulb-tee girders with projecting straight/U-shaped/headed steel bars. Arockiasamy et al. (1991) investigated experimentally the fatigue strength of joints in a two-span precast prestressed concrete double-tee beam with transverse and longitudinal post-tensioning. Static load and fatigue load at constant amplitude were applied on the model at typical locations simulating AASHTO HS20-44 truck loading. The researchers concluded that the bridge system was maintaining its structural integrity after 8 million cycles. Abendroth (1995) conducted experimental program to study the nominal flexure and shear strength of composite slab system with precast prestressed concrete panels in bridge construction. A total of five full scale models of composite slab specimens were tested under static loading to failure and the results were compared with analytical results using the yield line theory. Experimental results indicated that full-composite behavior was maintained between the reinforced concrete topping and the precast concrete panel and punching shear failure was the mode of failure. Hariatmadar (1997) performed experimental test program to study the seismic response of connection in precast concrete double-tees. A total of five types of connections, consisting of angle welded with either anchor bars or headed studs or combination of both, were tested under combinations of reversed cyclic shear and axial forces until failure. The researcher developed design equation to determine the strength for each connection type.

Yamane et al. (1998) developed new full depth precast prestressed concrete bridge deck panel system with stemmed precast panels, transverse grouted joints, longitudinal post-tensioning and welded threaded and headless studs. It was observed that punching shear was the mode of failure under fatigue and ultimate loading. Pincheira et al. (1998) conducted an experimental program to examine the strength and deformation capacity of double-tee flange-to-flange connectors when subjected to multi-axial and cyclic loading. They used a connector consisting of a steel plate with two filet- 
welded reinforcing bars embedded in a $50 \mathrm{~mm}$ thick concrete slab. The researchers observed moderate to high levels of ductility under monotonic loading, compared to limited deformation under cyclic loading.

Shah et al. $(2006 ; 2007)$ conducted research to investigate the feasibility of using prefabricated bulb-tee girders in Ontario. They developed five moment transferring connections and four intermittent bolted connections for bulb-tee girders. A total of 12 full-size bridge panels were tested to evaluate their structural behavior and the ultimate load carrying capacity when subjected to CHBDC wheel loading. Failure of the joints was observed to be due to either excessive deformation and yielding of the connecting steel plates or debonding of the studs embedded in concrete. Issa et al. (2007) carried out an experimental program on prefabricated full-depth precast concrete bridge deck panel system. In this study, 11 prefabricated, full depth, precast concrete panels were installed to form two-span continuous prototype bridge of $25 \mathrm{~m}$ long and $5.5 \mathrm{~m}$ wide. Two types of longitudinal post-tensioning systems were used in different sequences to tighten the transverse joints and the prototype was tested under static loading to simulate AASHTO HS20 truck loading. The precast concrete bridge deck system showed an acceptable structural behavior under service load and maximum deflection much lower than AASHTO limit for serviceability.

Badie, and Tadros (2008) developed guidelines for the design, fabrication, and construction of full-depth precast concrete bridge deck panel systems without the use of post-tensioning or overlays and connection details for new deck panel systems. Au et al. (2008) investigated two types of prefabricated concrete bridge systems under cyclic and static loading. The first system consisted of prefabricated slab-on-girder elements and casting closure strips between flanges. The second one consisted of full-depth precast concrete deck slabs, steel or prestressed concrete 
girders, and casting closure strips over the girders between adjacent deck slabs. Different types of connections using welded-wire reinforcement, L-shaped lapped bars, and U-shaped bars were tested. The test results demonstrated the excellent performance and integrity of the prefabricated bridge systems under the applied test loads.

Au et al. (2011) conducted an experimental test program on reduced-scale models of the closure strip system. Several precast slab joint details were developed incorporating different steel reinforcement lapping systems, namely: U-shaped, L-shaped, welded straight, and straight bars embedded in closure strips with full lap splice length or reduced lap length but confined by steel spirals or stirrups. The test results demonstrated the excellent performance of the closure strips with U-shaped, L-shaped, and welded straight bars. Zhu and Ma (2010) presented experimental test program for selecting closure pour materials for accelerated bridge construction. Two closure pour materials, overnight cure and 7-day cure, were proposed and studied. Based on this study, a performance criteria for selecting durable closure pour materials was recommended.

Mander et al. (2010) experimentally investigated the performance of a new full-depth precast overhang panel system for concrete bridge decks. Two full-scale, double-panel, specimens were tested by applying load near its edge to examine the collapse capacity and the associated failure modes particularly at panel-to-panel connections. Experimental results showed that the precast full-depth overhang introduced different behavior modes compared to a conventional cast-in-place overhang system, mainly due to the influence of the partial depth panel-to-panel connection, which reduced the capacity by $13 \%$. Mander et al. (2011) presented a modified yield-line theory for full-depth precast concrete bridge deck overhang panels. In this study, the conventional yieldline theory was modified to account for partially bonded bars. Two full-scale concrete bridge 
decks were tested by applying load near its edge to failure. It was observed that the loaded panel failed under flexure while the seam failed in shear. Also, there was a good agreement between the analytical prediction using the modified yield-line theory coupled with a panel-to-panel shear interaction and the experimental results.

\subsection{Anchorage of Steel-Headed Bars to Concrete}

Headed deformed reinforcing steel bars have been used successfully as longitudinal and transverse reinforcement for relatively large reinforced concrete structures. Headed bars can develop within a short distance and can be used to provide additional anchorage when there is insufficient straight length available to develop the required anchorage length. The use of headed bars can significantly reduce the steel congestion at beam-column joints, particularly when largediameter hooked reinforcing bars are used. Furthermore, headed reinforcing bars can reduce the width of longitudinal joint for decked precast prestressed concrete girder bridge, and help to easy construction and concrete placement. Recently, several studies have been conducted to investigate the performance and mechanism of headed reinforcing bars under idealized conditions. Many of these studies investigated the use of headed bars as shear reinforcement as in slab-column joint, while others investigated their use for longitudinal and transverse reinforcement as in closure strips of decked precast prestressed concrete girder bridges. Based on these studies, guidelines on the use of headed bars were introduced in ACI 352R-02 and ACI 421.1R-08. The following paragraph summarizes these studies.

Gayed, and Ghali (2002) investigated experimentally the use of double-head studs as a replacement of conventional stirrups in beams. In this study six reinforced concrete beams having I-shape cross-sections were tested and the results showed that the beams reinforced laterally with 
double-head studs exhibited 6-12\% higher shear strength and 5-11\% more ductility than the others with conventional stirrups. Thompson et al. (2006) presented results from two studies of headed reinforcement to develop a model for determining the anchorage capacity of headed reinforcement. The proposed model included two components that contribute to the total bar stress, namely: head bearing, and bond. The head bearing strength is calculated using the following equation considering strut-and-tie models:

$$
f_{\text {s, head }}=n_{5 \%} \cdot 2 \cdot f_{c}^{\prime} \cdot\left(\frac{c}{d_{b}}\right) \cdot \sqrt{\frac{A_{n h}}{A_{b}}} \cdot \Psi
$$

where $f_{s, \text { head }}$ is the bar stress provided by bearing of the head, $n_{5 \%}$ is a $5 \%$ fractile coefficient, $f_{c}^{\prime}$ is the concrete compression strength, $c$ is the minimum concrete cover dimension measured to bar center, $d_{b}$ is a bar diameter, $A_{n h}$ is the net area of the head, $A_{b}$ is the bar cross-sectional area, $\Psi=0.6+0.4\left(c_{2} / c\right) \leq 2.0$ is the radial disturbance factor, and $c_{2}$ is a minimum concrete cover dimension measured in a direction orthogonal to $c$. The bond strength is calculated using the following equation:

$$
f_{s, b o n d}=\chi \cdot\left(\frac{L_{a}}{L_{d}}\right) \cdot f_{y}
$$

where $f_{s, \text { bond }}$ is the bar stress provided by bond, $\chi=1-0.7\left(\frac{A_{n h} / A_{b}}{5}\right) \geq 0.3$ is a reduction factor, $L_{a}$ is the anchorage length, measured from the point at which the tie bar first intersects strut boundary to the end of the tie bar, $\mathrm{L}_{\mathrm{d}}$ is the bar development length, and $f_{y}$ is the bar yield stress. In this model, a minimum anchorage length $L_{a}$ of $6 d_{b}$ was recommended. 
Hong et al. (2007) proposed a strut-and-tie model to investigate the anchorage capacity of a headed bar terminated within an exterior beam-column joint. The proposed model explains force transfer from the headed bar to the joint and the state of stresses within the joint. Chun et al. (2009) carried out an experimental program to study the anchorage behavior of headed bars in exterior beam-column joints. A total of 30 specimens with headed or hooked beam reinforcement anchorage were tested. Based on the test results, a new model was developed that accounts for head bearing and bond capacity of the anchored bars. The total anchorage strength of a headed bar is calculated using the following equation:

$$
\begin{aligned}
P & =n_{5 \%}\left(P_{\text {bearing }}+P_{\text {bond }}\right) \\
& =0.78\left[\left(1+2.27 \frac{l_{e}-0.7 D_{c}}{D_{c}}\right) 0.85 f_{c}^{\prime} A_{n h}+0.504 \sqrt{f_{c}^{\prime}} \emptyset_{b}\left(l_{e}-d_{b}\right)\right] \quad[M P a] \\
& =0.78\left[\left(1+2.27 \frac{l_{e}-0.7 D_{c}}{D_{c}}\right) 0.85 f_{c}^{\prime} A_{n h}+6.07 \sqrt{f_{c}^{\prime}} \emptyset_{b}\left(l_{e}-d_{b}\right)\right] \quad[p s i]
\end{aligned}
$$

where $P$ is the bar total anchorage strength, $P_{\text {bearing }}$ is the bar strength provided by the head, $P_{\text {bond }}$ is the bar strength provided by bond, $n_{5 \%}$ is a $5 \%$ fractile coefficient, $l_{e}$ is the embedment length, $D_{c}$ is the depth of column, $f_{c}^{\prime}$ is the concrete compression strength, $A_{n h}$ is the net area of the head, $\emptyset_{b}\left(=\pi d_{b}\right)$ is the bar perimeter, and $d_{b}$ is the bar diameter.

(Kang et al. 2009) presented a detailed review of previous research on the use of headed bars in reinforced concrete beam-column joints subjected to quasi-static reversed cyclic loading. The investigated database comprised most available experimental tests on this subject around the world. The authors proposed design guidelines to supplement ACI 352R-02 and ACI 318-08 on the subject of headed bars anchored in beam-column joints. Kang et al. (2010) conducted experimental research to study the anchorage behavior of headed bars with small heads in exterior 
beam-column joints. Several pullout tests and two full-scale reinforced concrete beam-column joint tests were carried out to examine the anchorage behavior of headed bars subjected to monotonic and repeated loading, with different head size, shape, and head-attaching technique. The results revealed that small-headed bars perform well with a development length shorter than that needed for hooked bars.

Li et al. (2010a) presented an experimental test program of improved continuous longitudinal joint details for decked precast prestressed concrete girder bridge systems. Several reinforced concrete slab specimens connected with either lapped headed reinforcement or lapped welded wire reinforcement were tested under static loading. Based on the experimental results, a headed bar detail with a $152 \mathrm{~mm}$ lap length was recommended for DBT bridge system. Li et al. (2010b) carried out a parametric study and experimental test program for decked precast prestressed concrete girder bridge systems to examine their fatigue and ultimate load carrying capacity. Four full-scale slabs connected by No. 16 headed reinforcement detail using a $152 \mathrm{~mm}$ lap length were tested. Static and fatigue tests under four-point pure-flexural loading, as well as three-point flexural-shear loading, were conducted. Based on the experimental results, the improved longitudinal joint behaved well and after 2 million fatigue cycles, it has the same loading capacity as the slab under static load test.

\subsection{Punching Shear of FRP-Reinforced Slabs}

Extensive experimental and theoretical studies have been conducted to investigate the punching shear of steel reinforced concrete slabs. Most of these studies adopted an interior slab-column connections to develop models capable of predicting the direct punching shear strength of a slab without shear reinforcement. As a result, various theoretical strength models have been developed 
based on the yield-line method and fracture mechanics, a strut-and-tie method, or finite-element analysis (Johansen, 1962; Bažant and Cao, 1987; Alexander and Simmonds, 1987; David and Orit 1999, Nielsen 1999; Erberik and Elnashai, 2004; Park et al., 2006; Choi et al., 2007; Hegger et al., 2007; Silva et al., 2007; Ruiz and Muttoni, 2009; Eder et al., 2010; Park et al., 2011). Current design standards such as ACI 318R-08 and BS 8110-97 provide punching shear design equations, typically for use with slabs having steel reinforcement. Less is known about the punching shear behavior in concrete slabs reinforced with FRP composite bars.

According to ACI 318R-08, the punching shear capacity of an interior square column steel reinforced slab is given by

$$
V_{c}=\min \left\{\begin{array}{l}
0.33 \sqrt{f_{c}^{\prime}} b_{o} d \\
\left(0.167+\frac{0.33}{\beta_{c}}\right) \sqrt{f_{c}^{\prime}} b_{o} d \\
\left(0.167+\frac{3.32 d}{b_{o}}\right) \sqrt{f_{c}^{\prime}} b_{o} d
\end{array}\right.
$$

where $f_{c}^{\prime}$ is the specified cylinder compressive strength of concrete, $b_{o}$ is the perimeter at the critical section located at $0.5 d$ away from the column face, $d$ is the average effective slab flexural depth and $\beta_{c}$ is the ratio between the larger and smaller side of the column.

In BS 8110-97 for steel reinforced slabs, $V_{c}$ is calculated as

$$
V_{c}=0.79\left(100 \rho_{s}\right)^{1 / 3}\left(\frac{f_{c u}}{25}\right)^{1 / 3}\left(\frac{400}{d}\right)^{1 / 4} b_{o} d
$$


where $f_{c u}$ is the cube concrete compressive strength, $b_{o}$ is the rectangular perimeter at the critical section, regardless of the column shape, critical perimeter located at $1.5 d$ away from the column face and $\rho_{s}$ is the steel reinforcement ratio.

JSCE 1997 provides an equation for evaluating the punching shear capacity of FRP-reinforced slabs, which is a modification of the equation for steel-reinforced slabs, and given as follows

$$
V_{c}=\beta_{d} \beta_{p} \beta_{r} \frac{f_{p c d}}{\gamma_{b}} b_{o} d
$$

where $\quad \beta_{d}=(1 / d)^{1 / 4} \leq 1.5($ d in meters $), \quad \beta_{p}=\left(100 \rho_{f} E_{f} / E_{s}\right)^{1 / 3} \leq 1.5, \quad \beta_{r}=1+$ $1 /\left(1+0.25 b_{o} / d\right), f_{p c d}=0.2\left(f_{c d}\right)^{1 / 2} \leq 1.2 \mathrm{MPa}, E_{s}$ is the modulus of elasticity of steel, $b_{o}$ is perimeter of the reaction area of the supporting column, $f_{c d}$ is the design concrete compressive strength, and $\gamma_{b}$ is a partial safety factor equal to 1.3 or 1.5 for concrete strengths below and above $50 \mathrm{MPa}$, respectively.

To evaluate the punching shear capacity of FRP-reinforced slabs, researchers have modified the code equations for steel-reinforced slabs of ACI 318 and BS 8110, to account for the bond characteristics and lower elastic modulus of FRP reinforcement.

El-Ghandour et al. (1999) modified the ACI 318 equation by introducing the term $\left(E_{f} / E_{S}\right)^{1 / 3}$

$$
V_{c}=0.33 \sqrt{f_{c}^{\prime}}\left(E_{f} / E_{s}\right)^{1 / 3} b_{o} d
$$

where $E_{f}$ and $E_{s}$ are the modulus of elasticity of FRP and steel, respectively.

Matthys and Taerwe (2000) modified the BS 8110 equation and proposed the following equation for two-way slabs reinforced with FRP bars. 


$$
V_{c}=1.36\left[100 \rho_{f} f_{c}^{\prime}\left(E_{f} / E_{S}\right)\right]^{1 / 3}(1 / d)^{1 / 4} b_{o} d
$$

where $\rho_{f}$ is the FRP reinforcement ratio, and $E_{f}$ and $E_{s}$ are the modulus of elasticity of FRP and steel, respectively.

Ospina et al. (2003) refined Matthys and Taerwe model, and proposed the following empirical equation.

$$
V_{c}=2.77\left(\rho_{f} f_{c}^{\prime}\right)^{1 / 3}\left(E_{f} / E_{s}\right)^{1 / 2} b_{o} d
$$

where $\rho_{f}$ is the FRP reinforcement ratio, and $E_{f}$ and $E_{s}$ are the modulus of elasticity of FRP and steel, respectively.

Ospina (2005) modified the ACI 318 equation by including the effect of the slab reinforcement ratio, steel or FRP, and proposed the following equation.

$$
V_{c}=N \sqrt{f_{c}^{\prime}} b_{o} k d
$$

where $N$ is a constant equal to $5 / 6$ (for $f_{c}^{\prime}$ in $\mathrm{MPa}, b_{o}$ in $\mathrm{mm}$ and $d$ in $\mathrm{mm}$ ). The term $k d$ is the depth of the neutral axis assuming elastic, cracked conditions, where:

$$
k=\left[\left(\frac{E}{E_{c}} \rho\right)^{2}+2 \frac{E}{E_{c}} \rho\right]^{1 / 2}-\frac{E}{E_{c}} \rho
$$

and $E=E_{c}$ and $\rho=\rho_{s}$ for steel slabs, $E=E_{f}$ and $\rho=\rho_{f} E_{f} / E_{s}$ for FRP slabs, and $E_{c}$ is the modulus of elasticity of concrete. 
El-Gamal et al. (2005) proposed a model to predict the punching shear capacity of concrete twoway slabs reinforced with either FRP or steel reinforcement. They modified the ACI 318 equation by adding the effects of the flexural stiffness of the main bottom reinforcement, and the effect of the continuity in the longitudinal and/or in the transverse direction, and proposed the following equation.

$$
V_{c}=0.33 \sqrt{f_{c}^{\prime}} b_{o} d \alpha(1.2)^{N}
$$

where $\mathrm{N}$ represents the continuity effect of the slab on the punching capacity, $\mathrm{N}=0$ for one span slab in both directions; 1 for slab continuous along one direction; 2 for slabs continuous along their two directions; and $\alpha$ is a function of the flexural stiffness of the main bottom reinforcement, the area of the applied load, and the effective depth of the slab.

$$
\alpha=0.62\left(\rho_{\mathrm{f}} \mathrm{E}_{\mathrm{f}}\right)^{1 / 3}\left(1+\frac{8 \mathrm{~d}}{\mathrm{~b}_{\mathrm{o}}}\right)
$$

where $\rho_{f}$ and $E_{f}$ are the reinforcement ratio and modulus of elasticity (in GPa) of the main bottom reinforcement, respectively.

Recently, ACI 440.1R.06 provided an equation for evaluating the FRP reinforced slab punching shear capacity based on research by Ospina (2005) and Tureyen and Frosch (2003) given as

$$
V_{c}=\frac{4}{5} \sqrt{f_{c}^{\prime}} b_{o} c
$$

where $b_{o}$ is a perimeter of critical section for slabs, and $c(=k d)$ is a cracked transformed section neutral axis depth and $k$ is computed as follows

$$
k=\sqrt{2 \rho_{f} n_{f}+\left(\rho_{f} n_{f}\right)^{2}}-\rho_{f} n_{f}
$$


where $\rho_{f}$ is FRP reinforcement ratio, and $n_{f}\left(=E_{f} / E_{c}\right)$ is the modular ratio.

More recently, CSA S806-12 specified an equation for evaluating the punching shear capacity of an interior square column of FRP reinforced slab as follows.

$$
V_{c}=\min \left\{\begin{array}{l}
\left(0.028+\frac{0.056}{\beta_{c}}\right)\left(E_{f} \rho_{f} f_{c}^{\prime}\right)^{1 / 3} b_{o} d \\
\left(0.028+\frac{0.588 d}{b_{o}}\right)\left(E_{f} \rho_{f} f_{c}^{\prime}\right)^{1 / 3} b_{o} d \\
0.056\left(E_{f} \rho_{f} f_{c}^{\prime}\right)^{1 / 3} b_{o} d
\end{array}\right.
$$

where $\rho_{f}$ is FRP reinforcement ration, $E_{f}$ is the modulus of elasticity of FRP and $b_{o}$ is the perimeter at the critical section located at $0.5 d$ away from the column face.

Li et al. (2007) studied experimentally the behavior of flat plate slabs reinforced with CFRP rods in punching shear zone under constant gravity load and lateral displacements in a reversed cyclic manner. The results of the experiment indicated that the CFRP-reinforced specimen showed an excellent ductility. Theodorakopoulos and Swamy (2008) developed a design equation to predict the ultimate punching shear strength of FRP-reinforced concrete slabs. In this equation, the contribution of the FRP reinforcement ratio and concrete strength on the punching shear strength were both incorporated in a combined way. Lee et al. (2009) investigated experimentally the influence of the type of reinforcement (GFRP versus steel bars) on punching shear resistance. In this study, the punching shear capacity, strain distribution, and crack control were investigated. Test results indicated that concentrating the top mat of flexural reinforcement and the presence of steel fibers in concrete improve the punching shear capacity, crack control and post-cracking stiffness. 


\section{CHAPTER III \\ EXPERIMENTAL PROGRAM}

\subsection{General}

The experimental program was undertaken to investigate the use of glass fiber reinforced polymer (GFRP) bars to reinforce the cast-in-place bridge deck slabs as well as the precast bridge deck slab joints in prefabricated bridge bulb-tee (DBT) girders that can be used to accelerate bridge construction/replacement. In DBT system, the concrete deck slab is cast with the prestressed girder and closure strips are cast between the precast flanges to provide continuity between the girders. One of the main issues inherent in these prefabricated systems is the presence of cold joints created by the closure pours and their potential impact on the overall deck system behavior. In addition, it is important to develop effective connection details between the prefabricated elements to provide continuity of reinforcement in the closure strips so that load sharing between girders is not compromised.

\subsection{Proposed Bulb-Tee Girder Connection Details using GFRP Bars}

The intent of this study was to develop joint details between the precast flanges of the DBT girders, incorporating GFRP bars with headed ends and determine their ultimate load carrying capacity when subjected to CHBDC vehicular loads. Six connection details with closure strip widths of 300, 200 and $125 \mathrm{~mm}$ incorporating GFRP bars were proposed. Figure 3.1 shows schematic diagrams of the bulb-tee girders with projecting GFRP bars for the proposed joints. The main parameters studied herein were:

(i) bar embedment length in the closure strip;

(ii) bar shape (straight, headed-end and L-shaped); 
(iii) bar spacing (125 mm, $140 \mathrm{~mm}$ and $200 \mathrm{~mm})$;

(iv) bar bond (ribbed-surface and sand-coated surface of the bars); and

(v) closure strip fill (NS-grout and UHPC).

The first and second proposed connection details between precast flanges of bulb-tee pretensioned girders, shown in Fig. 3.2, have a $200 \mathrm{~mm}$ wide closure strip. In type (I) joint, the precast slab bottom transverse GFRP bars project into the joint with headed end to provide a $175 \mathrm{~mm}$ embedment length in the tension zone of the slab thickness, while the top transverse GFRP bars with straight ends project into the joint with a 175 -mm embedment length in the compression zone of the joint. Type (II) joint is similar to type (I) joint except that the precast slab bottom transverse GFRP bars project into the joint with L-shaped $\left(90^{\circ}\right.$ hooks $)$ to provide a $270 \mathrm{~mm}$ anchorage length in the closure strip. It is assumed that DBT girders will be aligned to provide $200 \mathrm{~mm}$ gap between the connecting precast deck slabs that can be filled using a minimum of $35 \mathrm{MPa}$ nonshrink grout. Figures 3.1-a and 3.1-b show schematic diagrams of the proposed prefabricated bulb-tee pre-tensioned girders with the proposed projecting GFRP bars with headed end and Lshaped end, respectively.

In bridge construction, Ontario Ministry of Transportation (MTO) adopts the standard $225 \mathrm{~mm}$ thick cast-in-place deck slab in Ontario bridges. This slab thickness incorporates a $65 \mathrm{~mm}$ top concrete cover as recommended by CHBDC for reinforcing steel bars for protection against possible corrosion. However, with the use of corrosion-resistant FRP bars, the top concrete cover can be reduced to $40 \mathrm{~mm}$ as specified in CHBDC with the use of FRP reinforcement. This makes the GFRP-reinforced deck slab thickness $200 \mathrm{~mm}$, thus reducing the material of the deck slab by about $12 \%$. As a result, it was decided to conduct this research using $200 \mathrm{~mm}$ thickness for all 
slabs considered in this study. The third and fourth connection details of $125 \mathrm{~mm}$ width were proposed as shown in Fig. 3.3. In type (III) connection, the precast slab bottom transverse GFRP bars project into the joint with headed end to provide a $100 \mathrm{~mm}$ embedment length in the tension zone of the slab thickness, while the top transverse GFRP bars with straight ends project into the joint with $100 \mathrm{~mm}$ embedment length in the compression zone of the joint. Type (IV) connection is similar to type (III) connection except that the precast slab bottom transverse GFRP bars project into the joint with L-shaped $\left(90^{\circ}\right.$ hooks) to provide a $195 \mathrm{~mm}$ embedment length in the closure strip. It is assumed that DBT girders will be aligned to provide a $125 \mathrm{~mm}$ gap that can be filled using ultra-high-performance concrete (UHPC). Figures 3.1-c and 3.1-d show schematic diagrams of the proposed prefabricated bulb-tee pre-tensioned girder with the proposed projecting GFRP bars with headed end and L-shaped end, respectively.

The fifth and sixth connection details of $300 \mathrm{~mm}$ width were proposed as shown in Fig. 3.4. Type (V) connection has a $100 \mathrm{~mm}$ wide closure strip with staggered trapezoidal-shaped (zigzaggedshaped) interlock between the precast flanges as shown in Fig. 3.4-a and in the plan of Fig. 3.9-c. The trapezoidal shape in plan is of length $100 \mathrm{~mm}$ and larger and smaller width of $140 \mathrm{~mm}$ and 70 $\mathrm{mm}$, respectively. In this connection, the precast slab bottom GFRP bars project into the joint with headed end to provide a $175 \mathrm{~mm}$ embedment length in the tension zone of the slab thickness, while the top transverse GFRP bars with straight ends project into the joint with $175 \mathrm{~mm}$ embedment length in the compression zone of the joint. It is assumed that DBT girders will be aligned to provide a $100 \mathrm{~mm}$ gap that can be filled using a minimum of 35-MPa non-shrink grout. Type (VI) connection has a $300 \mathrm{~mm}$ wide closure strip as shown in Fig. 3.4-b. In this connection the precast slab, both the top and bottom GFRP bars of straight ends project into the joint with a $275 \mathrm{~mm}$ embedment length. It is assumed that DBT girders will be aligned to provide a $300 \mathrm{~mm}$ 
gap that can be filled using a minimum of 35-MPa non-shrink grout. Figures 3.1-e and 3.1-f show schematic diagrams of the proposed prefabricated bulb-tee pre-tensioned girder with the proposed projecting GFRP bars with headed end and straight end, respectively. It should be noted that each joint has $50 \mathrm{~mm}$ deep, $40 \mathrm{~mm}$ wide, trapezoidal shape shear key throughout the slab length in the girder direction. Also Figs. 3.2, 3.3 and 3.4 show projecting GFRP bars from one side of the joint only for clarity and each joint would consist of staggered projecting bars that would allow for ease of assembly in the bridge site.

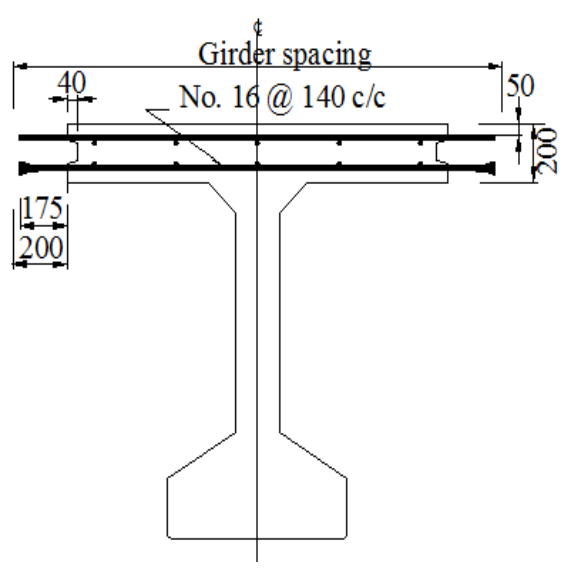

(a)

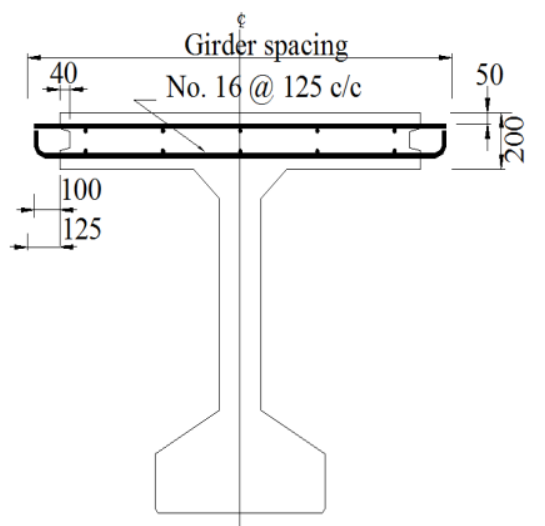

(d)

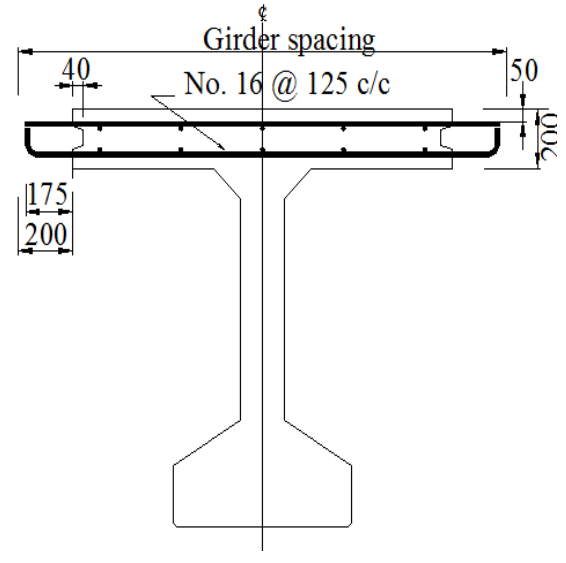

(b)

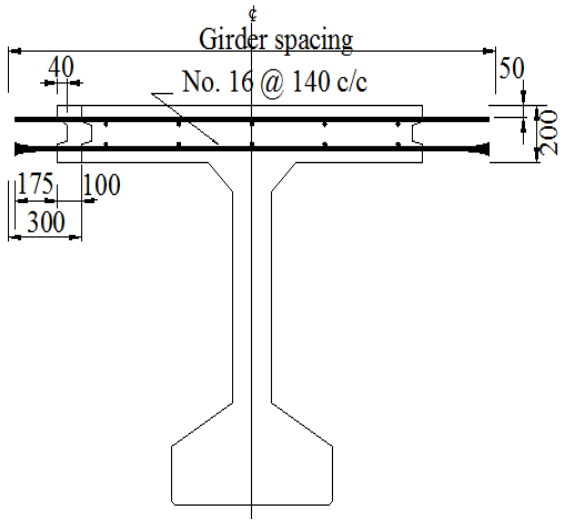

(e)

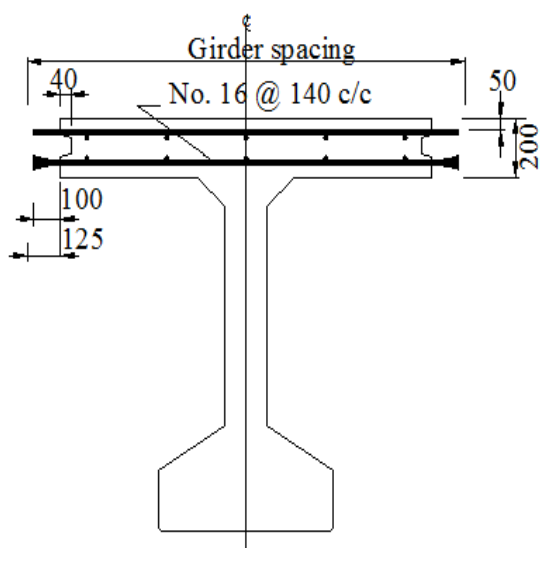

(c)

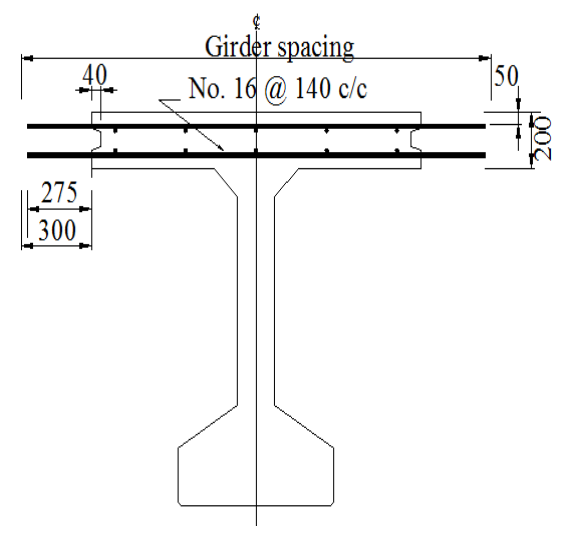

(f)

Figure 3.1 Schematic diagrams of the precast bulb-tee girders with the proposed joint details 
Closure strip filled with min. $35 \mathrm{MPa}$ concrete grout

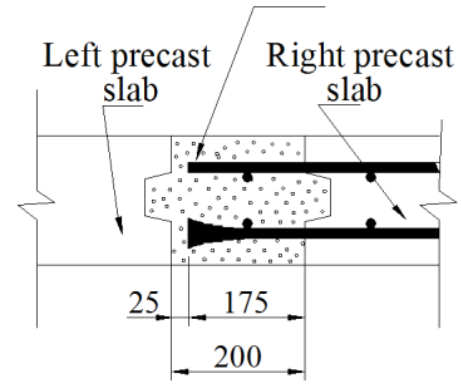

(a) Headed bar type I
Closure strip filled with min. $35 \mathrm{MPa}$ concrete grout

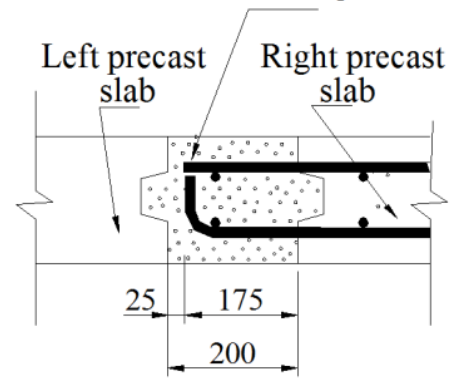

(b) L-shaped bar type II

Figure 3.2 Proposed $200 \mathrm{~mm}$ closure strip width details

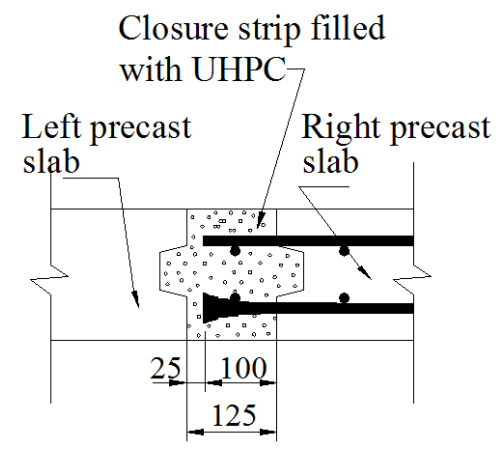

(a) Headed bar type III

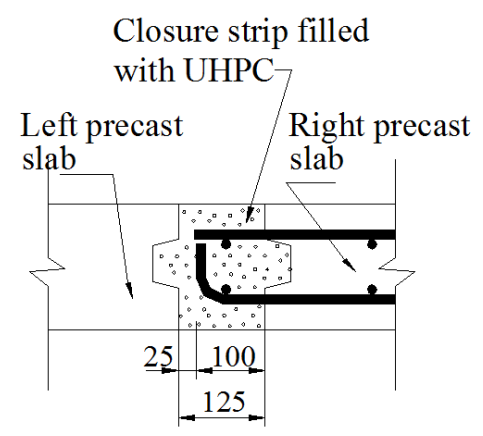

(b) L-shaped bar type IV

Figure 3.3 Proposed $125 \mathrm{~mm}$ closure strip width details

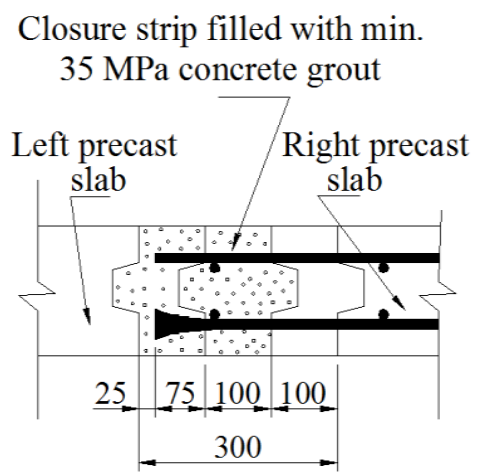

(a) Headed bar type V
Closure strip filled with min. $35 \mathrm{MPa}$ concrete grout

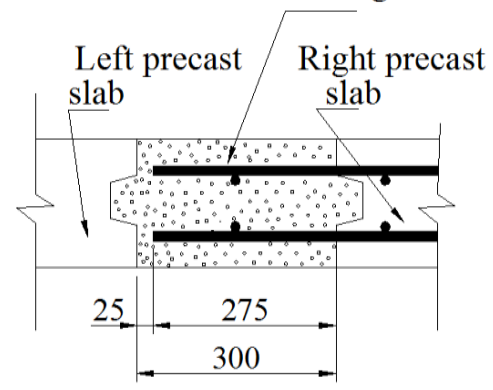

(b) Straight bar type VI

Figure 3.4 Proposed $300 \mathrm{~mm}$ closure strip width details 


\subsection{Phase I: Static Ultimate Load Tests on Simply-Supported Deck Slab Strips}

Phase I of the experimental program included sixteen full-scale deck slab specimens of $2500 \mathrm{~mm}$ length and $200 \mathrm{~mm}$ thick. Since flexural design approach was promoted herein, a $600 \mathrm{~mm}$ slab width was considered for a slab strip. The $600 \mathrm{~mm}$ width was assumed oriented in the direction of traffic while the slab span represented the spacing between precast girders. As such, the main tension reinforcement in the tested specimens represented deck slab reinforcement normal to the girders. It is understood that this slab configuration would provide conservative values for the flexural capacity at the mid-span of the slab since the wheel load would be distributed only over a $600 \mathrm{~mm}$ width. The span of the slab was taken $2000 \mathrm{~mm}$ with slab total length of $2500 \mathrm{~mm}$ to accommodate proper bar anchorage beyond the supporting points. Three groups of deck slabs were proposed in phase I, namely: (i) steel reinforced deck slabs; (ii) ribbed-surface GFRPreinforced deck slabs; and (iii) sand-coated GFRP-reinforced deck slabs.

\subsubsection{Steel-Reinforced Deck Slabs}

The first and second deck slab specimens, namely: SS0 and SS1, were formed of cast-in-place concrete reinforced with steel bars of $400 \mathrm{MPa}$ yield strength, representing the currently used deck slab in Ontario. According to the empirical method specified in Clause 8.18 .4 of the Canadian Highway Bridge Design Code (CHBDC, 2006), an isotropic steel reinforcement of 0.3\% ratio is specified in all directions for the bottom and top layers. This approach resulted in 10M steel bars spaced at $200 \mathrm{~mm}$.

\subsubsection{Ribbed-Surface GFRP-Reinforced Deck Slabs}

The third deck slab specimen, SS2, was similar to cast-in-place deck slab SS0 but with ribbedsurface GFRP bars rather than reinforcing steel bars. The main bottom transverse GFRP 
reinforcement for the deck slabs was based on the empirical design method specified by CHBDC Clause 16.8.8.1 for internally restrained cast-in-place deck slabs. According to this Clause, a minimum GFRP reinforcement area in the transverse bottom direction is set to be $500 d_{s} / E_{F R P}$ where $d_{s}$ is the distance from the top of the slab to the centroid of the bottom transverse reinforcement; and $E_{F R P}$ is the modulus of elasticity of GFRP bars. This reinforcement ratio was specified to have the same axial stiffness as the average between the minimum and the recommended steel reinforcement ratio $(0.25 \%)$ allowed by CHBDC Commentary Clause C.16.8.8.1. This approach results in using No. 16 GFRP bars spaced at $140 \mathrm{~mm}$ in the bottom transverse direction with a reinforcement ratio of about 0.93\%. CHBDC Clause 16.8.8.1 also specifies a minimum GFRP ratio of 0.0035 for the longitudinal bottom reinforcement as well as the longitudinal and transverse top reinforcement. However, Clause 16.8.8.2 refers to a distribution reinforcement to the main reinforcement of $120 /(S)^{0.5}$, up to a maximum of $67 \%$, as a percentage of the main reinforcement, if the main reinforcement is perpendicular to traffic. S herein is considered the spacing of the supporting beams in meters. In this research, the longitudinal bottom reinforcement for the third slab consisted of No. 16 GFRP bars spaced at 225 $\mathrm{mm}$ with a reinforcement ratio of $0.60 \%$. For the top reinforcement layers, No. 12 GFRP bars at $200 \mathrm{~mm}$ spacing were considered for the third slab. Views of the setup of slabs SSO, SS1 and SS2 are shown in Fig. 3.5.

The fourth deck slab specimen, SS3, was similar to second slab SS2 but considering the precast deck system shown in Fig. 3.1 and the precast flange-to-flange connection detail shown in Fig. 3.2-a. In this case, the deck slab represents the flange portions of adjacent bulb-tee precast pretensioned concrete girders. A closure strip was introduced between the connecting flanges as shown in Figs. 3.1-a and 3.2-a. The amount and spacing of GFRP bars reinforcement in the 
precast flanges were the same as those of the cast-in-place deck slab SS2, except that headed ends of the GFRP bar were projecting from each precast slab end and embedded in the closure strip as shown in Fig. 3.1-a. Figure 3.6 shows view of the setup of slab SS3.

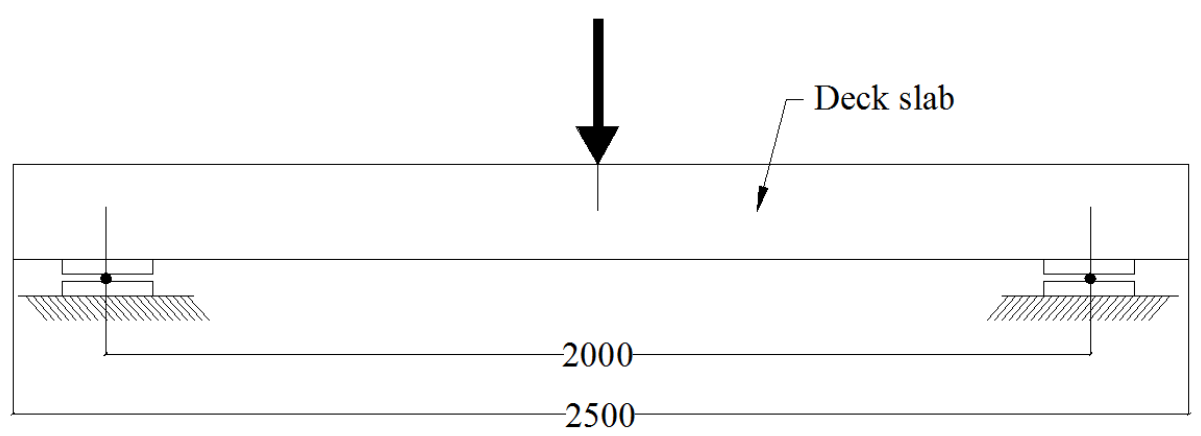

Figure 3.5 Schematic diagram of the test setup of slabs SS0, SS1 and SS2

The fifth deck slab specimen, SS4, was identical to the jointed precast slab SS3, except that the joint width was reduced from $200 \mathrm{~mm}$ to $125 \mathrm{~mm}$ to account for the increase in the bond resistance of the GFRP bar headed ends when embedded in ultra-high-performance concrete (UHPC) rather than non-shrink grout used in slab SS3. Figure 3.7 shows view of the setup of slab SS4 with connection detail shown in Fig. 3.3-a.

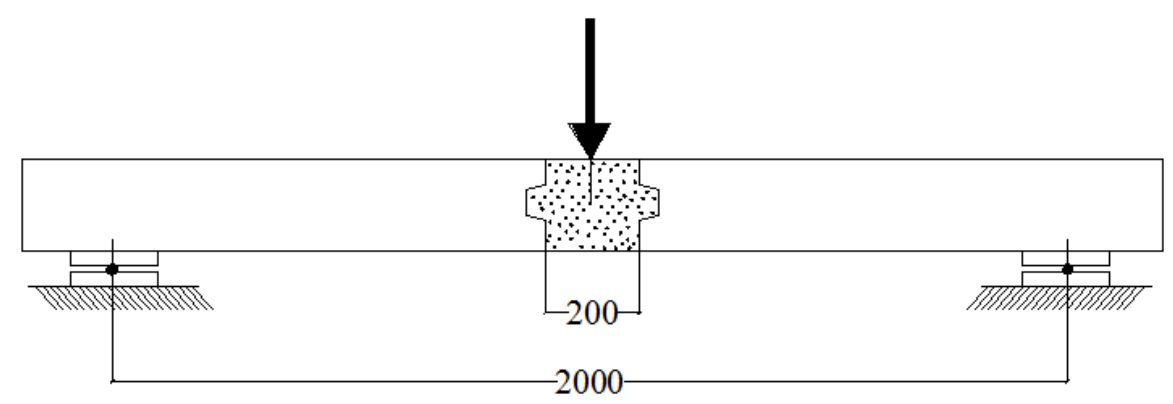

Figure 3.6 Schematic diagram of the test setup of slab SS3

The sixth deck slab specimen, SS5, was formed of precast deck system shown in Fig. 3.1-e and the precast flange-to-flange connection detail shown in Fig. 3.4-a. A trapezoidal-shaped 
(zigzagged-shaped) interlock closure strip was introduced between the connecting flanges as shown in Fig. 3.1-e. Headed end GFRP bars of $16 \mathrm{~mm}$ diameter, spaced at $200 \mathrm{~mm}$, were used in the bottom tension side of the slab thickness, while the top main and transverse reinforcement was taken $12 \mathrm{~mm}$ diameter GFRP bars spaced at $200 \mathrm{~mm}$. The bottom transverse reinforcement was taken $16 \mathrm{~mm}$ diameter GFRP bars, spaced at $225 \mathrm{~mm}$. The seventh deck slab specimen, SS6, was similar to third slab SS2, but considering the precast deck system shown in Fig. 3.1-f and the precast flange-to-flange connection detail shown in Fig. 3.4-b. The amount and spacing of GFRP bars in the precast flanges were the same as those for the cast-in-place deck slab SS2.

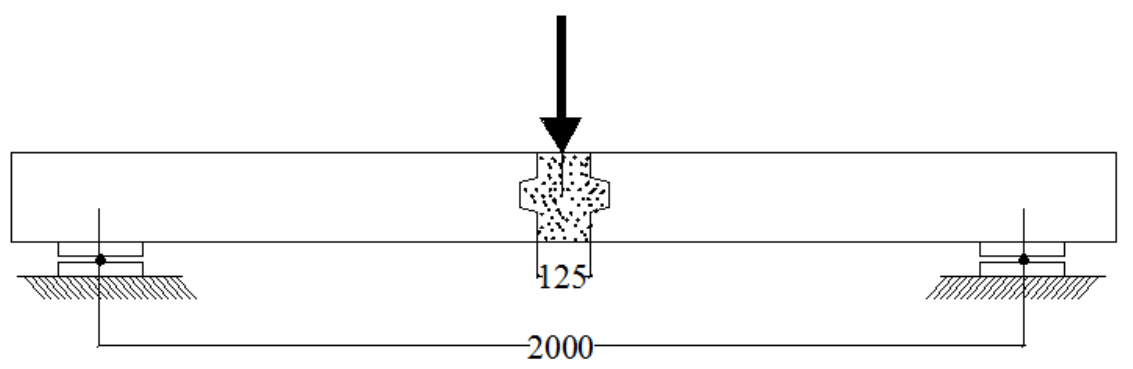

Figure 3.7 Schematic diagram of the test setup of slab SS4

Views of the reinforcement of slabs SS1, SS2, SS3, SS4, SS5 and SS6 are shown in Fig. 3.8, while Fig. 3.9 shows views of GFRP bars projecting in the closure strip of slabs SS2, SS3, SS4, SS5 and SS6 before casting the joint. The eighth, ninth, and tenth deck slabs, SS7, SS8, SS9 were similar to deck slabs SS2, SS3, and SS4, respectively, except that the main bottom transverse GFRP reinforcement spaced at $200 \mathrm{~mm}$. The eleventh deck slab specimen, SS10, was similar to precast deck slab SS6, except that the joint width was reduced from $300 \mathrm{~mm}$ to $200 \mathrm{~mm}$ and the main bottom transverse GFRP reinforcement spaced at $200 \mathrm{~mm}$. 


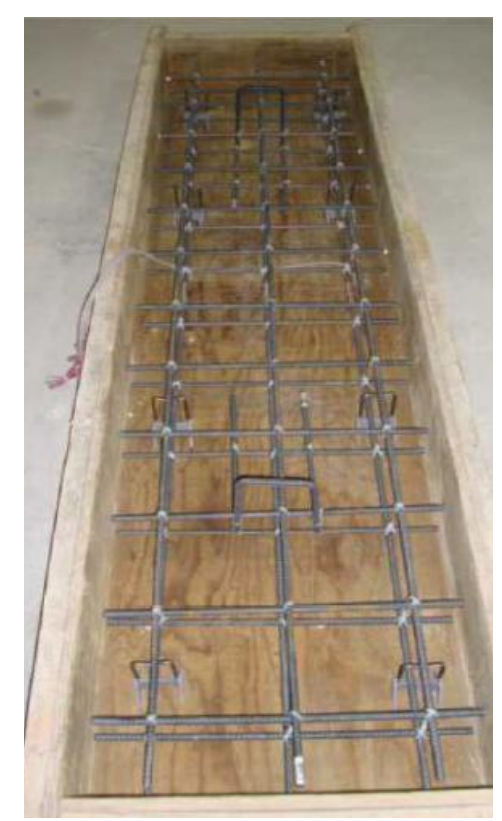

(a) Slab SS1

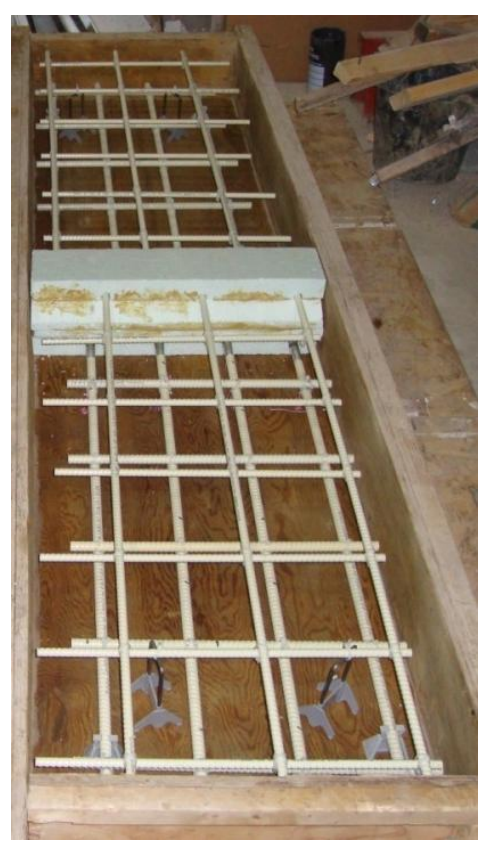

(d) Slab SS4

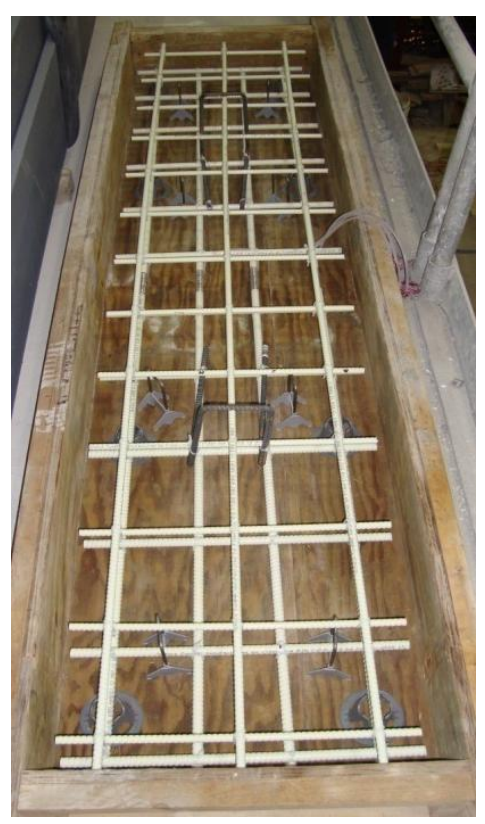

(b) Slab SS2

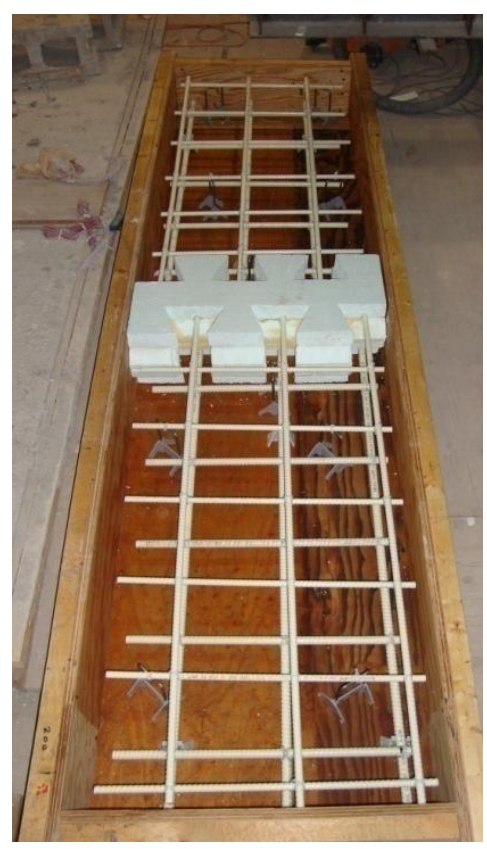

(e) Slab SS5

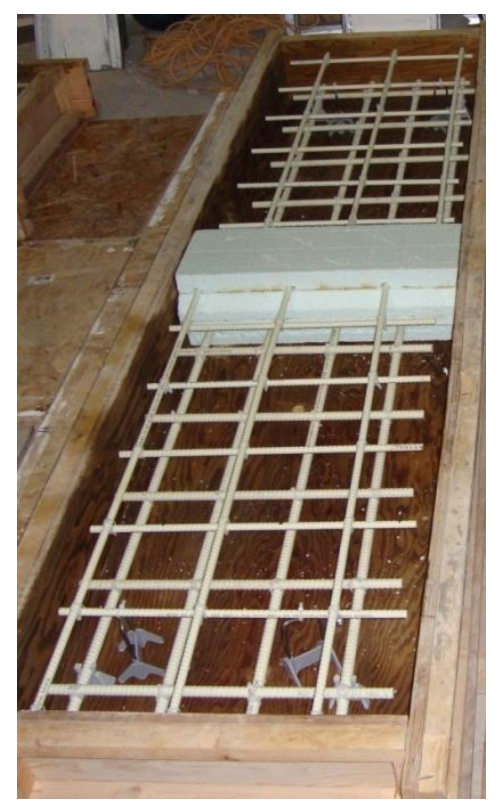

(c) Slab SS3

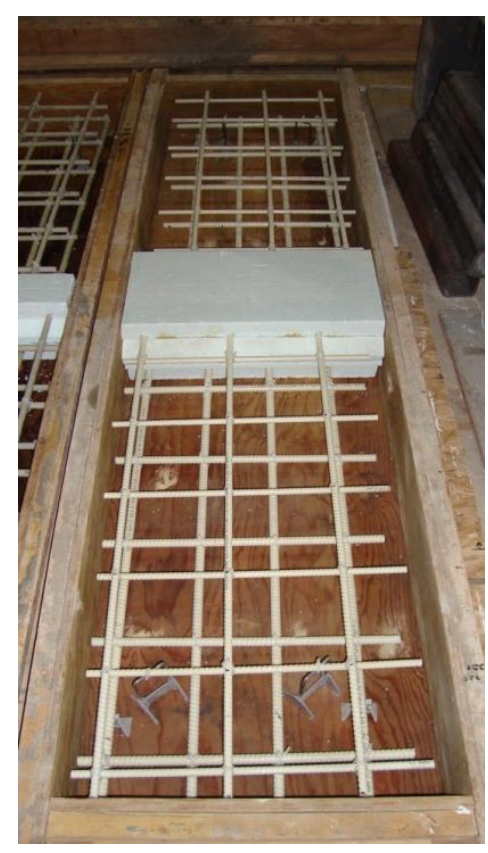

(f) Slab SS6

Figure 3.8 Reinforcement layout in slab specimens 


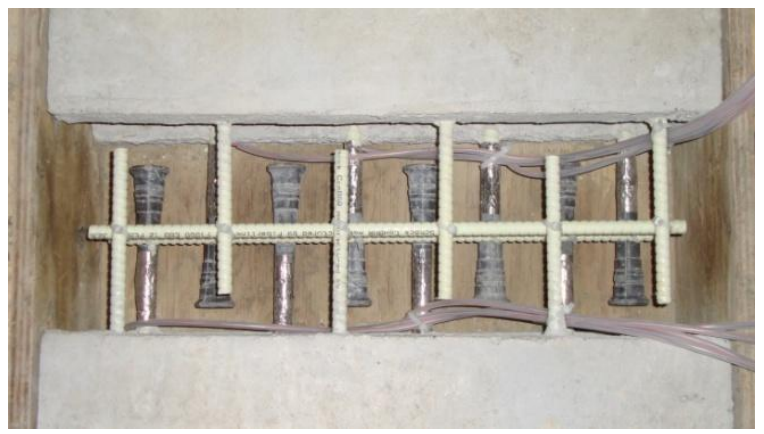

(a) Closure strip for slab SS3

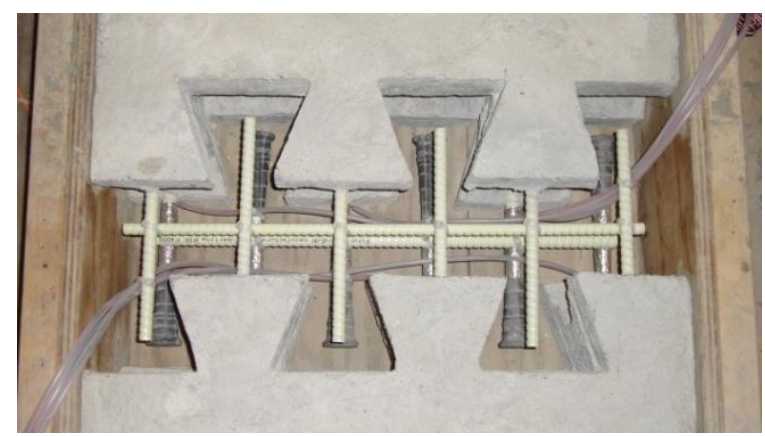

(c) Closure strip for slab SS5

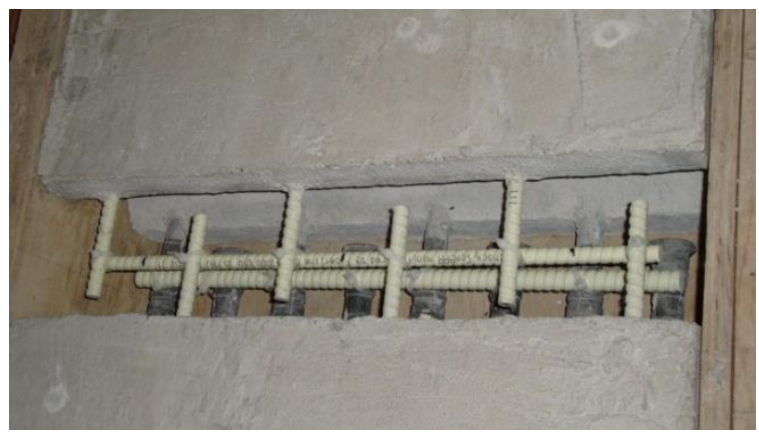

(b) Closure strip for slab SS4

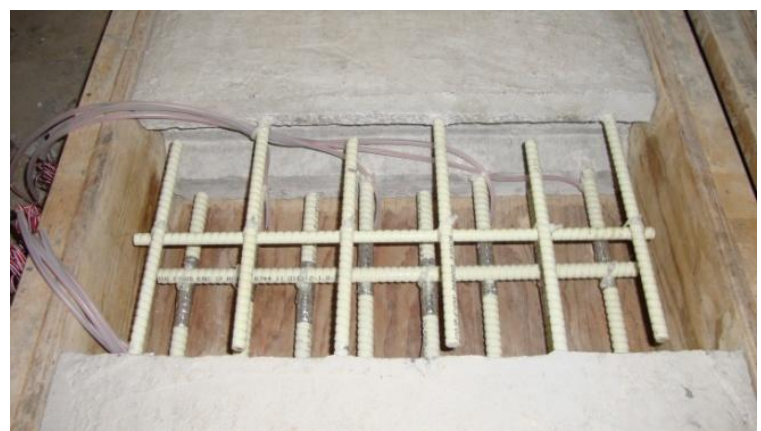

(d) Closure strip for slab SS6

Figure 3.9 Views of closure strips in jointed slabs

\subsubsection{Sand-Coated GFRP-Reinforced Deck Slabs}

The twelfth deck slab specimen, PS1, was identical to cast-in-place deck slabs SS2, but reinforced with sand-coated GFRP bars rather than ribbed-surface GFRP bars. The thirteenth deck slab specimen, PS2, was similar to deck slab PS1 but considering the precast deck system shown in Fig. 3.1-b and the precast flange-to-flange connection detail shown in Fig. 3.2-b. In this case, the deck slab represented the flange portions of adjacent bulb-tee precast pretensioned concrete girders. A closure strip was introduced between the connecting flanges as shown in Figs. 3.1-b 
and 3.2-b. The amount and spacing of GFRP bars reinforcement in the precast flanges were the same as those for the cast-in-place deck slab PS1, except that projecting bottom bars into the closure strip were of standard modulus (SM) L-shaped bars and spaced at $125 \mathrm{~mm}$. It should be noted that the reduction in the spacing to account for the low modulus of elasticity of this type of GFRP bars as compared to the high modulus (HM) bars.

The fourteenth deck slab specimen, PS3, was identical to the jointed precast slab PS2, except that projecting bottom bars into the closure strip were of high modulus (HM) headed end GFRP bars and spaced at $140 \mathrm{~mm}$. The fifteenth deck slab specimen, PS4, was identical to the jointed precast slab PS3, except that the joint width was reduced from 200 to $125 \mathrm{~mm}$ to account for the increase in bond resistance of the GFRP bars embedded in ultra-high-performance concrete (UHPC) rather than the non-shrink grout used in slab PS3. The sixteenth deck slab specimen, PS5, was similar to the jointed precast slab PS4, except that projecting bottom bars into the closure strip were of standard modulus (SM) L-shaped bars spaced at $125 \mathrm{~mm}$. Figures 3.1-d and 3.3-b show the precast deck system and the precast flange-to-flange connection detail for closure strip of deck slab PS5, respectively. Views of the reinforcement of slabs PS1, PS2, PS3, PS4, and PS5 are shown in Fig. 3.10. Figure 3.11 shows view of GFRP bars projecting in the closure strip of slabs PS2, PS3, PS4 and PS5 before casting the joint.

Table 3.1 summarizes the reinforcement details of the tested deck slabs in Phase I of this research. As indicated in Table 3.1, Phase I was limited to static ultimate load tests to examine the structural behavior and ultimate load carrying capacity of the proposed connection details for different precast deck slabs as compared to the control cast-in-place slabs with reinforcing steel, and GFRP 
bars. The results from this phase were used to form the basis for slab configurations used in Phase II of this experimental program.

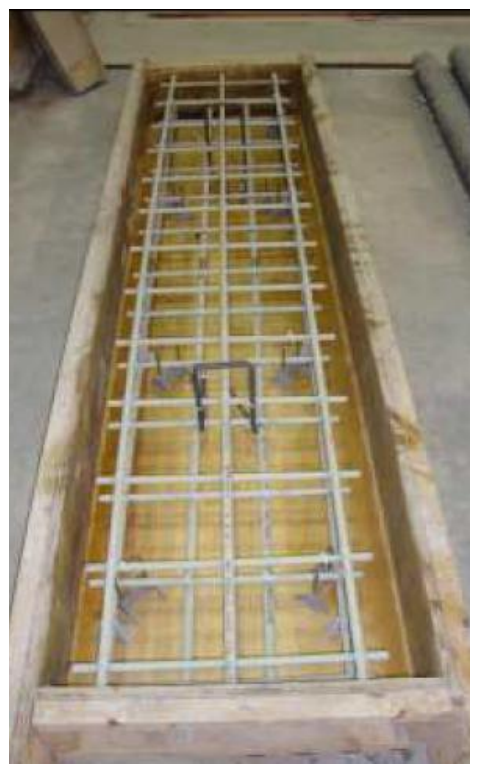

(a) Slab PS1

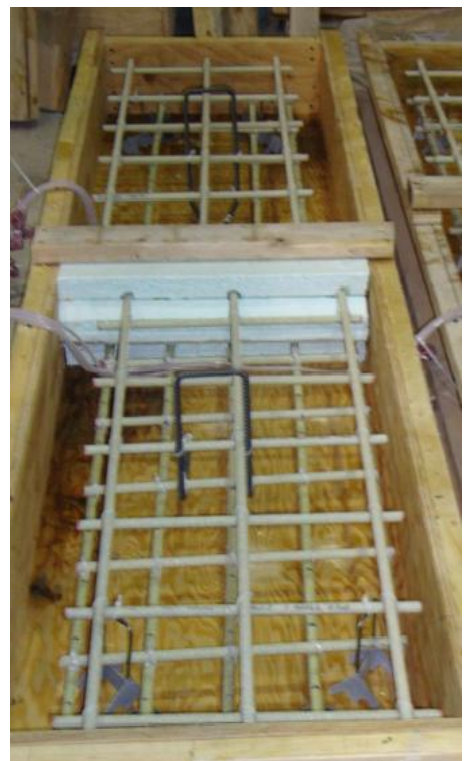

(b) Slab PS2

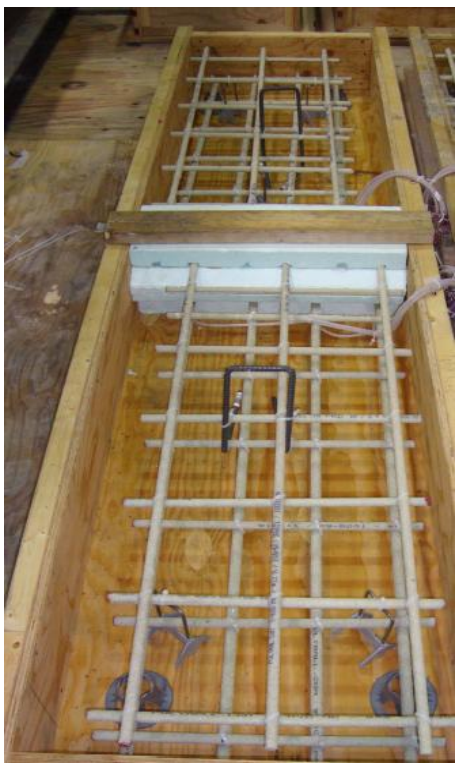

(c) Slab PS3

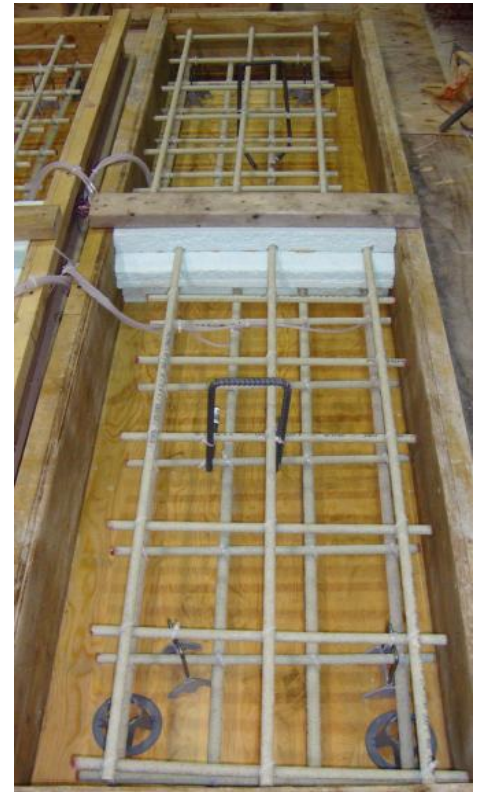

(d) Slab PS4

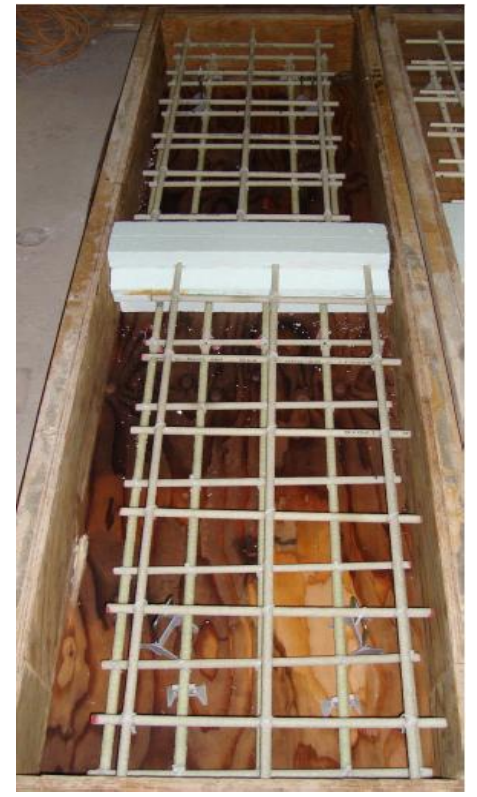

(e) Slab PS5

Figure 3.10 Reinforcement layout in slab specimens reinforced with sand-coated

\section{GFRP bars}




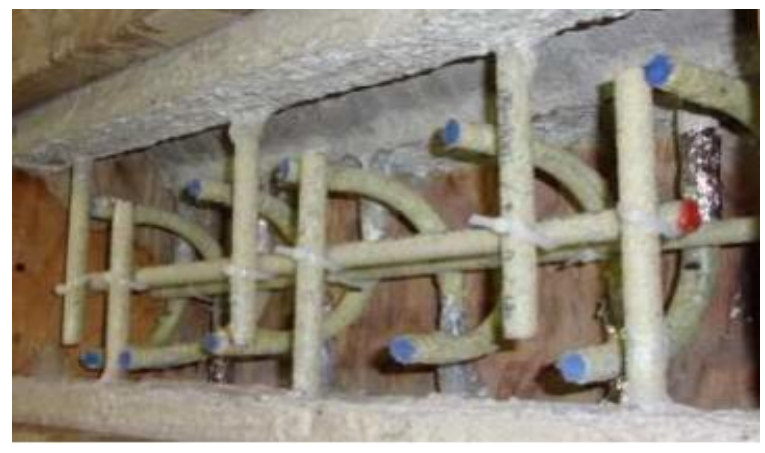

(a) Closure strip for slab PS2

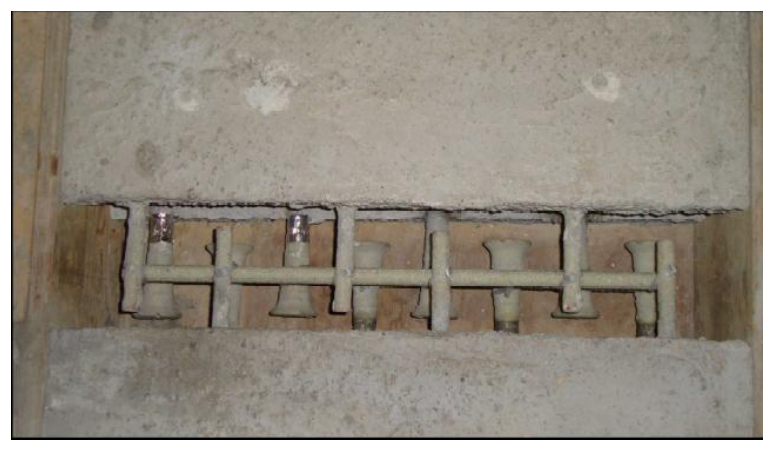

(c) Closure strip for slab PS4

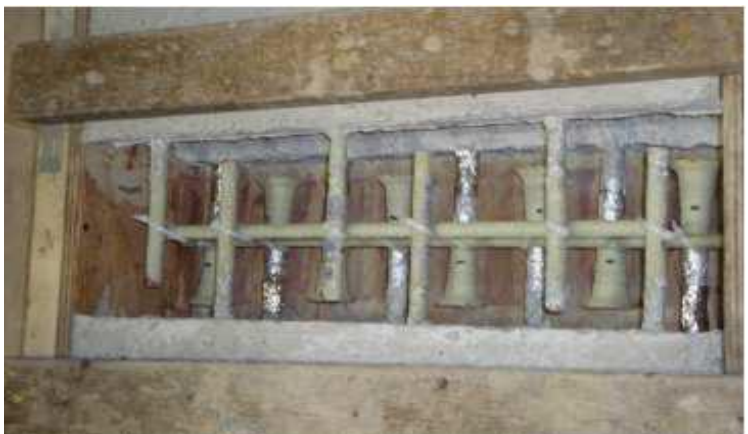

(b) Closure strip for slab PS3

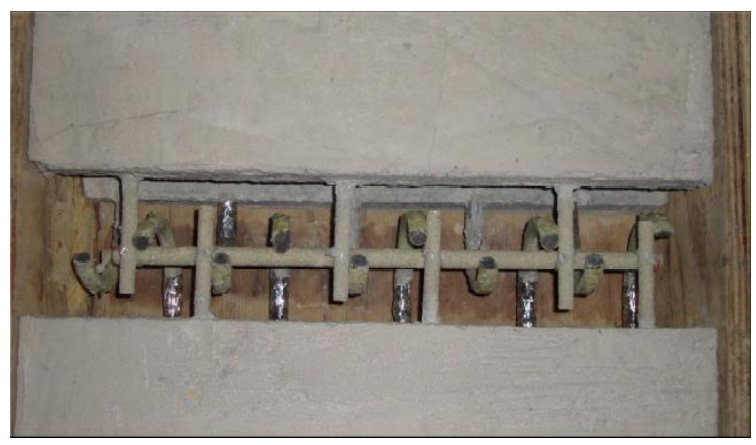

(d) Closure strip for slab PS5

Figure 3.11 Views of closure strip in jointed slabs reinforced with sand-coated GFRP bars

\subsection{Phase II: Static Ultimate Load Tests and Fatigue Load Tests on Internally Restrained Deck Slabs}

Phase II of the experimental program included eight full-scale interior deck slab panels between girders, representing three sets (I, II and III) of deck slab configurations. Sets I and III consisted of three identical deck slabs, so that the first deck slab was tested to-collapse under increasing monotonic wheel load. While the second deck slab was tested under variable amplitude fatigue loading as explained later. The third identical deck slab was tested under constant amplitude fatigue loading followed by static ultimate load test if it would not fail during fatigue loading. In 
case of set II the deck slab configuration consisted of two identical slabs, they were tested under the two different fatigue schemes.

Table 3.1 Summary of reinforcement details of the deck slabs in Phase I tested under static load

\begin{tabular}{|c|c|c|c|c|}
\hline $\begin{array}{l}\text { Specimen } \\
\text { No. }\end{array}$ & Slab & Reinforcement & Slab type & $\begin{array}{l}\text { Loading } \\
\text { procedure }\end{array}$ \\
\hline 1 & SS0 & $\begin{array}{l}\text { Steel straight bars }(3-10 \mathrm{~mm}) \\
\qquad \rho=0.32\end{array}$ & Cast-in-place & $\begin{array}{l}\text { Monotonic } \\
\text { SUL }^{*} \text { test }\end{array}$ \\
\hline 2 & SS1 & $\begin{array}{l}\text { Steel straight bars }(3-10 \mathrm{~mm}) \\
\rho \rho=0.32\end{array}$ & Cast-in-place & \multirow{6}{*}{$\begin{array}{l}\text { Incremental } \\
\mathrm{SUL}^{*} \text { test }\end{array}$} \\
\hline 3 & $\mathrm{SS} 2$ & $\begin{array}{l}\text { GFRP straight bars }(4-16 \mathrm{~mm}) \\
\text { HM }^{(1)} \text { Ribbed-surface } \rho=0.90\end{array}$ & Cast-in-place & \\
\hline 4 & SS3 & $\begin{array}{l}\text { GFRP headed bars }(4-16 \mathrm{~mm}) \\
\text { HM Ribbed-surface } \rho=0.90\end{array}$ & $\begin{array}{l}\text { Precast with } 200 \mathrm{~mm} \text { closure } \\
\text { strip filled with } \mathrm{NSG}^{\S}\end{array}$ & \\
\hline 5 & $\mathrm{SS} 4$ & $\begin{array}{l}\text { GFRP headed bars }(4-16 \mathrm{~mm}) \\
\text { HM Ribbed-surface } \rho=0.90\end{array}$ & $\begin{array}{l}\text { Precast with } 125 \mathrm{~mm} \text { closure } \\
\text { strip filled with UHPC }\end{array}$ & \\
\hline 6 & SS5 & $\begin{array}{l}\text { GFRP headed bars }(3-16 \mathrm{~mm}) \\
\text { HM Ribbed-surface } \rho=0.66\end{array}$ & $\begin{array}{l}\text { Precast with trapezoidal-shaped } \\
\text { closure strip filled with } \mathrm{NSG}^{\S}\end{array}$ & \\
\hline 7 & SS6 & $\begin{array}{l}\text { GFRP straight bars }(4-16 \mathrm{~mm}) \\
\text { HM Ribbed-surface } \rho=0.90\end{array}$ & $\begin{array}{l}\text { Precast with } 300 \text { mm closure } \\
\text { strip filled with } \mathrm{NSG}^{\S}\end{array}$ & \\
\hline 8 & SS7 & $\begin{array}{l}\text { GFRP straight bars }(3-16 \mathrm{~mm}) \\
\text { HM Ribbed-surface } \rho=0.66\end{array}$ & Cast-in-place & \multirow{4}{*}{$\begin{array}{l}\text { Monotonic } \\
\text { SUL }{ }^{*} \text { test }\end{array}$} \\
\hline 9 & SS8 & $\begin{array}{l}\text { GFRP headed bars }(3-16 \mathrm{~mm}) \\
\text { HM Ribbed-surface } \rho=0.66\end{array}$ & $\begin{array}{c}\text { Precast with } 200 \mathrm{~mm} \text { closure } \\
\text { strip filled with } \mathrm{NSG}^{\S}\end{array}$ & \\
\hline 10 & SS9 & $\begin{array}{l}\text { GFRP headed bars }(3-16 \mathrm{~mm}) \\
\text { HM Ribbed-surface } \rho=0.66\end{array}$ & $\begin{array}{l}\text { Precast with } 125 \mathrm{~mm} \text { closure } \\
\text { strip filled with UHPC }\end{array}$ & \\
\hline 11 & SS10 & $\begin{array}{l}\text { GFRP straight bars }(3-16 \mathrm{~mm}) \\
\text { HM Ribbed-surface } \rho=0.66\end{array}$ & $\begin{array}{l}\text { Precast with } 200 \mathrm{~mm} \text { closure } \\
\text { strip filled with } \mathrm{NSG}^{\S}\end{array}$ & \\
\hline 12 & PS1 & $\begin{array}{c}\text { GFRP straight bars }(4-16 \mathrm{~mm}) \\
\text { HM Sand-coated } \rho=0.90\end{array}$ & Cast-in-place & \multirow{5}{*}{$\begin{array}{l}\text { Incremental } \\
\text { SUL }^{*} \text { test }\end{array}$} \\
\hline 13 & PS2 & $\begin{array}{c}\text { GFRP L-shaped bars (5-16mm) } \\
\text { SM }^{(2)} \text { Sand-coated } \rho=1.10\end{array}$ & $\begin{array}{l}\text { Precast with } 200 \mathrm{~mm} \text { closure } \\
\text { strip filled with } \mathrm{NSG}^{\S}\end{array}$ & \\
\hline 14 & PS3 & $\begin{array}{c}\text { GFRP headed bars (4-16 mm) } \\
\text { HM Sand-coated } \rho=0.90\end{array}$ & $\begin{array}{c}\text { Precast with } 200 \mathrm{~mm} \text { closure } \\
\text { strip filled with } \mathrm{NSG}^{\S}\end{array}$ & \\
\hline 15 & PS4 & $\begin{array}{c}\text { GFRP headed bars }(4-16 \mathrm{~mm}) \\
\text { HM Sand-coated } \rho=0.9\end{array}$ & $\begin{array}{l}\text { Precast with } 125 \mathrm{~mm} \text { closure } \\
\text { strip filled with UHPC }\end{array}$ & \\
\hline 16 & PS5 & $\begin{array}{l}\text { GFRP L-shaped bars }(5-16 \mathrm{~mm}) \\
\text { SM Sand-coated } \rho=1.10\end{array}$ & $\begin{array}{l}\text { Precast with } 125 \mathrm{~mm} \text { closure } \\
\text { strip filled with UHPC }\end{array}$ & \\
\hline
\end{tabular}

SUL $^{*}$ test= Static ultimate load test; $\$ N S G=35$ MPa non-shrink grout; UHPC ${ }^{* * *}=$ Ultra-high-performance concrete;

(1) $\mathrm{HM}=$ High-modulus; (2) SM = Standard-modulus. 
Each deck slab has $200 \mathrm{~mm}$ thickness, $2500 \mathrm{~mm}$ width normal to traffic and $3500 \mathrm{~mm}$ length in the direction of traffic. The deck slab was supported over two W610X241 steel beams with transverse bracing at their ends to provide lateral restraints to the deck slab as specified in the CHBDC empirical design method. The centre-to-centre spacing of the supporting beams was taken as $2000 \mathrm{~mm}$. The deck slabs and the supporting beams were made fully composite with shear connector pockets and shear studs as shown in Figs. 3.12 and 3.13.

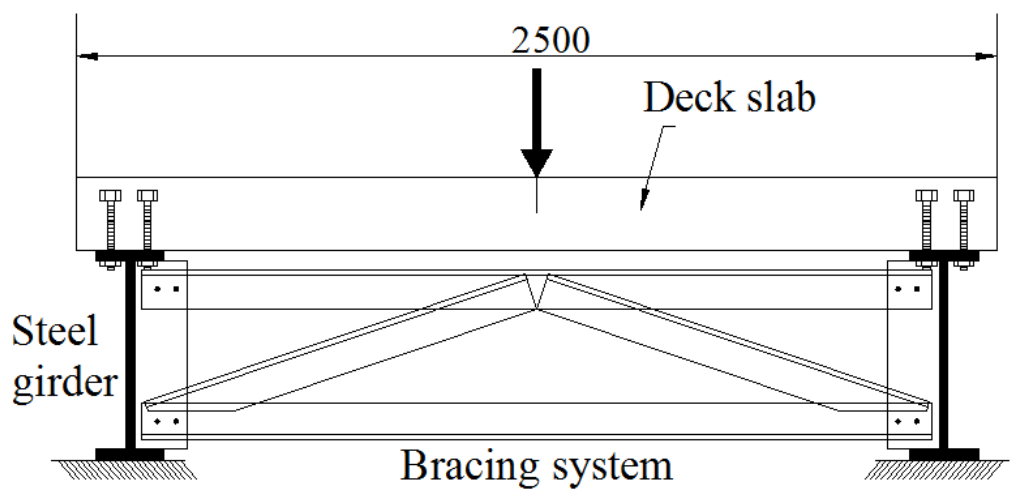

Figure 3.12 Typical schematic diagram of the test setup of the cast-in-place slabs

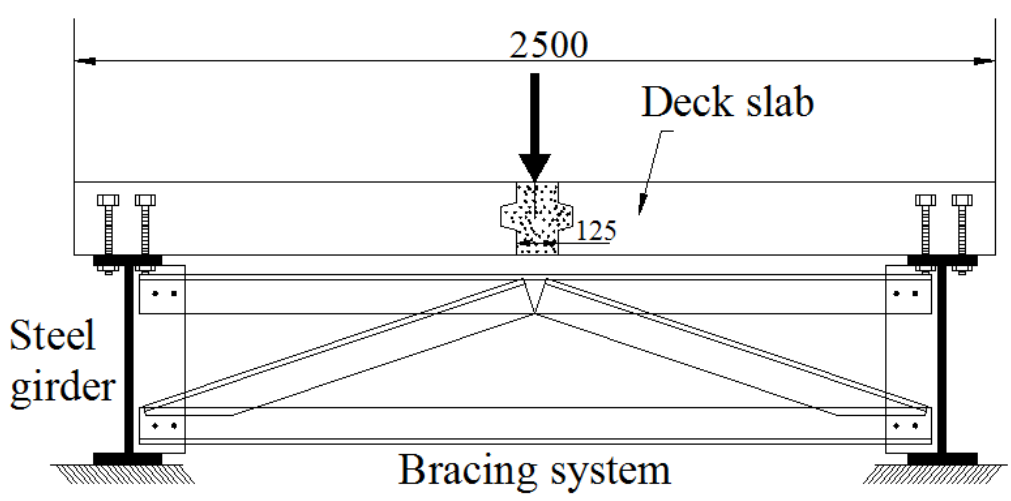

Figure 3.13 Typical schematic diagram of the test setup of the jointed precast slabs

Table 3.2 summarizes the configurations of the three sets of deck slabs on steel girders tested under static and fatigue loading. The first set of deck slabs included three identical slab panels, namely: S1, S2 and S3, made of cast-in-place concrete reinforced with ribbed-surface GFRP bars. 
Table 3.2 Summary of tested slab configurations for phase II

\begin{tabular}{|c|c|c|c|c|c|c|c|c|}
\hline \multirow{2}{*}{ Group } & \multirow{2}{*}{ Slab } & \multirow{2}{*}{ Bar type } & \multirow{2}{*}{ Slab type } & \multicolumn{2}{|c|}{$\begin{array}{l}\text { Transverse reinforcement } \\
\text { (normal to girders) }\end{array}$} & \multicolumn{2}{|c|}{$\begin{array}{l}\text { Longitudinal reinforcement } \\
\text { (parallel to girders) }\end{array}$} & \multirow{2}{*}{$\begin{array}{l}\text { Test } \\
\text { type * }\end{array}$} \\
\hline & & & & Bottom & Top & Bottom & Top & \\
\hline \multirow{3}{*}{ I } & $\mathrm{S} 1$ & \multirow{3}{*}{$\begin{array}{c}\text { GFRP } \\
\text { Ribbed-surface }\end{array}$} & \multirow{3}{*}{ Cast-in-place } & \multirow{3}{*}{$\begin{array}{l}\text { Straight end } \\
\text { No. } 16 \\
\text { @140 mm }\end{array}$} & \multirow{3}{*}{$\begin{array}{l}\text { Straight end } \\
\text { No.12@ } \\
200 \mathrm{~mm}\end{array}$} & \multirow{3}{*}{$\begin{array}{l}\text { Straight end } \\
\text { No.16@ } \\
225 \mathrm{~mm}\end{array}$} & \multirow{3}{*}{$\begin{array}{l}\text { Straight end } \\
\text { No. } 12 @ \\
200 \mathrm{~mm}\end{array}$} & SUL test \\
\hline & $\mathrm{S} 2$ & & & & & & & VAF test \\
\hline & $\mathrm{S} 3$ & & & & & & & CAF test \\
\hline \multirow{2}{*}{ II } & $\mathrm{S} 4$ & \multirow{2}{*}{$\begin{array}{c}\text { GFRP } \\
\text { Ribbed-surface }\end{array}$} & \multirow{5}{*}{$\begin{array}{c}\text { Precast with } 125 \mathrm{~mm} \\
\text { closure strip filled } \\
\text { with } \mathrm{UHPC}^{\S}\end{array}$} & \multirow{2}{*}{$\begin{array}{l}\text { Headed end } \\
\text { No. } 16 \\
\text { @ } 140 \mathrm{~mm}\end{array}$} & \multirow{2}{*}{$\begin{array}{l}\text { Straight end } \\
\text { No.12@ } \\
200 \mathrm{~mm}\end{array}$} & \multirow{2}{*}{$\begin{array}{l}\text { Straight end } \\
\text { No.16@ } \\
225 \mathrm{~mm}\end{array}$} & \multirow{2}{*}{$\begin{array}{l}\text { Straight end } \\
\text { No. } 12 @ \\
200 \mathrm{~mm}\end{array}$} & CAF test \\
\hline & S5 & & & & & & & VAF test \\
\hline \multirow{3}{*}{ III } & S6 & \multirow{3}{*}{$\begin{array}{c}\text { GFRP } \\
\text { Sand-coated }\end{array}$} & & \multirow{3}{*}{$\begin{array}{l}\text { Headed end } \\
\text { No. } 16 \\
@ 140 \mathrm{~mm}\end{array}$} & \multirow{3}{*}{$\begin{array}{l}\text { Straight end } \\
\text { No.12@ } \\
200 \mathrm{~mm}\end{array}$} & \multirow{3}{*}{$\begin{array}{l}\text { Straight end } \\
\text { No.16 @ } \\
225 \mathrm{~mm}\end{array}$} & \multirow{3}{*}{$\begin{array}{l}\text { Straight end } \\
\text { No.12@ } \\
200 \mathrm{~mm}\end{array}$} & SUL test \\
\hline & S7 & & & & & & & VAF test \\
\hline & S8 & & & & & & & CAF test \\
\hline
\end{tabular}

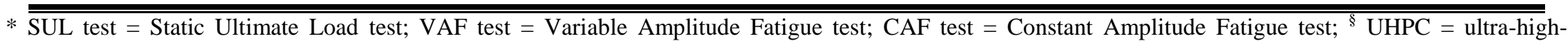
performance concrete. 
The main bottom transverse GFRP reinforcement for these GFRP-reinforced deck slabs was based on the empirical design method recommended by CHBDC Clause 16.8.8.1 for internally restrained cast-in-place deck slabs. The slab reinforcement was identical to those for slab SS2 in Phase I, but over $3500 \mathrm{~mm}$ width rather that $600 \mathrm{~mm}$ width in the direction of traffic. This set was used as a control set to examine the significance of using headed end GFRP bars in precast slab system in lieu of currently used reinforcing steel bars. Figures 3.14 and 3.15 show the reinforcement layout and the fabrication of this set of deck slabs.

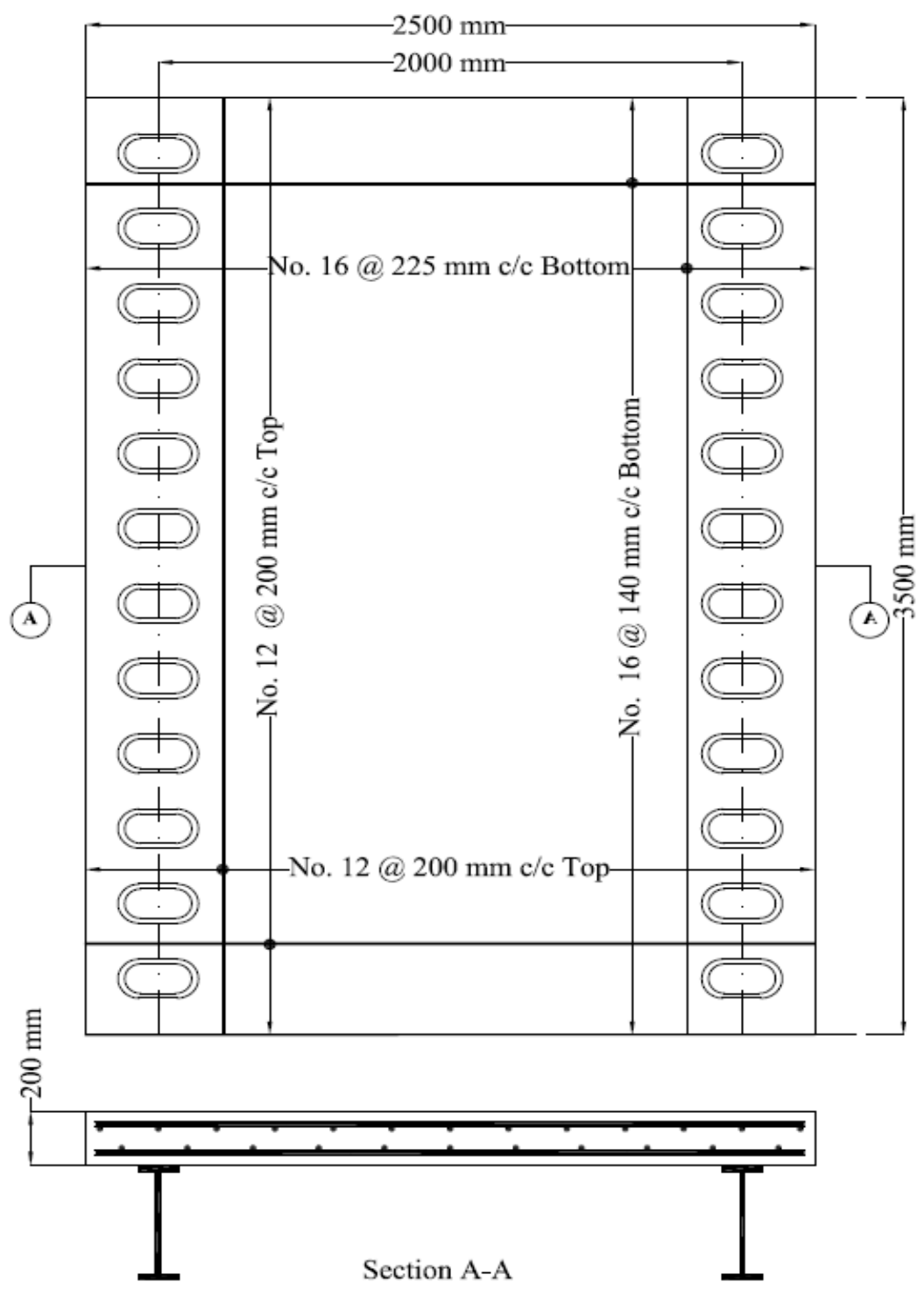

Figure 3.14 Reinforcement layout for cast-in-place deck slabs 


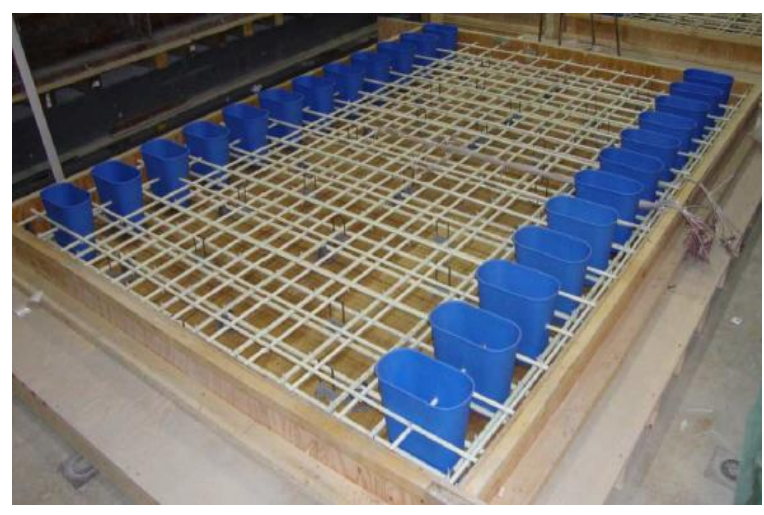

(a) Before pouring concrete

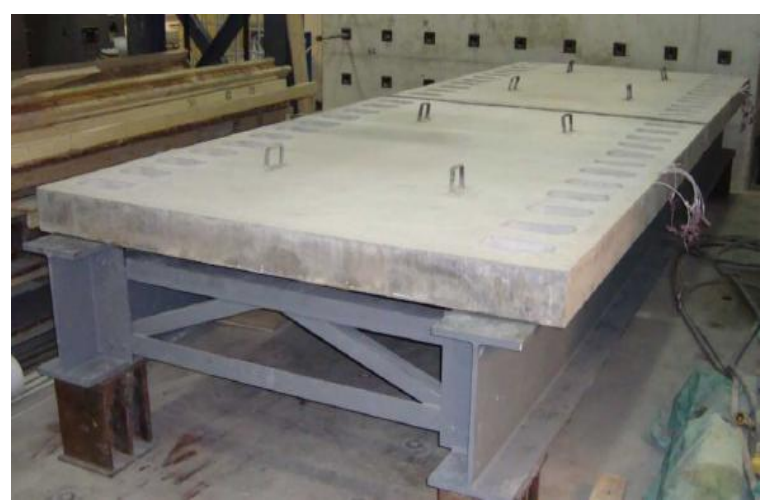

(c) Before grouting

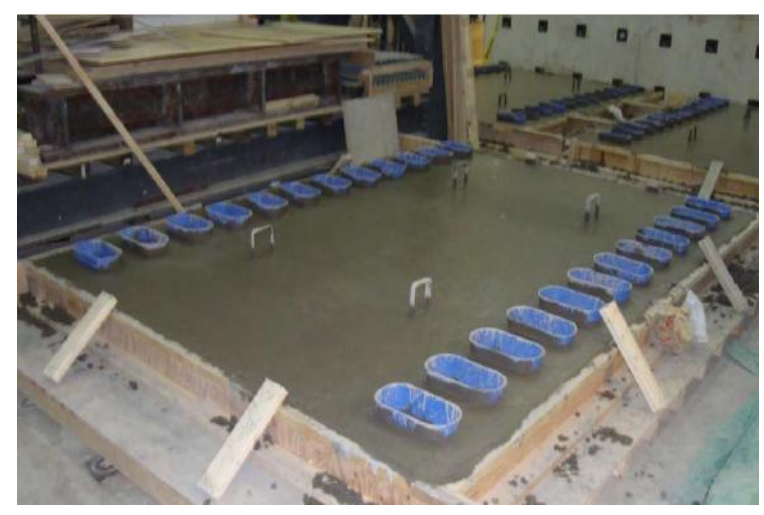

(b) After pouring concrete

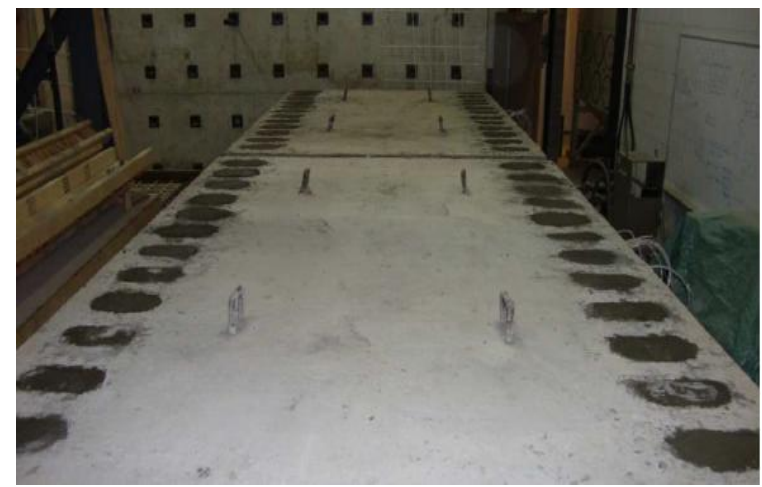

(d) After grouting

Figure 3.15 Cast-in-place deck slabs fabrication

The second set of deck slab panels has two identical slabs S4, and S5. Each slab was formed of two identical $3500 \times 1187.5 \times 200 \mathrm{~mm}$ precast slab panels, with a 50-mm deep, 40-mm wide, trapezoidal shape shear key throughout the slab length in the girder direction. The precast slabs represented the flange portions of adjacent bulb-tee precast pretensioned concrete girders shown in Fig. 3.1-c. A $125 \mathrm{~mm}$ wide closure strip was introduced between the precast flanges of bulbtee girders as shown in Fig. 3.3-a and Fig. 3.13. The precast slab bottom GFRP bars project into the joint with headed ends to provide a $100 \mathrm{~mm}$ embedment length in the tension zone of the slab 
thickness, while the top transverse GFRP bars with straight ends project into the joint with a 100 mm embedment length in the compression zone of the joint. It is assumed that DBT girders would be aligned to provide a $125 \mathrm{~mm}$ gap that can be filled with UHPC having a minimum specified strength of $100 \mathrm{MPa}$. It should be noted that Fig. 3.3-a shows projecting GFRP bars from one side of the joint only for clarity and the joint would consist of staggered projecting bars that would allow for ease of assembly in the bridge site. The amount and spacing of GFRP reinforcement in the precast flanges were identical to those for slab SS4 in Phase I but over $3500 \mathrm{~mm}$ width rather that $600 \mathrm{~mm}$ width in the direction of traffic. Figure 3.16 shows the reinforcement layout of jointed deck slabs.

The third set of deck slabs in phase II has three identical slabs, namely: S6, S7 and S8. Those slabs were similar to the joined precast deck slabs S4 and S5 in the second set, except that the reinforcing GFRP bars were of sand-coated surface rather than ribbed-surface. Figure 3.13 shows view of the setup of this set of slabs, with the connection detail shown in Fig. 3.3-a. As indicated in Table 3.2, phase II included fatigue load tests on which first set of slabs would be control slabs (made of GFRP-reinforced cast-in-place concrete) for possible comparison with jointed precast

deck slab system in the second and third sets. Figure 3.17 shows views of the fabrication of jointed deck slabs.

\subsection{Materials}

\subsubsection{Concrete}

All cast-in-place and precast deck slabs in phase I and II were fabricated using ready mix concrete, while non-shrink (NS) grout and ultra-high-performance concrete (UHPC) were used for the closure strips fill. 


\subsubsection{Ready Mix Concrete}

A ready mix concrete having a specified 28-day compressive strength of $35 \mathrm{MPa}$ was used for the deck slabs. Standard cylinders of $150 \mathrm{~mm}$ diameter and $300 \mathrm{~mm}$ height were cast concurrently with the casting of the deck slabs. The cylinders were cast and stored close to test specimens to ensure the same curing conditions after casting. A minimum of three cylinders were tested to get the compressive strength of each specimen on the testing day.

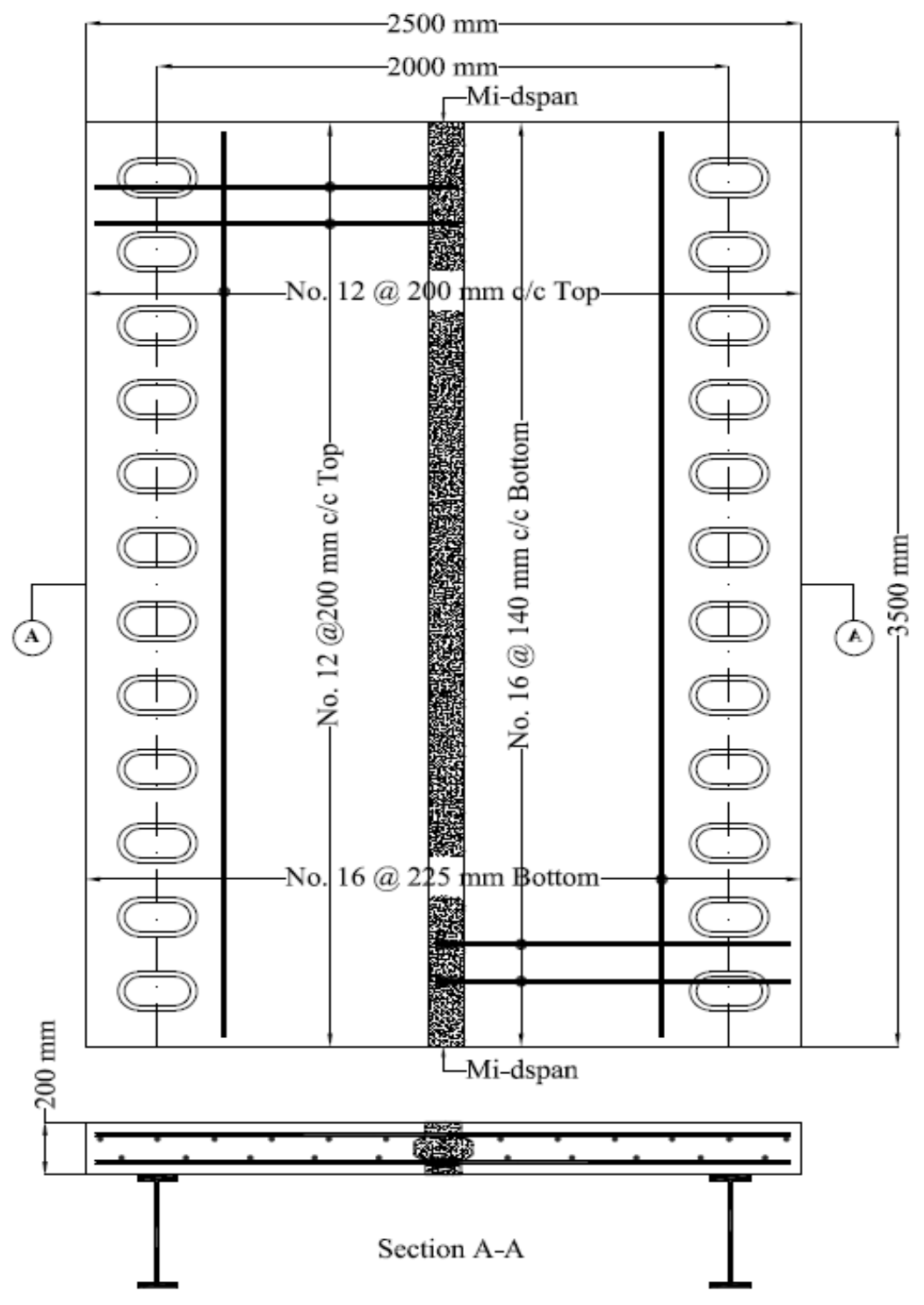

Figure 3.16 Reinforcement layout for the jointed precast deck slabs 


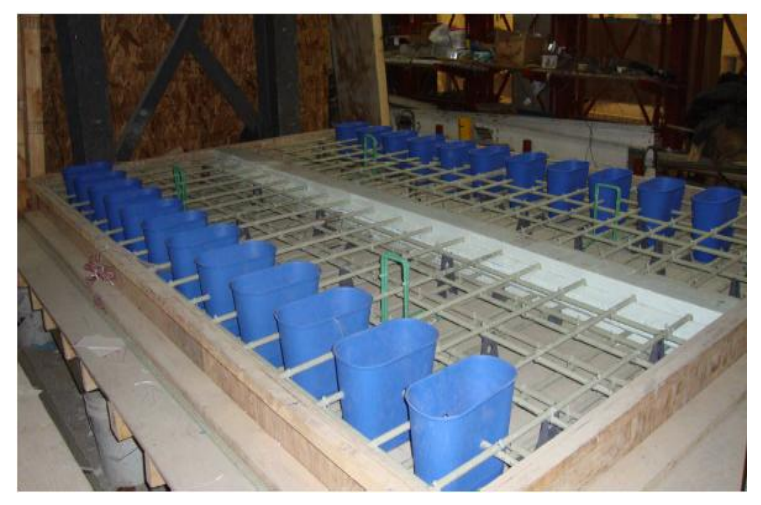

(a) Before pouring concrete

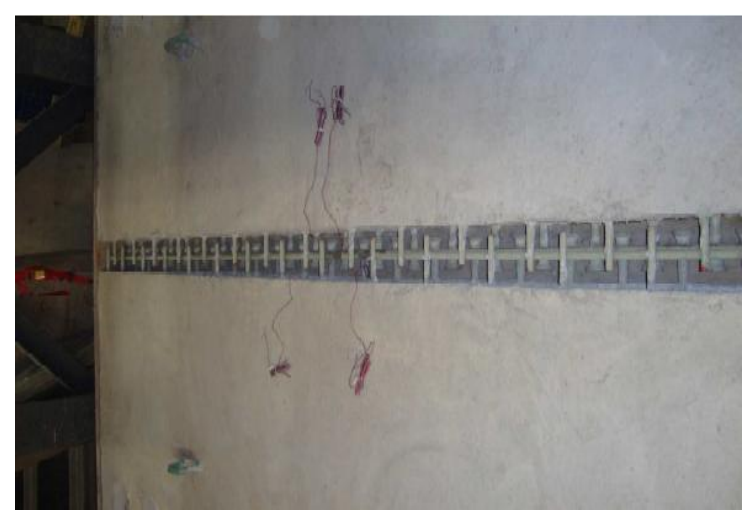

(c) Before pouring UHPC

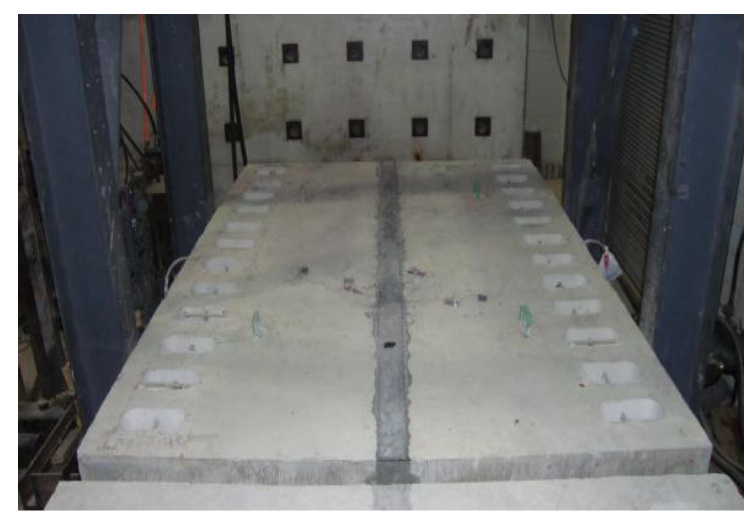

(e) Before grouting

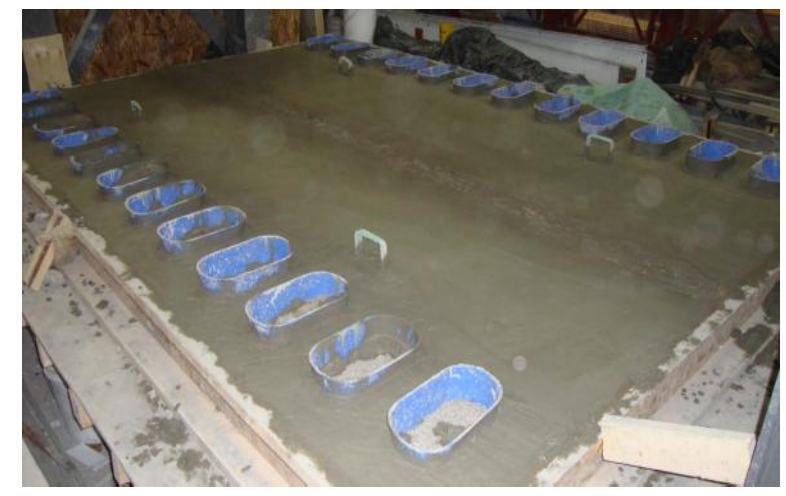

(b) After pouring concrete

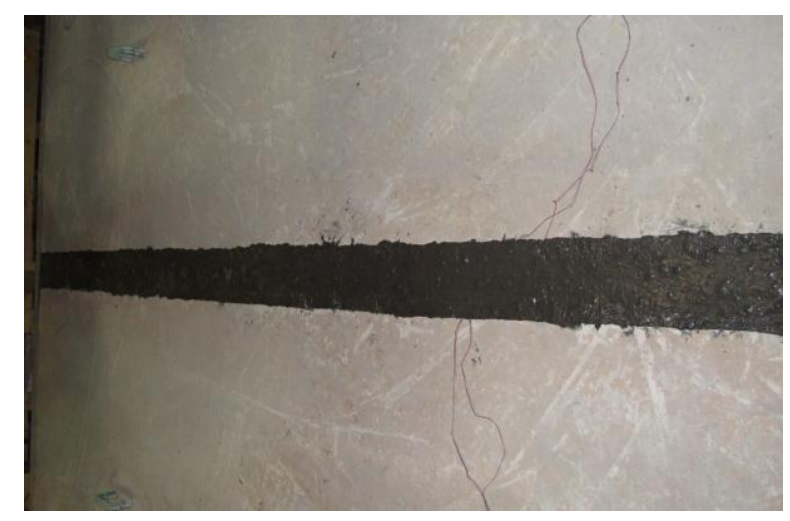

(d) After pouring UHPC

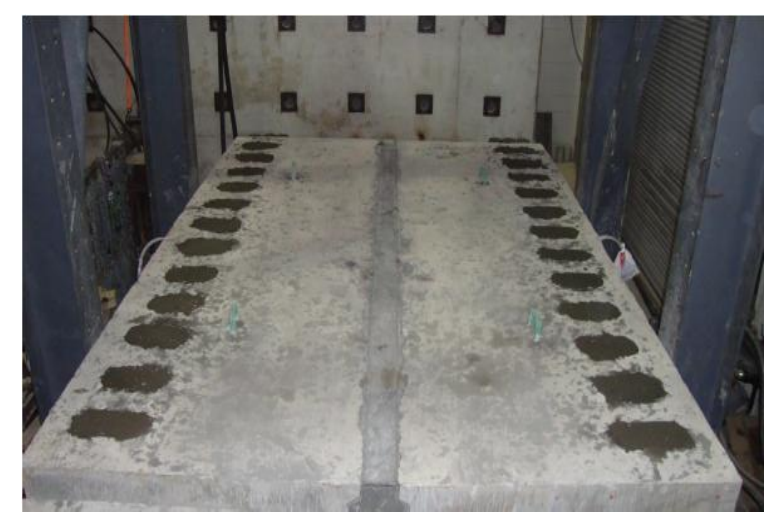

(f) After grouting

Figure 3.17 Jointed precast deck slabs fabrication 


\subsubsection{Non-Shrink Grout}

A pre-bagged non-shrink grout extended with $9.5 \mathrm{~mm}$ pea gravel was mixed according to the manufacturer's recommendation and was used to fill the closure strips and shear pockets. The grout has a specified 3-day compressive strength of $31 \mathrm{MPa}$ and 28-day strength of $59 \mathrm{MPa}$. During pouring of the grout into the closure strip or shear pockets, standard cylinders of $100 \mathrm{~mm}$ diameter and $200 \mathrm{~mm}$ height were cast and kept close to test specimens. A minimum of three cylinders were tested to get the compressive strength of the grout on the testing day.

\subsubsection{Ultra-High-Performance Concrete}

Ultra-High-Performance Concrete (UHPC) having a 28-day specified design strength of $100 \mathrm{MPa}$ was used for closure strips. The pre-bagged UHPC was mixed according to the manufacturer's recommendation. During pouring of the UHPC into the precast deck slab closure strip, standard cylinders of $100 \mathrm{~mm}$ diameter and $200 \mathrm{~mm}$ height were cast and kept close to the test specimens. The cylinders were prepared for testing by grinding both ends to create parallel surfaces through the use of a fixed end grinder. Three tests were carried out on the cylinders on the testing day, namely: density, compressive strength, and splitting. Figure 3.18 shows sequence of mixing and placing of UHPC into closure strip.

\subsubsection{Reinforcement}

Three types of reinforcing bars were used in the experimental program, namely: ribbed-surface GFRP bars, sand-coated GFRP bars, and Grade 400 steel bars.

\subsubsection{Ribbed-Surface GFRP Bars}

The ribbed-surface GFRP reinforcing bars, supplied by Schoeck Canada Inc., are manufactured by 
the pultrusion process. The reinforcing bar consists of a multitude continuous E-glass fibers, each with a diameter of approximately $20 \mu \mathrm{m}$ and more than $85 \%$ fiber content. They are embedded in a highly durable Vinyl-Ester resin matrix. The special "ribbed" surface profile of these bars, shown in Fig. 3.19-a and 3.19-b, ensures optimal bond between concrete and the bar. In this research, GFRP bars with headed ends were introduced in the precast deck joints to reduce their development length into the joint, and thus reducing the closure strip width. The bar head is made of high compressive strength thermo-setting polymeric concrete that is cast onto the end of the straight bar and hardened at elevated temperatures. The constituent materials of the concrete mix of the head are Vinyl Ester resin and a mixture of fine aggregates. The head of $16 \mathrm{~mm}$ diameter bar used in this study is approximately $100 \mathrm{~mm}$ long, with outer diameter of $40 \mathrm{~mm}$ (2.5 times the diameter of the bar). It tapers in five steps to the outer diameter of the blank bar. This geometry ensures optimal anchorage forces and minimal transverse splitting action in the vicinity of the head. Figures 3.19-a and 3.19-b show views of ribbed-surface GFRP bars with headed and straight ends, respectively.

\subsubsection{Sand-Coated GFRP Bars}

The sand-coated GFRP reinforcing bars, supplied by V-ROD Canada Inc., are manufactured by the pultrusion process. The reinforcing bar consists of high strength E-glass fibers with a minimum volume of fraction of $75 \%$ embedded in Vinyl-Ester resin matrix. The special "sandcoated" surface of these bars, shown in Figs. 3.19-c through 3.19-e, ensure optimal bond between concrete and the bar. In this research, high modulus (HM) and standard modulus (SM) sandcoated GFRP bars were used. Standard modulus GFRP bars with $90^{\circ}$ hook and high modulus headed end bars were introduced in precast deck joints to reduce their development length into the 
joint, and thus minimizing the closure strip width. The head of the $16 \mathrm{~mm}$ diameter bar used in this study is approximately $100 \mathrm{~mm}$ long, with outer diameter of $50 \mathrm{~mm}$ (3 times the diameter of the bar). It tapers in five steps to the outer diameter of the bar. Figures 3.19-c, 3.19-d and 3.19-e show views of sand-coated GFRP bars with headed end, $90^{\circ}$ hook and straight ends, respectively.

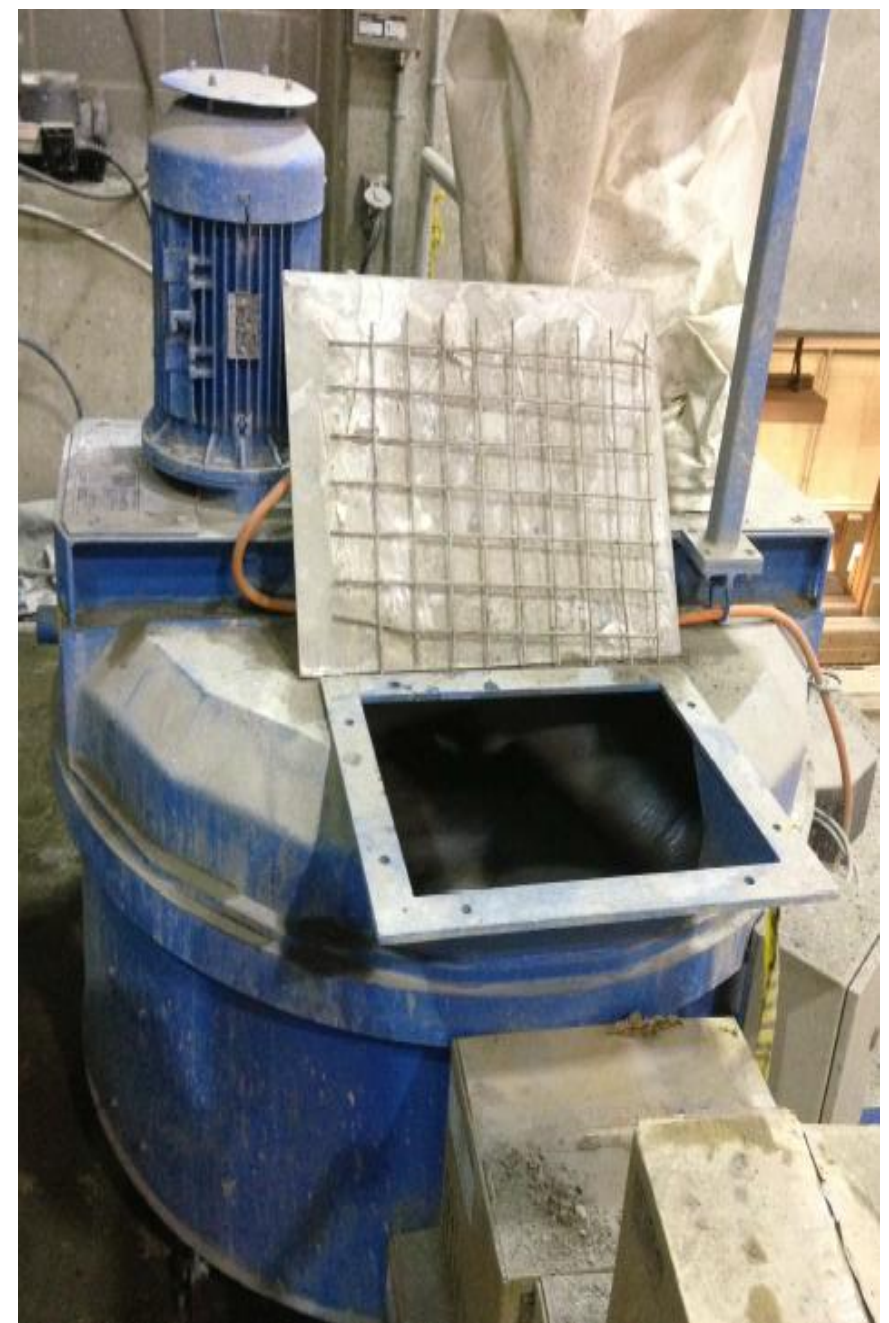

(a) Mixing UHPC

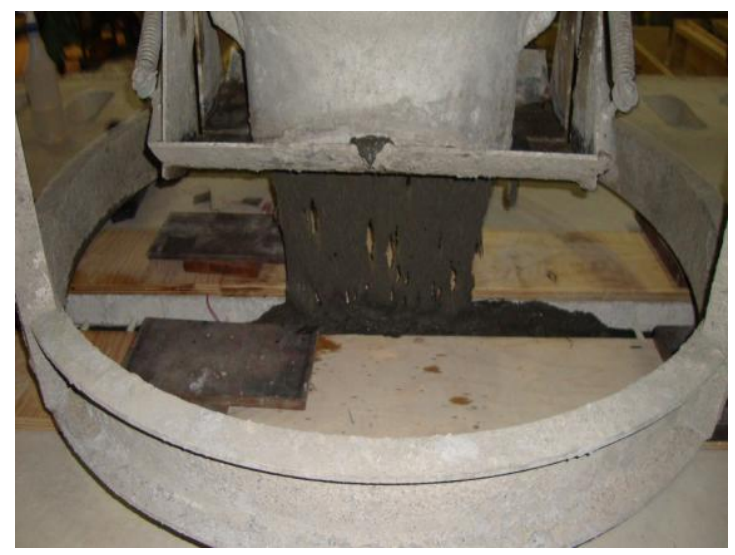

(b) Close-up view of placement of UHPC into connection

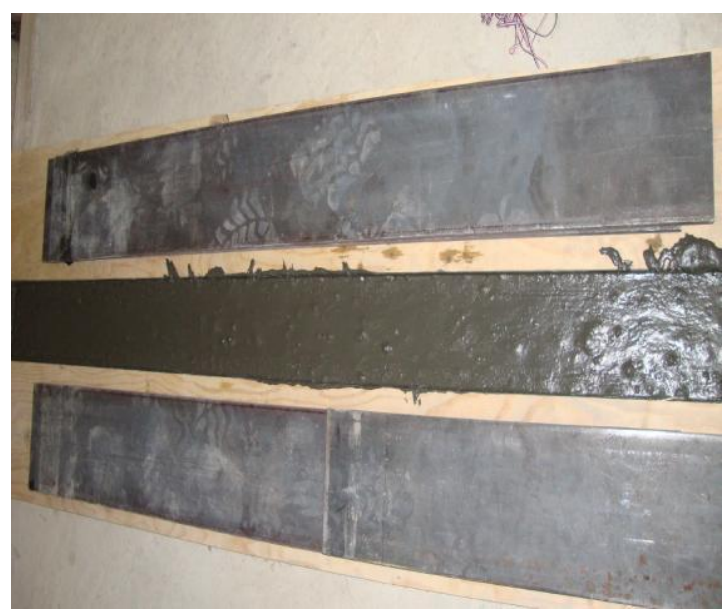

(c) After filling connection with UHPC

Figure 3.18 Sequence of mixing and placing of UHPC into connection 


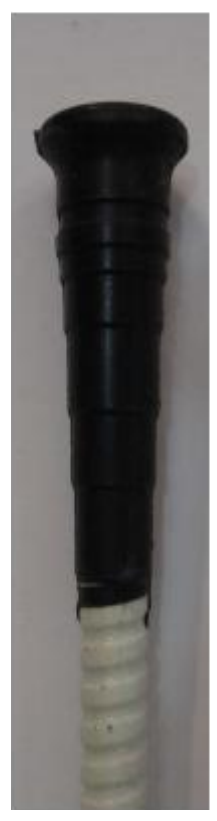

(a) Ribbed-surface GFRP bars with headed end
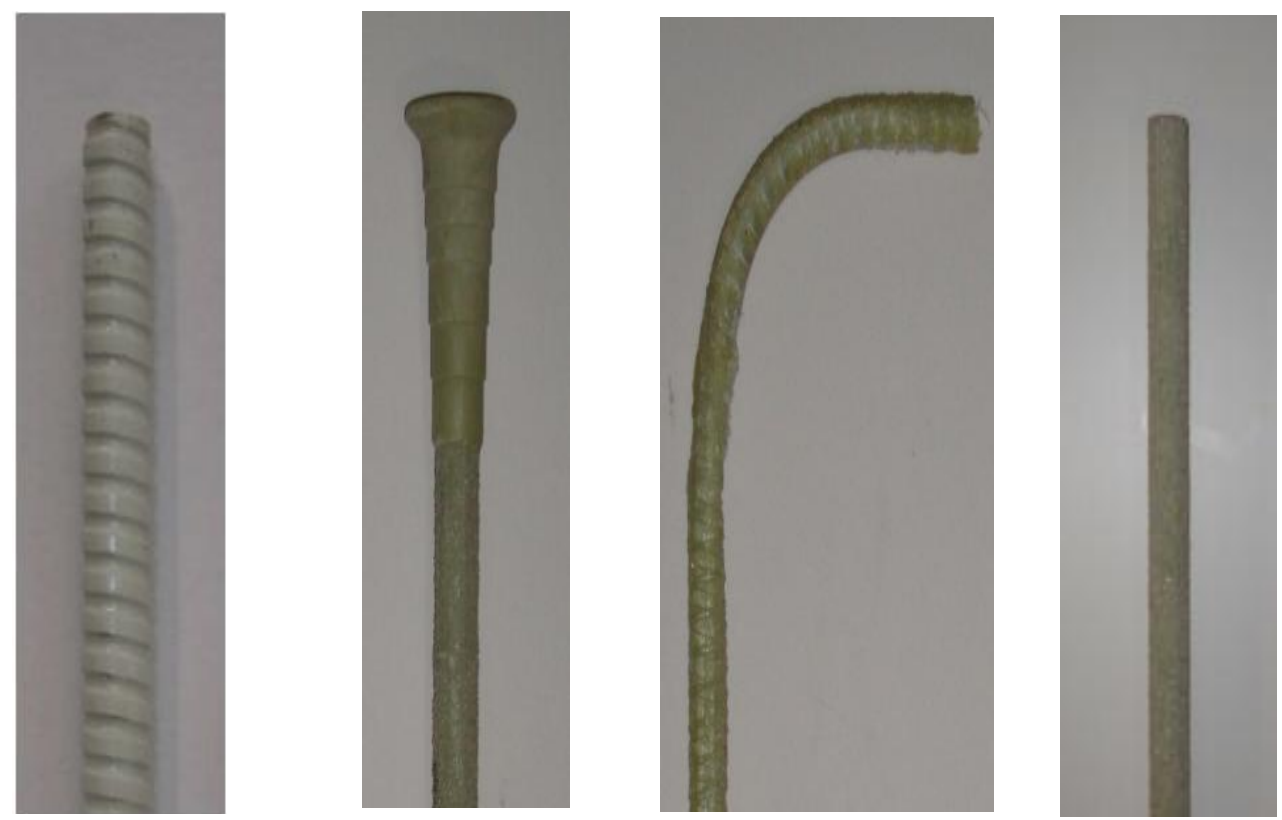

(b) Ribbed-surface GFRP bars with straight end (c) Sand-coated (d) Sand-coated GFRP bars with GFRP bars with headed end $\quad 90^{\circ}$ hook (e) Sand-coated GFRP bars with straight end

Figure 3.19 Views of GFRP bars considered in this study

\subsubsection{Reinforcing Steel Bars}

In this research, $10 \mathrm{M}$ steel bars of $400 \mathrm{MPa}$ yield strength were used to reinforce the control castin-place deck slabs. Table 3.3 summarizes the mechanical properties of the reinforcement used in this research.

\subsubsection{Shear Stud Connectors}

To create composite action between the precast deck slabs and the supporting beams, the deck slabs and the supporting beams were made fully composite with shear connector pockets and shear studs. High strength structural bolts and nuts conforming to ASTM A325 Standard were used as shear stud connectors. The deck slabs were designed to have two rows of $25 \mathrm{~mm}$ diameter high 
strength steel bolts spaced at $280 \mathrm{~mm}$ in the longitudinal direction and $150 \mathrm{~mm}$ in the transverse direction. The bolts were fastened on top flanges of the supporting steel beams by first drilling two rows of $28 \mathrm{~mm}$ diameter holes spaced at $280 \mathrm{~mm} \mathrm{c} / \mathrm{c}$ and then each bolt was fastened by using two nuts and two washers.

Figure 3.20 shows view of bolts fixed on the top flanges of the supporting steel beams. Two rows of elliptical-shaped shear pockets of 276x146 mm on the top tapered to 230x110 mm on the bottom and spaced at $280 \mathrm{~mm} \mathrm{c} / \mathrm{c}$ in the longitudinal direction, were created in the panels over the supporting beam lines to accommodate the shear connectors extending from the supporting beams into the precast deck. Figure 3.21 shows the geometric details of a typical shear pocket and the layout of the shear studs inside the shear pockets.

Table 3.3 Summary of commercial mechanical properties of the reinforcement used in this research

\begin{tabular}{|c|c|c|c|c|c|}
\hline Product type & Bar size & $\begin{array}{c}\text { Bar area } \\
\left(\mathrm{mm}^{2}\right)\end{array}$ & $\begin{array}{c}\text { Guaranteed } \\
\text { tensile strength } \\
(\mathrm{MPa})\end{array}$ & $\begin{array}{c}\text { Modulus of } \\
\text { elasticity } \\
\text { (GPa) }\end{array}$ & $\begin{array}{l}\text { Strain at } \\
\text { failure }\end{array}$ \\
\hline \multirow{2}{*}{$\begin{array}{c}\text { ComBAR } \\
\text { (Ribbed-surface) }\end{array}$} & $12 \mathrm{M}(\# 4)$ & 113 & \multirow{2}{*}{1188} & \multirow{2}{*}{64} & \multirow{2}{*}{$2.6 \%$} \\
\hline & $16 \mathrm{M}(\# 5)$ & 201 & & & \\
\hline \multirow{2}{*}{$\begin{array}{c}\text { V-ROD-HM } \\
\text { (Sand-coated) }\end{array}$} & $12 \mathrm{M}(\# 4)$ & 126.7 & 1312 & $65.6 \pm 2.5$ & $2.0 \%$ \\
\hline & $15 \mathrm{M}(\# 5)$ & 197.9 & 1184 & $62.5 \pm 2.5$ & $1.89 \%$ \\
\hline $\begin{array}{c}\text { V-ROD-SM } \\
\text { (Sand-coated) }\end{array}$ & 15M (\#5) & 197.9 & 934 & 55.4 & $1.69 \%$ \\
\hline Steel & $10 \mathrm{M}$ & 100 & $f_{y}^{*}=400$ & 200 & $\varepsilon_{y}^{* *}=0.2 \%$ \\
\hline
\end{tabular}




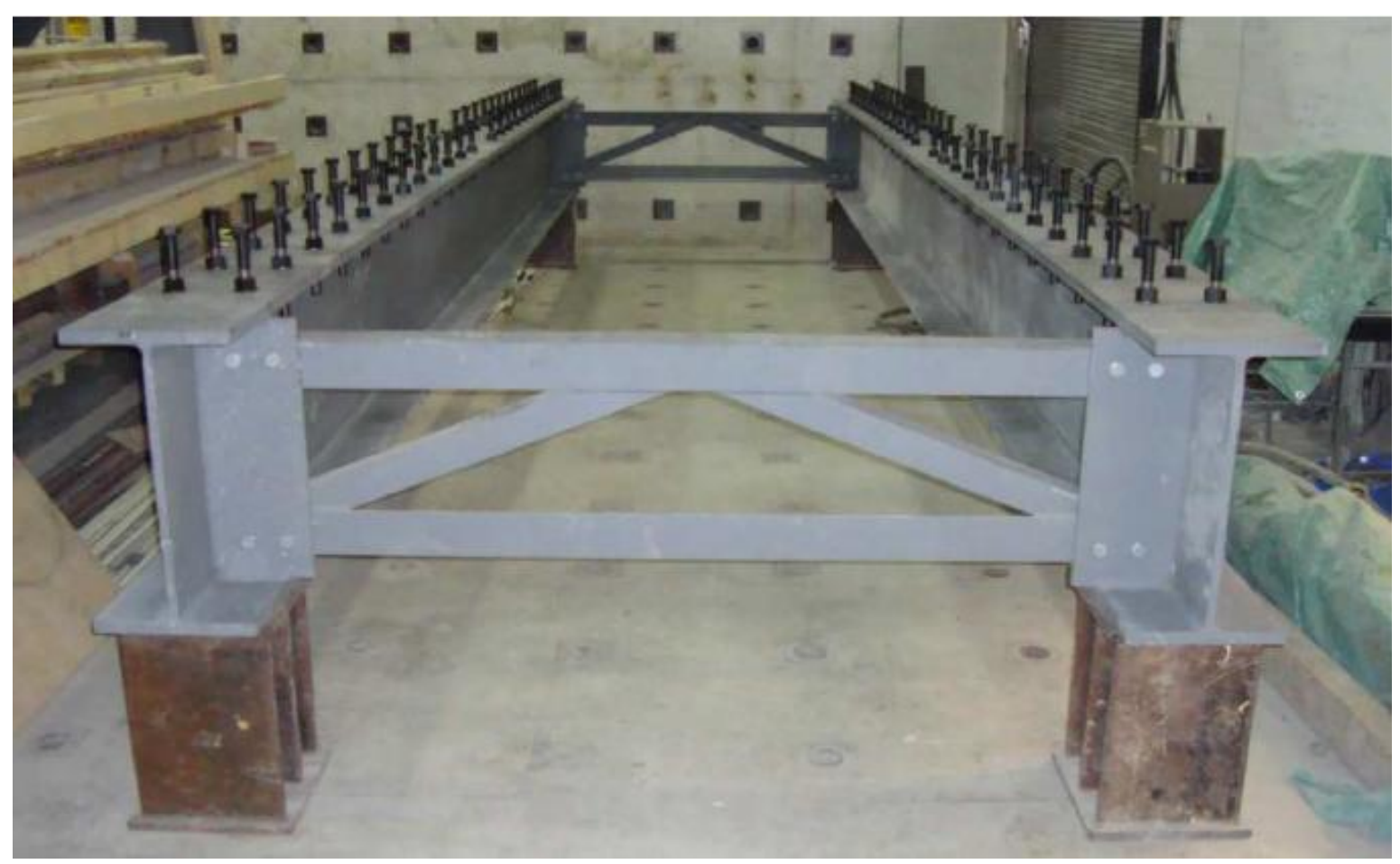

Figure 3.20 View of bolts fixed on the top flanges of the twin-girder system

\subsection{Fabrication of Bridge Deck Slabs}

The fabrication of the bridge deck slabs was completed in two phases. The first phase included the fabrication of 16 deck slab specimens representing the one-way slab action considering the flexural design approach, while the second phase included fabrication of 8 deck slab specimens representing the restrained deck slabs over supporting beams. A $19 \mathrm{~mm}\left(3 / 4^{\prime \prime}\right)$ thick plywood sheets and pieces of wood sizes $38 \times 89 \mathrm{~mm}\left(2^{\prime \prime} \times 4^{\prime \prime}\right)$ and $52 \times 52 \mathrm{~mm}\left(2^{\prime \prime} \times 2^{\prime \prime}\right)$ were used for preparing the concrete formwork. Styrofoam insulation sheets, measuring $2438 \times 1219 \times 25 \mathrm{~mm}$, were used to form the closure strip joints in the precast deck slabs. The styrofoam sheets were cut into pieces to form the configuration of the joint and shear key. To get the required thickness of the deck slab, four layers of styrofoam were glued together using PL 300 foam-board adhesive 
and placed in position. Figure 3.8-c through 3.8-f show various views of forming the joints. After the forms were prepared, steel and GFRP bars were placed to form both top and bottom reinforcement layers. Plastic ties were used to tightly tie the bars together to maintain the required spacing between the bars. Rebar plastic chairs were used to hold the two meshes of reinforcement and to maintain constant top and bottom cover of $38 \mathrm{~mm}$.

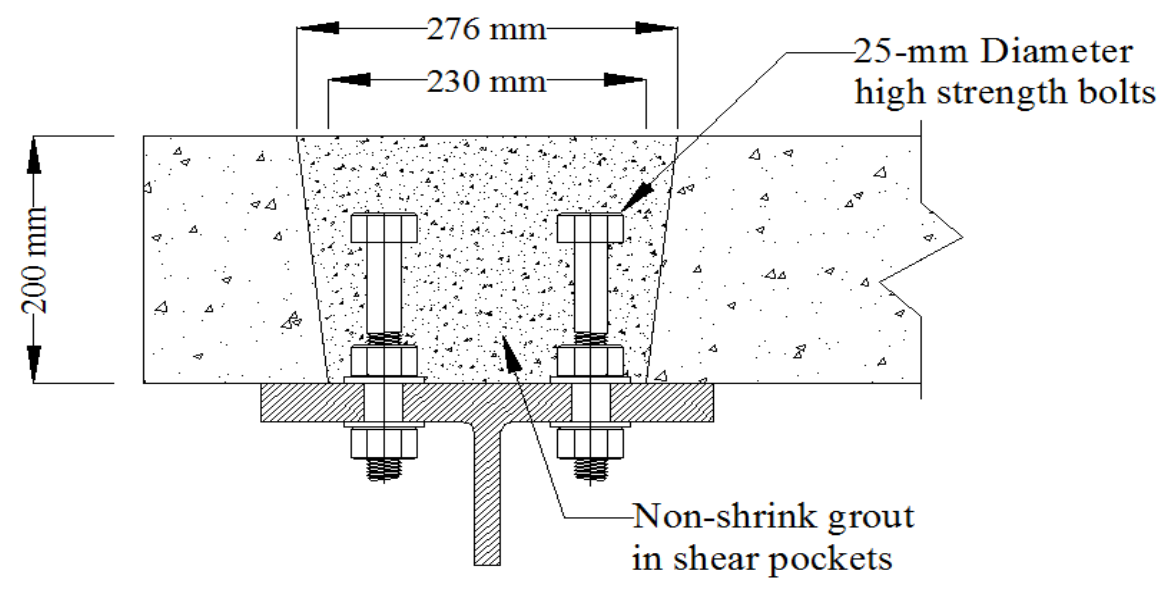

(a) Cross section
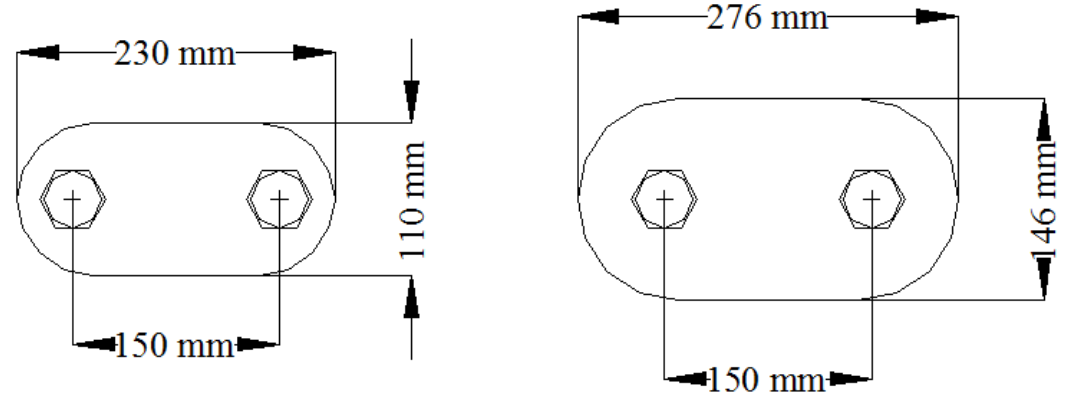

$\begin{array}{ll}\text { (b) Plan at bottom of pocket } & \text { (c) Plan at top of pocket }\end{array}$

Figure 3.21 Geometric details of shear pocket and shear studs inside the shear pockets

After placing the reinforcement, the concrete was poured and the top surface of deck slabs were covered with wet burlaps and plastic sheets, and cured with water for a minimum of two weeks. Figure 3.22 shows photos during concreting and curing of a precast deck slab from phase II. After 
concrete was cured, the styrofoam was removed from the joints using crowbar and then the surfaces of the shear key were grinded using steel brush to create a surface roughness to enhance a mechanical bond between the closure strips fill and precast concrete slabs. Figures 3.23 and 3.24 show the profiles of joint surfaces before and after grinding for selected deck slabs from phases I and II, respectively. After cleaning the joints, the closure strips were filled with non-shrink grout or UHPC, as appropriate, to complete the structural element of the bridge deck. After 7 days of curing, the precast deck slabs were stacked on top of each other to perform the test. Figure 3.25 shows views of selected deck slabs after casting the NS-grout and the UHPC.

\subsection{Instrumentations}

\subsubsection{Electrical Strain Gauges}

Electrical strain gauges were installed on the reinforcing bars and the top surface of the deck slab around the loaded area to monitor the strain in the rebar and concrete, respectively. Electrical strain gauges type C2A-06-250LW-120 having a resistance of $120 \pm 0.6 \%$ ohms, and a gauge factor of $2.085 \pm 0.5 \%$ and $10 \mathrm{~mm}$ length were used for reinforcing bars. The strain gauges were mounted at different locations on both top and bottom reinforcing bars to measure the strain in the transverse and longitudinal directions. Figures 3.26 and 3.27 show layout and photos of strain gauges on the GFRP reinforcing bars in cast-in-place and precast deck slabs, respectively. Electrical strain gauges type N11-FA-60-120-11 having a resistance of $120 \pm 0.3 \%$ ohms, a gauge factor of $2.12 \pm 1 \%$ and $60 \mathrm{~mm}$ length were used to monitor the strain on concrete surface. For each deck slab, 10 strain gauges were installed at different locations around the loaded area to measure the concrete strain. Figure 3.28 shows layout and photos of strain gauges installed on the concrete surface. 


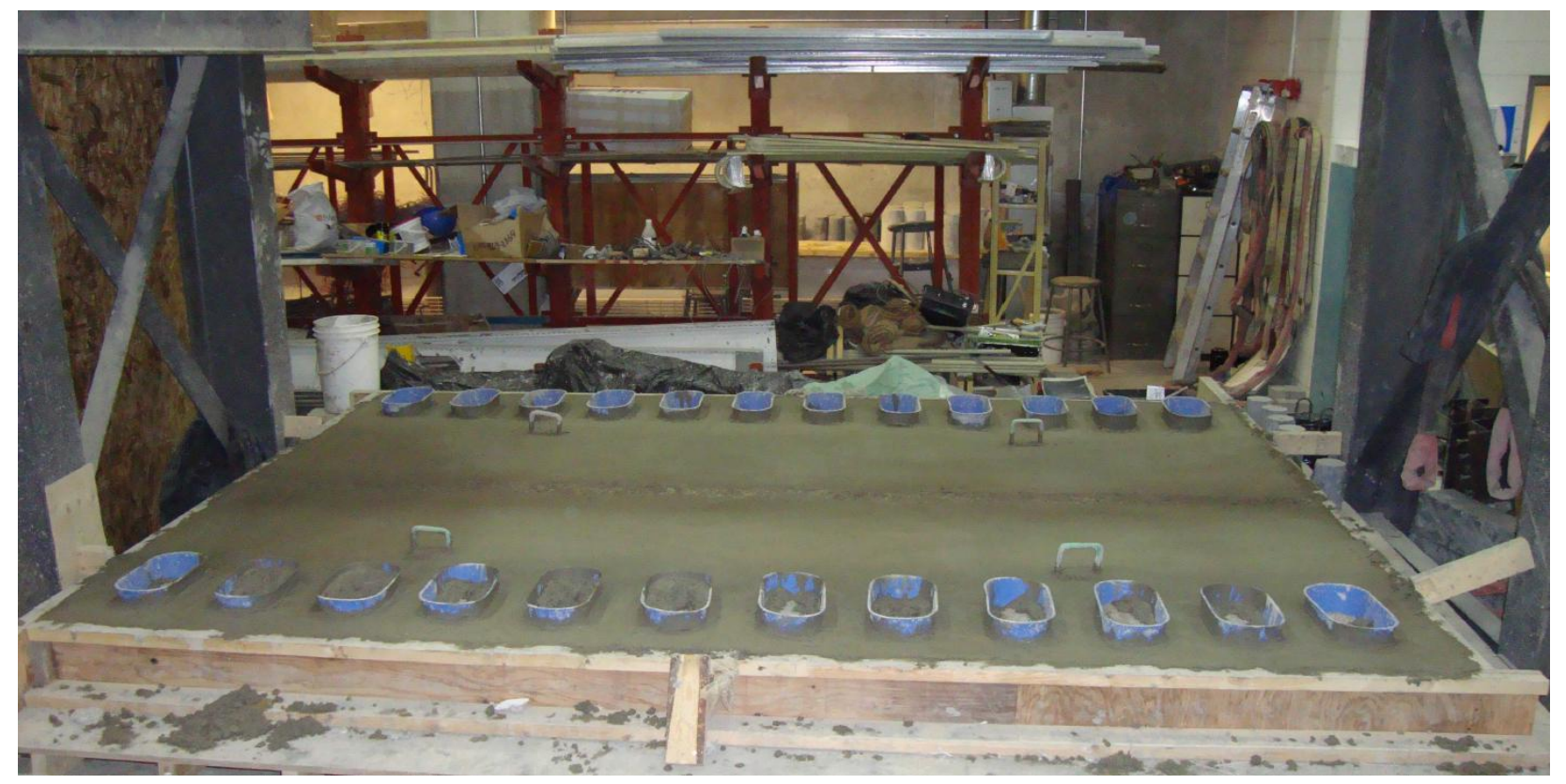

(a) After casting concrete

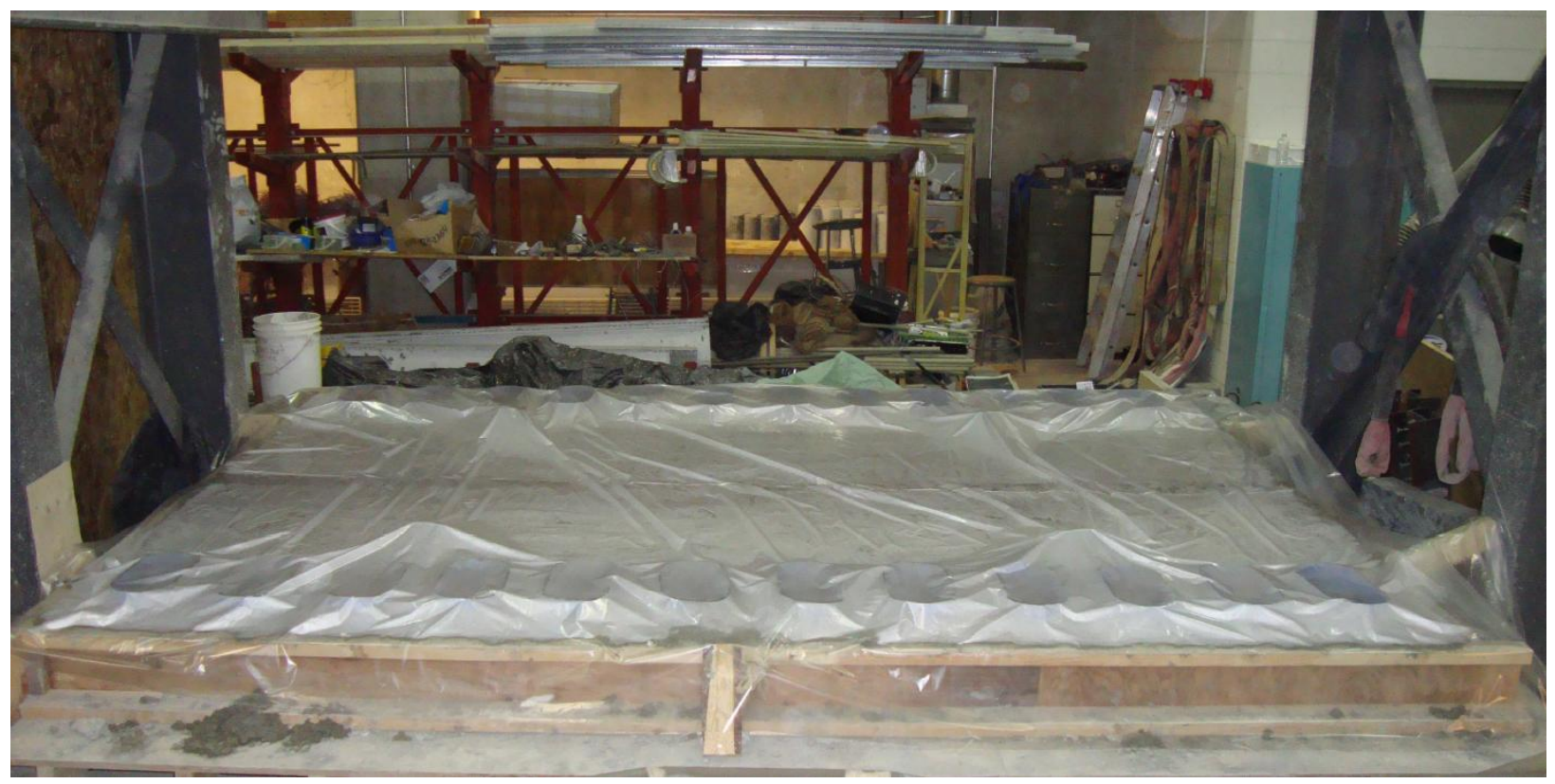

(b) Deck slab covered with plastic bags

Figure 3.22 Photos during concreting and curing of a precast deck slab 


\subsubsection{Deflection Instrumentations}

Potentiometers (POTs) and linear variable differential transformers (LVDTs) were used to measure the vertical deflections at specified locations of the deck slabs. In the case of simplysupported slabs in phase I, three POTs were mounted at three different locations at mid-span to measure the vertical deflection. In the case of restrained slabs in phase II, 5 POTs and 6 LVDTs were mounted along the centrelines in the transverse and longitudinal directions of the deck slab and under the steel beam to measure the vertical deflection at these locations. The locations of the POTs and LVDTs are shown in Fig. 3.29.

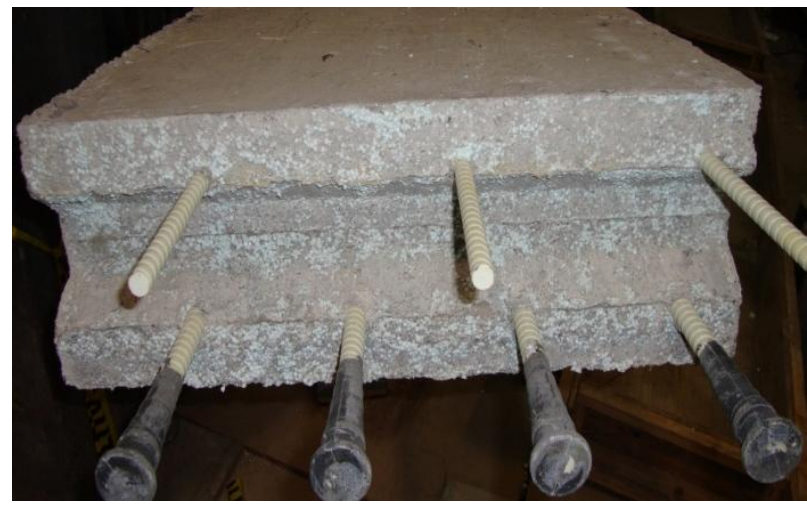

(a) Before grinding

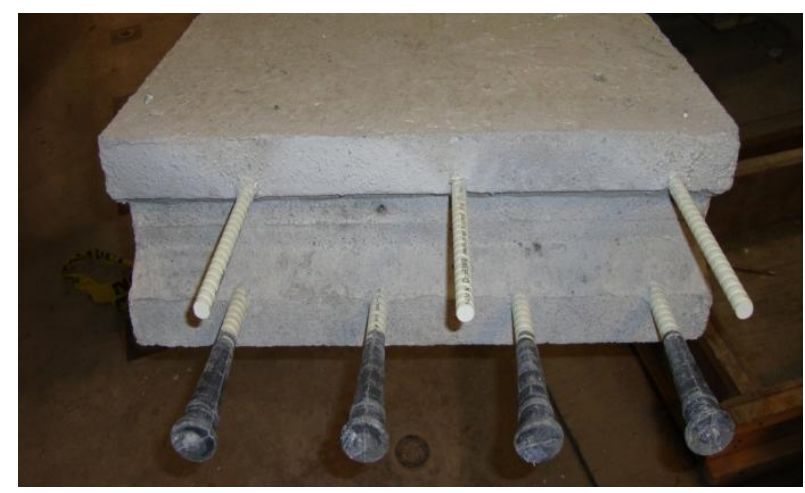

(b) After grinding

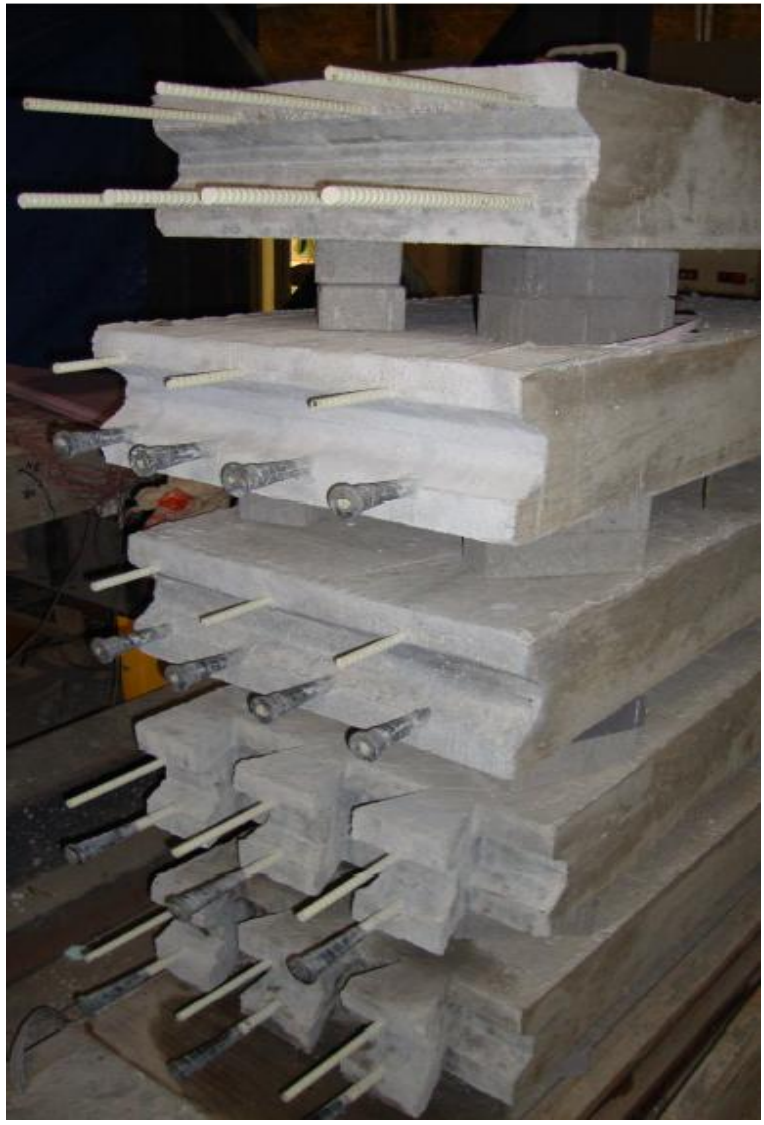

(c) Stacked samples after grinding

Figure 3.23 Profiles of surfaces at the joints before and after grinding for simply-supported deck slabs 


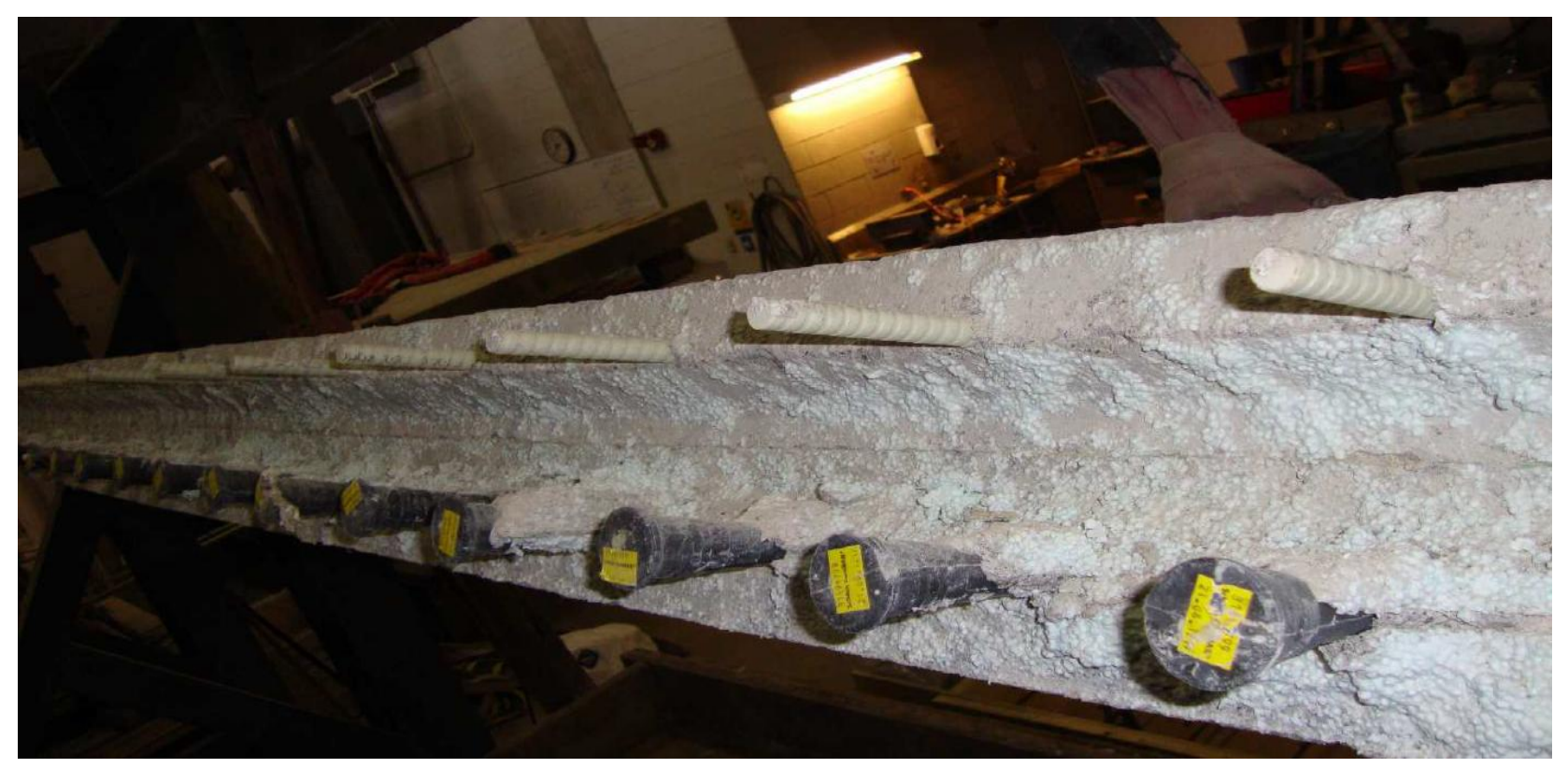

(a) Before grinding

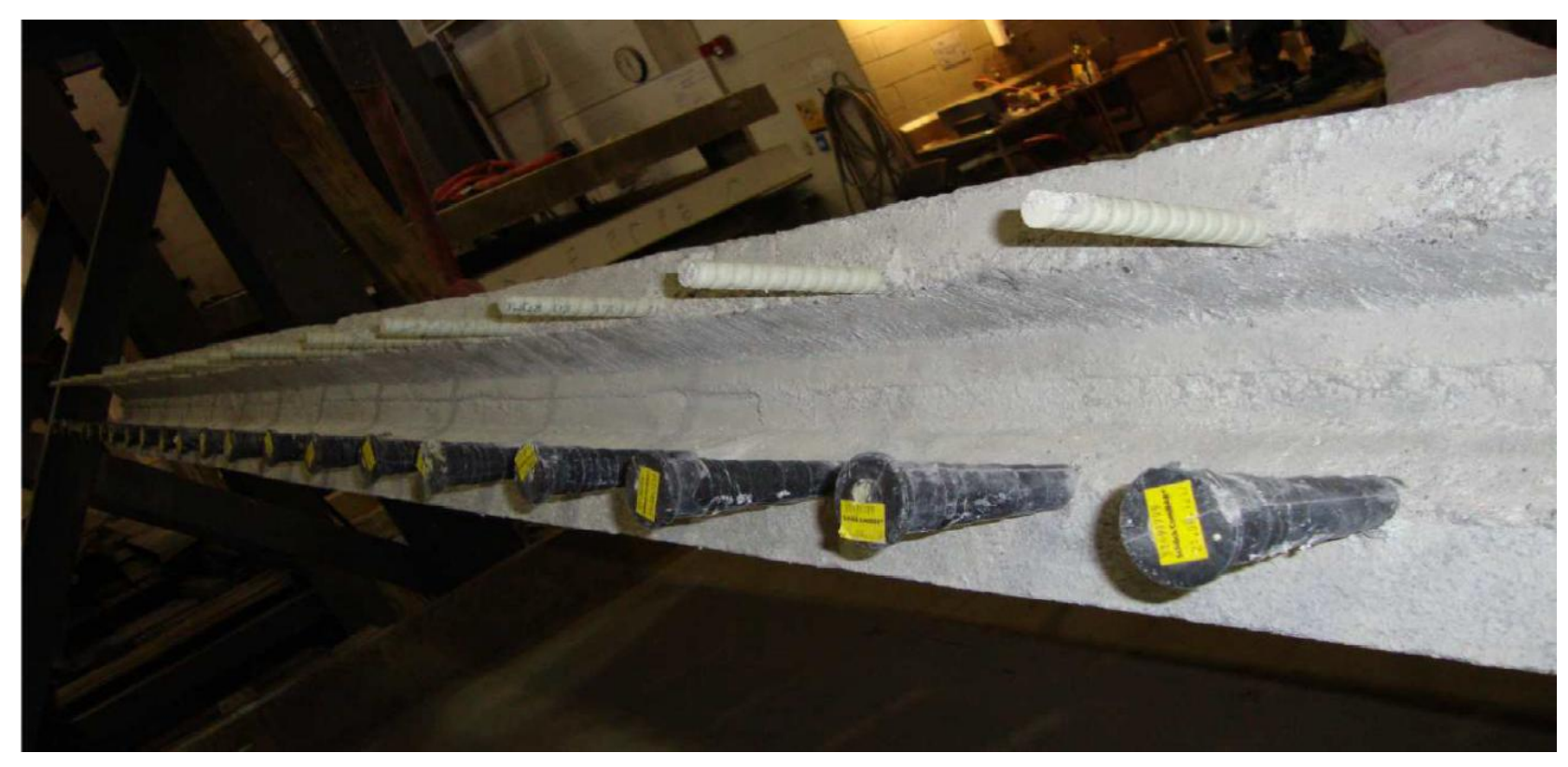

(b) After grinding

Figure 3.24 Profiles of the surface of the joint before and after grinding for a restrained deck slab 


\subsubsection{Crack Displacement Transducers}

Crack displacement transducers were used to measure the crack width for the deck slabs in phase

II. Two crack displacement transducers type KG-5A of capacity $\pm 5.0 \mathrm{~mm}$ and input/output resistance of $350 \mathrm{ohms}$ were used to measure the crack width. The crack gauges were set across the first crack in the cast-in-place deck slabs and across the cold joint between the interface of precast panel and the closure strip in the jointed deck slabs.

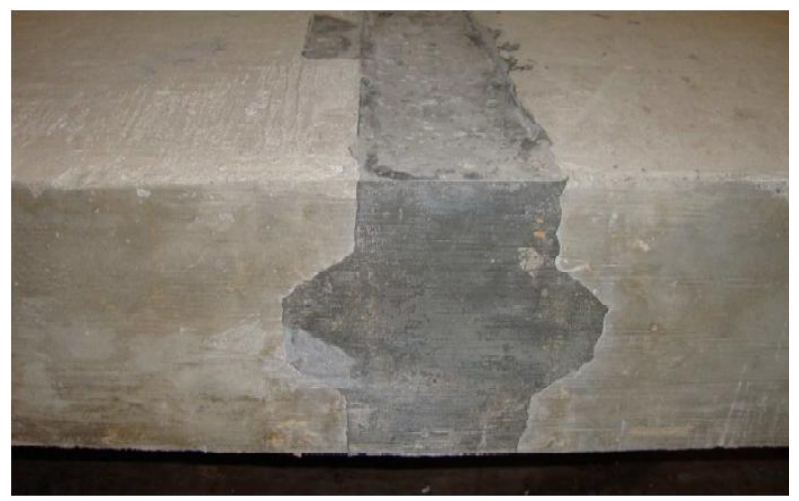

(a) 125-mm joint after casting UHPC

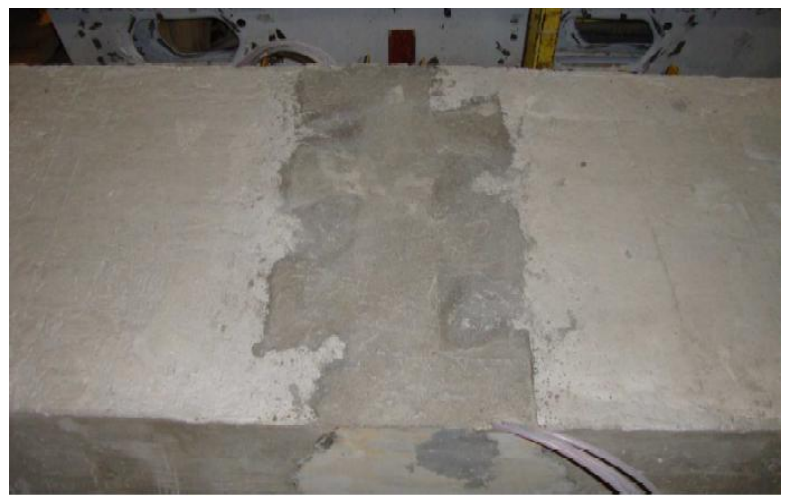

(b) Zigzagged joint after casting non-shrink grout

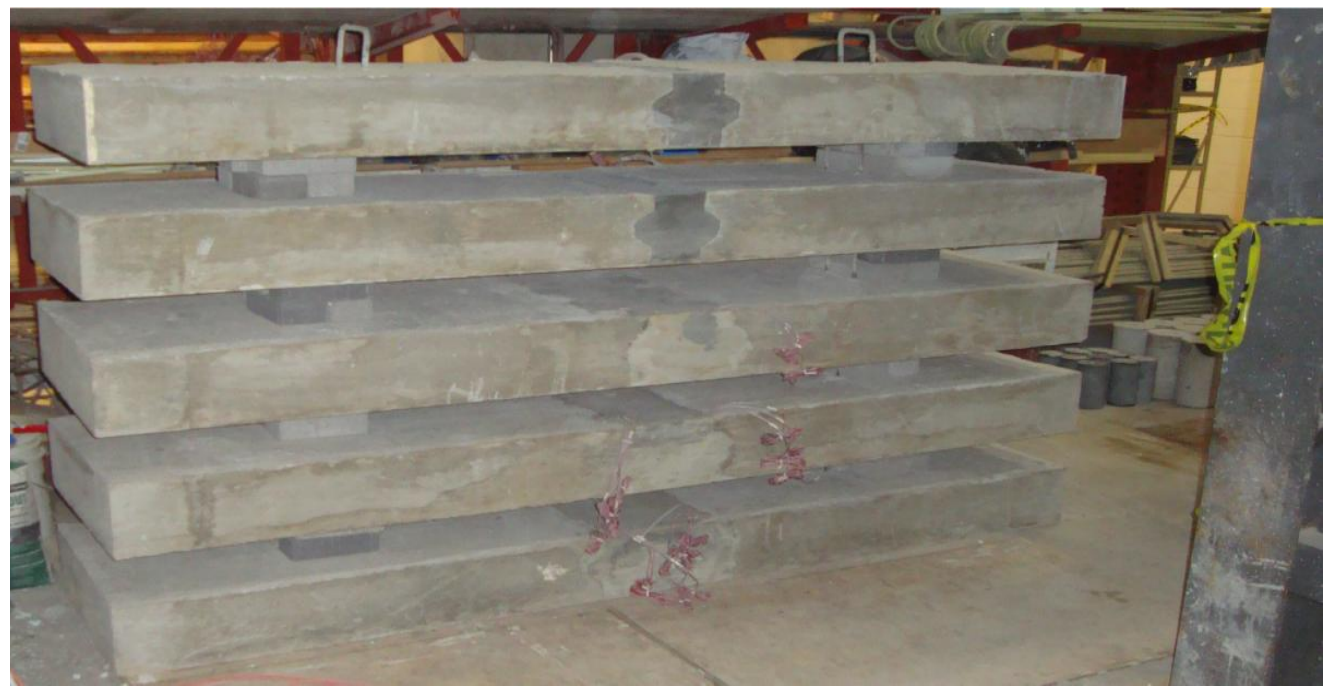

(c) Stacked jointed deck slabs

Figure 3.25 Selected deck slabs after casting non-shrink grout and UHPC 


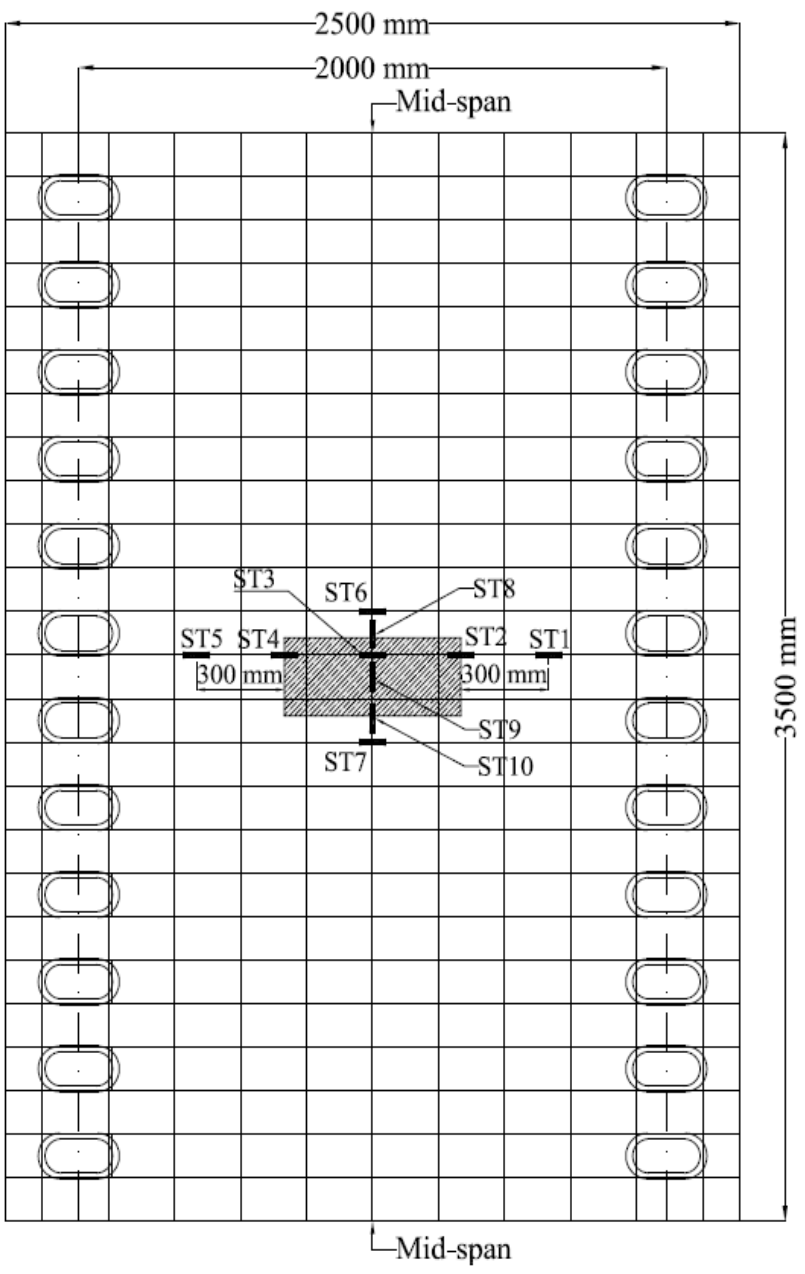

(a) Bottom GFRP layer

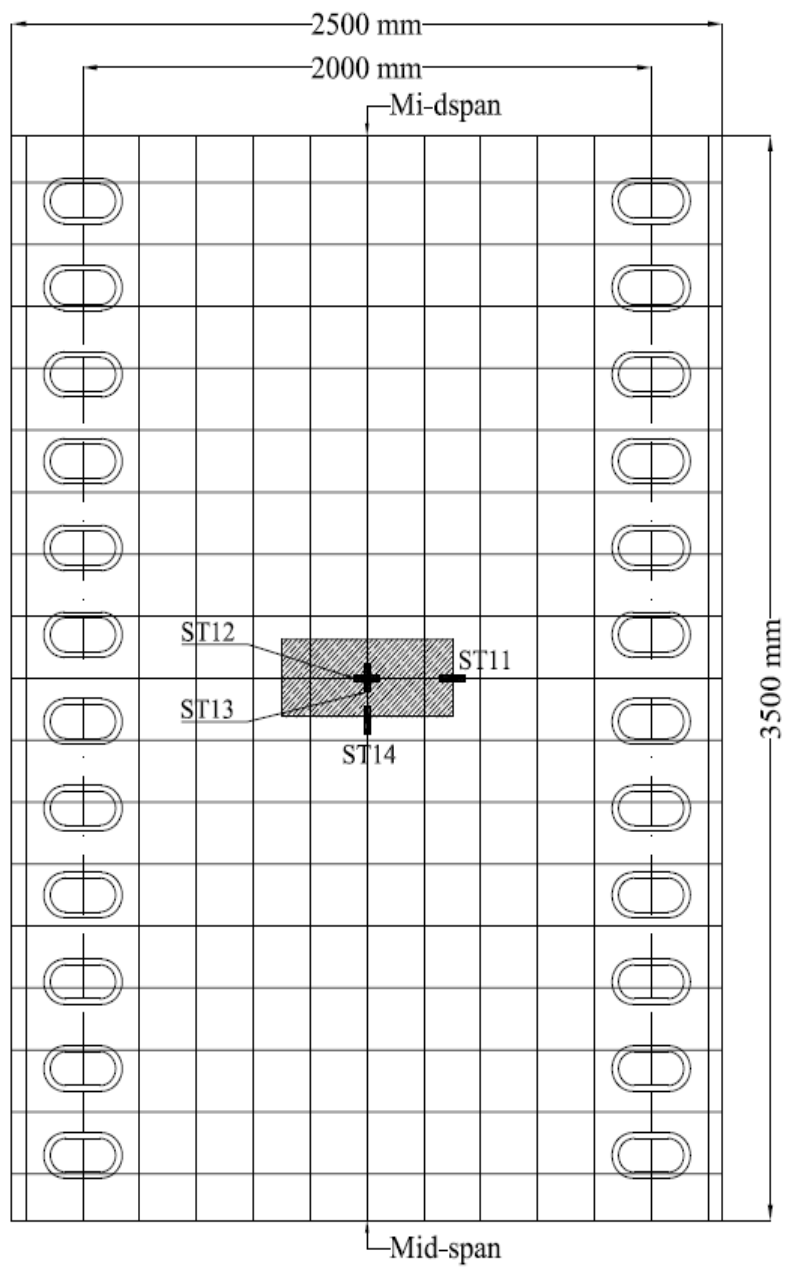

(b) Top GFRP layer

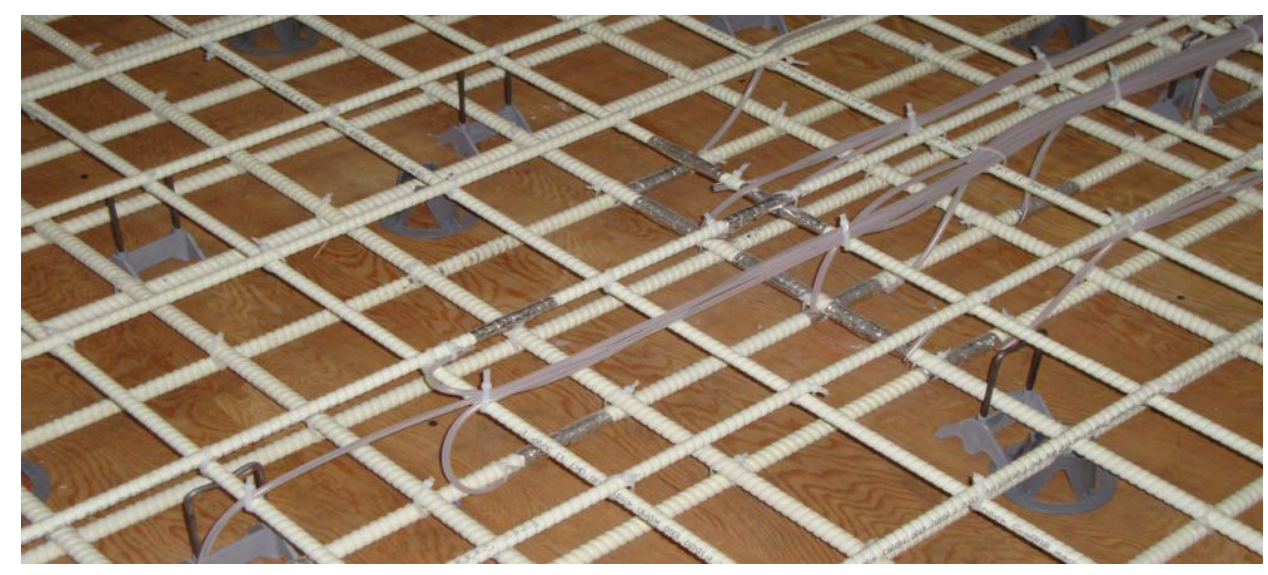

(c) Photo of strain gauges installed on GFRP bars

Figure 3.26 Strain gauge layout on GFRP bars in cast-in-place deck slab 


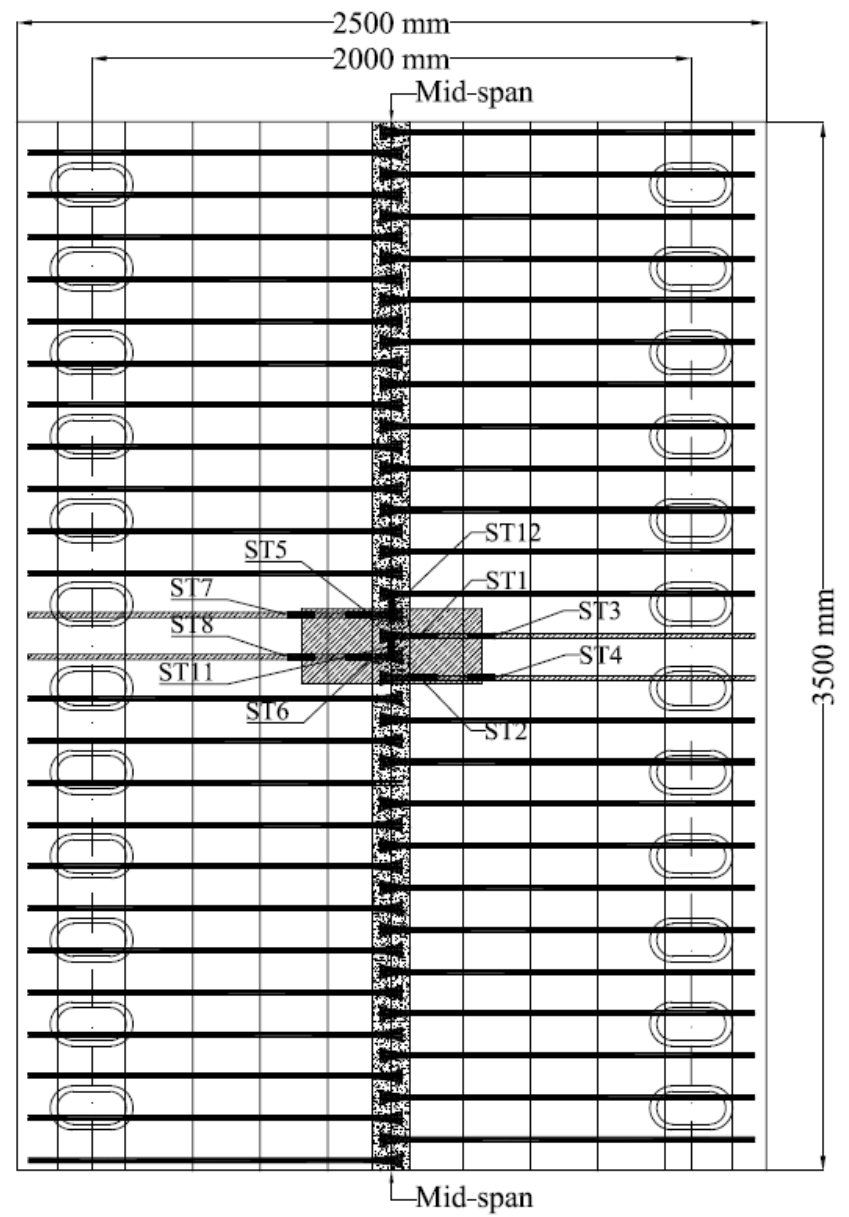

(a) Bottom GFRP layer

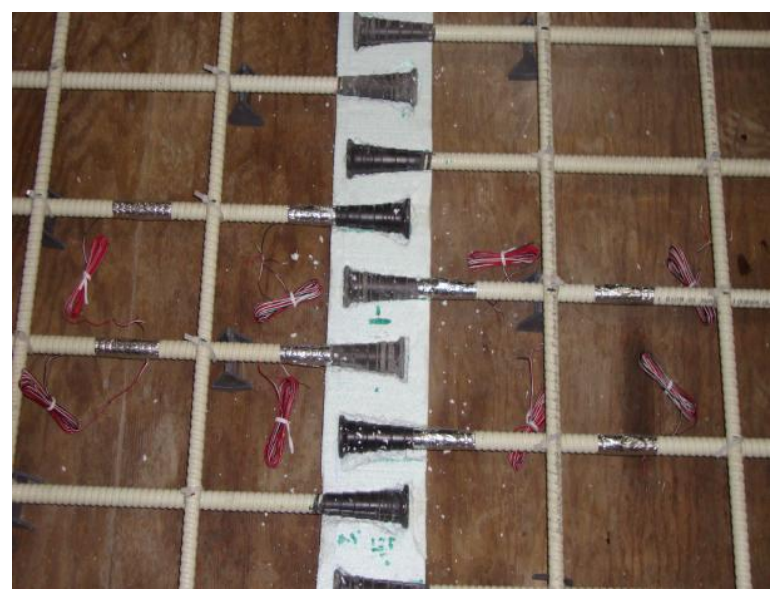

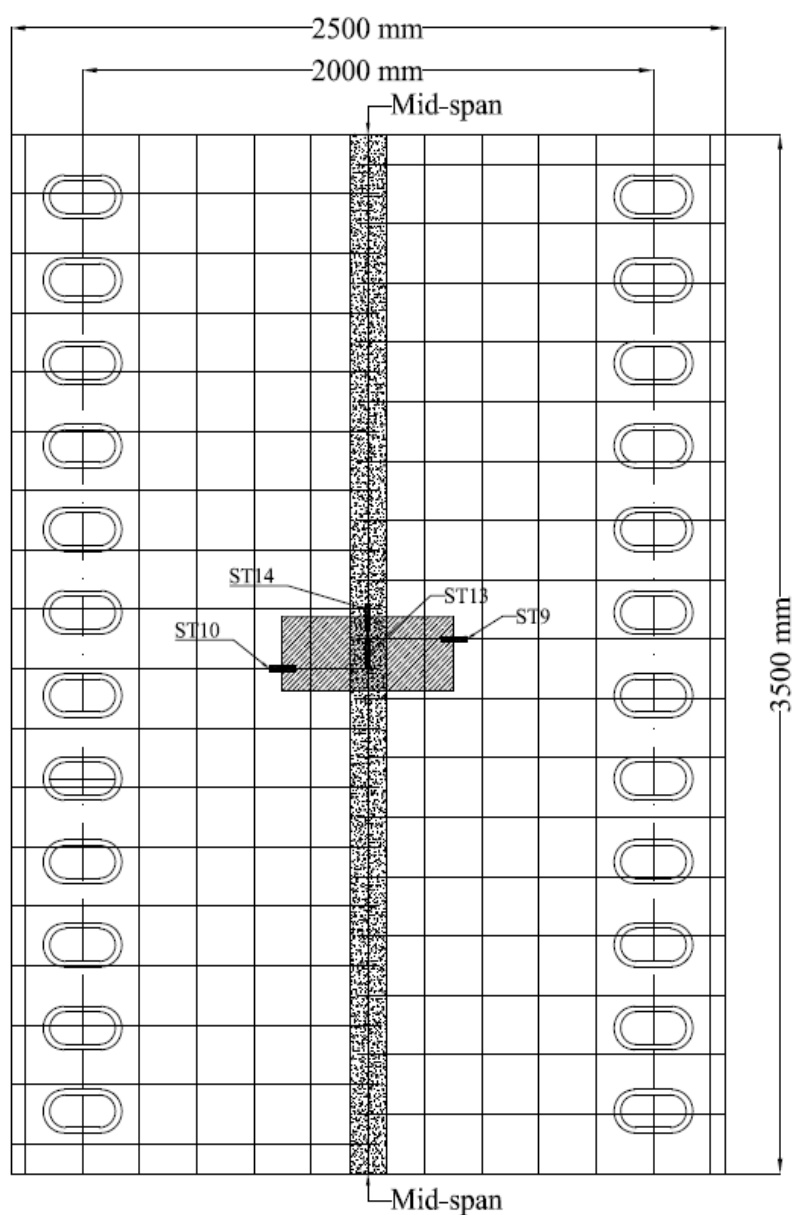

(b) Top GFRP layer

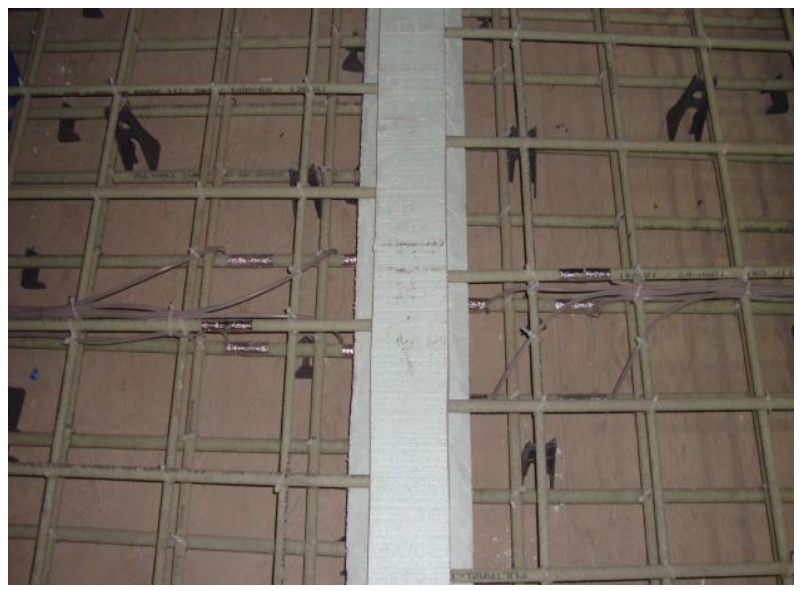

(c) Photos of strain gauges installed on GFRP bars

Figure 3.27 Strain gauge layout on GFRP bars in precast deck slab 


\subsection{Test Equipment}

\subsubsection{Hydraulic Jack}

The static loading was completed through the use of manually operated hydraulic jack with $1,300 \mathrm{kN}$ capacity. Figure 3.32 shows the hydraulic jack mounted on the steel loading frame.

\subsubsection{Hydraulic Actuator}

The fatigue load cycles were applied through the use of MTS series 244 hydraulic actuator with $500 \mathrm{kN}$ capacity and $250 \mathrm{~mm}$ stroke. Figure 3.31 shows views of the actuator mounted on the steel loading frame.

\subsubsection{Data Acquisition Systems}

Two data acquisition systems were used in the experimental program. During the static load tests in phase I and II, the structural response of the deck slab was captured through the use of electronic instrumentation (load cell, POTs, LVDTs, strain gauges and crack displacement transducers) connected to an electronic data acquisition system (SYSTEM 5000) for monitoring and data recording. The system was adjusted to record the data at a rate of 10 and 5 readings per second for phase I and II, respectively. The second data acquisition system was the MTS controller used during the cyclic and static load tests for deck slabs in phase II. Both data acquisition systems were adjusted to record the data at a rate of 20 readings per second during the cyclic and static load tests for deck slabs in phase II. 


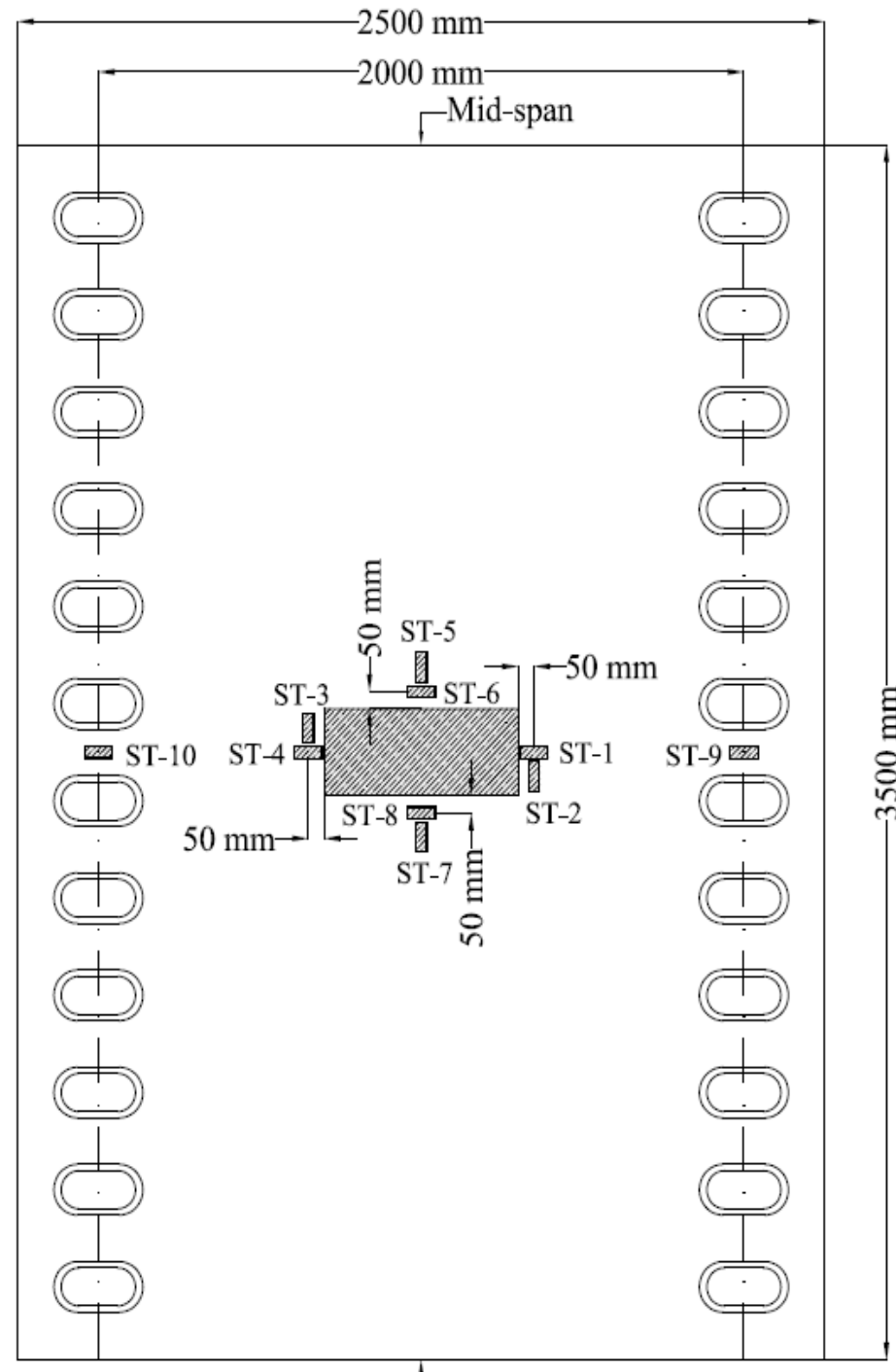

LMi-dspan

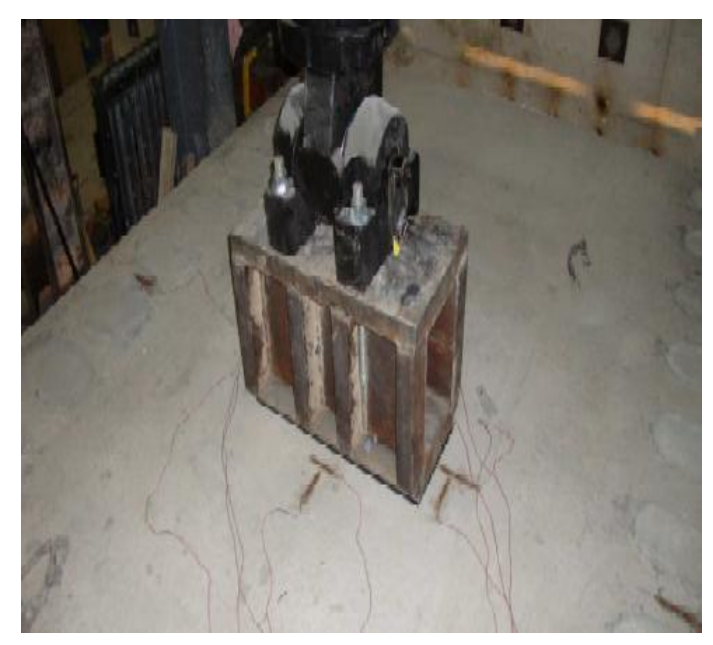

(b)

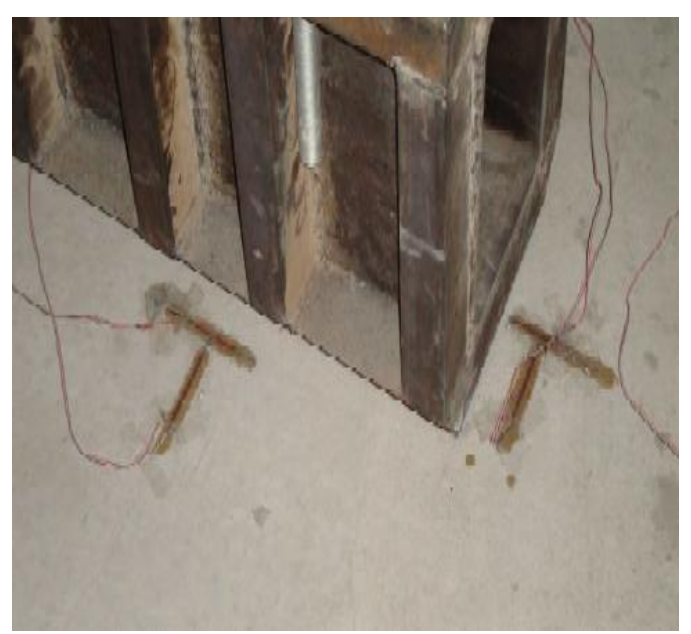

(c)

Figure 3.28 Concrete strain gauge layout

\subsection{Test Setup and Loading Plan}

\subsubsection{Phase I: Simply-Supported Deck Slab Strips}

In phase I of the experimental program, a static patch load simulating CHBDC truck wheel load was applied to examine the structural behavior and ultimate load carrying capacity of the 
proposed connection details as compared to the control cast-in-place slabs reinforced with steel and GFRP bars. All slabs were tested under a 250x600 mm single patch load at the center of their clear span. This patch load is equivalent to the foot print of CHBDC wheel load of $87.5 \mathrm{kN}$. The slab ends were simply-supported over roller support at one end and hinged support at the other end. Figure 3.30 shows the experimental setup used for testing the deck slab samples. As depicted in Fig. 3.30, the $600 \mathrm{~mm}$ length of the wheel load was divided into two segments, one from each side of the mid-span using two steel plates of $250 \mathrm{~mm}$ length each and $100 \mathrm{~mm}$ gap between them to allow for steel plate rotation at the mid-span with load increase. To conduct static load tests to failure, the jacking load was applied in monotonic increments to allow for observing the behavior of the specimen visually and to mark cracks. The available data acquisition system 5000 was used to capture readings from sensors as well as the load cell located between the jacking piston and the top of the deck slab. After every load increment, initiation of tension cracks and crack propagations were monitored. It should be noted that two loading procedures were considered during testing of slabs in this phase of the experimental program. In the first loading procedure, the jacking load was applied in monotonic increments to failure. This loading procedure was applied for slab specimens SS0, SS7, SS8, SS9 and SS10. A second incremental loading procedure was considered during testing in which the specimen was loaded to $10 \mathrm{kN}$, followed by load release. Then, the specimen was loaded to $20 \mathrm{kN}$, followed by load release. These incremental loading steps were repeated with a total load increase of $10 \mathrm{kN}$ in each step until the specimen failed. This loading procedure was applied for slab specimens SS1 through SS6 and PS1 through PS5. Figure 3.30 shows the testing setup for phase I deck slabs. 


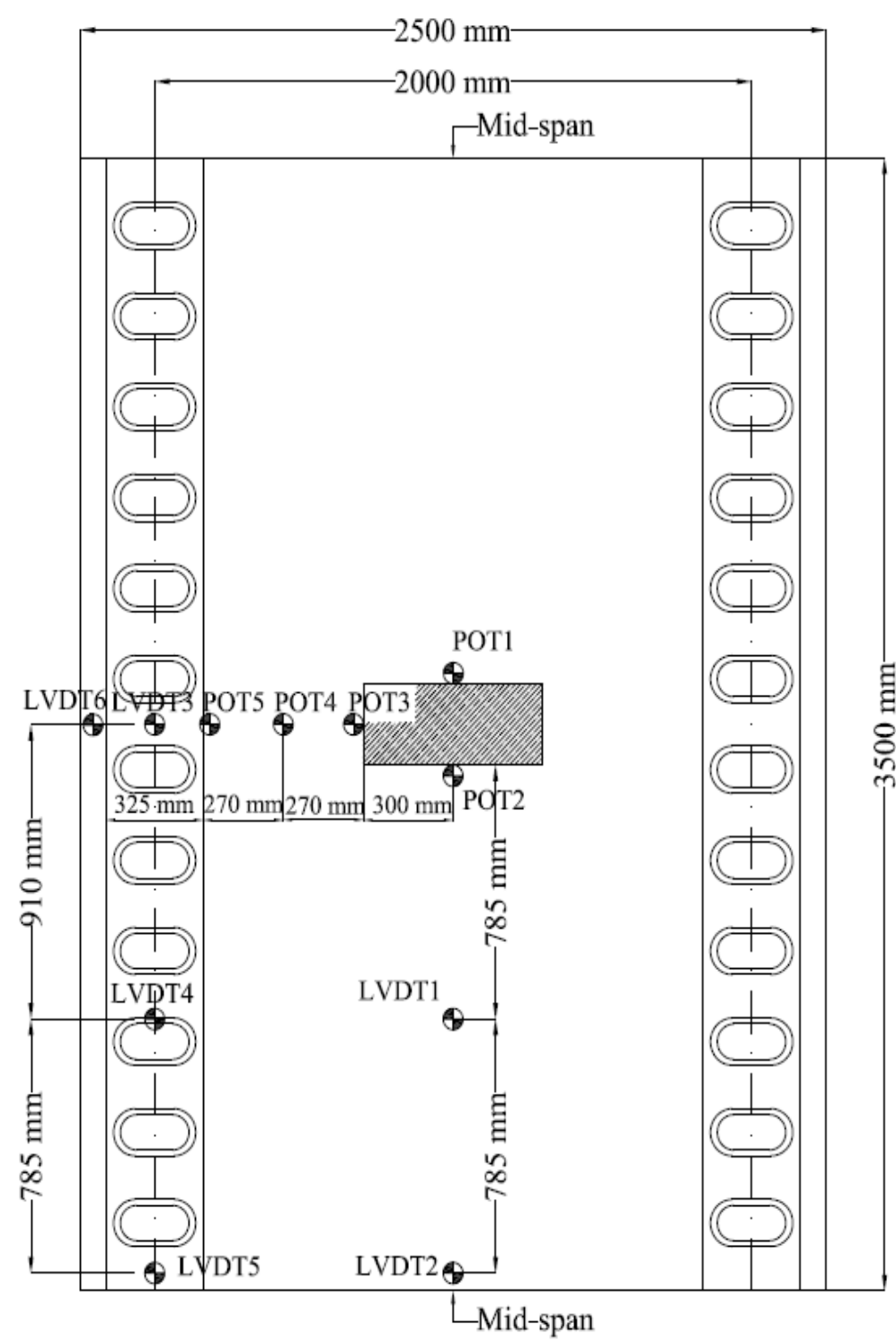

(a)

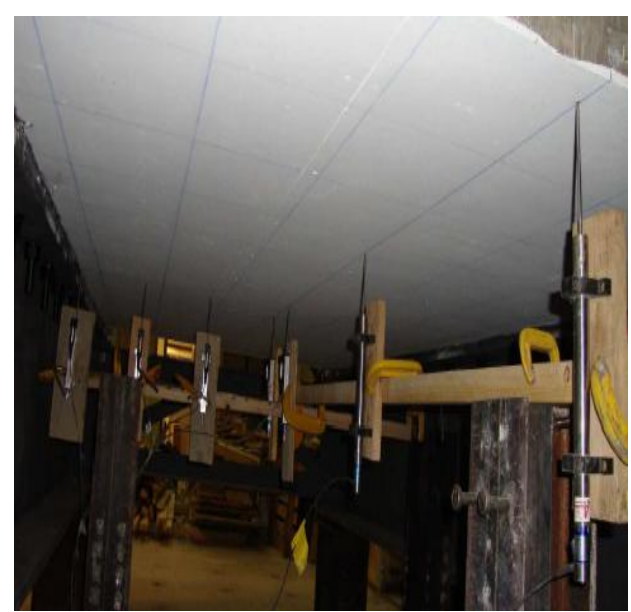

(b)

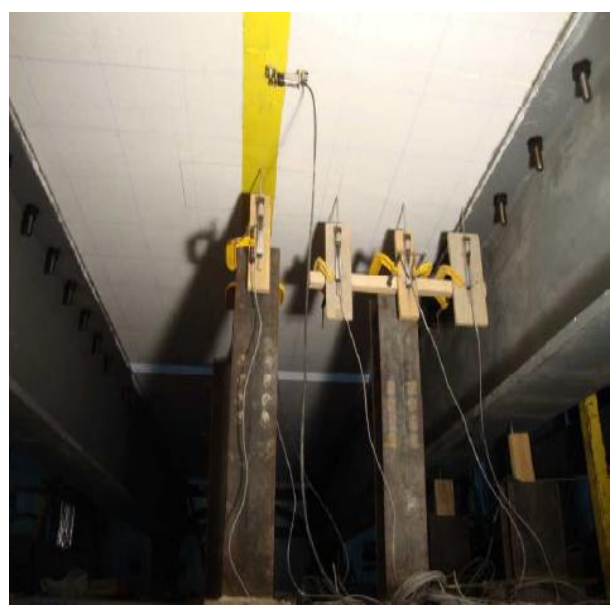

(c)

Figure 3.29 Layout of POTs and LVDTs at the underside of the deck slabs

\subsubsection{Phase II: Internally Restrained Deck Slabs}

All deck slabs were tested under a 250x600 mm single patch load at the center of their clear span. This patch load is equivalent to the foot print of CHBDC wheel load of $87.5 \mathrm{kN}$. A $50 \mathrm{~mm}$ thick steel plate was used to transfer the load to the bridge deck slab; neoprene pad was used to ensure 
an even distribution of the load pressure on the contact areas of the deck slab surface. To apply restraint to the slab ends over the steel girders, pair of slabs and the supporting girders were made fully composite with shear connector pockets and shear studs as shown in Figs. 3.15-d and 3.17-f. A 140-mm gap was kept between the two deck slabs that were placed side-by-side over the steel girders as depicted in Fig. 3.31-c . The steel girders were simply-supported over steel pedestals with a clear span of 7,000 mm. Elastomeric pads of 330x330x25 mm were placed between the steel pedestals and the steel girders to ensure that the boundary conditions were achieved. A hydraulic jack with $1,300 \mathrm{kN}$ capacity was used to apply static loads while a $500 \mathrm{kN}$ capacity actuator with $250 \mathrm{~mm}$ stroke was used to apply fatigue loads. Figures 3.31 and 3.32 show the experimental setup used for testing the deck slab specimens in phase II under fatigue and static loading, respectively.

\subsubsection{Cyclic Load Tests}

In this research, two different fatigue loading schemes were used, namely: accelerated fatigue loading with variable amplitude (VAF) and constant amplitude fatigue (CAF) loading. The fatigue load cycles were applied through the use of a servo-hydraulic controlled actuator operated under load control. Prior to starting fatigue load tests, each slab was pre-cracked by performing a static load test up to 1.5 times the fatigue limit state (FLS) loading of $183.75 \mathrm{kN}$ and unloaded to zero. This test was conducted first to determine the cracking load and initiate cracks to simulate real bridge state of stress.

\subsection{Accelerated Variable Amplitude Fatigue (VAF) Loading}

In the accelerated VAF loading test, the slab was subjected to sinusoidal waveform fatigue load cycles between a minimum load level and variable maximum load levels. The minimum load level 
was set as about $15 \mathrm{kN}$ and the different peak load levels were selected as multiples of the fatigue limit state (FLS) loading as specified in CHBDC (2006). The CHBDC FLS load was specified using the maximum wheel load of $87.5 \mathrm{kN}$ with $40 \%$ dynamic load allowance and a FLS live load factor of 1.0. This leads to a FLS load range of $87.5 \times 1.4 \times 1.0=122.5 \mathrm{kN}$, according to CHBDC Clause 3.5.1. In this research, maximum peak load levels of 1.0, 1.5, 2.0, 2.5, 3.0, 3.5 and 4 times the FLS load, which correspond to $122.5,183.75,245.00,306.25,367.50,428.75$ and $490.00 \mathrm{kN}$, respectively, were considered in the VAF loading test. Each maximum peak load level was applied for 100,000 cycles at frequencies of $2 \mathrm{~Hz}$ or less, depending on the stiffness of the specimen and supporting framing system, with the lowest frequencies occurring as the specimen was approaching failure. An illustration of the VAF loading test is shown in Fig 3.33-a. It should be noted that at the end of each 100,000 cycles at a specified load level, a static load test similar to the pre-cracked static load test was conducted to assess the degradation that may occur in the deck slab due to fatigue loadings. This VAF loading was applied to slabs, S2, S5 and S7.

\subsection{Constant Amplitude Fatigue (CAF) Loading}

A constant amplitude fatigue (CAF) loading test was applied for deck slab, S3, S4 and S8. In this loading test, constant amplitude of load, representing the FLS load specified in CHBDC of 122.5 $\mathrm{kN}$, was applied at a frequency of $4 \mathrm{~Hz}$ for 4 million cycles. An illustration of the CAF loading test is shown in Fig. 3.33-b. Similar to the VAF, but at the end of each 250,000 cycles at $122.5 \mathrm{kN}$ load level, a static load test was conducted to assess the degradation that may occur in the deck slab due to fatigue loadings. 


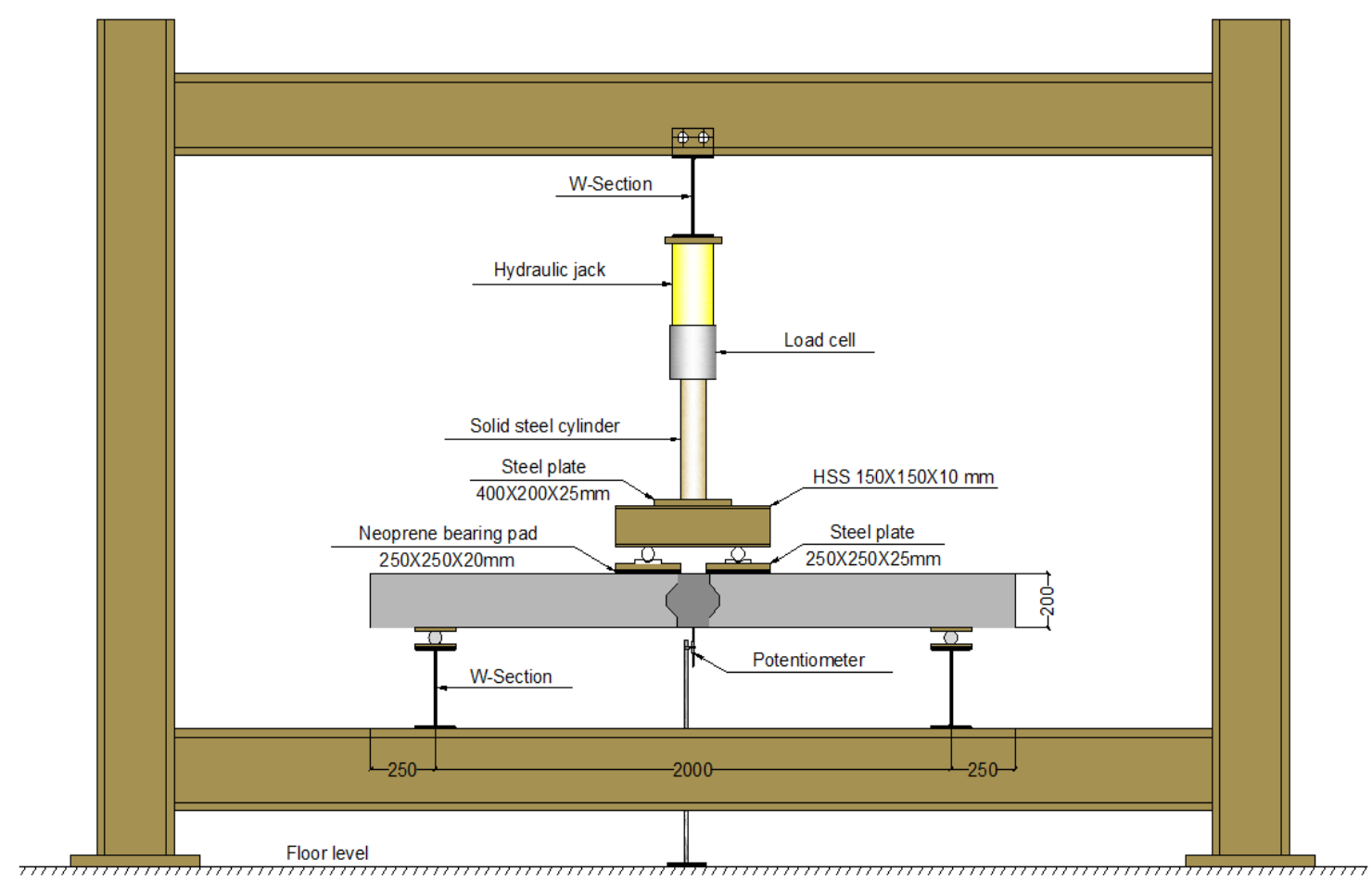

(a) Schematic diagram

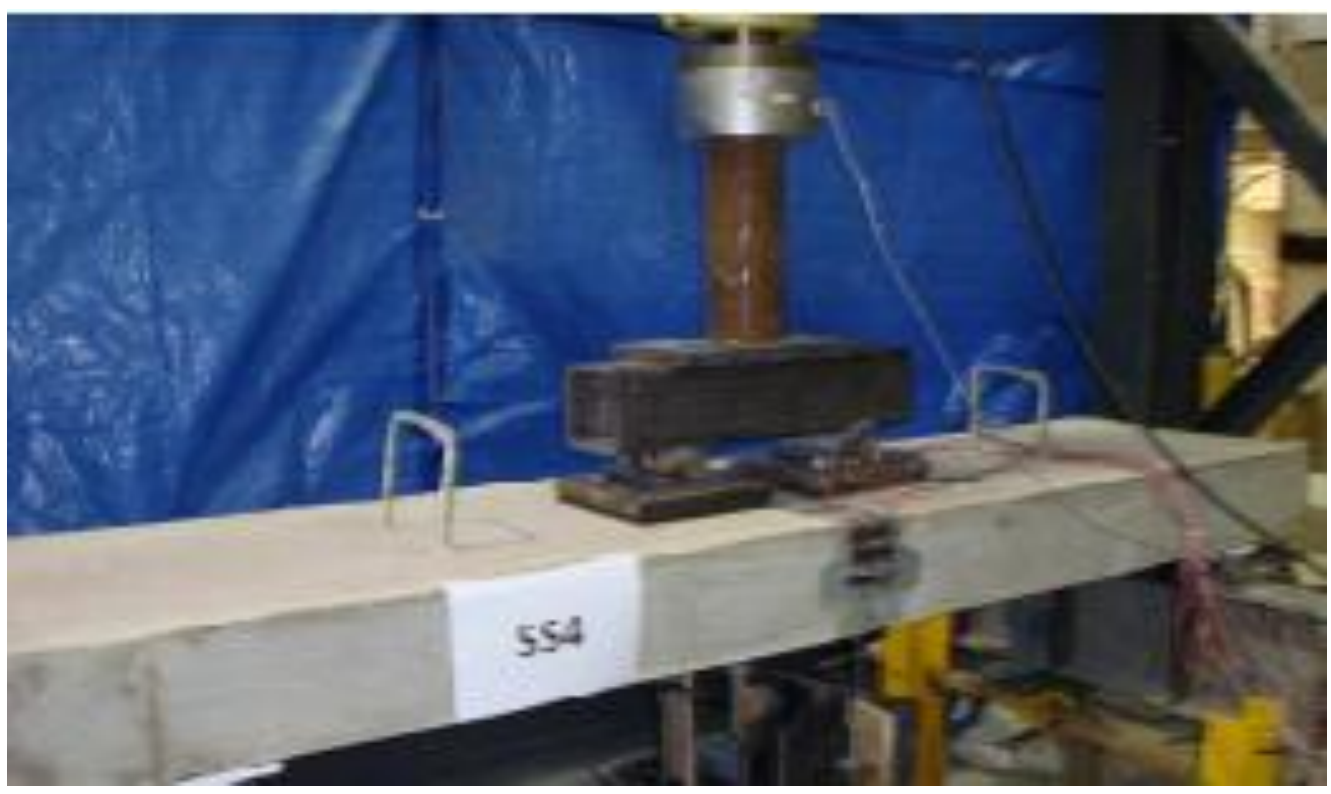

(b) Photo of test setup

Figure 3.30 Testing setup for phase I 


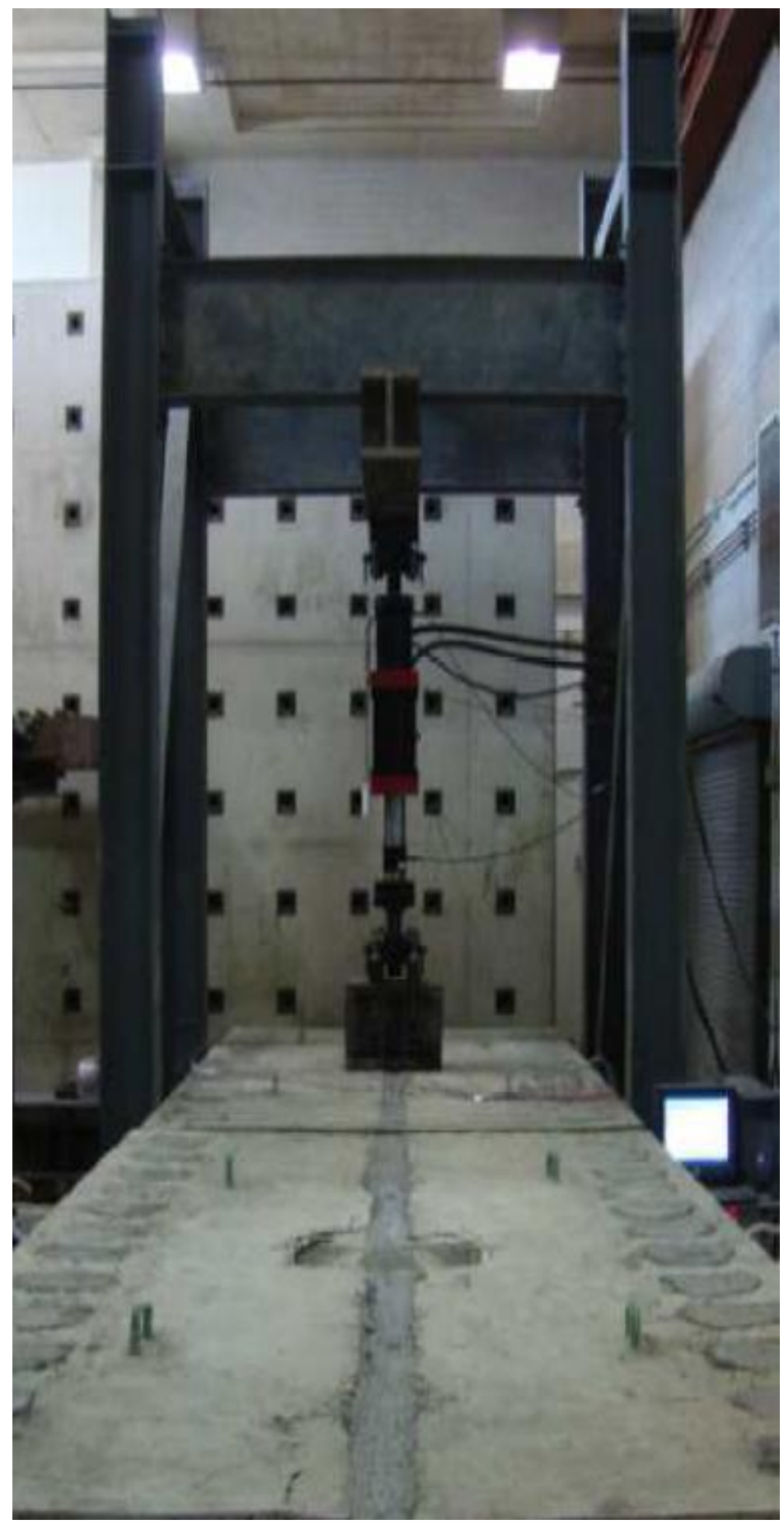

(a)

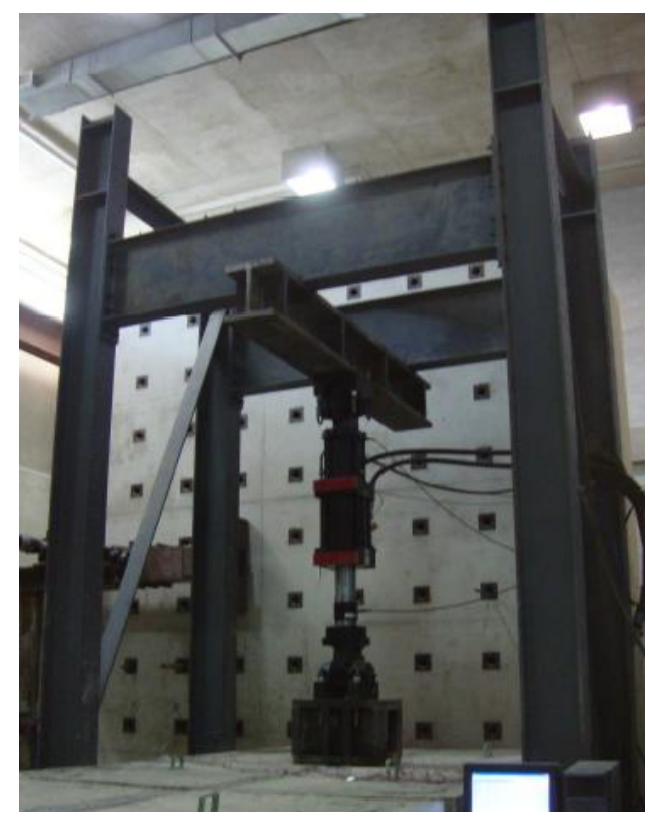

(b)

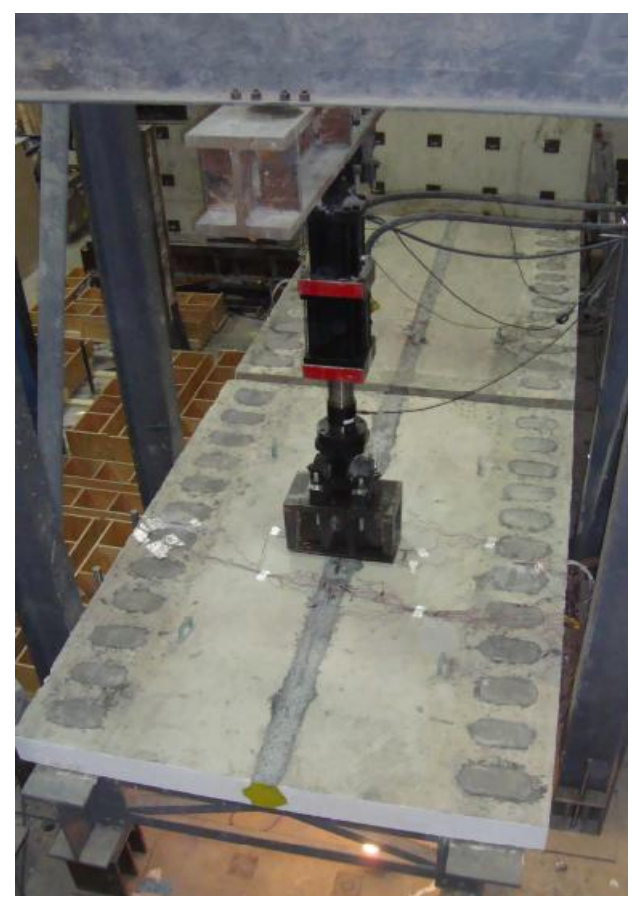

(c)

Figure 3.31 Views of fatigue load test setup 


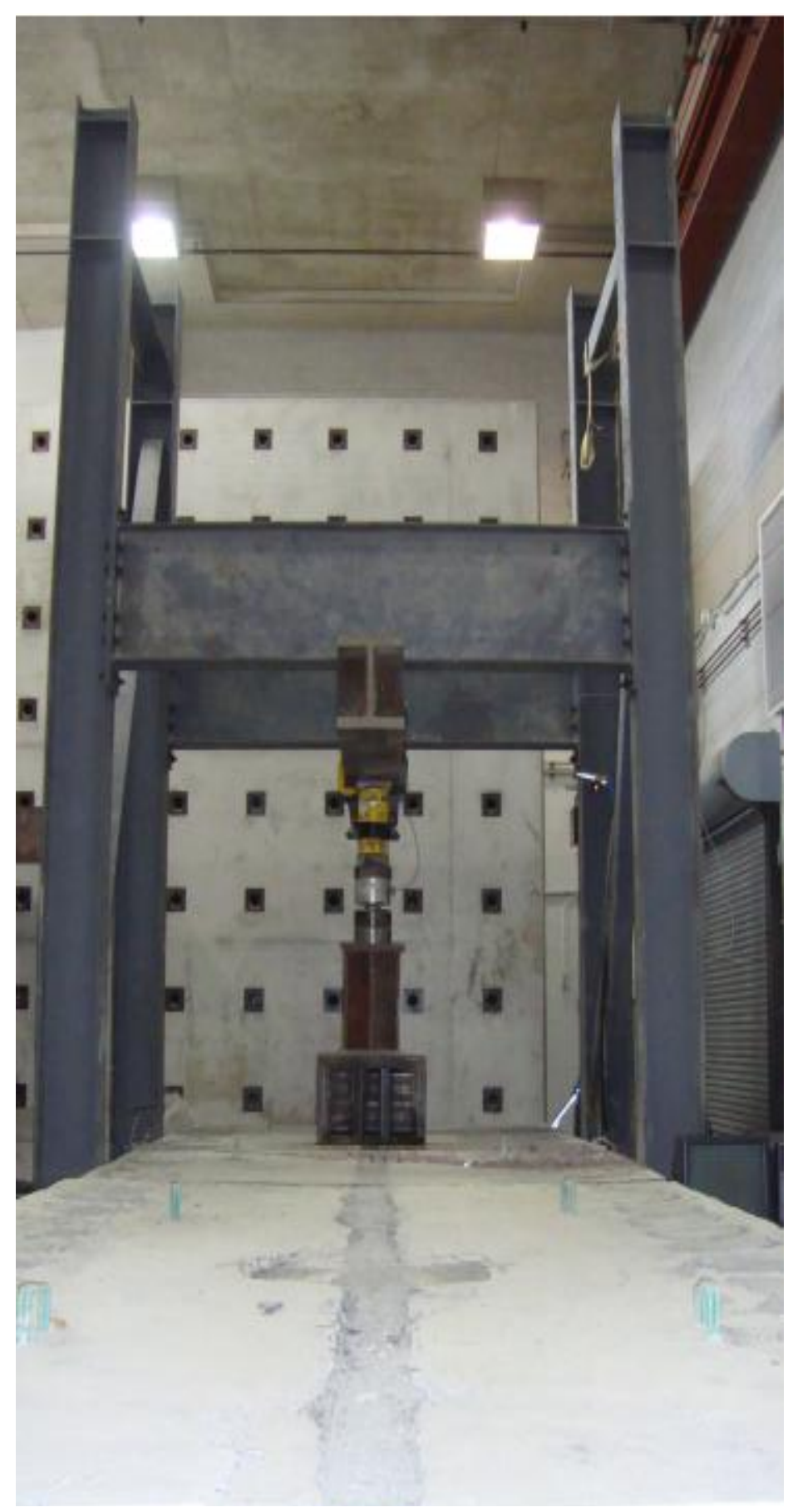

(a)

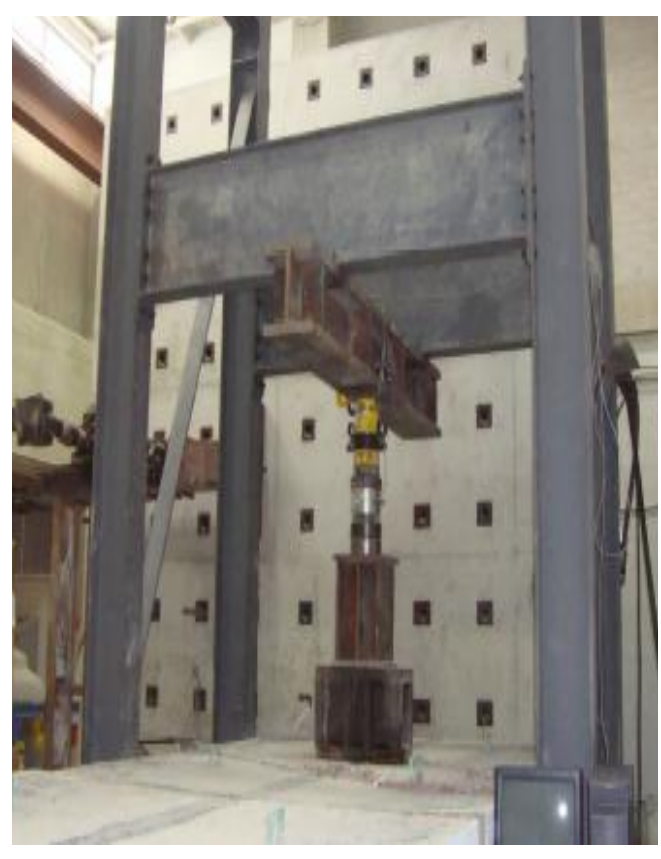

(b)

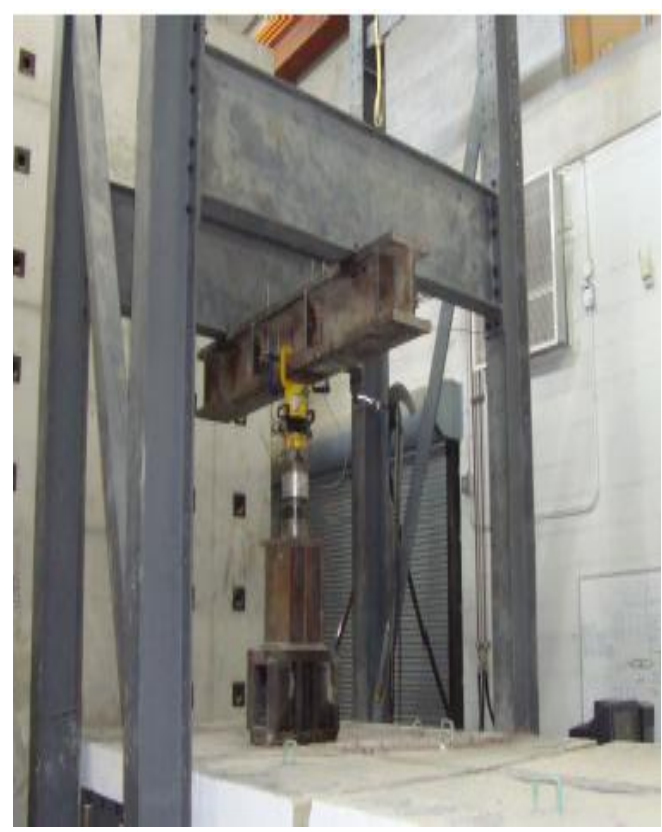

(c)

Figure 3.32 Views of static load test setup 


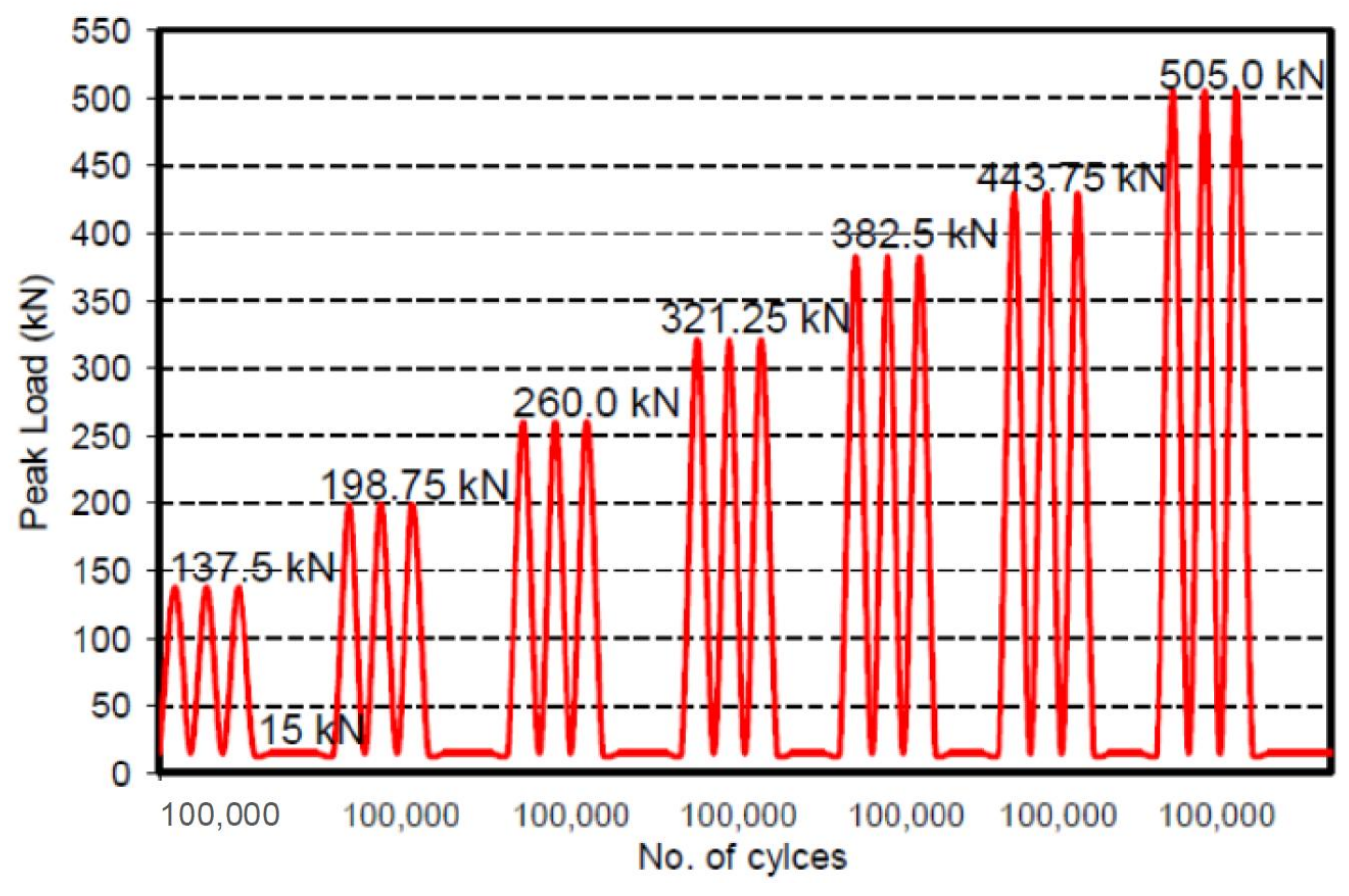

(a) Variable amplitude fatigue (VAF) loading

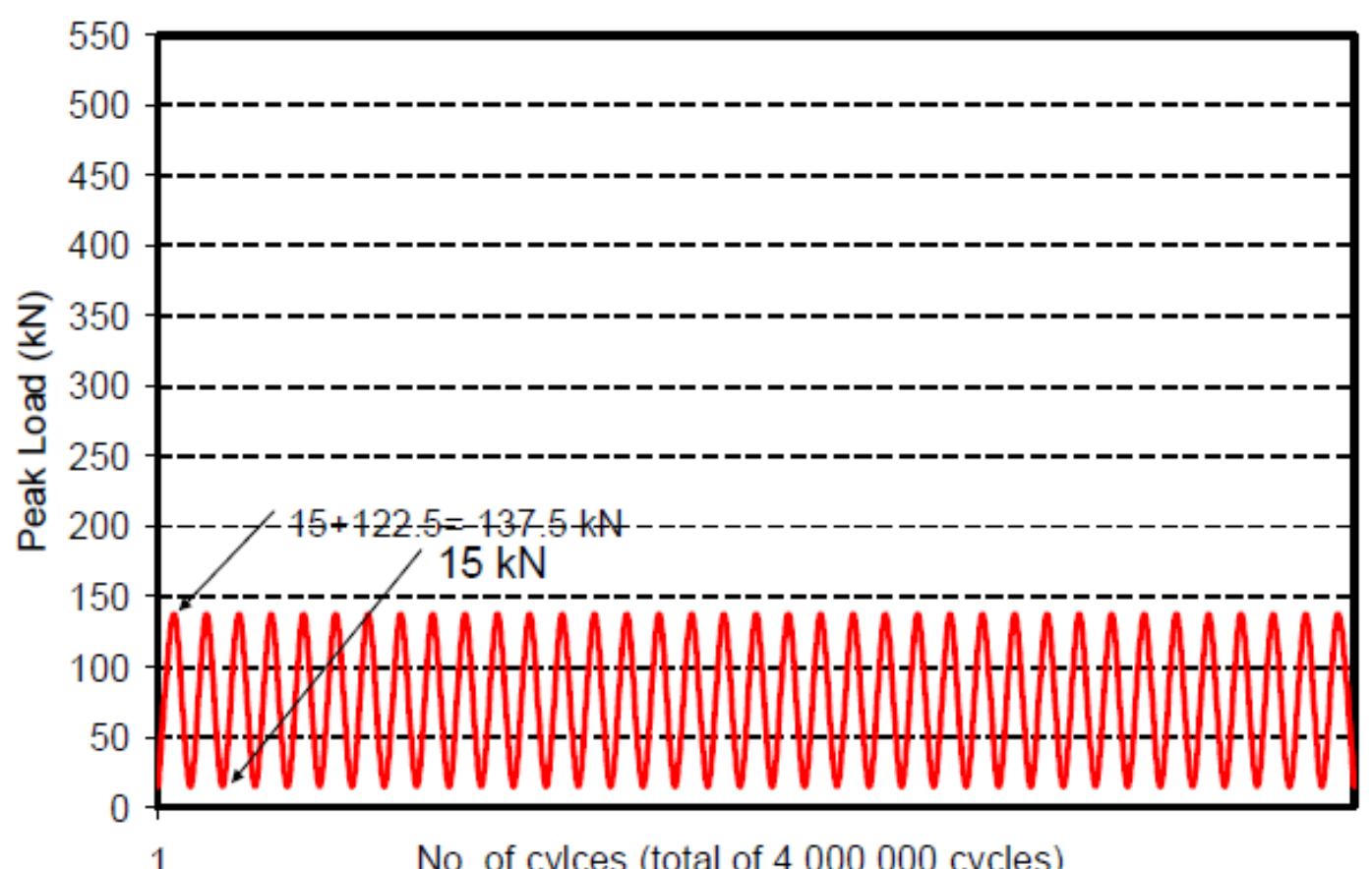

(b) Constant amplitude fatigue (CAF) loading

Figure 3.33 Fatigue loading histories considered in this study 


\subsubsection{Static Load Tests}

In this research, the cast-in-place deck slab S1 and the precast deck slab S6 were tested to failure under a statically applied concentrated load simulating CHBDC wheel load. The static loading was completed through the use of manually operated hydraulic jack and the load was applied in monotonic increments with temporary holds occurring at approximately $50 \mathrm{kN}$ intervals to allow for inspection of crack initiation and propagation. Prior to starting the static load test, slabs S1 and S6 were pre-cracked by performing static load test up to $250 \mathrm{kN}$, and $183.75 \mathrm{kN}$, respectively, to determine the cracking load and initiate cracks to simulate real bridge state of stress. In addition, a similar static load to failure was applied to deck slabs S3, S4, and S8 after completing the fatigue loadings of 4 million cycles at constant amplitude. This test was conducted to determine the ultimate load carrying capacity and the performance of the deck slabs after fatigue life test. 


\section{CHAPTER IV EXPERIMENTAL RESULTS}

\subsection{General}

The intent of this research was to contribute to the efficient design of GFRP-reinforced concrete bridge deck slabs by developing experimentally calibrated models capable of predicting accurately their response when subjected to static and fatigue loading. Two phases of the experimental program were considered: the one-way slab action considering the flexural design approach and the restrained slabs over supporting beams considering punching shear phenomena. In the first phase, a total of 16 cast-in-place bridge deck slabs and jointed precast bridge deck slabs in prefabricated bridge bulb-tee (DBT) were tested under static load to failure. Then the successful control joint out of the developed joints in phase I was further tested in the second phase of the experimental program. A total of 8 full-scale cast-in-place bridge deck slabs and jointed precast deck slabs in prefabricated bridge bulb-tee (DBT) were tested under static load and two types of fatigue loading programs, namely: (i) accelerated variable amplitude fatigue (VAF) loading and (ii) constant amplitude fatigue (CAF) loading, followed by loading the slab monotonically to failure. This chapter discusses the test results in terms of crack width, crack pattern, bar condition at failure, slab deflection, number of load cycles and ultimate load carrying capacity. In addition, Appendices A, B and C provide additional experimental findings for future use.

\subsection{Phase I: Experimental Results}

This section discusses the structural behavior of the simply-supported decks slabs tested under static load to failure. 


\subsubsection{Cracking and Failure Types}

\subsubsection{Steel-Reinforced Deck Slabs}

Figures 4.1 and 4.2 show the crack pattern at failure of the cast-in-place deck slabs SS0 and SS1 with reinforcing steel bars. It should be noted that slab SS0 was tested under monotonically increasing load to failure, while slab SS1 was tested under incremental loading to failure. It was observed that the first visual flexural crack for slabs SS0 and SS1, appeared at the bottom of the slab at the mid-span location at loads of $24 \mathrm{kN}$ and $30 \mathrm{kN}$, respectively. Other flexural cracks appeared within the quarter points of the span and propagated towards the top surface of the slabs with increase in load till failure occurred due to crushing of concrete at the top surface of slabs at the mid-span location. Slabs, SS0 and SS1 failed at a load of $77 \mathrm{kN}$ and $95 \mathrm{kN}$, respectively.

\subsubsection{Ribbed-Surface GFRP-Reinforced Deck Slabs}

Figures 4.3 and 4.4 show the crack pattern at failure of the cast-in-place deck slabs, SS2 and SS7 with ribbed-surface GFRP bars. It should be noted that slab SS2 was tested under incremental loading to failure, while slab SS7 was tested under monotonically increasing load to failure. It was observed that the first visible flexural cracks for slabs, SS2 and SS7 appeared at loads of $30 \mathrm{kN}$ and $23 \mathrm{kN}$, respectively. Other flexural cracks appeared at higher load increments and spread over a length greater than that for slabs SS0 and SS1. However, a diagonal shear crack suddenly appeared between the load location and quarter point location that widened and propagated to the vicinity of the applied load location and the support causing concrete crushing at the top surface of slabs, as shown in Figs. 4.3-a and 4.4-a for slabs SS2 and SS7, respectively, leading to slab collapse. Failure of slabs SS2 and SS7 occurred at an ultimate loads of $166 \mathrm{kN}$ and $130 \mathrm{kN}$, respectively, due to combined shear and bending. 
By comparing the ultimate load capacity of slabs SS1 and SS2, it can be observed that the GFRPreinforced slab exhibited a flexural strength about $75 \%$ greater than that for a similar slab reinforced with steel bars. It should be noted that both slabs were reinforced per the reinforcement ratios specified in CHBDC. Given the fact that slab SS7 has 3 main bars in the tension side in contrast to 4 bars in the other GFRP-reinforced slab, SS2, the ultimate load SS7 can be approximated as $130 \times(4 / 3)=173 \mathrm{kN}$ which is about $82 \%$ greater than that for the steelreinforced slab SS1.

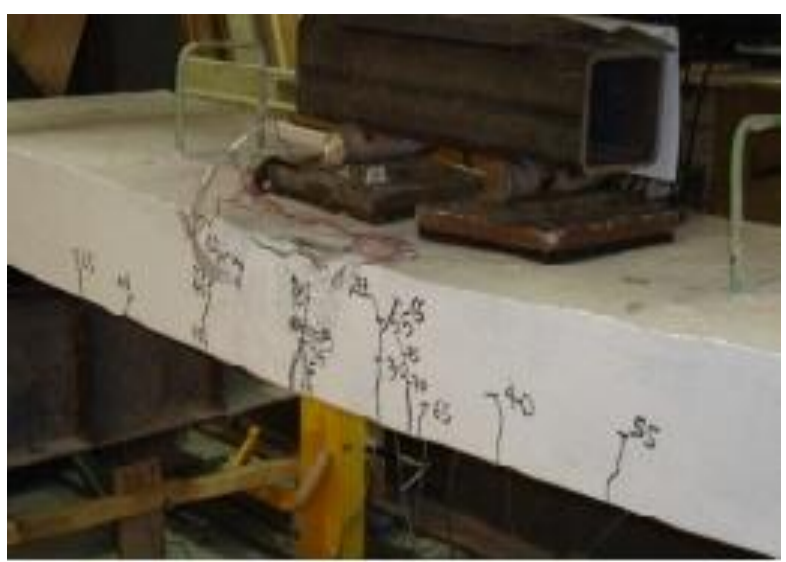

(a) Side view

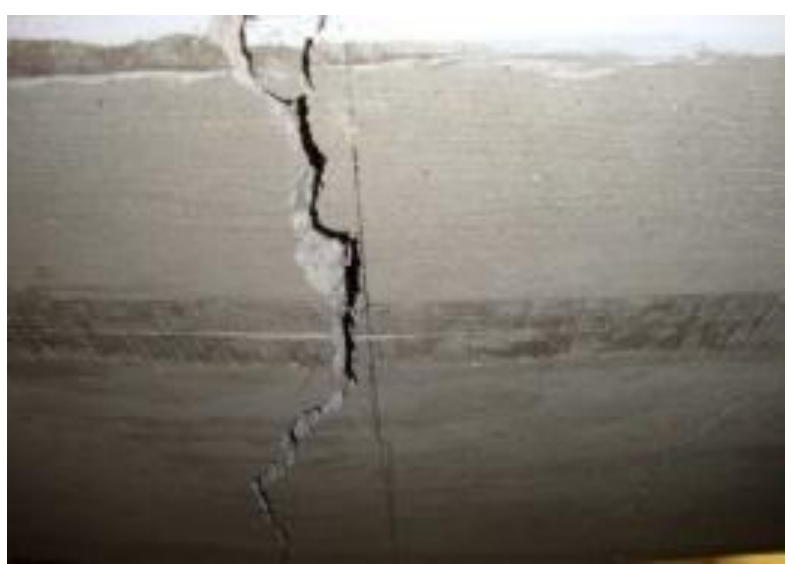

(b) Bottom view

Figure 4.1 Crack pattern for deck slab SS0

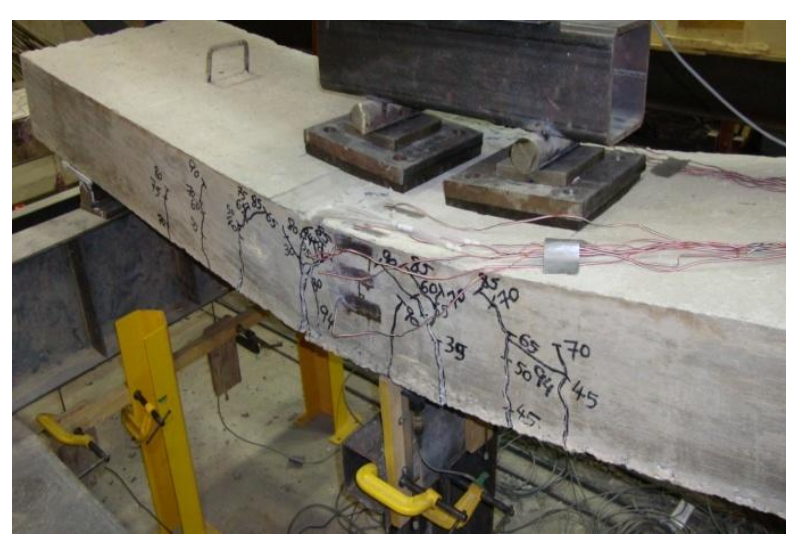

(a) Side view

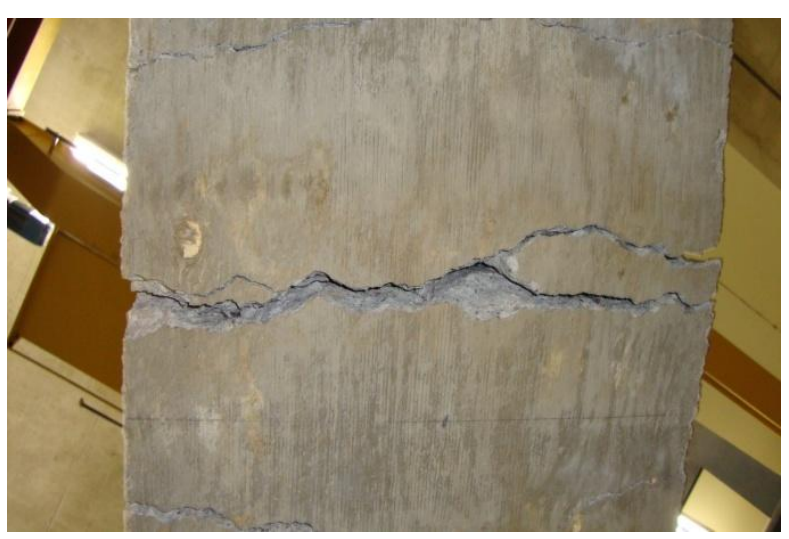

(b) Bottom view

Figure 4.2 Crack pattern for deck slab SS1 
Figure 4.5 shows the crack pattern at failure of precast slab SS3 with 200-mm wide closure strip filled with NSG and projected bottom headed-end GFRP bars. It was noticed that the first hairline cracks were formed at the cold joint between the precast concrete and the closure strip at a load of $16 \mathrm{kN}$. These fine cracks started to widen gradually with increase in applied load. Few flexural cracks appeared in the precast slab closer to the closure strip as depicted in Fig. 4.5-a. Close to failure, a wide transverse cracks propagated along the underside of the cold joint indicting a loss of bond, followed by propagation of a wide flexural crack at both sides of the cold joint as shown in Fig. 4.5-a. Failure of slab SS3 at $80.5 \mathrm{kN}$ ultimate load was due to loss of bond combined with breakage of the bar head within the closure strip as shown in Fig. 4.12-a. It can be observed that slab SS3 is not considered as good as the steel-reinforced slab SS1 for ultimate strength since its ultimate capacity is $15 \%$ less than that for slab SS1.

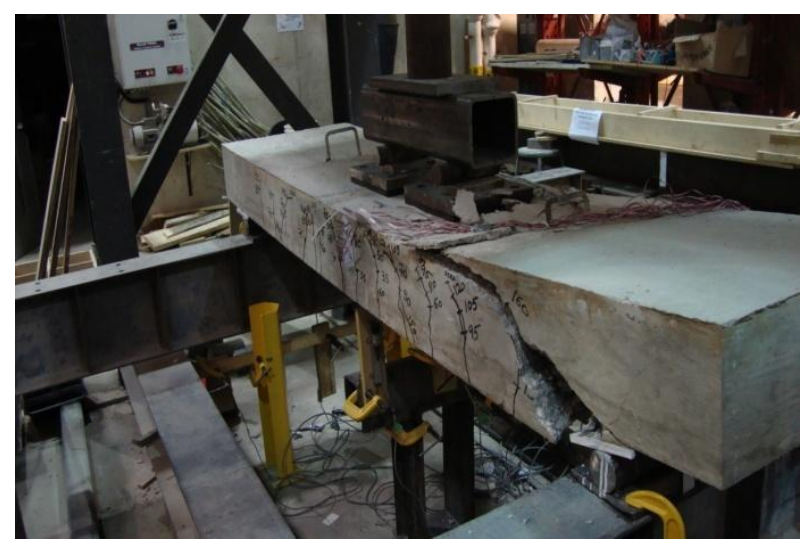

(a) Side view

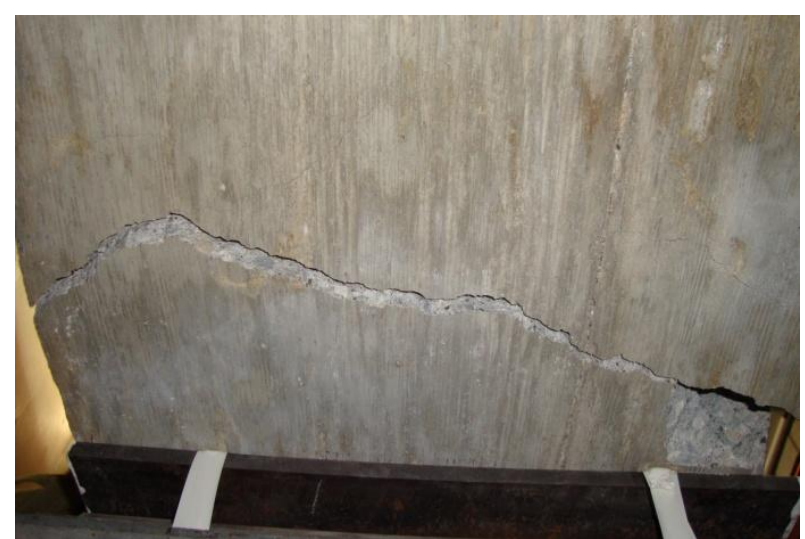

(b) Bottom view

Figure 4.3 Crack pattern for deck slab SS2 


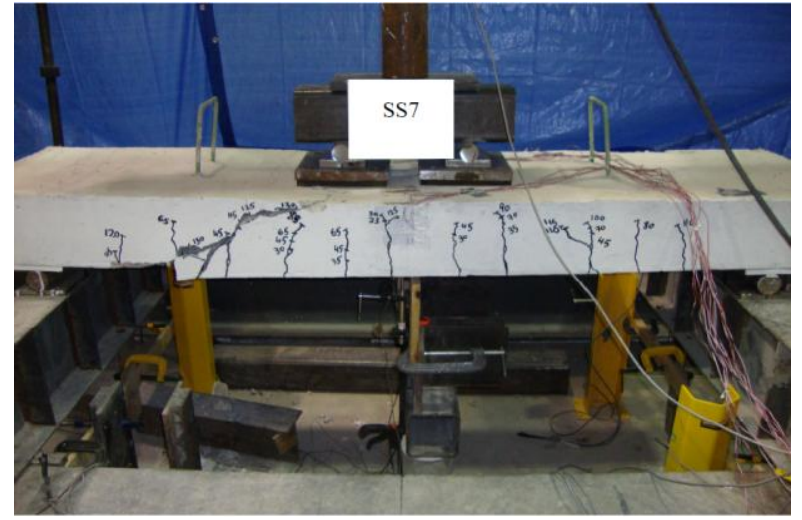

(a) Side view

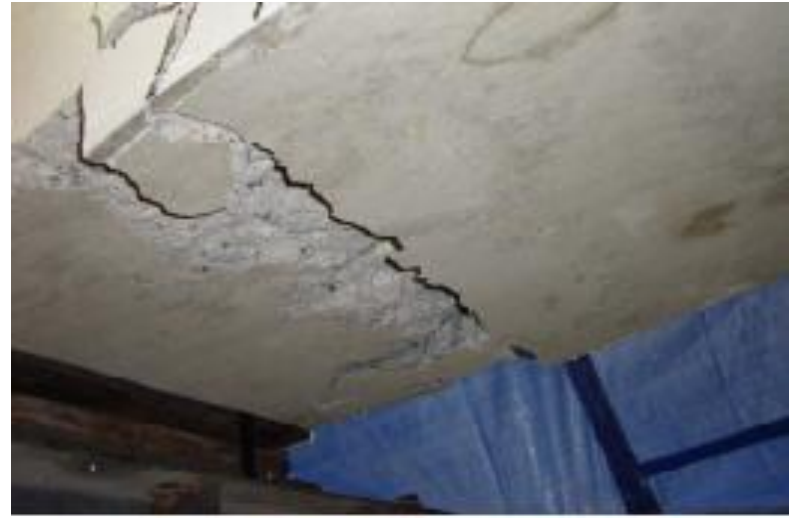

(b) Bottom view

Figure 4.4 Crack pattern for deck slab SS7

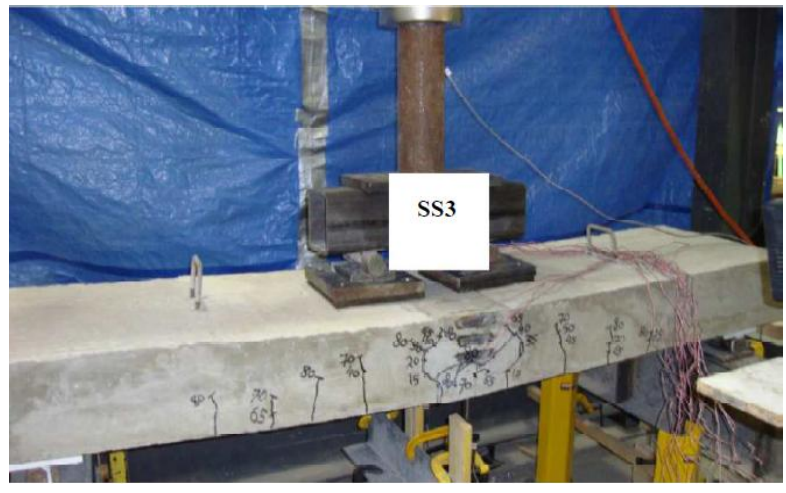

(a) Side view

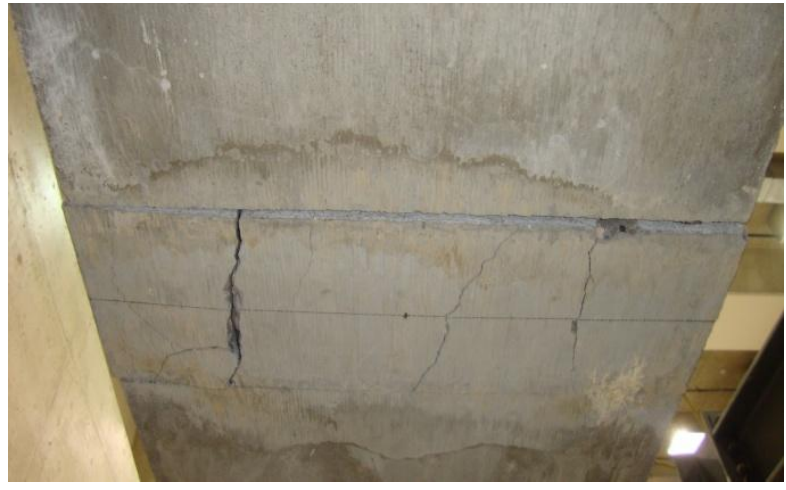

(b) Bottom view

Figure 4.5 Crack pattern for deck slab SS3

Figure 4.6 shows the crack pattern at failure of the precast slab SS4 with $125-\mathrm{mm}$ wide closure strip filled with UHPC and projected bottom headed-end GFRP bars embedded into it. It was observed that the first hairline cracks were formed at the cold joint between the precast concrete and the closure strip at a load of $20 \mathrm{kN}$. These fine cracks started to widen gradually with the increase in applied load. A few flexural cracks appeared in the precast slab closer to the closure strip as shown in Fig. 4.6-a. Prior to failure, a wide flexural crack propagated along the underside 
of the slab at the interface between the precast concrete and the closure strip as shown in Fig. 4.6b leading to concrete crushing at top surface of precast slab at interface with the cold joint as depicted in Fig.4.12-b. In addition, slight slippage of bar from the headed-end outer disk was observed as shown in Fig. 4.12-c. This type of deformation was observed after taking a core sample of the joint and slicing it using saw-cutting. As such, failure of slab SS4 was due to slippage of the bars from the head within the closure strip combined with crushing of top concrete surface at $120.4 \mathrm{kN}$ ultimate load. It can be noted that slab SS4 is considered as good as the steelreinforced slab SS1 since its ultimate capacity is $27 \%$ greater than that for slab SS1.

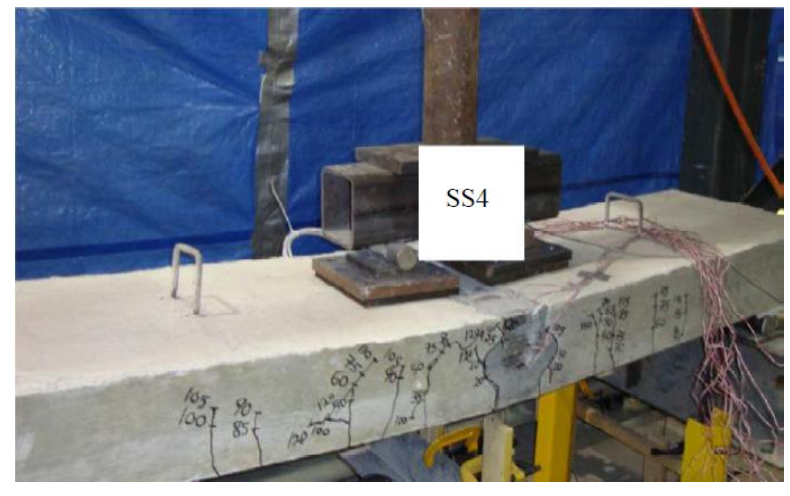

(a) Side view

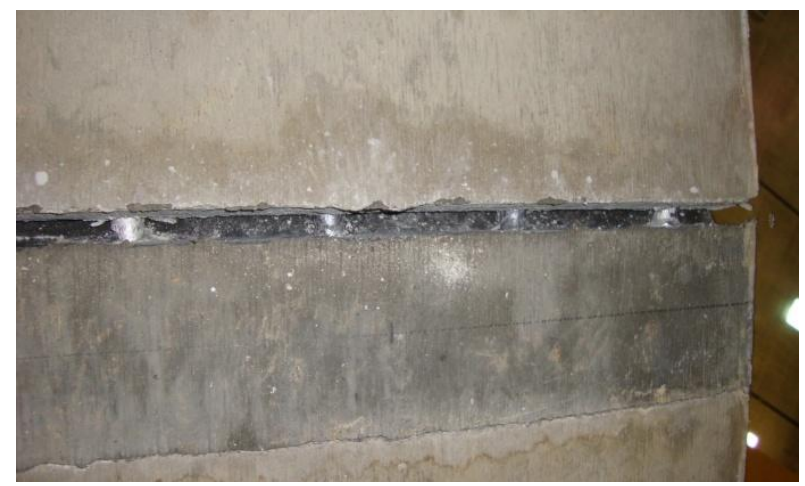

(b) Bottom view

Figure 4.6 Crack pattern for deck slab SS4

Figure 4.7 shows the crack pattern at failure of precast slab SS5 with 100-mm wide closure strip filled with NSG and staggered 100-mm wide trapezoidal-shaped interlock, and projected bottom headed GFRP bars. It was noticed that the first hairline cracks were formed at the cold joint between the precast concrete and the closure strip at a load of $15 \mathrm{kN}$. These fine cracks started to widen gradually with the increase in applied load. A few flexural cracks appeared in the precast slab closer to the closure strip as shown in Fig. 4.7-a. Close to failure, large longitudinal and transverse cracks propagated along the underside of the cold joint followed by formation of a wide 
flexural crack at both sides of the cold joint as depicted in Fig. 4.7-a. Failure of slab SS5 at 68 kN ultimate load was due to loss of bond combined with breakage of the bar head as shown in Fig. 4.12-d. Given the fact that this specimen has 3 main bars in the tension side in contrast to 4 bars in other GFRP-reinforced slabs, the ultimate load can be approximated as $67.99 \mathrm{x}(4 / 3)=90.65 \mathrm{kN}$ which is still less than that for the steel-reinforced slab SS1. As such, it can be concluded that slab SS5 is not considered as good as the steel-reinforced slab SS1 with respect to ultimate strength. However, future research with the use of UHPC as a closure strip filler other than NSG would increase the ultimate load carrying capacity of the slab.

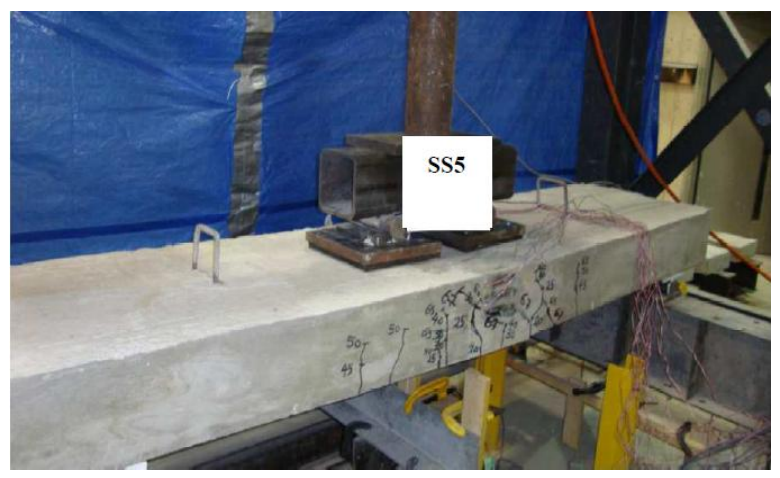

(a) Side view

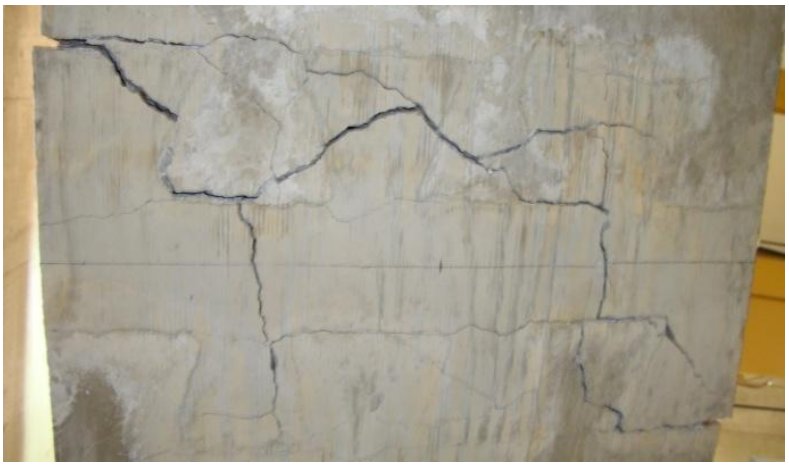

(b) Bottom view

Figure 4.7 Crack pattern for deck slab SS5

Figure 4.8 shows the crack pattern at failure of precast slab SS6 with 300-mm wide closure strip filled with NSG and projected bottom straight GFRP bars. It was observed that the first hairline cracks were formed at the cold joint between the precast concrete and the closure strip at a load of $10 \mathrm{kN}$. These fine cracks started to widen gradually with increase in applied load. Several flexural cracks appeared in the precast slab closer to the closure strip as depicted in Fig. 4.8-a. Prior to failure, set of deep longitudinal and transverse cracks propagated along the underside of the cold joint followed by development of a wide flexural crack at both sides of the cold joint as shown in 
Fig. 4.8-b. Failure of slab SS6 at $80.8 \mathrm{kN}$ ultimate load was due to loss of bond combined with slippage of the GFRP bars from the cold joint as depicted in Fig. 12-e.

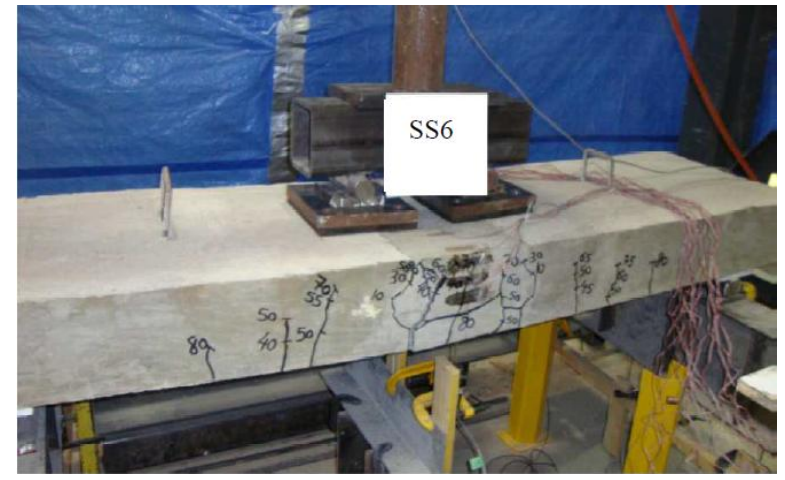

(a) Side view

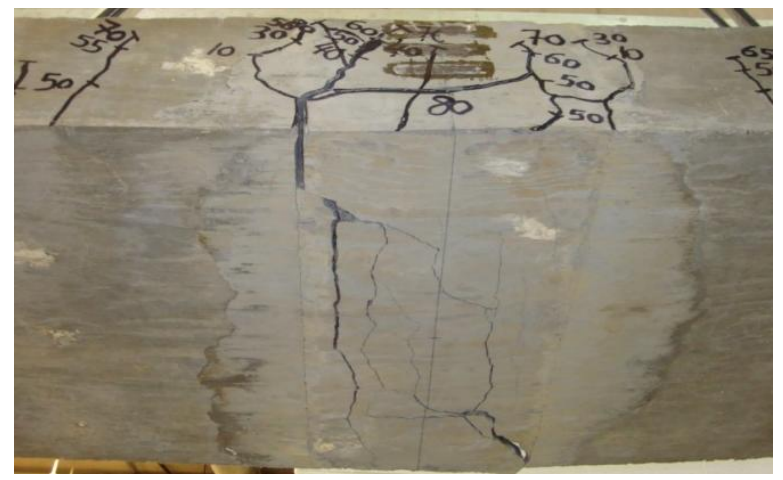

(b) Bottom view

Figure 4.8 Crack pattern for deck slab SS6

Figure 4.9 shows the crack pattern at failure of precast slab SS8 with 200-mm wide closure strip filled with NSG and projected bottom headed-end GFRP bars. In contrast to slab SS3, it should be noted that slab SS8 was tested under increasing load to failure. It was observed that the first hairline cracks were formed at the cold joint between the precast concrete and the closure strip at a load of $10 \mathrm{kN}$. These fine cracks started to widen gradually as the load increased. Very few flexural cracks appeared in the precast slab closer to the closure strip as depicted in Fig. 4.9-a. Failure of slab SS8 at $60 \mathrm{kN}$ ultimate load was due to breakage of the bar head.

Figure 4.10 shows the crack pattern at failure of precast slab SS9 with 125-mm wide closure strip filled with UHPC and projected bottom headed-end GFRP bars embedded into the joint. It was observed that the first hairline cracks were formed at the cold joint between the precast concrete and the closure strip at a load of $20 \mathrm{kN}$. These fine cracks started to widen gradually with the increase in applied load. A few flexural cracks appeared in the precast slab closer to the closure 
strip as depicted in Fig. 4.10-a. Failure of slab SS9 occurred at an ultimate load of $77 \mathrm{kN}$. The failure mode of this slab was identical to that for slab SS4; due to slippage of the bars from head ends within the closure strip as shown in Fig. 4.12-f. As it can be observed, the closure strip of 200-mm width filled with non-shrink grout in slab SS8 had a load carrying capacity less than that for slab SS0 reinforced with steel bars by $22 \%$. However, the $125-\mathrm{mm}$ wide closure strip filled with UHPC has a load carrying capacity similar to that for the steel-reinforced concrete slab, SSO.

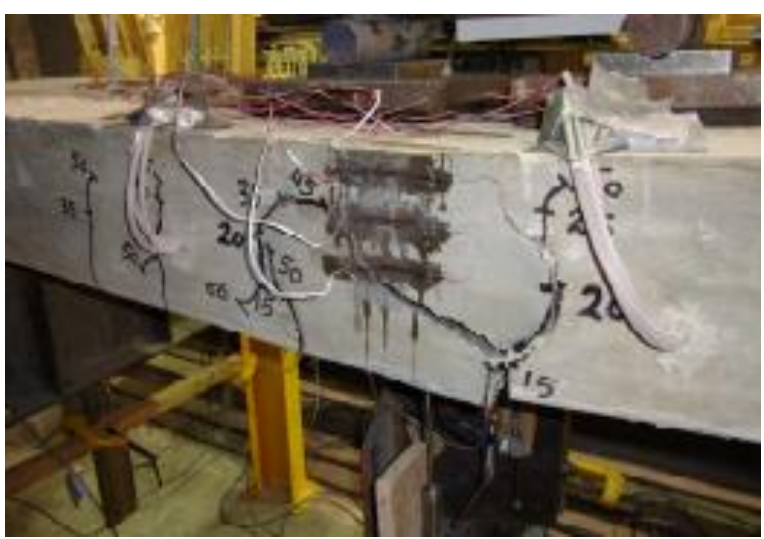

(a) Side view

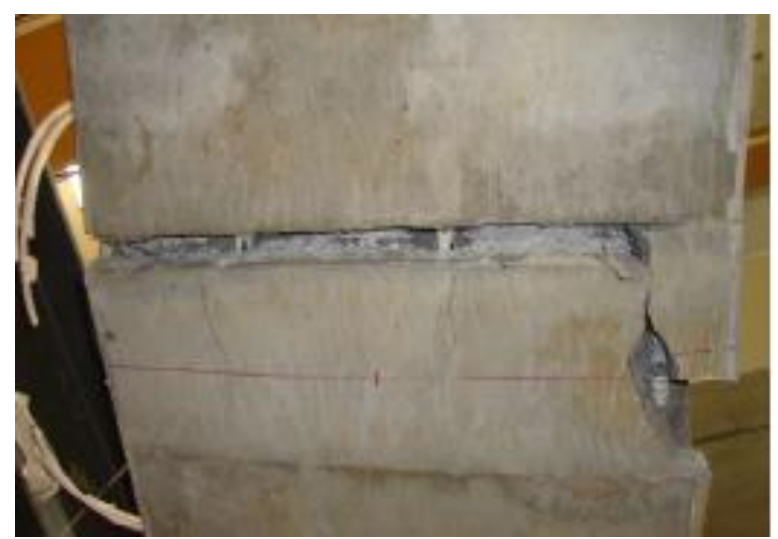

(b) Bottom view

Figure 4.9 Crack pattern for deck slab SS8

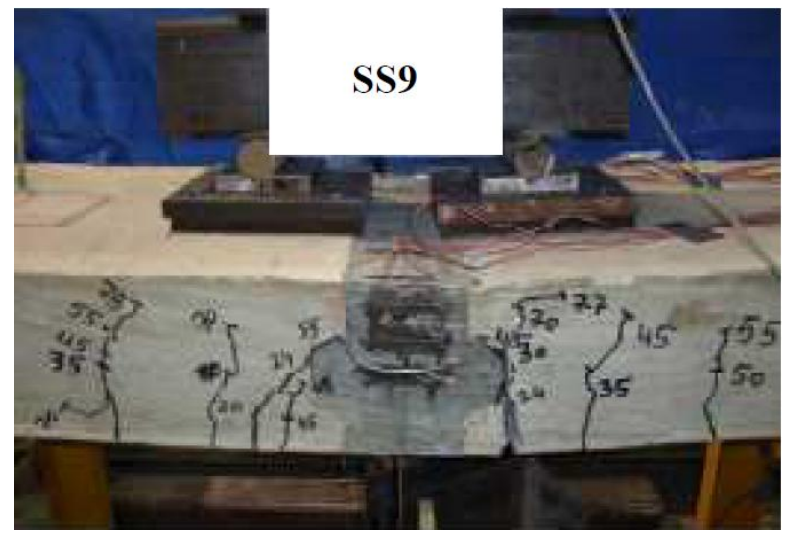

(a) Side view

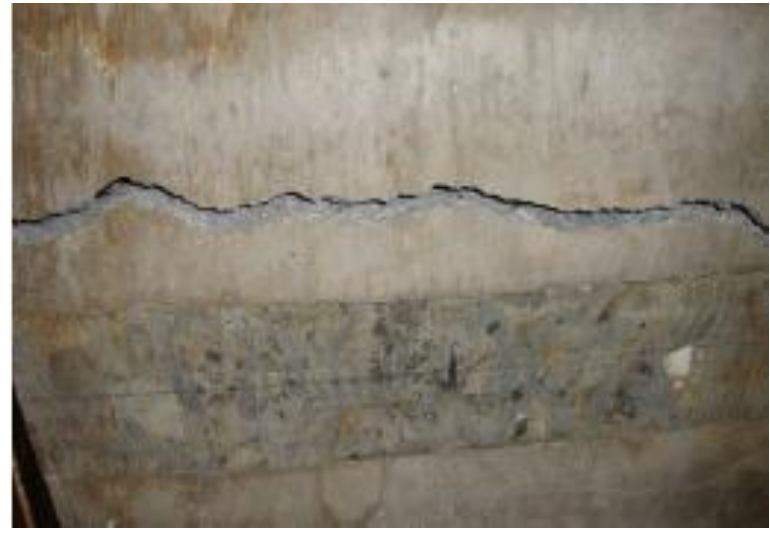

(b) Bottom view

Figure 4.10 Crack pattern for deck slab SS9 
Figure 4.11 shows the crack pattern at failure of precast slab SS10 with 200-mm wide closure strip filled with NSG and projected bottom straight GFRP bars. It was observed that the first hairline cracks were formed at the cold joint between the precast concrete and the closure strip at a load of $12 \mathrm{kN}$. These fine cracks started to widen gradually with the increase in applied load. Failure of slab SS10 occurred at a load of $29 \mathrm{kN}$ which was far below the experimental ultimate load for steel-reinforced slab SSO. The failure was observed to be due to slippage of bars from the cold joint.

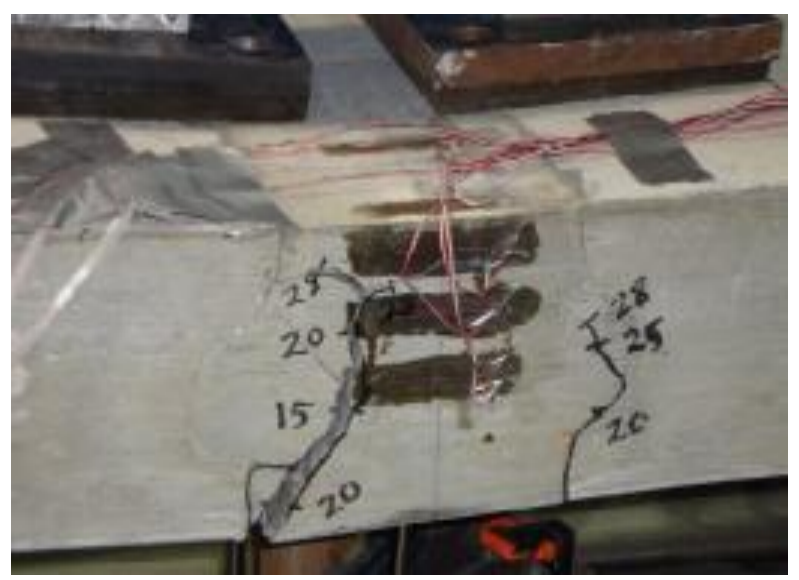

(a) Side view

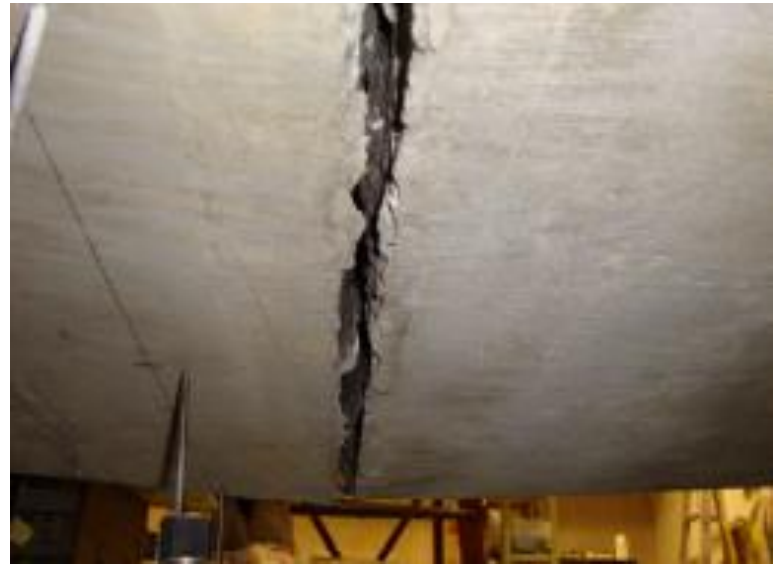

(b) Bottom view

Figure 4.11 Crack pattern for deck slab SS10 


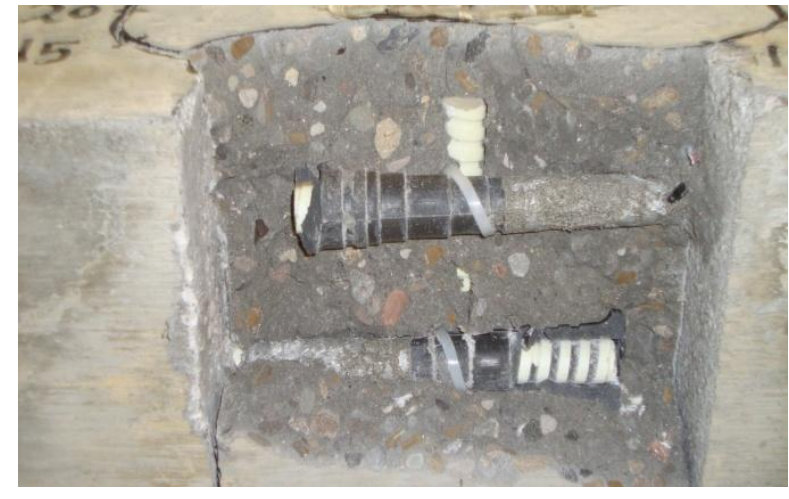

(a) Bar head breakage in slab SS3

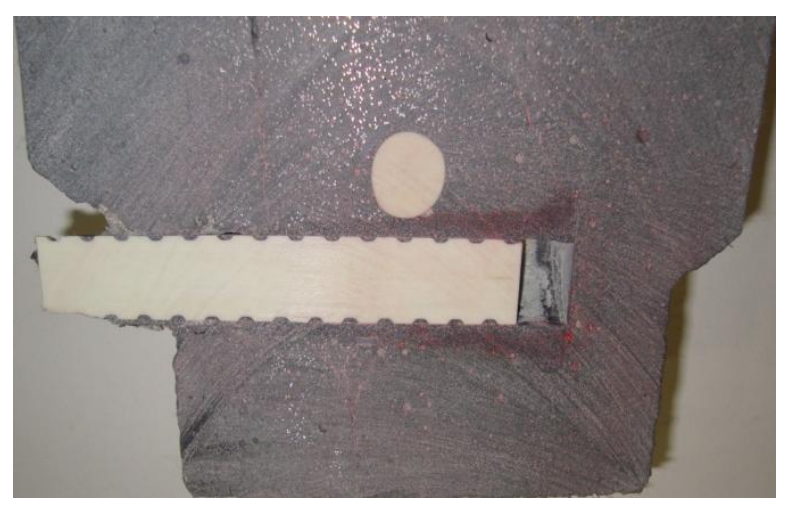

(c) Bar slippage from the head in slab SS4

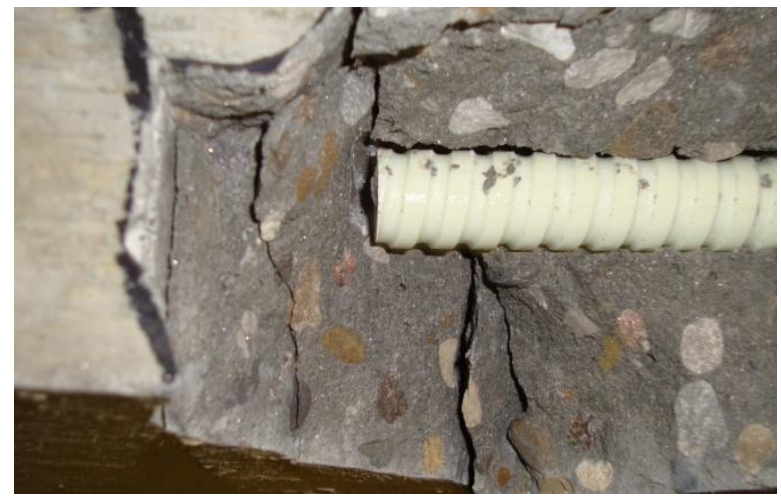

(e) Bar debonding in slab SS6

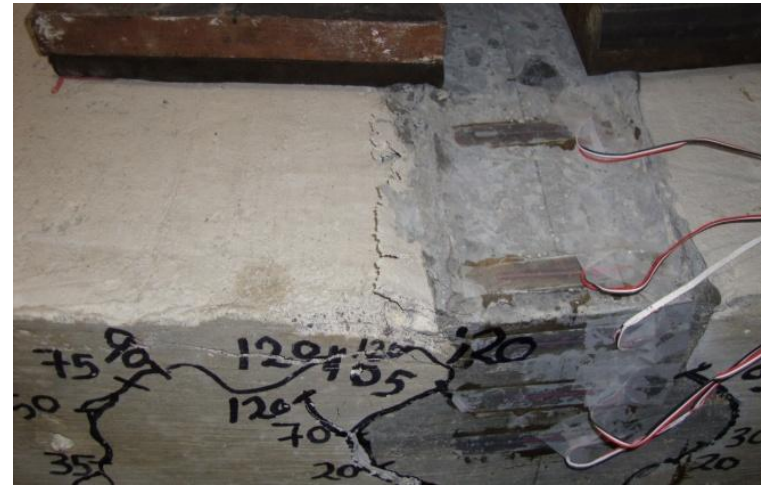

(b) Concrete crushing in slab SS4

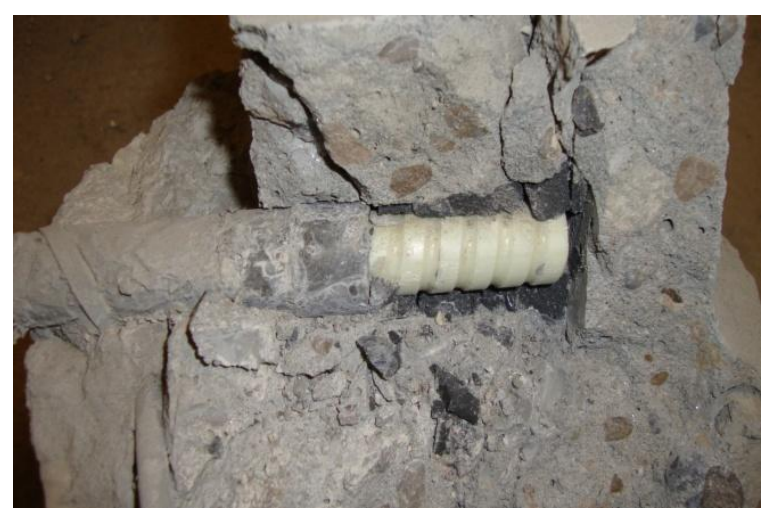

(d) Bar head breakage in slab SS5

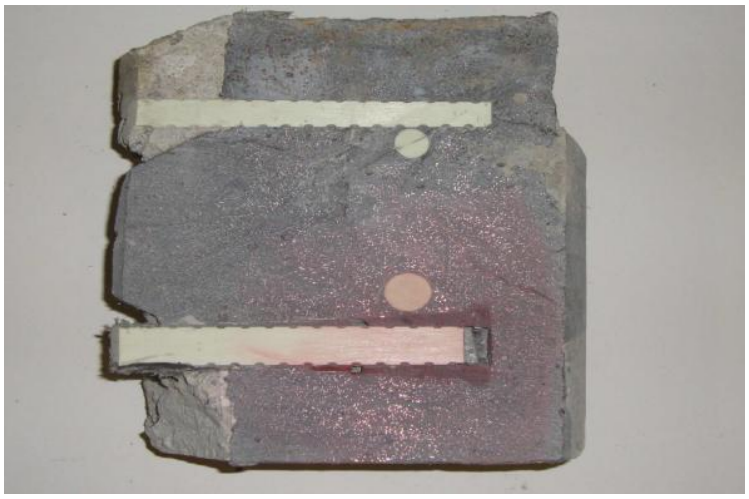

(f) Bar slippage from the head in slab SS9

Figure 4.12 Selected failure modes in ribbed-surface GFRP-reinforced slabs 


\subsubsection{Sand-Coated GFRP-Reinforced Deck Slabs}

Slabs, PS1 through PS5 were reinforced with sand-coated GFRP bars and tested under incremental loading to failure. It should be noted that the amount of the reinforcement used in each slab was dependent on whether HM or SM bars were used as depicted in Table 4.1. Figure 4.13 shows the crack pattern at failure of the cast-in-place slab, PS1, reinforced with straight GFRP bars. It was observed that the first visible flexural crack appeared at a load of $30 \mathrm{kN}$. Other flexural cracks appeared at higher load increments and spread over a length greater than that for steel-reinforced slab SS1. A diagonal shear crack suddenly appeared between the load location and quarter point location that widened and propagated to the vicinity of the applied load location causing concrete crushing at the top surface of slab, as shown in Fig. 4.13-a, leading to failure of the slab. The failure occurred at an ultimate load of $158 \mathrm{kN}$ due to combined shear and bending. By comparing the ultimate load capacities of slabs SS1 and PS1 that were tested under incremental loading, it can be observed that the GFRP-reinforced slab exhibited a flexural strength about $66 \%$ greater than that for a similar slab reinforced with steel bars.

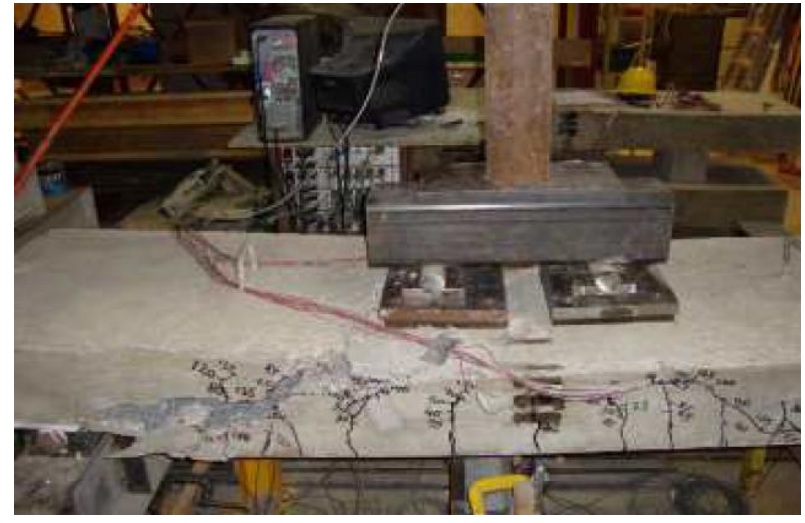

(a) Side view

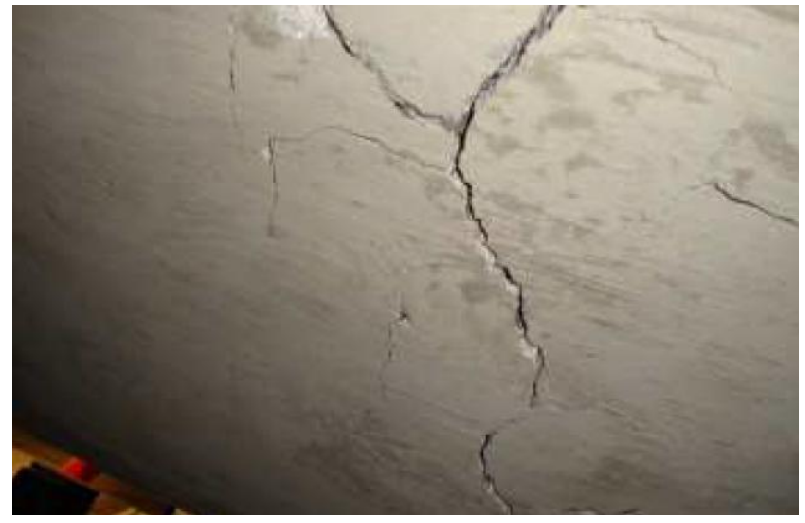

(b) Bottom view

Figure 4.13 Crack pattern for deck slab PS1 
Figure 4.14 shows the crack pattern at failure of precast slab PS2 with 200-mm wide closure strip filled with NSG and projected bottom L-shaped GFRP bars. It was noticed that the first hairline cracks were formed at the cold joint between the precast concrete and the closure strip at a load of $10 \mathrm{kN}$. These fine cracks widened gradually with the increase in applied load. A few flexural cracks appeared in the precast slab closer to the closure strip as depicted in Fig. 4.14-a. Prior to failure, a wide longitudinal and transverse crack propagated along the underside of the cold joint followed by falling of the grout under the GFRP bars as depicted in Fig. 4.14-b. Failure of slab PS2 at $119 \mathrm{kN}$ ultimate load was due to loss of bond combined with rupture of GFRP bars at the bend part as shown in Fig. 4.18-a. It can be observed that slab PS2 exhibited a flexural strength about $25 \%$ greater than that for a similar slab, SS1, reinforced with steel bars.

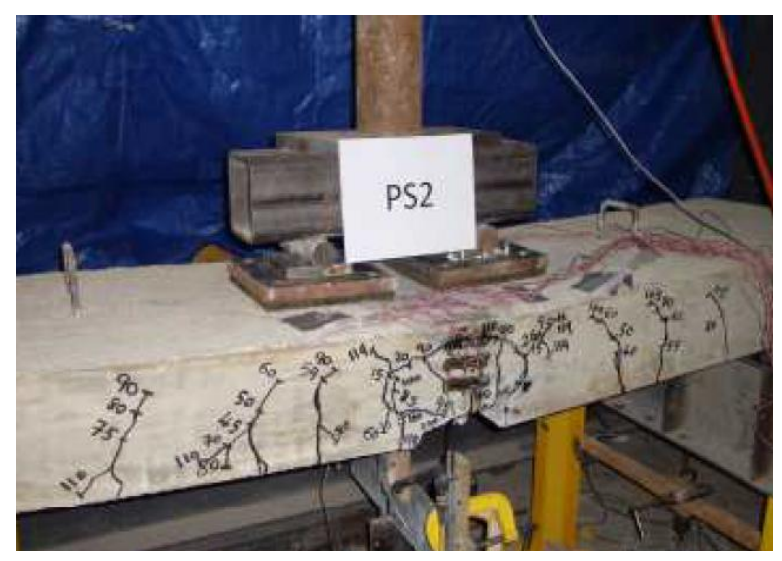

(a) Side view

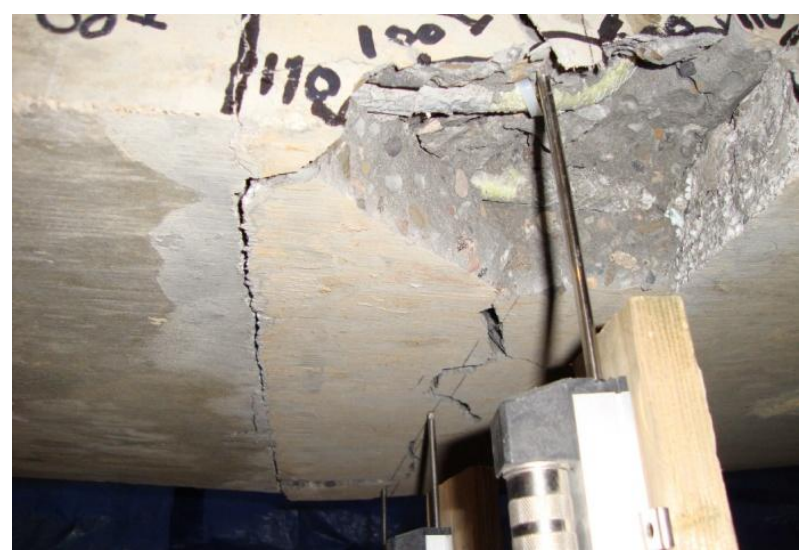

(b) Bottom view

Figure 4.14 Crack pattern for deck slab PS2

Figure 4.15 shows the crack pattern at failure of precast slab PS3 with 200-mm wide closure strip filled with NSG and projected bottom headed-end GFRP bars. It was observed that the first hairline cracks were formed at the cold joint between the precast concrete and the closure strip at a load of $13 \mathrm{kN}$. These fine cracks widened gradually with the increase in applied load. Compared 
to slab PS2, very few flexural cracks appeared in the precast slab closer to the closure strip as depicted in Fig. 4.15-a. Close to failure, the grout under the headed bars fell down indicating a loss of bond. Failure of slab PS3 was recorded at $70.7 \mathrm{kN}$ due loss of bond combined with breakage of the bar head as shown in Fig. 4.18-b. It can be noted that slab PS3 was considered not as good as the steel-reinforced slab SS1 since its ultimate capacity is $26 \%$ less than that for slab SS1.

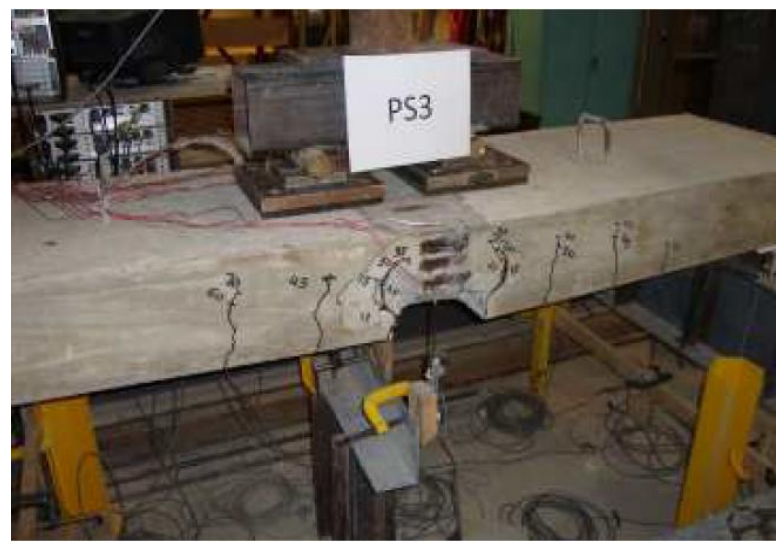

(a) Side view

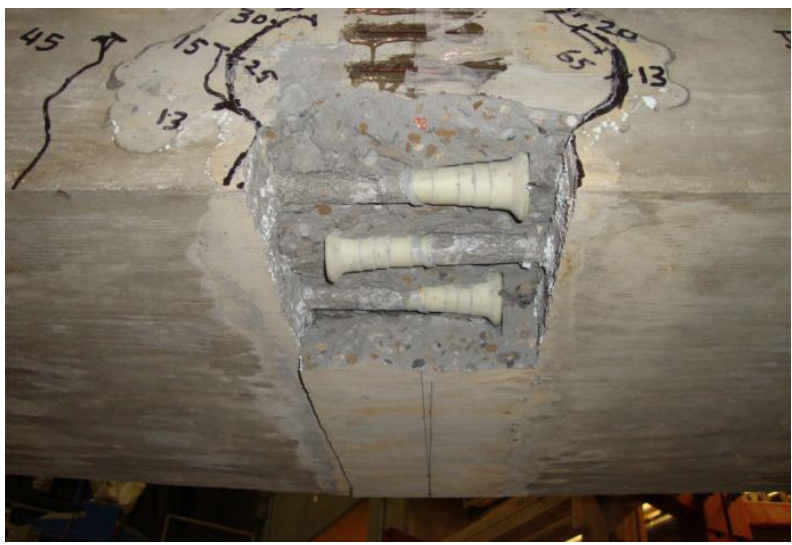

(b) Bottom view

Figure 4.15 Crack pattern for deck slab PS3

Figure 4.16 shows the crack pattern at failure of precast slab PS4 with 125-mm wide closure strip and projected bottom headed-end GFRP bars embedded in UHPC. It was observed that the first hairline cracks were formed at the cold joint between the precast concrete and the closure strip at a load of $10 \mathrm{kN}$. These fine cracks widened gradually with the increase in applied load. A few flexural cracks appeared in the precast slab closer to the closure strip as shown in Fig. 4.16-a. Prior to failure, a wide flexural crack propagated along the underside of the cold joint at mid-span as depicted in Fig. 4.16-b. This flexure crack passed through the head of GFRP bar leading to head failure around the bar as shown in Fig. 4.18-c. It can also be observed that the head 
breakage forced the end of the straight bar to carry the tensile force leading to slight slippage from the head outer disk as shown in the right image of Fig.4.18-c. As such, failure of slab PS4 was due to breakage of the bar head within the closure strip at $120.5 \mathrm{kN}$ ultimate load. It can be noted that slab PS4 was considered as good as the steel-reinforced slab SS1 since its ultimate capacity is $27 \%$ greater than that for slab SS1.

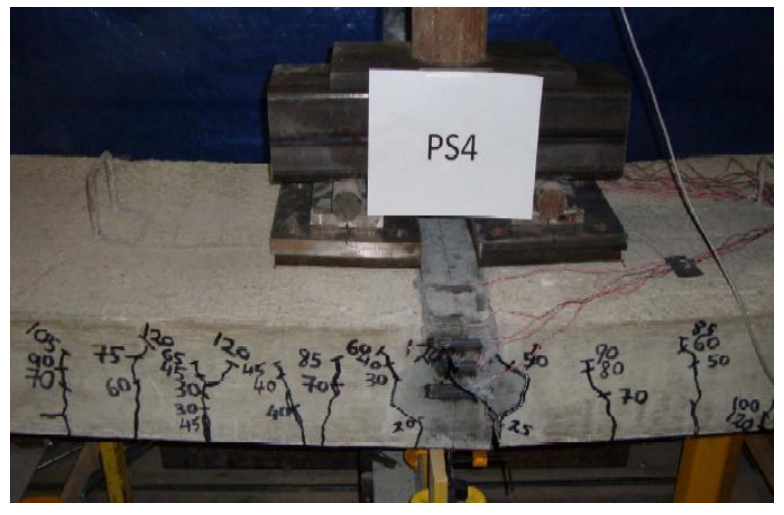

(a) Side view

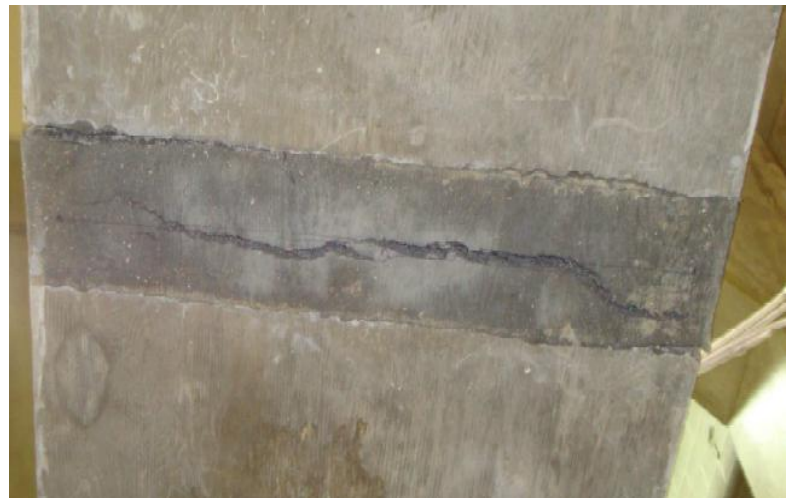

(b) Bottom view

Figure 4.16 Crack pattern for deck slab PS4

Figure 4.17 shows the crack pattern at failure of precast slab PS5 with 125-mm wide closure strip and projected bottom L-shaped GFRP bars embedded in UHPC. It was observed that the first hairline cracks formed at the cold joint between the precast concrete and the closure strip at a load of $20 \mathrm{kN}$. These fine cracks started to widen gradually as the loading increased. Several flexural cracks appeared in the precast slab closer to the closure strip as shown in Fig. 4.17-a. Close to failure, a diagonal flexural crack was developed at one side of the cold joint, while the failure was observed to be due to slippage and rupture of bars from the cold joint as depicted in Figs. 4.18-d and 4.18-e that were taken from core samples at the joint. Figure 4.18-d shows the GFRP bar end slipped off the concrete while the bottom side of the bar at the beginning of the $90^{\circ}$ bent showed 
ruptures in the fibres and bond-shear crack at the interface with the UHPC. Slicing another core sample taken from the UHPC joint showed another GFRP bar completely ruptured at the beginning of the $90^{\circ}$ bent as depicted in Fig. 4.18-e. This slab failed at ultimate load of $120.5 \mathrm{kN}$. It can be noted that slab PS5 was considered as good as the steel-reinforced slab SS1, since its ultimate capacity is $27 \%$ greater than that for slab SS1.

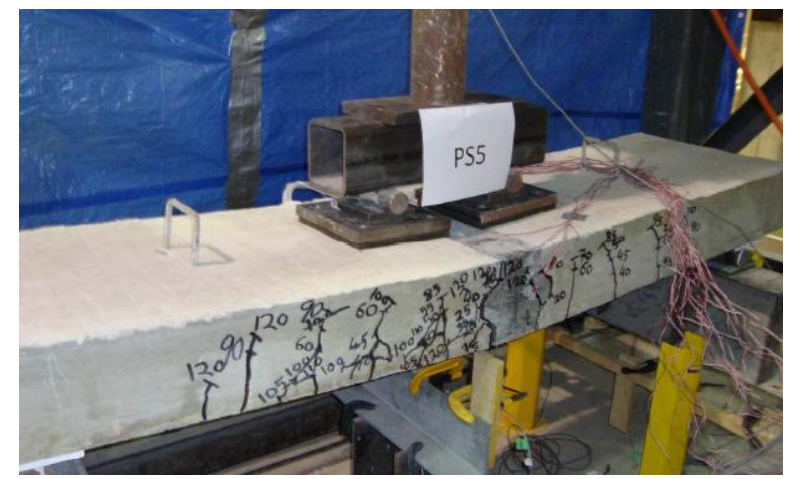

(a) Side view

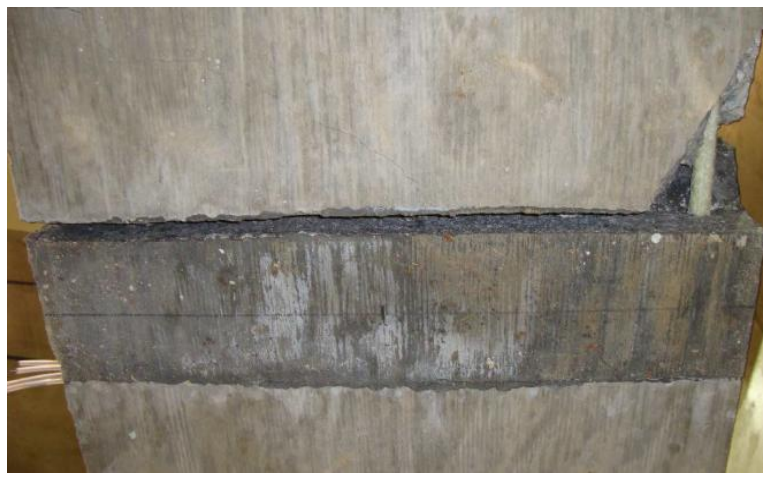

(b) Bottom view

Figure 4.17 Crack pattern for deck slab PS5

\subsubsection{Deflection Patterns}

Figure 4.19 depicts the incremental load-deflection history of the control cast-in-place deck slabs, SS1 and SS2 and the four jointed precast deck slabs, SS3, SS4, SS5 and SS6, whereas Fig. 4.20 shows comparison between the load-deflection relationships of these slabs using the envelope of all phases of incremental loading. It is obvious from Fig 4.19-a and 4.19-b that the control slabs exhibited a similar linear load-deflection relationship up to an applied load of about $30 \mathrm{kN}$, after which the slope of the control specimen SS1 became very flat up to the ultimate load of $95 \mathrm{kN}$ and deflection of $99 \mathrm{~mm}$, while the control specimen SS2 continued with a steep linear slope up to failure at a load of $166 \mathrm{kN}$ and deflection of $39 \mathrm{~mm}$, exceeding the ultimate capacity of the steel reinforced control specimen by $75 \%$. 


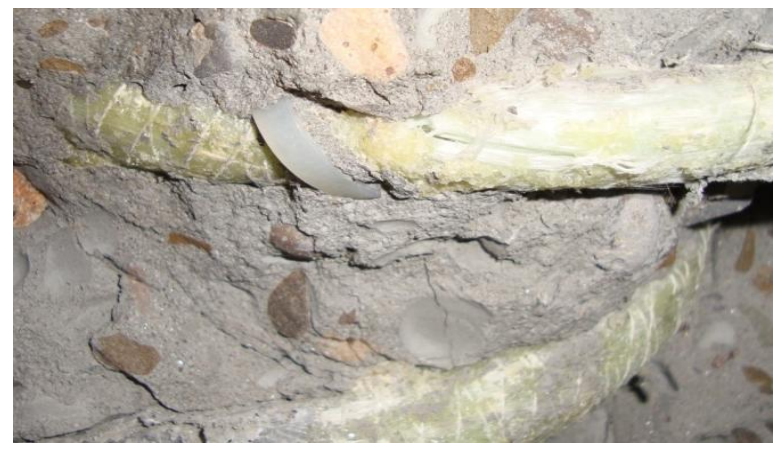

(a) Bar rupture in PS2

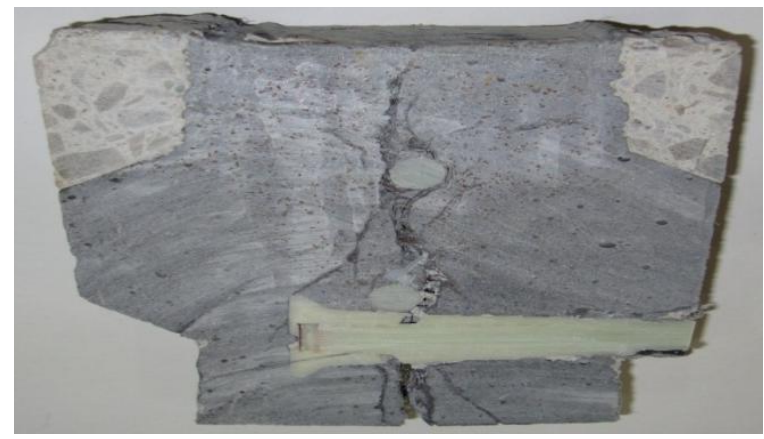

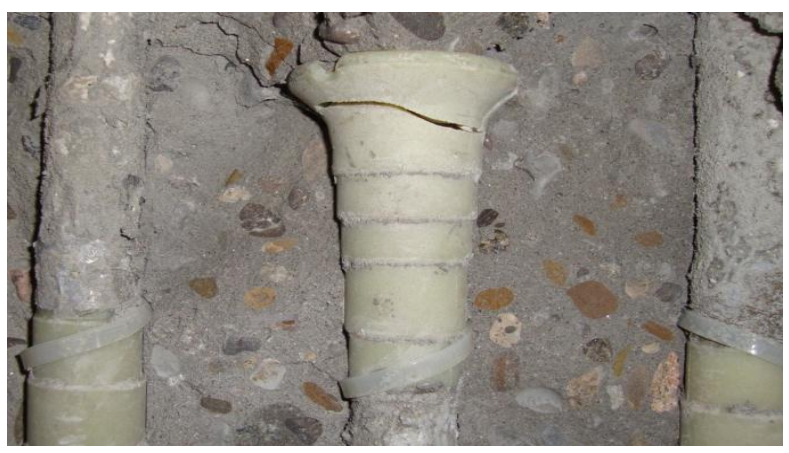

(b) Head tension crack near its end in PS3

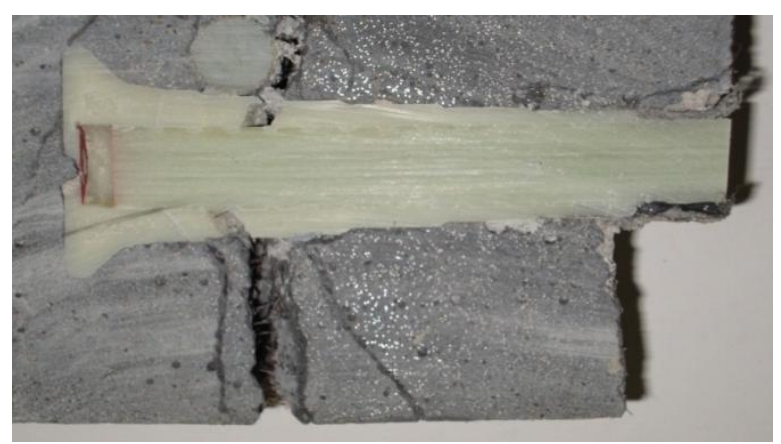

(c) UHPC joint in PS4 showing head rupture at flexural crack location and GFRP slip at head end disk

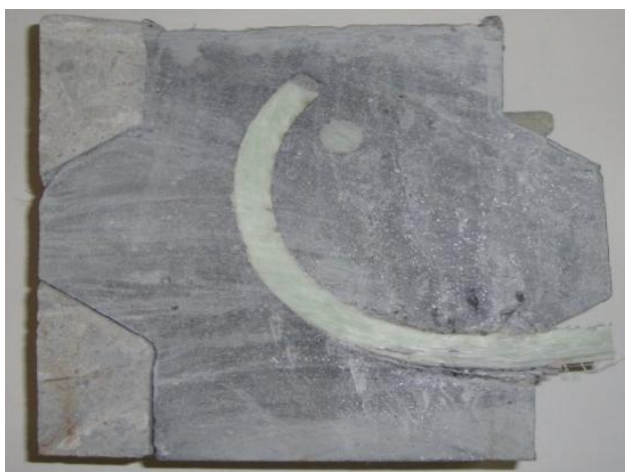

(d) UHPC joint in PS5 showing GFRP bar slip at its end, fibre rupture and bond shear crack at bar-UHPC interface

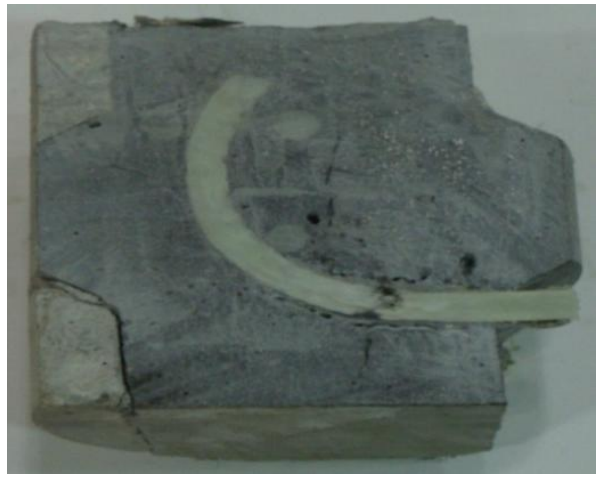

(e) UHPC joint in PS5 showing GFRP bar rupture at flexural crack location

Figure 4.18 Selected failure modes in sand-coated GFRP-reinforced slabs

Comparing the jointed slabs SS3, SS4, SS5 and SS6 to the control specimen SS2, it is clear that the four jointed slabs exhibited a bit linear behavior up to loads of 16, 20, 15 and $10 \mathrm{kN}$ 
respectively, before undergoing a change in slope as the flexural stiffness gradually decreased. Also, it can be observed that maximum deflection at failure of the best GFRP-reinforced jointed slab SS4 was $25 \mathrm{~mm}$ compared to $99 \mathrm{~mm}$ for the control slab SS1 reinforced with steel bars. In addition, the failure load of slab SS4 was $120.42 \mathrm{kN}$ compared to $95 \mathrm{kN}$ for slab SS1. As such, it can be concluded that jointed slab SS4 with closure strip filled with UHPC has the best joint among other proposed joints and that it was proved to be as good as the CHBDC-specified steelreinforced cast-in-place slab with respect to ultimate and serviceability limit state requirements.

Figure 4.21 shows comparison between the load-deflection relationships of the control deck slabs, SS0 and SS7 with three jointed deck slabs, SS8, SS9, and SS10. It should be noted that these five deck slabs were tested under static loading using the first loading procedure explained in details in chapter III. It is obvious from Fig. 4.21 that both control specimens exhibited a similar linear load-deflection relationship up to an applied load of about $24 \mathrm{kN}$, after which the slope of the control specimen SS0 became very flat up to the ultimate load of $77 \mathrm{kN}$, while the control specimen SS7 continued with a steep linear slope up to a failure load equal to $130 \mathrm{kN}$ exceeding the steel reinforced control specimen by $69 \%$. It should be noted that both specimens failed at vertical deflection of about $40 \mathrm{~mm}$. Comparing the jointed deck slab specimens SS8, SS9 and SS10 with the control specimen SS7, it is clear that the three jointed slabs exhibited a bit linear behavior up to loads of 10,20 and $12 \mathrm{kN}$, respectively, before undergoing a change in slope as the flexural stiffness gradually decreased. Also the control specimen SS7 showed a steeper initial load-deflection slope, leading to lower initial deflections than the jointed slab specimens. Slab, SS9 exhibited a similar load-deflection curve to that of the control specimen SS7 up to a load of $65 \mathrm{kN}$, after which the slope of SS9 became very flat leading to higher deflection with a slight load increase until it failed at a vertical deflection of $35 \mathrm{~mm}$. Slab specimens SS8 and SS10 
exhibited somewhat linear load-deflection slope up to failure loads of 60 and $29 \mathrm{kN}$, respectively. It is obvious from Fig. 4.21 that slab specimen SS9 failed at load equal to $77 \mathrm{kN}$ similar to the steel reinforced control specimen SSO.

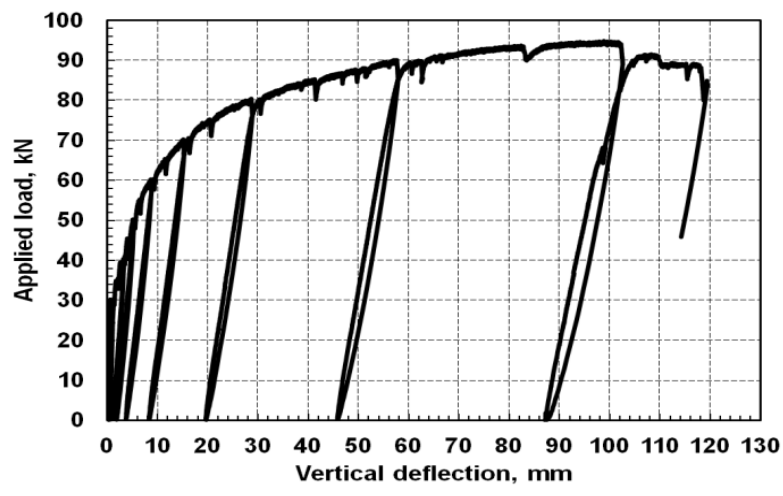

(a) Slab SS1

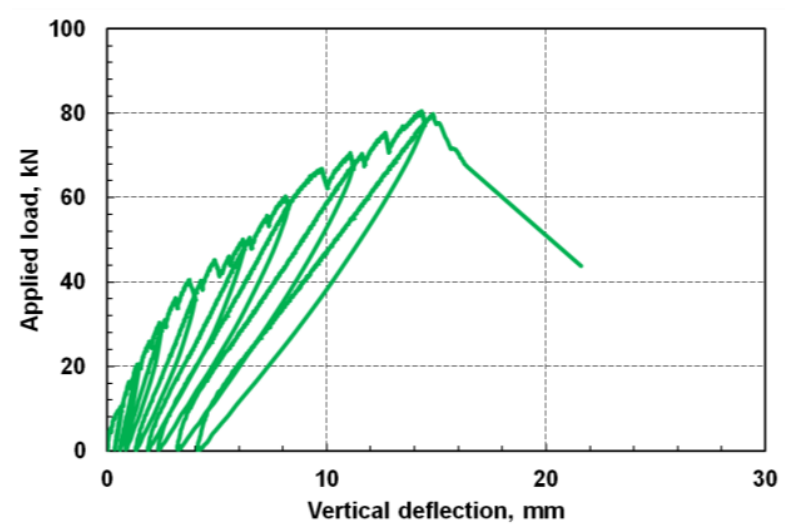

(c) Slab SS3

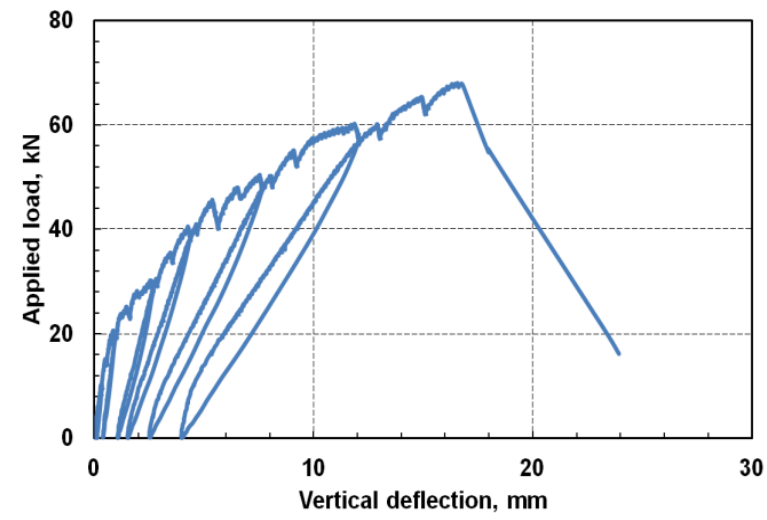

(e) Slab SS5

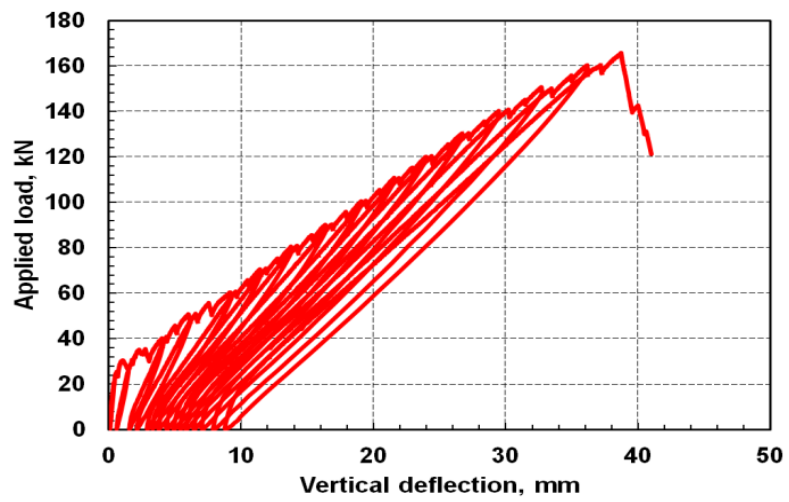

(b) Slab SS2

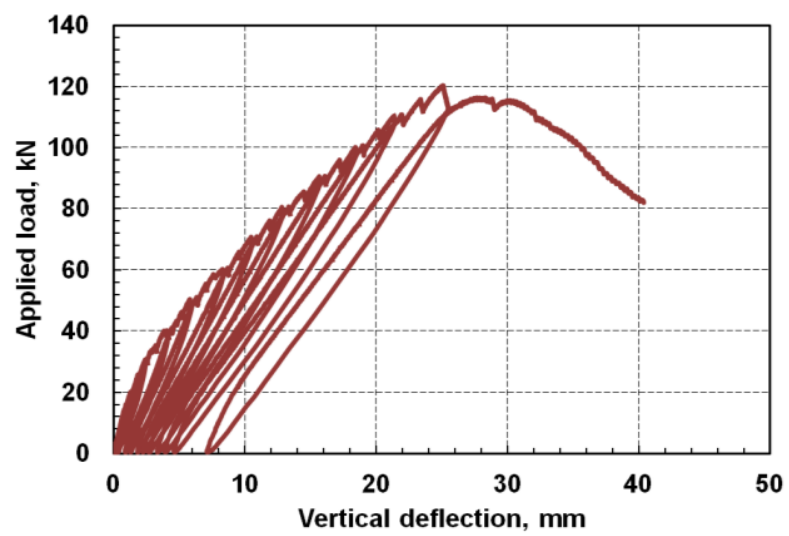

(d) Slab SS4

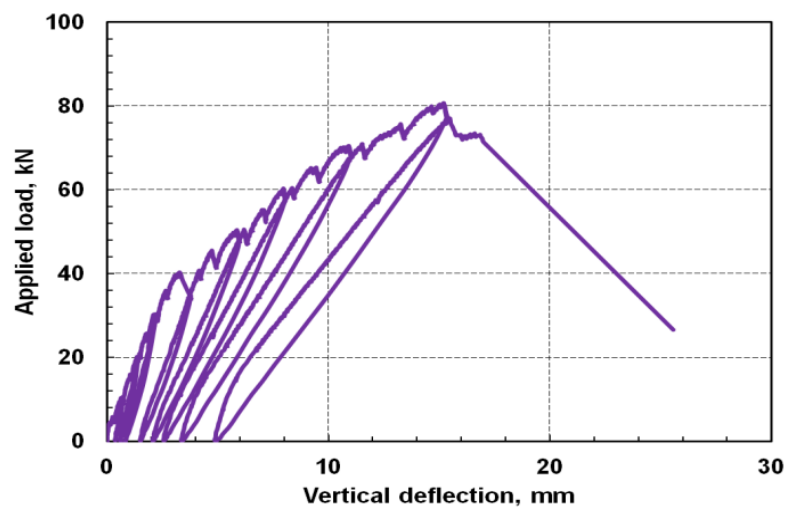

(f) Slab SS6

Figure 4.19 Load-deflection relationships obtained at mid-span of slabs SS1 through SS6 under incremental loading to failure 


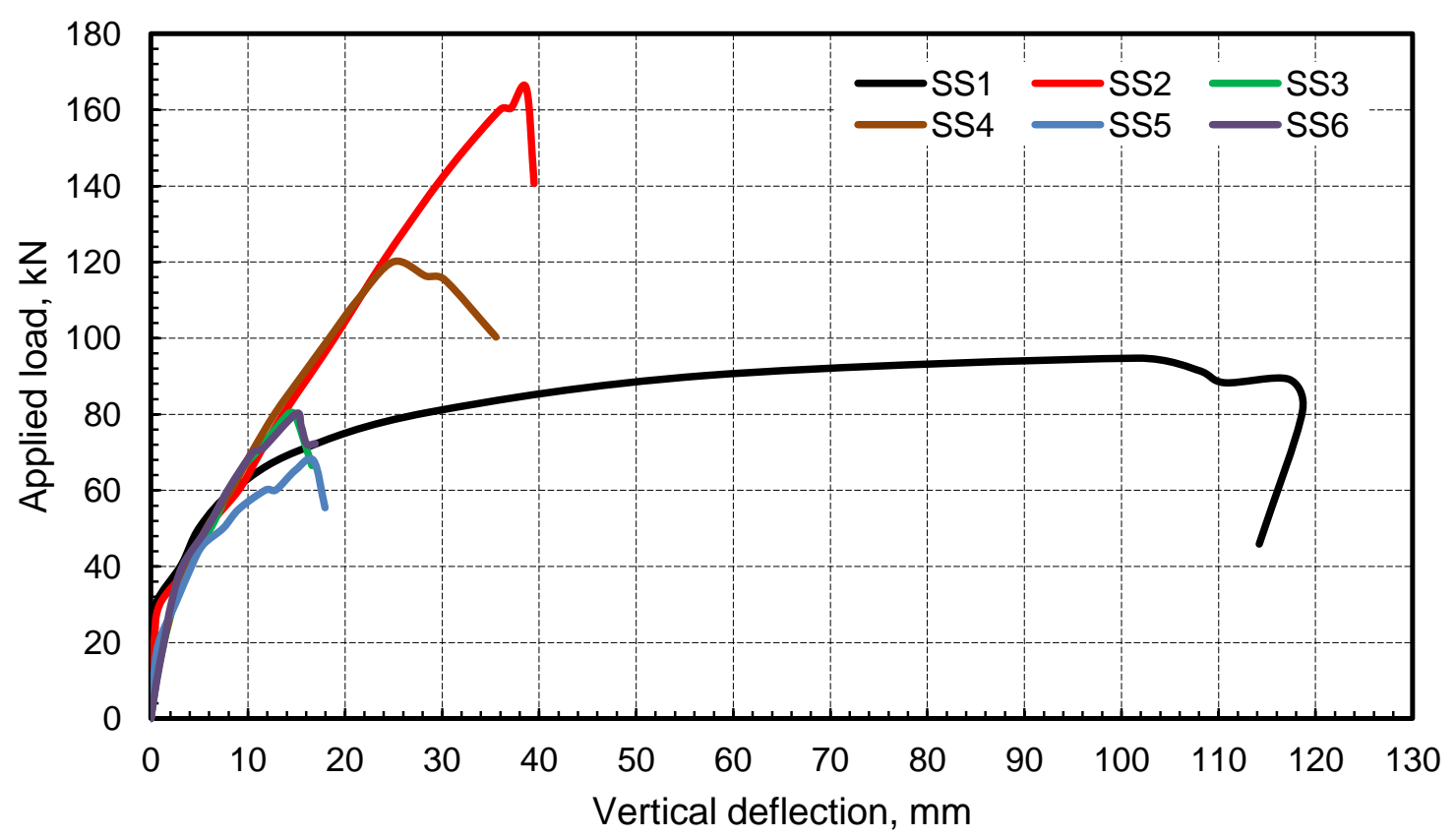

Figure 4.20 Envelopes of the load-deflection relationships obtained at mid-span of slabs SS1 through SS6 subjected to incremental loading to failure

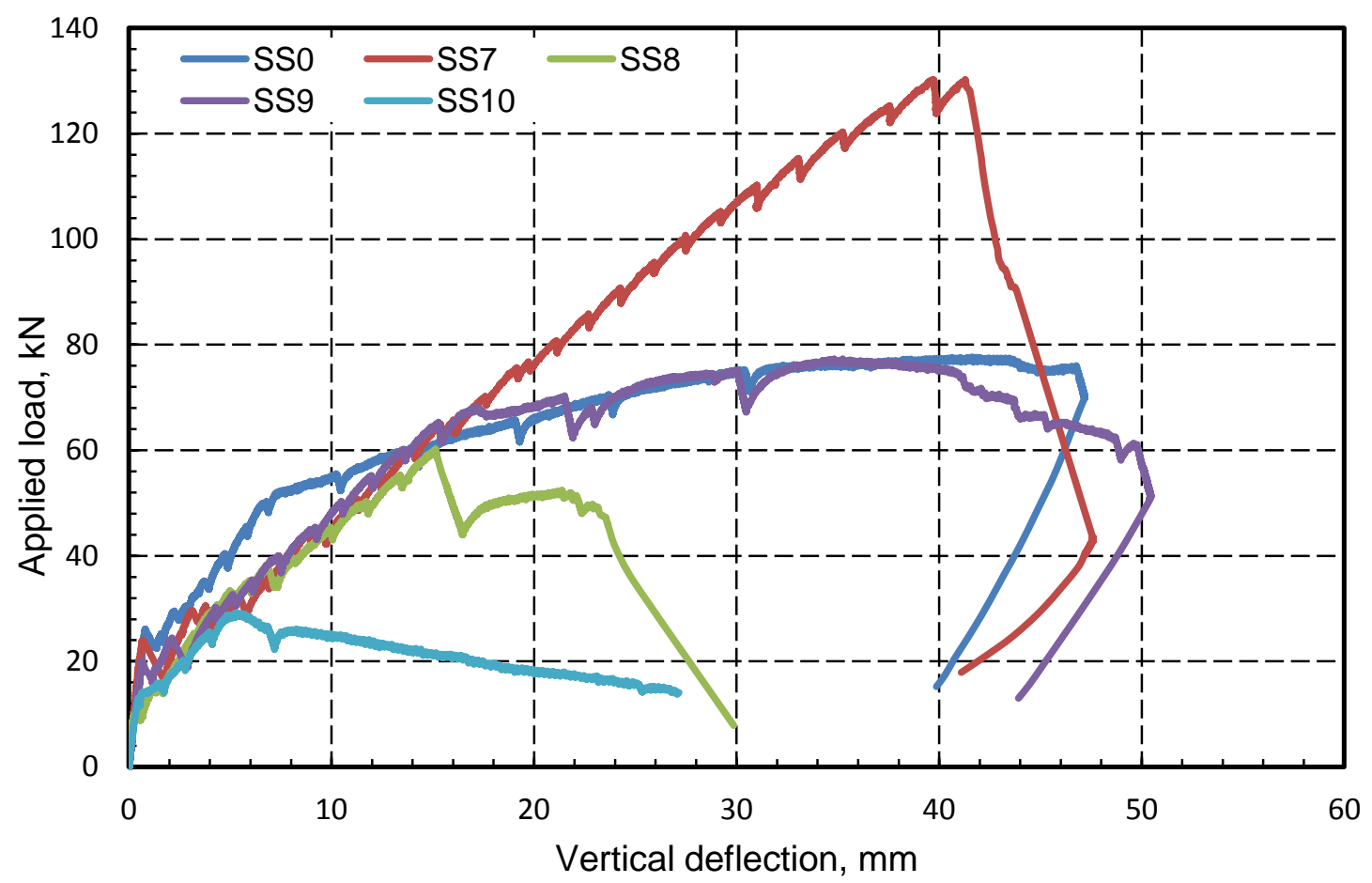

Figure 4.21 Load-deflection relationships obtained at mid-span of slabs SS0, SS7, SS8, SS9 and SS10 subjected to increasing load to failure 
Figure 4.22 shows the incremental load-deflection history of the control deck slabs, PS1 with the four jointed deck slabs, PS2, PS3, PS4 and PS5, whereas Fig. 4.23 shows comparison between the load-deflection relationships of these slabs using the envelope of all phases of incremental loading. It is clear from Figs. 4.19-a for the steel-reinforced slab SS1 and 4.22-a for the GFRPreinforced slab PS1 that both control deck slabs exhibited a similar linear load-deflection relationship up to an applied load of about $30 \mathrm{kN}$, after which the slope of the control specimen SS1 became very flat up to the ultimate load of $95 \mathrm{kN}$ and deflection of $99 \mathrm{~mm}$, while the control specimen PS1 continued with a steep linear slope up to failure at a load of $158 \mathrm{kN}$ and deflection of $39 \mathrm{~mm}$, exceeding the ultimate capacity of the steel reinforced control specimen by $66 \%$.

Comparing the jointed slabs PS2, PS3, PS4 and PS5 to the control specimen PS1, it is obvious that the four jointed slabs exhibited a bit linear behavior up to loads of $10,13,10$ and $20 \mathrm{kN}$ respectively, before undergoing a change in slope as the flexural stiffness gradually decreased. After cracking, the three slabs, PS2, PS4 and PS5 exhibited similar behaviors as the control slab, PS1, while slab PS3 showed less deflection at failure as depicted in Fig. 4.23. In addition, the deck slabs, PS2, PS4 and PS5 failed at approximately equal ultimate load of $120 \mathrm{kN}$ compared to $95 \mathrm{kN}$ for steel-reinforced slab SS1, and maximum deflections of $30 \mathrm{~mm}, 26 \mathrm{~mm}$ and $36 \mathrm{~mm}$, respectively, compared to $99 \mathrm{~mm}$ in case of reinforced-steel cast-in-place slab SS1. Also, it can be observed that the jointed slab, PS4, with closure strip filled with UHPC and headed-end GFRP bars had the least deflection at failure among the other two jointed slabs. As such, it can be concluded that the jointed slab, PS4, has the best joint among other proposed joints and that it proved to be as good as the CHBDC-specified steel-reinforced cast-in-place slab with respect to ultimate and serviceability limit state requirements. Tables 4.1 and 4.2 summarize slab configurations and test results. 


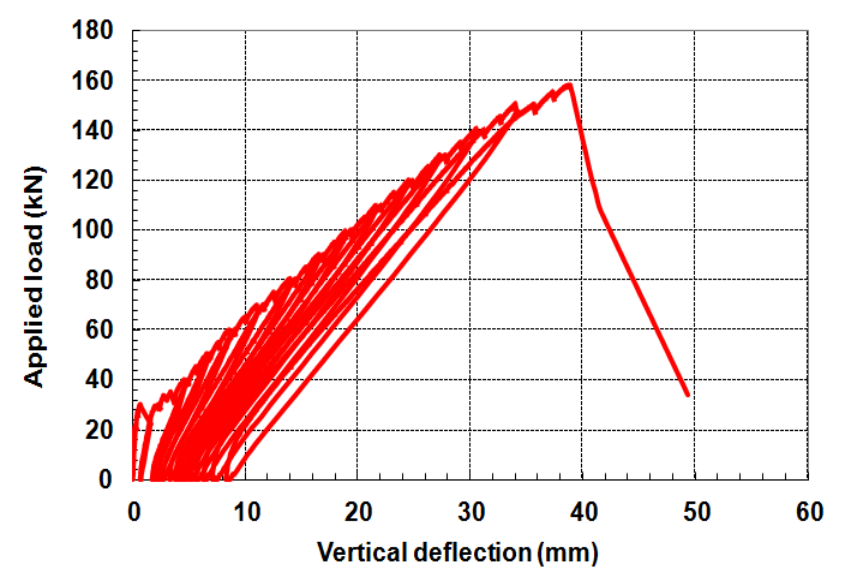

(a) Slab PS1

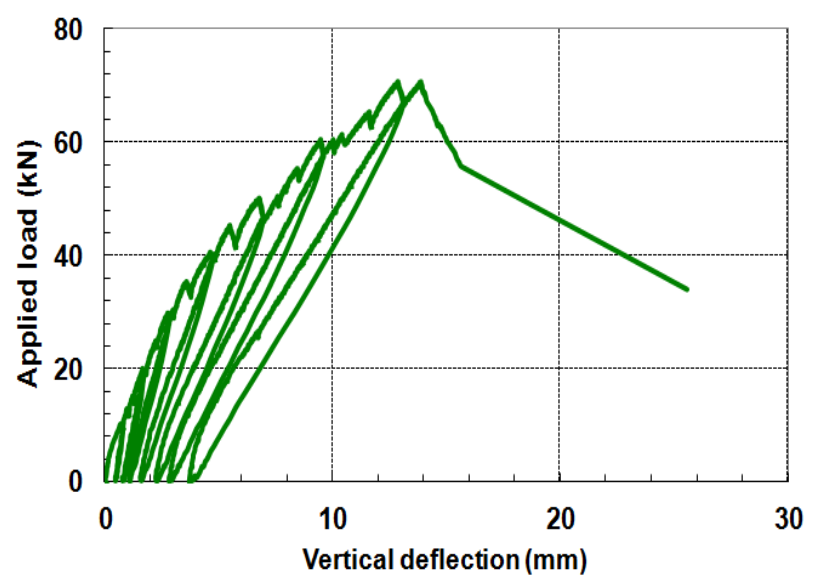

(c) Slab PS3

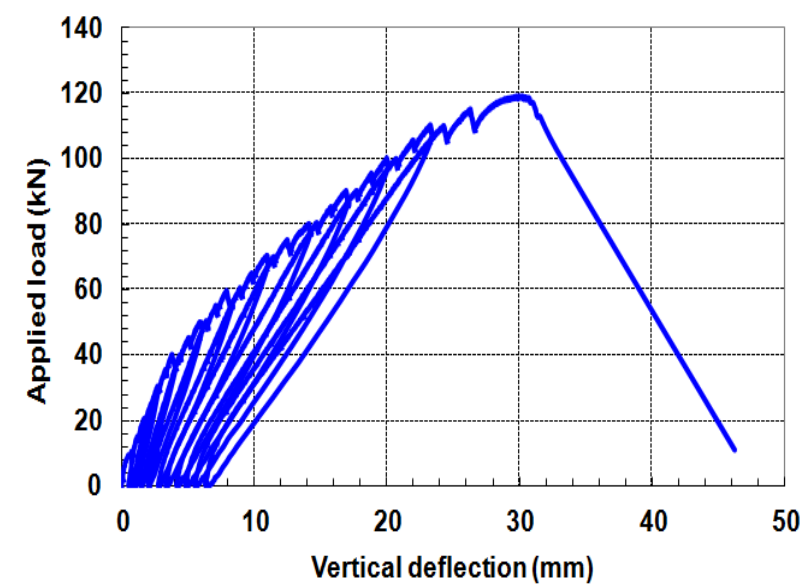

(b) Slab PS2

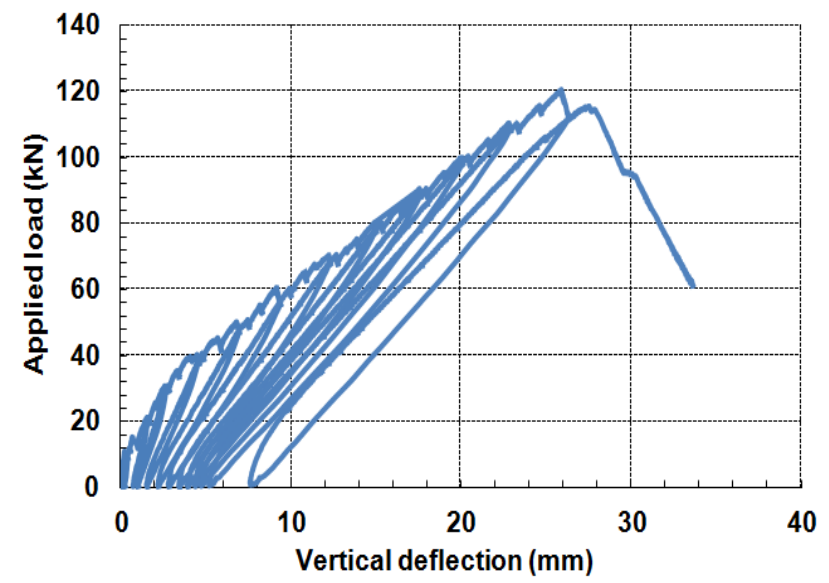

(d) Slab PS4

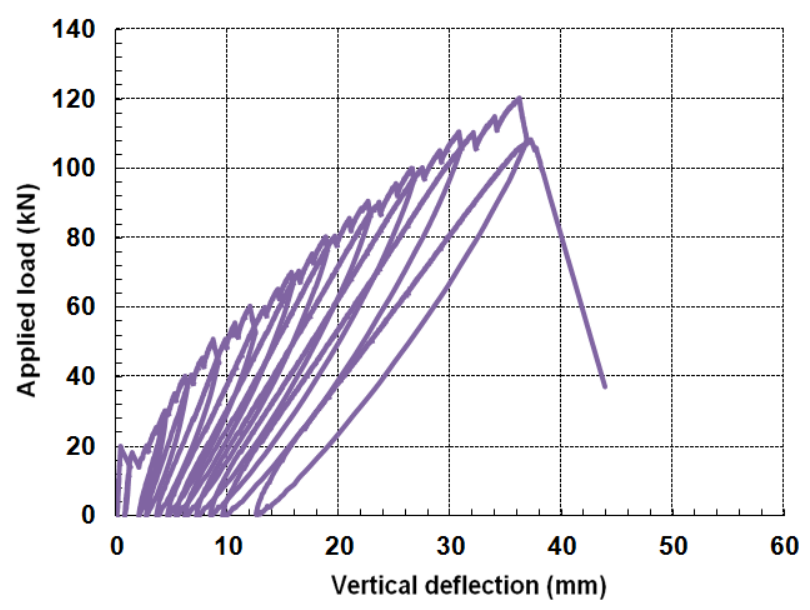

(e) Slab PS5

Figure 4.22 Load-deflection relationships obtained at mid-span of slabs PS1 through PS5 subjected to incremental loading to failure 


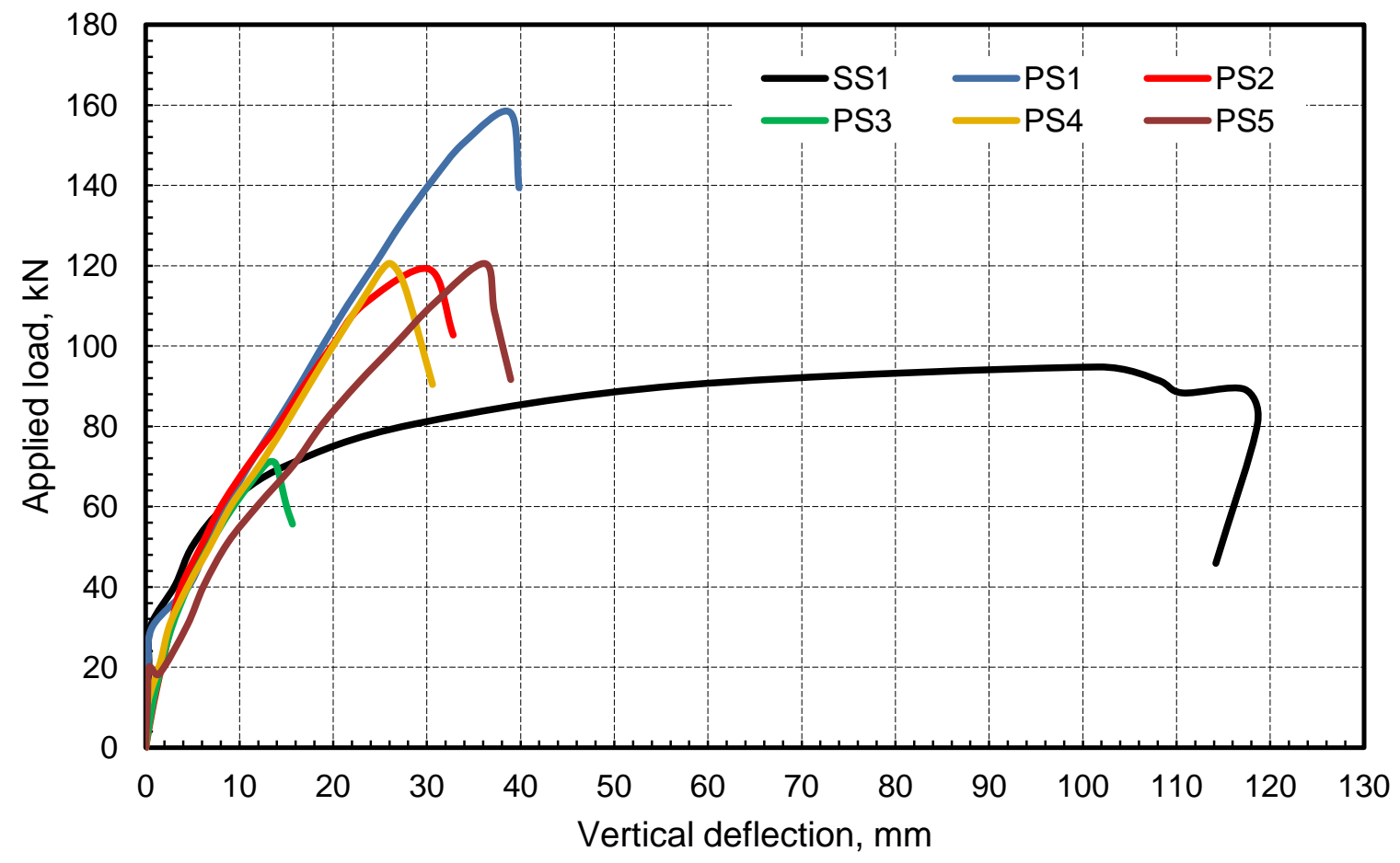

Figure 4.23 Envelopes of the load-deflection relationships obtained at mid-span of slabs SS1, PS1, PS2, PS3, PS4 and PS5 subjected to incremental loading to failure

\subsubsection{Ultimate Load Comparisons}

Table 4.2 shows the compressive strength of the concrete of tested deck slabs. Since the deck slabs were cast from different batches of concrete, unexpected difference in the concrete strength was observed. According to different international standards, the shear strength of RC is in direct proportion with the square root of the concrete compressive strength, $\left(f_{c}^{\prime}\right)^{0.5}$. Therefore, to minimize the effect induced by the variation in the strengths of concrete in comparing the test results of different specimens, the test load was normalized using the square root of the concrete compressive strength, $\sqrt{f_{c}^{\prime}}$ as shown in Table 4.2. 
Table 4.1 Summary of tested slab configurations

\begin{tabular}{|c|c|c|c|c|}
\hline $\begin{array}{l}\text { Specimen } \\
\text { No. }\end{array}$ & Slab & Reinforcement & Slab type & Test type** \\
\hline 1 & SS0 & $\begin{array}{l}\text { Steel straight bars }(3-10 \mathrm{~mm}) \\
\rho \rho=0.32\end{array}$ & Cast-in-place & $\mathrm{SUL}^{(2)}$ \\
\hline 2 & SS1 & $\begin{array}{l}\text { Steel straight bars }(3-10 \mathrm{~mm}) \\
\rho=0.32\end{array}$ & Cast-in-place & $\mathrm{SUL}^{(1)}$ \\
\hline 3 & SS2 & $\begin{array}{l}\text { GFRP straight bars (4-16 mm) } \\
\mathrm{HM}^{(3)} \text { Ribbed-surface } \rho=0.90\end{array}$ & Cast-in-place & SUL $^{(1)}$ \\
\hline 4 & SS3 & $\begin{array}{l}\text { GFRP headed bars }(4-16 \mathrm{~mm}) \\
\text { HM Ribbed-surface } \rho=0.90\end{array}$ & $\begin{array}{l}\text { Precast with } 200 \mathrm{~mm} \text { closure } \\
\text { strip filled with } \mathrm{NSG}^{\S}\end{array}$ & $\mathrm{SUL}^{(1)}$ \\
\hline 5 & SS4 & $\begin{array}{l}\text { GFRP headed bars }(4-16 \mathrm{~mm}) \\
\text { HM Ribbed-surface } \rho=0.90\end{array}$ & $\begin{array}{l}\text { Precast with } 125 \text { mm closure } \\
\text { strip filled with UHPC }\end{array}$ & $\mathrm{SUL}^{(1)}$ \\
\hline 6 & SS5 & $\begin{array}{l}\text { GFRP headed bars }(3-16 \mathrm{~mm}) \\
\text { HM Ribbed-surface } \rho=0.66\end{array}$ & $\begin{array}{l}\text { Precast with Zigzag closure } \\
\text { strip filled with } \mathrm{NSG}^{\S}\end{array}$ & $\mathrm{SUL}^{(1)}$ \\
\hline 7 & SS6 & $\begin{array}{l}\text { GFRP straight bars }(4-16 \mathrm{~mm}) \\
\text { HM Ribbed-surface } \rho=0.90\end{array}$ & $\begin{array}{l}\text { Precast with } 300 \text { mm closure } \\
\text { strip filled with } \mathrm{NSG}^{\S}\end{array}$ & $\mathrm{SUL}^{(1)}$ \\
\hline 8 & SS7 & $\begin{array}{l}\text { GFRP straight bars }(3-16 \mathrm{~mm}) \\
\text { HM Ribbed-surface } \rho=0.66\end{array}$ & Cast-in-place & $\mathrm{SUL}^{(2)}$ \\
\hline 9 & SS8 & $\begin{array}{l}\text { GFRP headed bars }(3-16 \mathrm{~mm}) \\
\text { HM Ribbed-surface } \rho=0.66\end{array}$ & $\begin{array}{l}\text { Precast with } 200 \text { mm closure } \\
\text { strip filled with } \mathrm{NSG}^{\S}\end{array}$ & $\mathrm{SUL}^{(2)}$ \\
\hline 10 & SS9 & $\begin{array}{l}\text { GFRP headed bars }(3-16 \mathrm{~mm}) \\
\text { HM Ribbed-surface } \rho=0.66\end{array}$ & $\begin{array}{l}\text { Precast with } 125 \mathrm{~mm} \text { closure } \\
\text { strip filled with UHPC }\end{array}$ & $\mathrm{SUL}^{(2)}$ \\
\hline 11 & SS10 & $\begin{array}{l}\text { GFRP straight bars }(3-16 \mathrm{~mm}) \\
\text { HM Ribbed-surface } \rho=0.66\end{array}$ & $\begin{array}{l}\text { Precast with } 200 \mathrm{~mm} \text { closure } \\
\text { strip filled with } \mathrm{NSG}^{\S}\end{array}$ & $\mathrm{SUL}^{(2)}$ \\
\hline 12 & PS1 & $\begin{array}{c}\text { GFRP straight bars }(4-16 \mathrm{~mm}) \\
\text { HM Sand-coated } \rho=0.90\end{array}$ & Cast-in-place & $\mathrm{SUL}^{(1)}$ \\
\hline 13 & PS2 & $\begin{array}{l}\text { GFRP L-shaped bars (5-16mm) } \\
\text { SM }^{(4)} \text { Sand-coated } \rho=1.10\end{array}$ & $\begin{array}{l}\text { Precast with } 200 \mathrm{~mm}^{\text {closure }} \\
\text { strip filled with } \mathrm{NSG}^{\S}\end{array}$ & $\mathrm{SUL}^{(1)}$ \\
\hline 14 & PS3 & $\begin{array}{c}\text { GFRP headed bars }(4-16 \mathrm{~mm}) \\
\text { HM Sand-coated } \rho=0.90\end{array}$ & $\begin{array}{l}\text { Precast with } 200 \text { mm closure } \\
\text { strip filled with } \mathrm{NSG}^{\S}\end{array}$ & $\mathrm{SUL}^{(1)}$ \\
\hline 15 & PS4 & $\begin{array}{c}\text { GFRP headed bars }(4-16 \mathrm{~mm}) \\
\text { HM Sand-coated } \rho=0.9\end{array}$ & $\begin{array}{l}\text { Precast with } 125 \text { mm closure } \\
\text { strip filled with UHPC }\end{array}$ & $\mathrm{SUL}^{(1)}$ \\
\hline 16 & PS5 & $\begin{array}{l}\text { GFRP L-shaped bars }(5-16 \mathrm{~mm}) \\
\quad \text { SM Sand-coated } \rho=1.10\end{array}$ & $\begin{array}{l}\text { Precast with } 125 \mathrm{~mm} \text { closure } \\
\text { strip filled with UHPC }\end{array}$ & $\mathrm{SUL}^{(1)}$ \\
\hline
\end{tabular}

§NSG = non-shrink grout; *UHPC = ultra-high-performance concrete; $* *$ SUL test $=$ static ultimate load test; (1) incremental loading of $10 \mathrm{kN}$ until failure; (2) increasing static load until failure; (3) $\mathrm{HM}$ = high-modulus; (4) $\mathrm{SM}=$ standard-modulus. 
Table 4.2 Summary of test results in phase I

\begin{tabular}{|c|c|c|c|c|c|c|c|c|c|}
\hline \multirow{2}{*}{ Slab } & \multicolumn{2}{|c|}{$f_{c}^{\prime} \mathrm{MPa}$} & \multirow{2}{*}{$\begin{array}{c}\text { Cracking } \\
\text { load } \\
(\mathrm{kN})\end{array}$} & \multirow{2}{*}{$\begin{array}{l}\text { Ultimate } \\
\text { load } \\
(\mathrm{kN})\end{array}$} & \multirow{2}{*}{$\begin{array}{l}\text { Ultimate } \\
\text { deflection } \\
\quad(\mathrm{mm})\end{array}$} & \multirow{2}{*}{$\begin{array}{l}\text { Max. } \\
\text { concrete } \\
\text { strain } \\
(\mu \varepsilon)\end{array}$} & \multirow{2}{*}{$\begin{array}{c}\text { Max. } \\
\text { reinforcement } \\
\text { strain } \\
(\mu \varepsilon)\end{array}$} & \multirow{2}{*}{ Ultimate load $/ \sqrt{f_{c(\text { conc. })}^{\prime}}$} & \multirow{2}{*}{ Failure type } \\
\hline & Concrete & NSG/UHPC & & & & & & & \\
\hline SS0 & 34.7 & - & 24 & 77.65 & 43 & - & - & 13.18 & Flexure \\
\hline SS1 & 38.3 & - & 30 & 95 & 99 & - & - & 15.35 & Flexure \\
\hline SS2 & 41.36 & - & 30 & 165.74 & 38.69 & -3139 & 15930 & 25.77 & Combined shear and flexure \\
\hline SS3 & 65.03 & 68.76 & 16 & 80.54 & 14.33 & -1152 & 6120 & 10 & $\begin{array}{c}\text { Flexure and loss of bond combined } \\
\text { with breakage of bar head }\end{array}$ \\
\hline SS4 & 56.36 & 159.83 & 20 & 120.42 & 25.1 & -1023 & 10575 & 16.04 & $\begin{array}{c}\text { Flexure and slippage of bar from } \\
\text { head }\end{array}$ \\
\hline SS5 & 57.76 & 62.84 & 15 & 67.99 & 16.57 & -1009 & 6048 & 8.95 & $\begin{array}{c}\text { Flexure and loss of bond combined } \\
\text { with breakage of bar head }\end{array}$ \\
\hline SS6 & 57.76 & 63.05 & 10 & 80.76 & 15.2 & -1316 & 6596 & 10.63 & $\begin{array}{c}\text { Flexure and loss of bond followed } \\
\text { by slippage of bars }\end{array}$ \\
\hline SS7 & 32.7 & - & 23 & 130 & 40 & -3700 & 13399 & 22.73 & Combined shear and flexure \\
\hline SS8 & 38.9 & 57.9 & 10 & 60 & 15 & -1038 & 6327 & 9.62 & $\begin{array}{c}\text { Flexure and breakage of the bar } \\
\text { head }\end{array}$ \\
\hline SS9 & 39.2 & 129.7 & 20 & 77.32 & 35 & -784 & 12292 & 12.35 & $\begin{array}{c}\begin{array}{c}\text { Flexure and slippage of bar from } \\
\text { head }\end{array} \\
\end{array}$ \\
\hline SS10 & 39.9 & 57.9 & 12 & 29 & 5 & -687 & 3342 & 4.59 & Flexure and slippage of bars \\
\hline PS1 & 47.7 & - & 30 & 158.2 & 39 & -2778 & 11556 & 22.91 & Combined shear and flexure \\
\hline PS2 & 50.7 & 54.5 & 10 & 119.2 & 30 & -1987 & 12526 & 16.74 & $\begin{array}{c}\text { Flexure and loss of bond combined } \\
\text { with rupture of GFRP bars }\end{array}$ \\
\hline PS3 & 48.6 & 54.5 & 13 & 70.7 & 14 & -1066 & 6276 & 10.14 & $\begin{array}{c}\text { Flexure and loss of bond combined } \\
\text { with breakage of bar head }\end{array}$ \\
\hline PS4 & 53.5 & 150.7 & 10 & 120.5 & 25.9 & -1109 & 7104 & 16.47 & $\begin{array}{c}\text { Flexure and breakage of the bar } \\
\text { head }\end{array}$ \\
\hline PS5 & 59 & 145.2 & 20 & 120.5 & 36.2 & -1502 & - & 15.69 & $\begin{array}{c}\text { Flexure with slippage and rupture } \\
\text { of bars }\end{array}$ \\
\hline
\end{tabular}




\subsection{Phase II: Experimental Results}

This section discusses the structural behavior of 8 internally restrained deck slabs tested under static and fatigue loadings in phase II of the experimental program. Five of these slabs were reinforced with ribbed-surface GFRP bars, while the other three slabs were reinforced with sandcoated GFRP bars. Tables 4.3 and 4.4 summarize the experimental findings of phase II testing.

\subsubsection{Cracking Patterns and Crack Width}

All eight deck slabs exhibited similar crack patterns and failed in punching shear irrespective of whether they were subjected to static or fatigue loading. The first deck slab, S1 representing the cast-in-place slab reinforced with ribbed-surface GFRP bars, was tested to failure under static loading. Figure 4.24 shows the crack pattern at failure on top and underside of deck slab, S1. Prior to starting the static load test, the slab was pre-cracked by performing a static load test up to $250 \mathrm{kN}$, followed by unloading to zero. This load represented more than two times the CHBDC service load of $110.25 \mathrm{kN}\left(\mathrm{P}_{\mathrm{SLS}}=87.5 \times 1.4 \times 0.9=110.25 \mathrm{kN}\right.$, where $87.5 \mathrm{kN}$ is the specified wheel load, 1.4 is the dynamic load allowance and 0.9 is the load factor for serviceability limit state design). During the pre-cracked loading, it was observed that the first hairline cracks were formed at mid-span in the longitudinal direction (parallel to the supporting girders) at $167 \mathrm{kN}$, which is more than the service load by $51 \%$. The maximum measured crack widths at the service load level were $0.1 \mathrm{~mm}$, which is less than $0.5 \mathrm{~mm}$, the allowable limit specified by section 16 of CHBDC (2006). Slab S1 failed due to punching shear at peak load of $751.4 \mathrm{kN}$ and maximum vertical deflection of $21.6 \mathrm{~mm}$. CHBDC specifies truck wheel load of $87.5 \mathrm{kN}$, load factor of 1.7 and dynamic load allowance of 0.40 for the design of deck slabs. This makes the factored applied design wheel load $208.25 \mathrm{kN}\left(P_{f}=87.5 \times 1.4 \times 1.7=208.25 \mathrm{kN}\right)$. Since the experimental ultimate load of the tested slab is $751.4 \mathrm{kN}$, one may conclude that the 
experimental ultimate load is more than three times the factored load specified by CHBDC. Since the cracking load of slab S1 was observed to be $167 \mathrm{kN}$, it was decided to pre-crack the remaining deck slabs by performing a static load test up to 1.5 times the FLS loading of 183.75 $\mathrm{kN}$ followed by unloading to zero before conducting further tests.

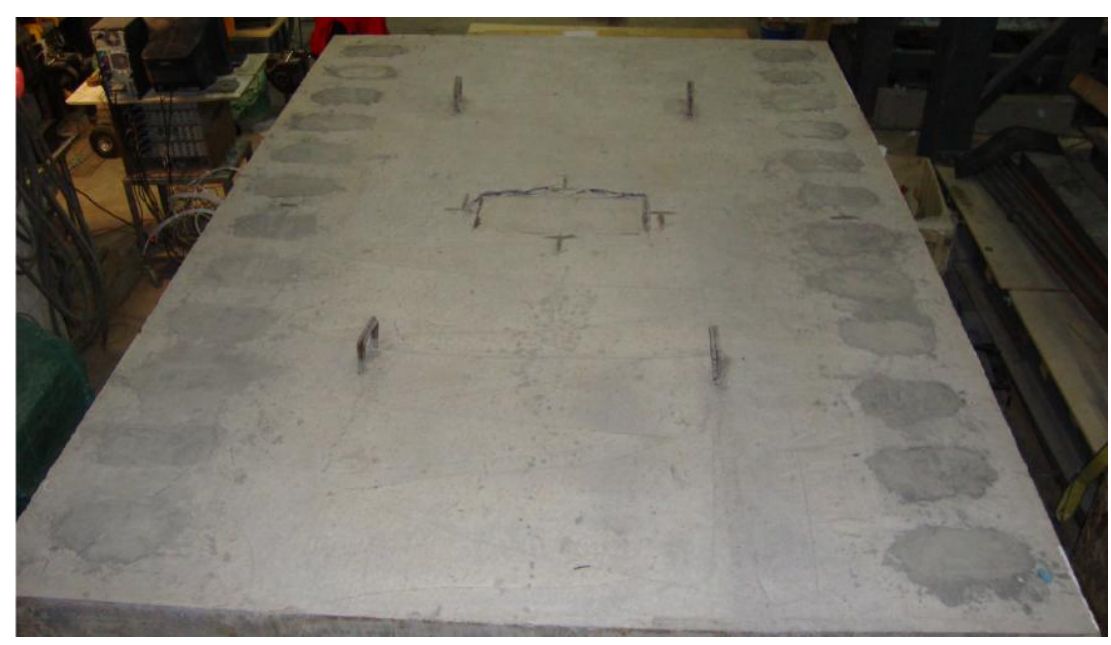

(a) Top surface

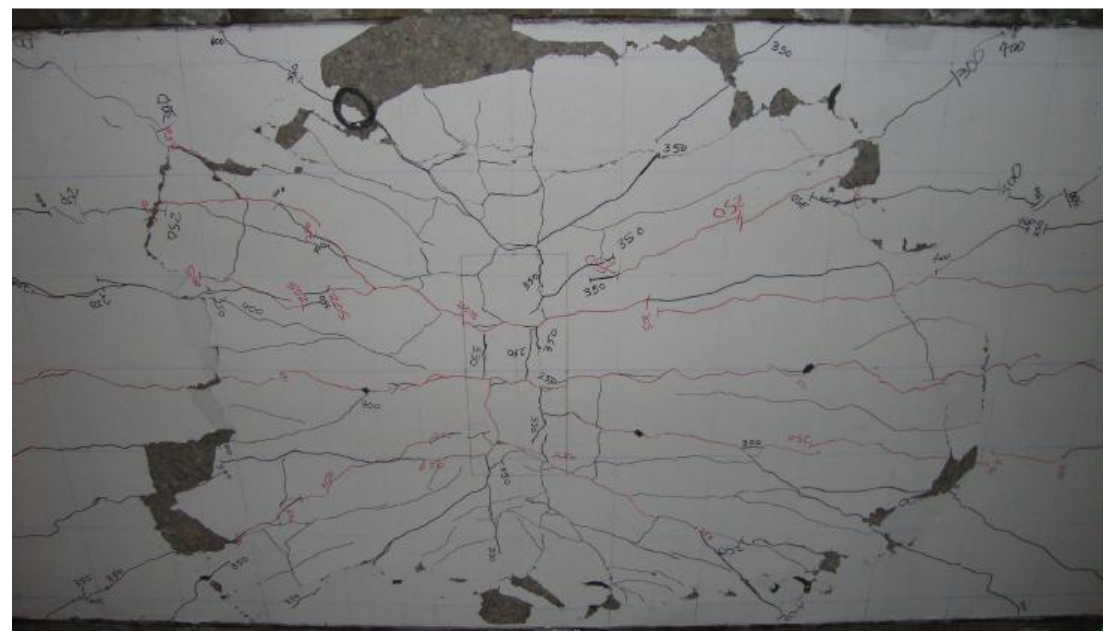

(c) Bottom surface

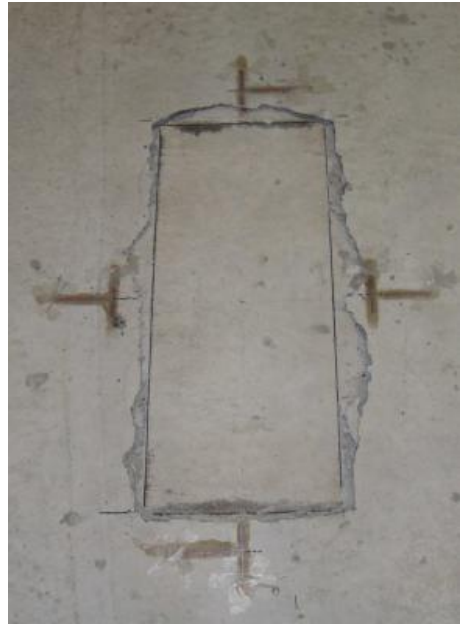

(b) Top surface close-up

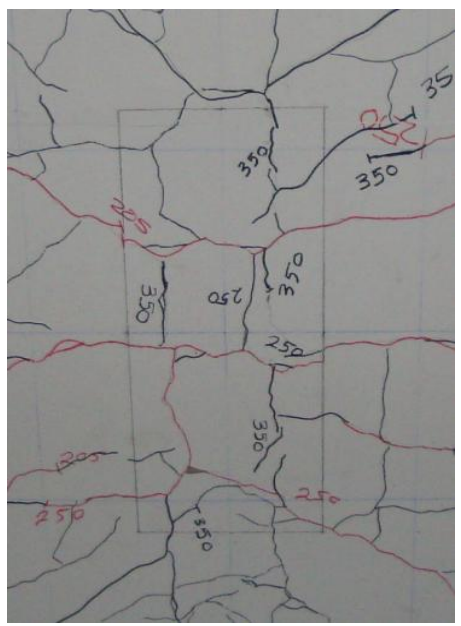

(d) Bottom surface close-up

Figure 4.24 Crack pattern at failure of deck slab S1

The second deck slab S2 that was identical to slab S1, was tested under VAF loading and the test was completed according to the process described previously in chapter III. Figure 4.25 shows 
the crack pattern at failure on top and underside of the precast deck slab S2. During the precracking test for the deck slab, it was observed that first hairline cracks formed at mid-span in the longitudinal direction (parallel to the supports) at $119 \mathrm{kN}$, and the maximum measured crack width at service load level was $0.1 \mathrm{~mm}$. After applying the second 100,000 cycles at a peak load of $183.75 \mathrm{kN}$ and a frequency of $2 \mathrm{~Hz}$, new transverse cracks propagated at mid-span under the loaded area. With increase of the load cycles, these cracks continued to propagate deeper and more cracks developed in the longitudinal and radial directions. It was observed that after completing 100,000 cycles at peak load of $245 \mathrm{kN}$, the deck slab started to undergo a drastic decrease in the flexural stiffness and the remaining peak loads were completed with reduced frequencies. It should be noted that the maximum peak load reached at the final peak load was $475 \mathrm{kN}$ at frequency of $0.5 \mathrm{~Hz}$. In addition, the deck slab S2 failed under punching shear and the failure was sudden and abrupt, occurred at a peak load of $475 \mathrm{kN}$ after completing 808,651 load cycles and a maximum deflection of $27.6 \mathrm{~mm}$.

The third deck slab, S3 which was identical to slabs S1 and S2, was tested under CAF loading and the test was completed according to the process described previously in chapter III. Figure 4.26 shows the crack pattern at failure on top and underside of the precast deck slab S3. During the pre-cracking test for the deck slab, it was noticed that the first hairline cracks formed at midspan in the longitudinal direction at $153 \mathrm{kN}$, and the maximum measured crack width at service load level was $0.1 \mathrm{~mm}$. The slab was subjected to $4,000,000$ cycles at a fatigue load range of $122.5 \mathrm{kN}$ and a frequency of $4 \mathrm{~Hz}$. After completing the cyclic load, a static load test was applied until failure. The slab failed at a maximum load of $803.4 \mathrm{kN}$ and a maximum deflection of 23.6 $\mathrm{mm}$. The failure was due to punching shear as shown in Fig. 4.26. Since the experimental ultimate load of the tested slab was $803.4 \mathrm{kN}$, one may conclude that the GFRP-reinforced slab 
showed high fatigue performance and there was no observed fatigue damage when subjected to 4 million cycles under FLS load range of $122.5 \mathrm{kN}$ specified in CHBDC. In addition, the ultimate load capacity of the pre-fatigued GFRP-reinforced cast-in-place deck slab was observed to be more than three times the design factored load $(208.25 \mathrm{kN})$ specified by CHBDC.
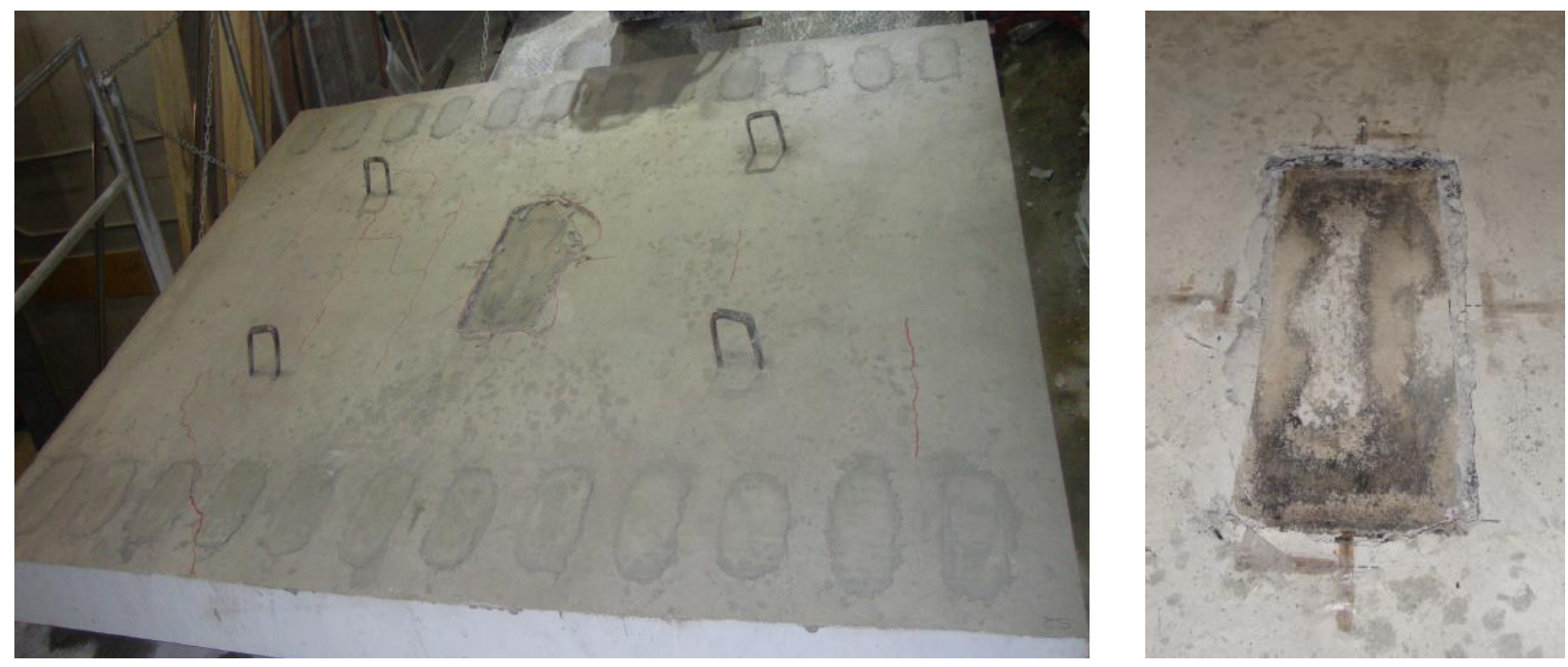

(a) Top surface

(b) Top surface close-up
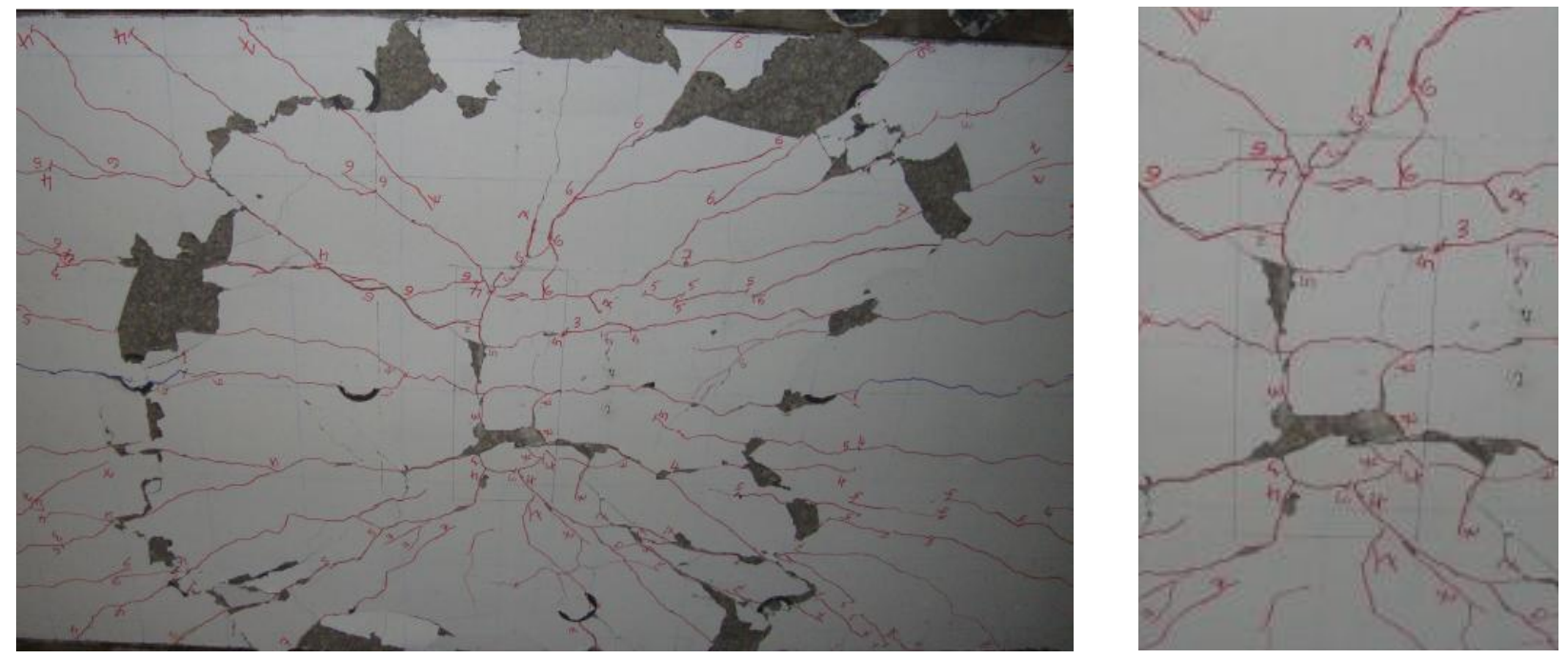

(c) Bottom surface

(d) Bottom surface close-up

Figure 4.25 Crack pattern at failure of deck slab S2 
Table 4.3 Typical field-cast concrete and UHPC material properties used in phase II

\begin{tabular}{|c|c|c|c|c|c|c|c|c|c|c|}
\hline \multirow[t]{2}{*}{ Slab } & \multirow[t]{2}{*}{ Bar type } & \multirow[t]{2}{*}{ Slab type } & \multicolumn{3}{|c|}{$f_{c}^{\prime}(\mathrm{MPa})$} & \multicolumn{2}{|c|}{ Density $\left(\mathrm{kg} / \mathrm{m}^{3}\right)$} & \multirow{2}{*}{$\begin{array}{c}E_{c} \\
(\mathrm{GPa})\end{array}$} & \multicolumn{2}{|c|}{$\begin{array}{l}\text { Split cylinder cracking } \\
\text { strength }(\mathrm{MPa})\end{array}$} \\
\hline & & & Concrete & $\mathrm{UHPC}^{\S}$ & $\mathrm{NSG}^{*}$ & Concrete & $\mathrm{UHPC}^{\S}$ & & Concrete & $\mathrm{UHPC}^{\S}$ \\
\hline $\mathrm{S} 1$ & \multirow{5}{*}{$\begin{array}{c}\text { GFRP } \\
\text { Ribbed-surface }\end{array}$} & \multirow{3}{*}{ Cast-in-place } & 55.48 & - & 70.43 & \multirow{3}{*}{2459} & \multirow{3}{*}{-} & \multirow{3}{*}{35} & \multirow{3}{*}{4.22} & \multirow{3}{*}{-} \\
\hline $\mathrm{S} 2$ & & & 55.51 & - & 68.64 & & & & & \\
\hline S3 & & & 56.19 & - & 66.23 & & & & & \\
\hline $\mathrm{S} 4$ & & \multirow{5}{*}{$\begin{array}{l}\text { Precast with } \\
125 \mathrm{~mm} \\
\text { closure strip } \\
\text { filled with } \\
\text { UHPC }^{\S}\end{array}$} & 53.78 & 192 & 67.29 & 2443 & 2678 & 34 & - & 21.85 \\
\hline S5 & & & 51.03 & 183.19 & 58.13 & 2438 & 2674 & 33 & - & 18.24 \\
\hline S6 & & & 58.75 & 173.37 & 58.88 & 2460 & 2684 & 36 & \multirow{2}{*}{3.36} & 21.25 \\
\hline S7 & $\begin{array}{c}\text { GFRP } \\
\text { Sand-coated }\end{array}$ & & 57.53 & 166.16 & 47.3 & 2438 & 2657 & 35 & & 17.70 \\
\hline S8 & & & 44.02 & 165.52 & 53.96 & 2463 & 2678 & 32 & 3.5 & 19.13 \\
\hline
\end{tabular}

$\overline{\mathrm{UHPC}^{\S}}=$ ultra-high-performance concrete; $\mathrm{NSG}^{*}=$ non-shrink grout

Table 4.4 Summary of test results of phase II

\begin{tabular}{|c|c|c|c|c|c|c|c|}
\hline Slab & Test & $\begin{array}{c}\text { Peak cyclic load } \\
(\mathrm{kN})\end{array}$ & $\begin{array}{l}\text { Frequency } \\
(\mathrm{Hz})\end{array}$ & $\begin{array}{c}\text { No of load } \\
\text { cycles }\end{array}$ & $\begin{array}{l}\text { Ultimate load } \\
\qquad(\mathrm{kN})\end{array}$ & $\begin{array}{c}\text { Ultimate } \\
\text { deflection }(\mathrm{mm})\end{array}$ & $\begin{array}{l}\text { Failure } \\
\text { mode }\end{array}$ \\
\hline $\mathrm{S} 1$ & Static & - & - & - & $751.40^{*}$ & 21.59 & Punch \\
\hline $\mathrm{S} 2$ & Cyclic (VAF) & $122.5-475$ & $2-0.5$ & 808,651 & $475.00^{* *}$ & 27.60 & Punch \\
\hline $\mathrm{S} 3$ & Cyclic + static (CAF) & 122.5 & 4 & $4,000,000$ & $803.39^{*}$ & 23.63 & Punch \\
\hline $\mathrm{S} 4$ & Cyclic + static (CAF) & 122.5 & 4 & $4,000,000$ & $758.51^{*}$ & 22.85 & Punch \\
\hline S5 & Cyclic (VAF) & $122.5-475$ & $2-0.5$ & 616,145 & $475.00^{* *}$ & 26.01 & Punch \\
\hline S6 & Static & - & - & - & $853.26^{*}$ & 26.50 & Punch \\
\hline S7 & Cyclic (VAF) & $122.5-475$ & $2-0.5$ & 886,346 & $475.00^{* *}$ & 27.23 & Punch \\
\hline S8 & Cyclic + static (CAF) & 122.5 & 4 & $4,000,000$ & $801.58^{*}$ & 24.41 & Punch \\
\hline
\end{tabular}




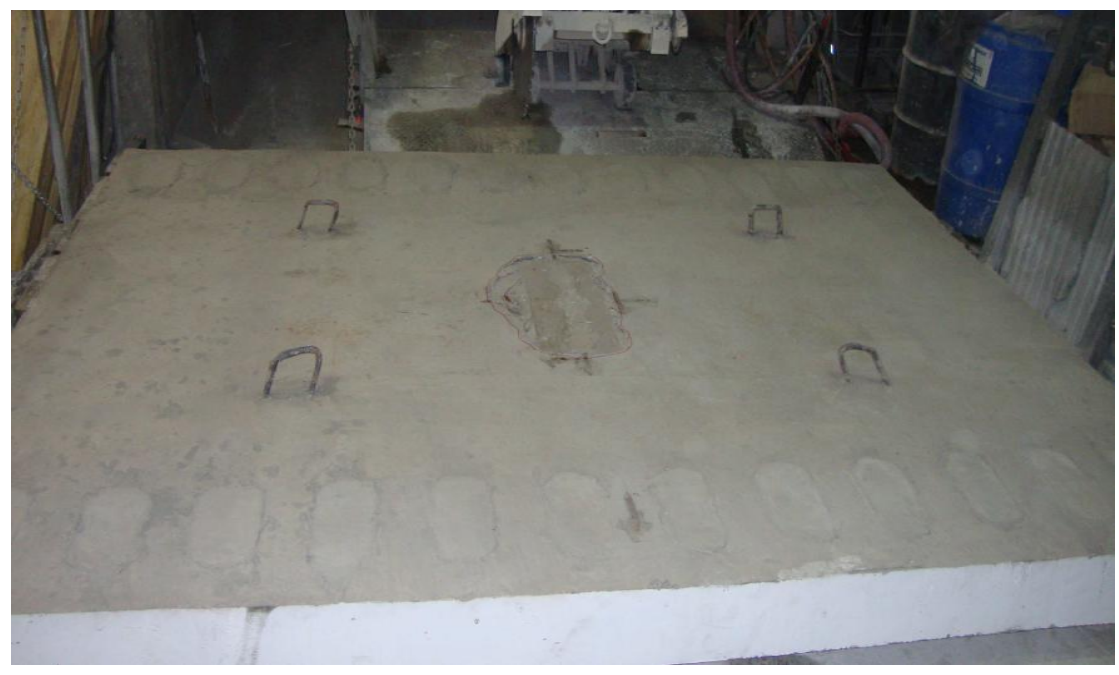

(a) Top surface

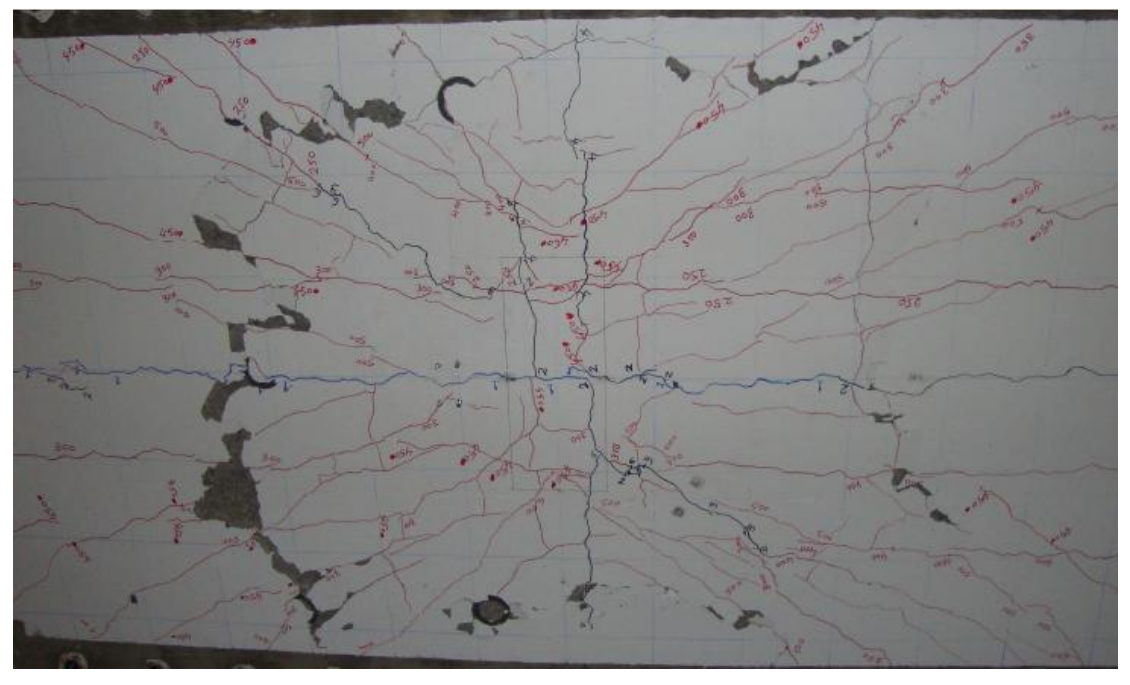

(c) Bottom surface

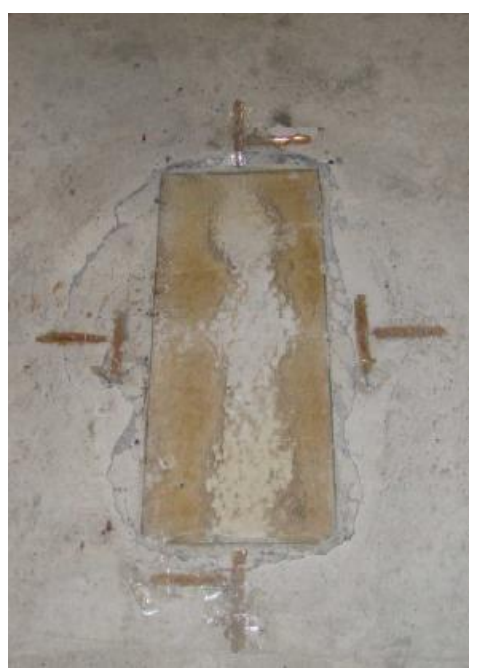

(b) Top surface close-up

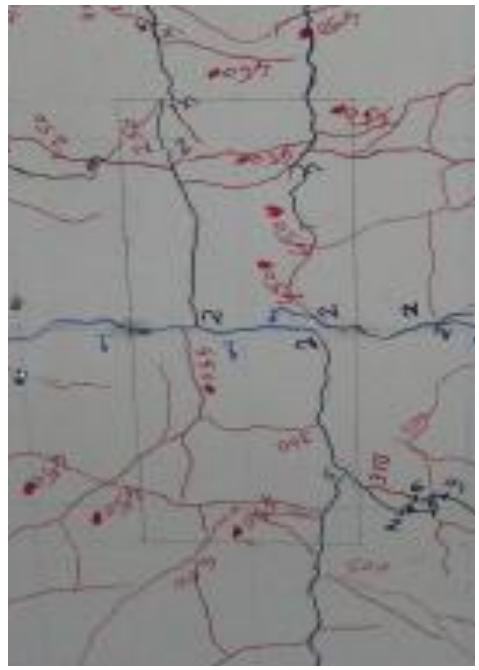

(d) Bottom surface close-up

Figure 4.26 Crack pattern at failure of deck slab S3

The fourth deck slab, S4 which had the 125-mm closure strip filled with UHPC, was tested under CAF loading. Figure 4.27 shows the crack pattern at failure on top and underside of the precast deck slab S4. The slab was subjected to 4,000,000 cycles at a fatigue load range of 122.5 $\mathrm{kN}$ and a frequency of $4 \mathrm{~Hz}$. Prior to starting the fatigue load test, the slab was pre-cracked by applying a static load of $183.75 \mathrm{kN}$, followed by unloading to zero. It was observed that the first 
hairline cracks formed at the cold joint between the precast concrete and the closure strip at 25 $\mathrm{kN}$ and the maximum measured crack width at service load level was $0.08 \mathrm{~mm}$. After completing the cyclic loading, a static load was applied until failure. It was observed that slab S4 failed at a maximum load of $758 \mathrm{kN}$ and a maximum deflection of $22.85 \mathrm{~mm}$. The failure was due to punching shear as shown in Fig. 4.27. In contrast to the punching shear perimeter that was observed to be rectangular in shape and formed around the perimeter of the footprint of the wheel load as depicted in Figs. 4.24-b, 4.25-b and 4.26-b for cast-in-place deck slabs S1, S2 and S3, respectively, the punching shear perimeter for the jointed slab S4 shown in Figs. 4.27-a and 4.27-b, diverted at the UHPC joint and followed the direction of the joint. This would support the hypothesis that the presence of the UHPC closure strip assisted in distributing the wheel load over longer length of the slab, leading to more flexural deformation, rather than pure punching shear crack pattern at failure.

The fifth deck slab, S5 which is identical to the jointed slab S4, was tested under VAF loading. Figure 4.28 shows the crack pattern at failure on top and underside of the precast deck slab S5. During the pre-cracking test for the deck slab, it was observed that first hairline cracks were formed at the cold joint between the precast concrete and the closure strip at $44 \mathrm{kN}$ and the maximum measured crack width at service load level was $0.08 \mathrm{~mm}$. After applying the first 100,000 cycles at a fatigue load range of $122.5 \mathrm{kN}$ and a frequency of $2 \mathrm{~Hz}$, these fine cracks continued to widen gradually and propagated deeper, and new transverse cracks appeared and propagated at mid-span under the loaded area. With increasing load cycles, more cracks were developed in the longitudinal (parallel to the supports) and radial directions. After completing 100,000 cycles at peak load of $245 \mathrm{kN}$, a transverse crack was observed across the closure strip at mid-span under the loaded area. After that the deck slab started to undergo drastic decrease in 
flexural stiffness and the remaining peak loads were completed with reduced frequencies. It should be noted that the maximum peak load reached at the final peak load was $475 \mathrm{kN}$ at frequency of $0.5 \mathrm{~Hz}$. The deck slab,S5, failed under punching shear and failure occurred at peak load of $475 \mathrm{kN}$ and after completing 616,145 cycles.

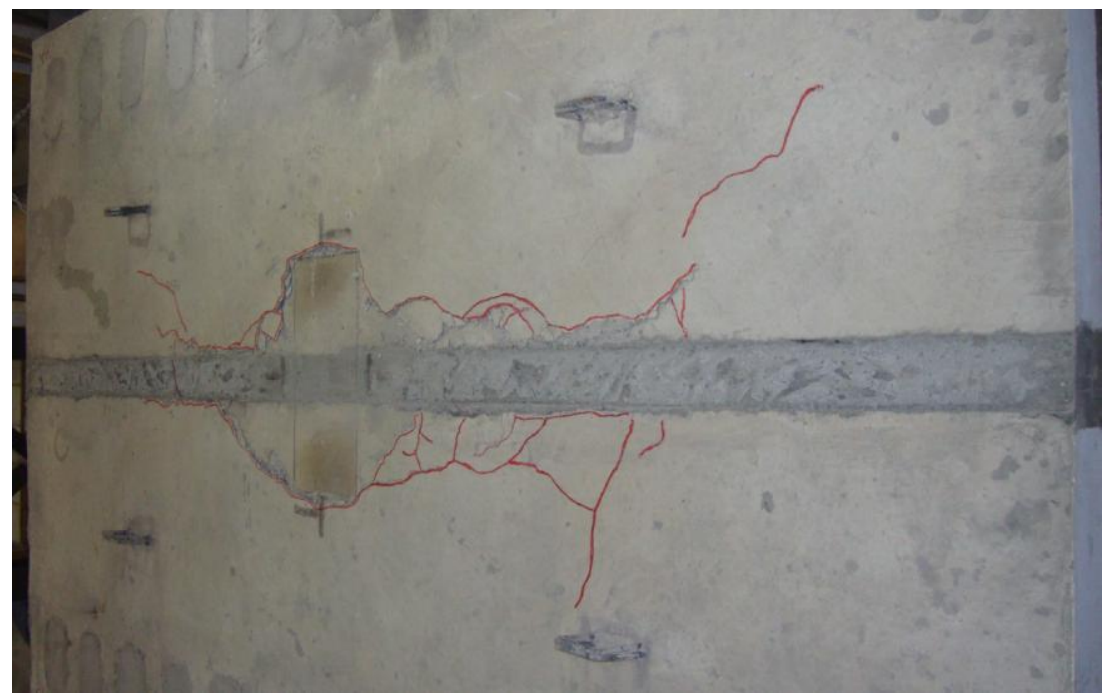

(a) Top surface

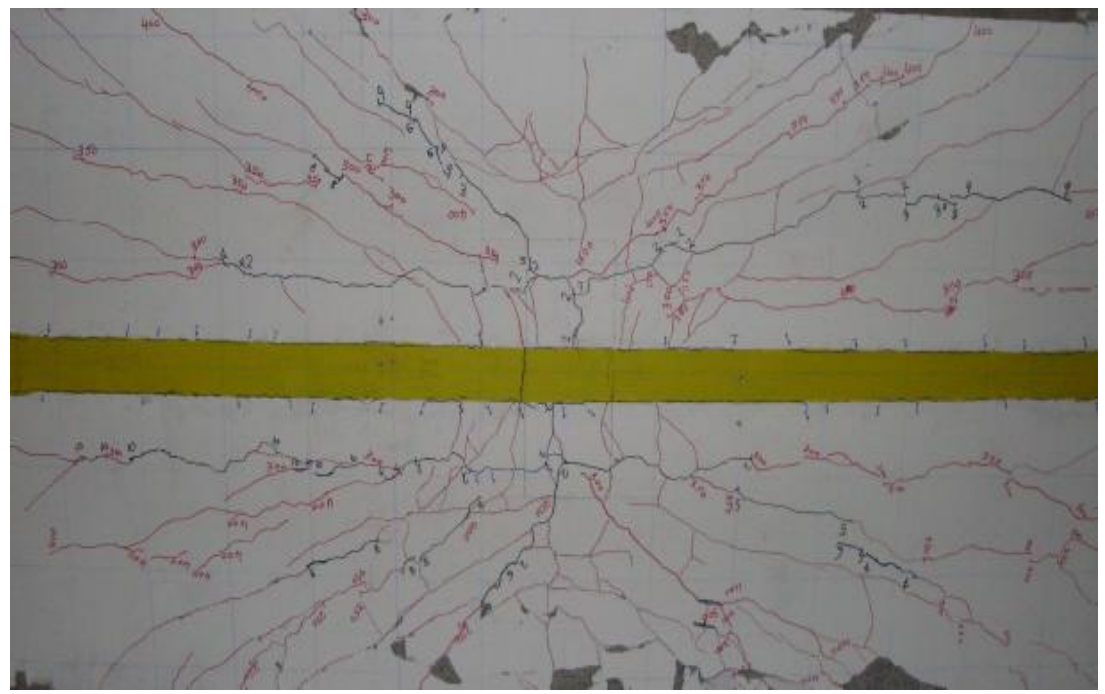

(c) Bottom surface

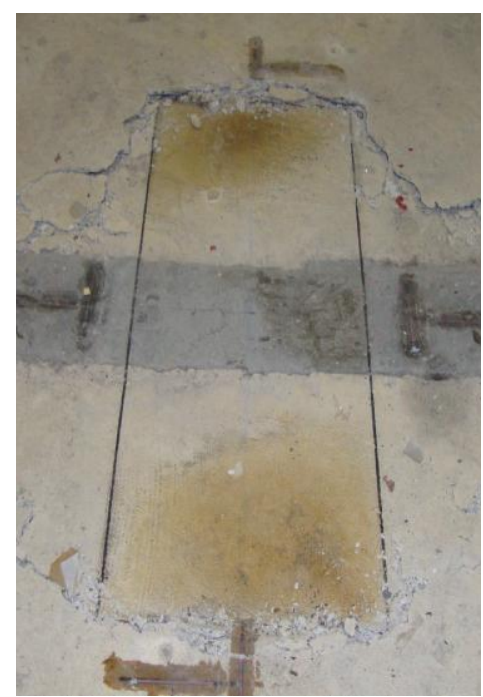

(b) Top surface close-up

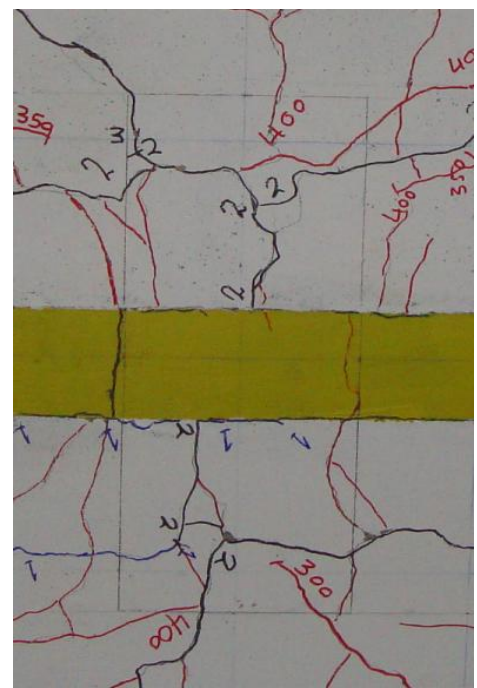

(d) Bottom surface close-up

Figure 4.27 Views of punching shear crack pattern and failure of precast jointed slab S4 
The sixth deck slab, S6 which was jointed slab reinforced with sand-coated GFRP bars, was tested to failure under static loading. Figure 4.29 shows the crack pattern at failure on top and underside of the precast deck slab S6. During the pre-cracking test for the deck slab, it was observed that first hairline cracks were formed at the cold joint between the precast concrete and the closure strip at $24 \mathrm{kN}$ and the maximum measured crack width at service load level was 0.12 mm. During the static load test, these fine cracks widened gradually and propagated deeper. With increasing the load, new transverse cracks developed and then propagated at mid-span under the loaded area, followed by cracks formed in the longitudinal and radial directions. At a load of $500 \mathrm{kN}$, a transverse crack was observed across the closure strip at mid-span under the loaded area. The deck slab failed under punching shear at a peak load of $853.3 \mathrm{kN}$ and a maximum deflection of $26.5 \mathrm{~mm}$. It can be concluded that the experimental ultimate load of slab S6 was more than four times CHBDC factored design load of $208.25 \mathrm{kN}$.

The seventh deck slab, S7 which was identical to jointed slab S6, was tested under VAF loading. Figure 4.30 shows the crack pattern at failure on top and underside of the precast deck slab S7. During the pre-cracking test for the deck slab, it was observed that first hairline cracks formed at the cold joint between the precast concrete and the closure strip at $47 \mathrm{kN}$ and the maximum measured crack width at service load level was $0.11 \mathrm{~mm}$. After starting the cyclic loading, these fine cracks started to widen gradually and propagated deeper, and new transverse cracks developed at mid-span under the loaded area. With increasing load cycles, more cracks developed in the longitudinal and radial directions. After completing 100,000 cycles at a peak load of $367.5 \mathrm{kN}$, a transverse crack was observed across the closure strip at mid-span under the loaded area. After that the deck slab started to undergo drastic decrease in flexural stiffness and the remaining peak loads were applied with reduced frequencies. It should be noted that the 
maximum peak load reached at the final peak load level was $475 \mathrm{kN}$ at a frequency of $0.5 \mathrm{~Hz}$. The jointed deck slab, S7, failed under punching shear at a peak load of $475 \mathrm{kN}$ and after completing 886,346 cycles.
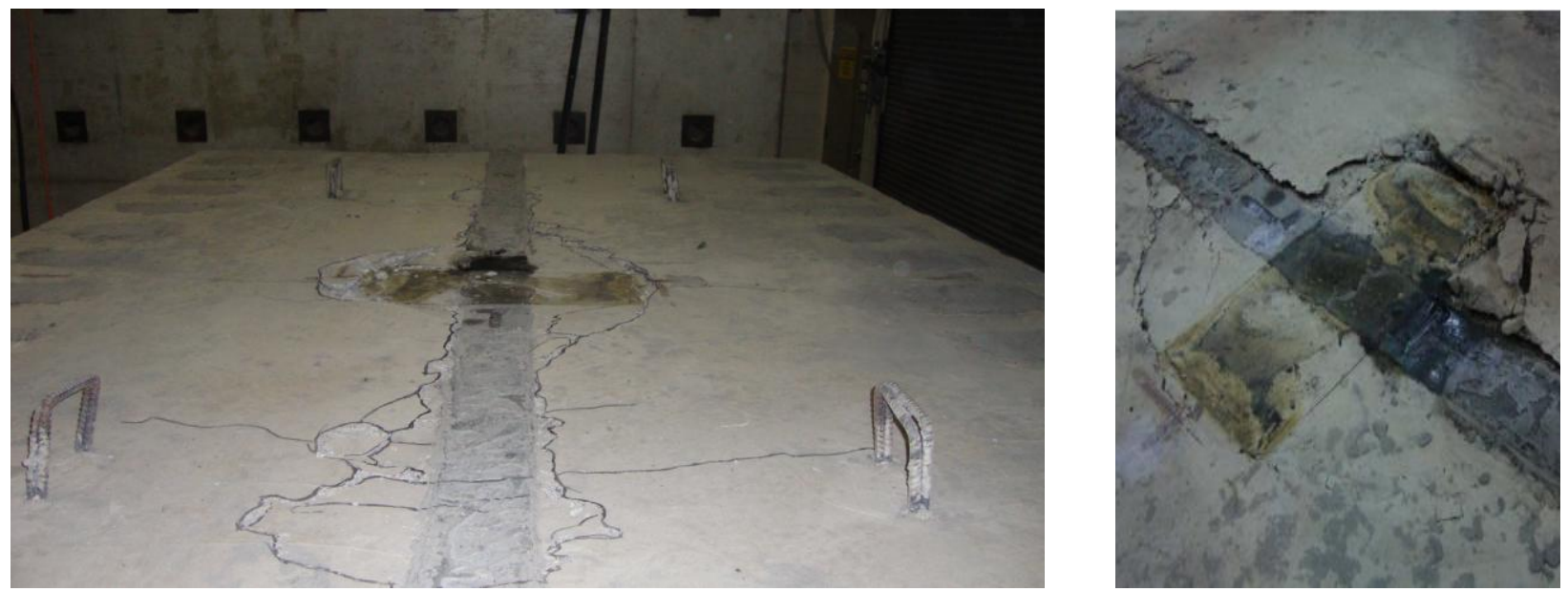

(a) Top surface

(b) Top surface close-up
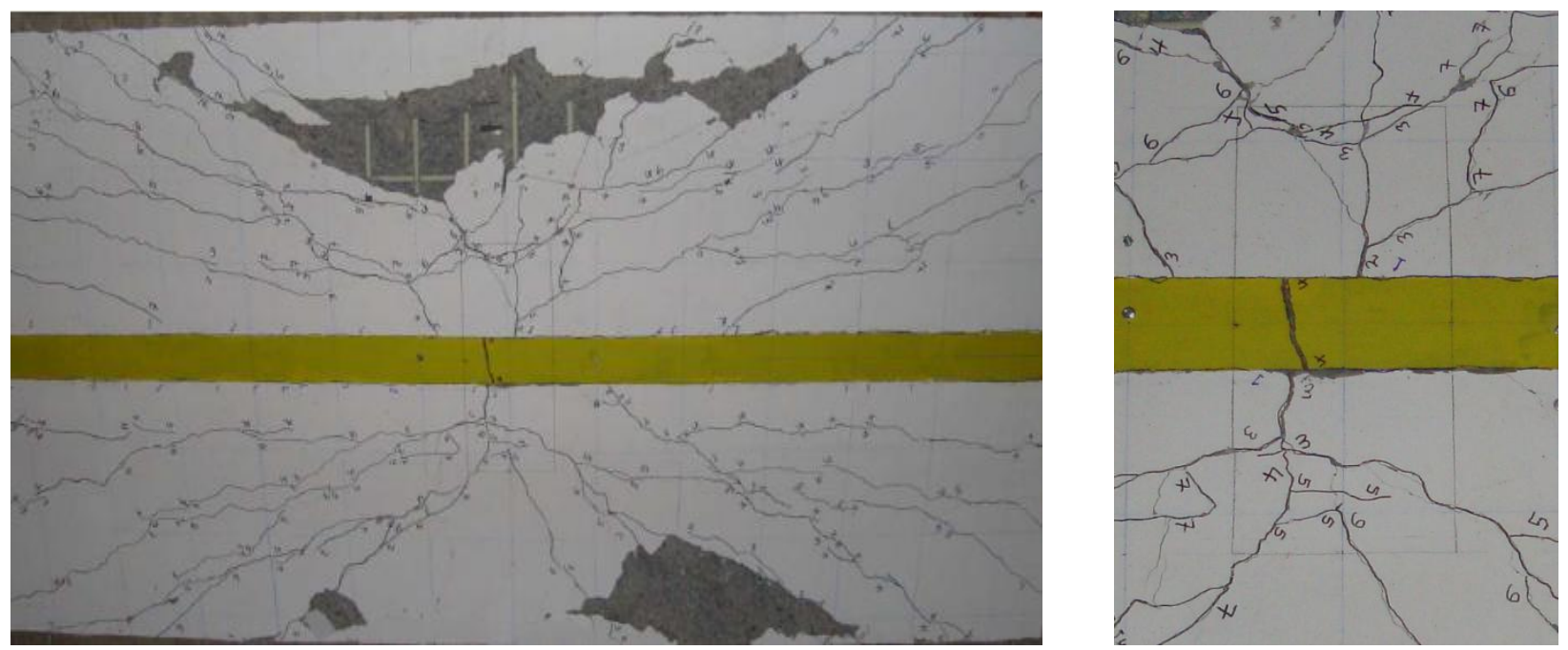

(c) Bottom surface

(d) Bottom surface close-up

Figure 4.28 Views of punching shear crack pattern and failure of precast jointed slab S5 


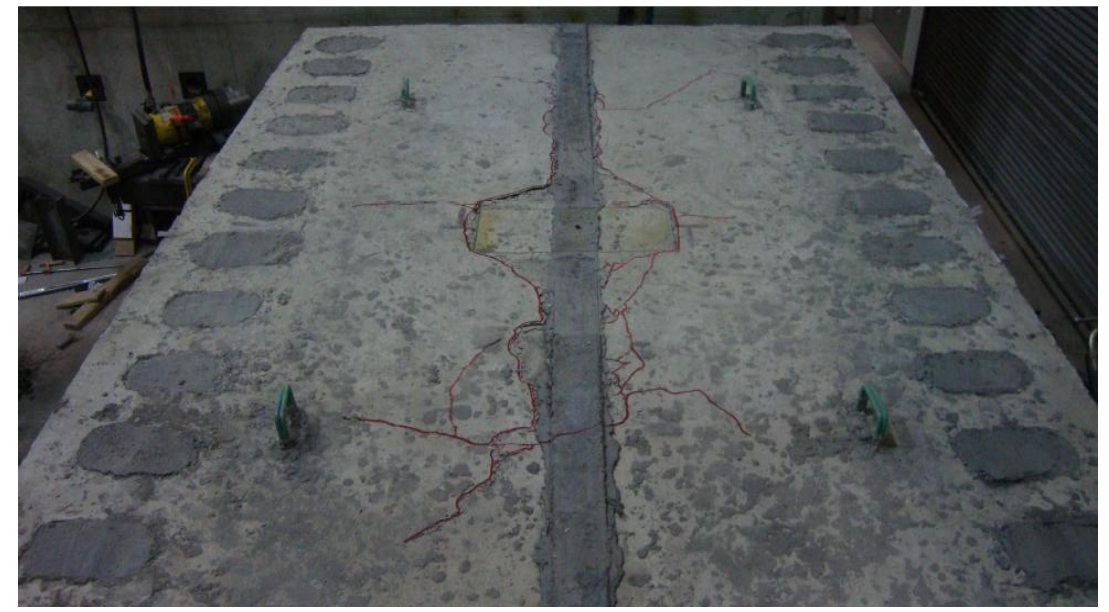

(a) Top surface

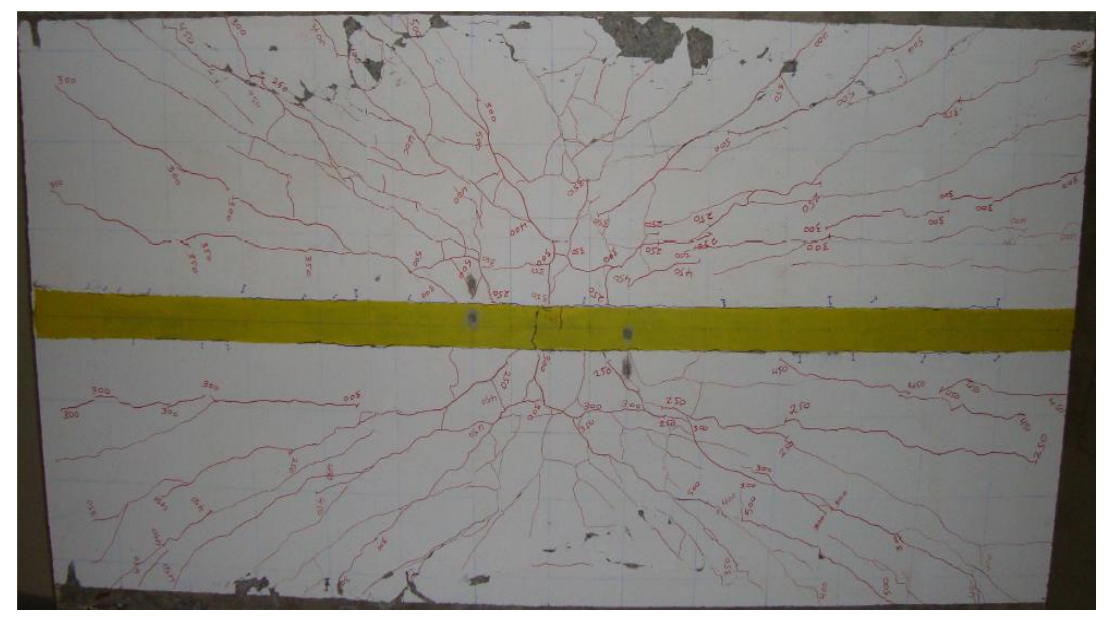

(c) Bottom surface

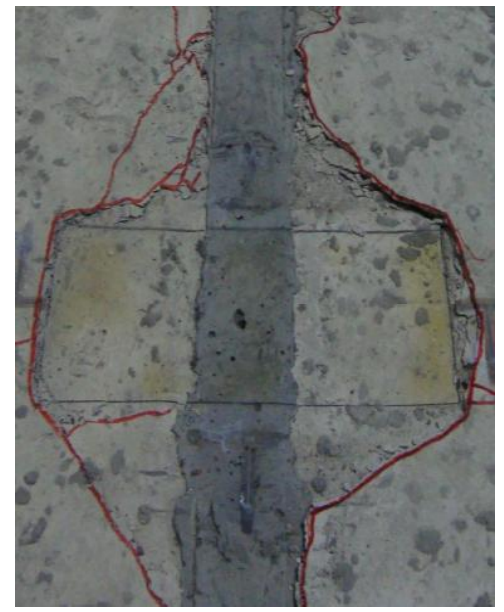

(b) Top surface close-up

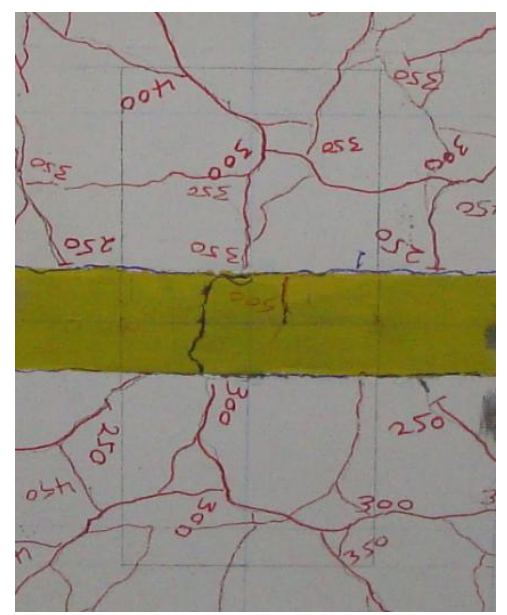

(d) Bottom surface close-up

Figure 4.29 Views of punching shear crack pattern and failure of precast jointed slab S6

The eighth deck slab, S8 which is identical to jointed slabs S6 and S7, was tested under CAF loading. Figure 4.31 shows the crack pattern at failure on top and underside of deck slab, S8. Before starting the pre-cracking test, there were few cracks at the underside of the deck slab in the longitudinal and transverse directions. These cracks occurred during transportation of the slab specimen and the maximum measured width of these cracks was $0.175 \mathrm{~mm}$. During the pre- 
cracking test for the deck slab, it was observed that first hairline cracks formed at the cold joint between the precast concrete and the closure strip. After the pre-cracking test, the deck slab was subjected to 4,000,000 cycles at a fatigue load range of $122.5 \mathrm{kN}$ and a frequency of $4 \mathrm{~Hz}$. After completing the cyclic load, the slab did not fail and a static test was applied until failure. The deck slab failed at a maximum load of $801.58 \mathrm{kN}$ and a maximum deflection of $24.41 \mathrm{~mm}$. The failure was due to punching shear as shown in Fig. 4.31.

It can be observed that the perimeter of punching shear for all five jointed deck slabs, S4 through S8, did not follow the traditional pattern of being along the perimeter of the 250x600 mm loaded area. Due the presence of the stiff UHPC in the closure strip, the punching shear crack at the top surface deviate to the longitudinal direction of the joint rather than crossing the joint. This made the punching shear perimeter at the bottom of the slab to appear close to the supporting steel girders without being connected across the UHPC-filled joint, as shown in Figs. 4.27 through 4.31 .

\subsubsection{Deflection Patterns}

Potentiometers and (LVDTs) were used to measure deflections at specified locations along the centrelines in the longitudinal and transverse directions of the deck slabs as shown in Fig. 3.29 in chapter III. As expected, the maximum measured vertical deflections were recorded from POT1 and POT2 in the longitudinal direction under the loaded area. Figure 4.32 shows the loaddeflection relationships obtained at the mid-lines in the longitudinal and transverse directions of deck slabs S1, S3, S4, S6 and S8 under static load to failure. It was obvious that the maximum recorded deflections for all slabs were obtained from POT 2 located directly under the loaded 
area, while the deflections at the outer edge LVDT 6 of all slabs were negative, indicating upward deflection at this location as expected.
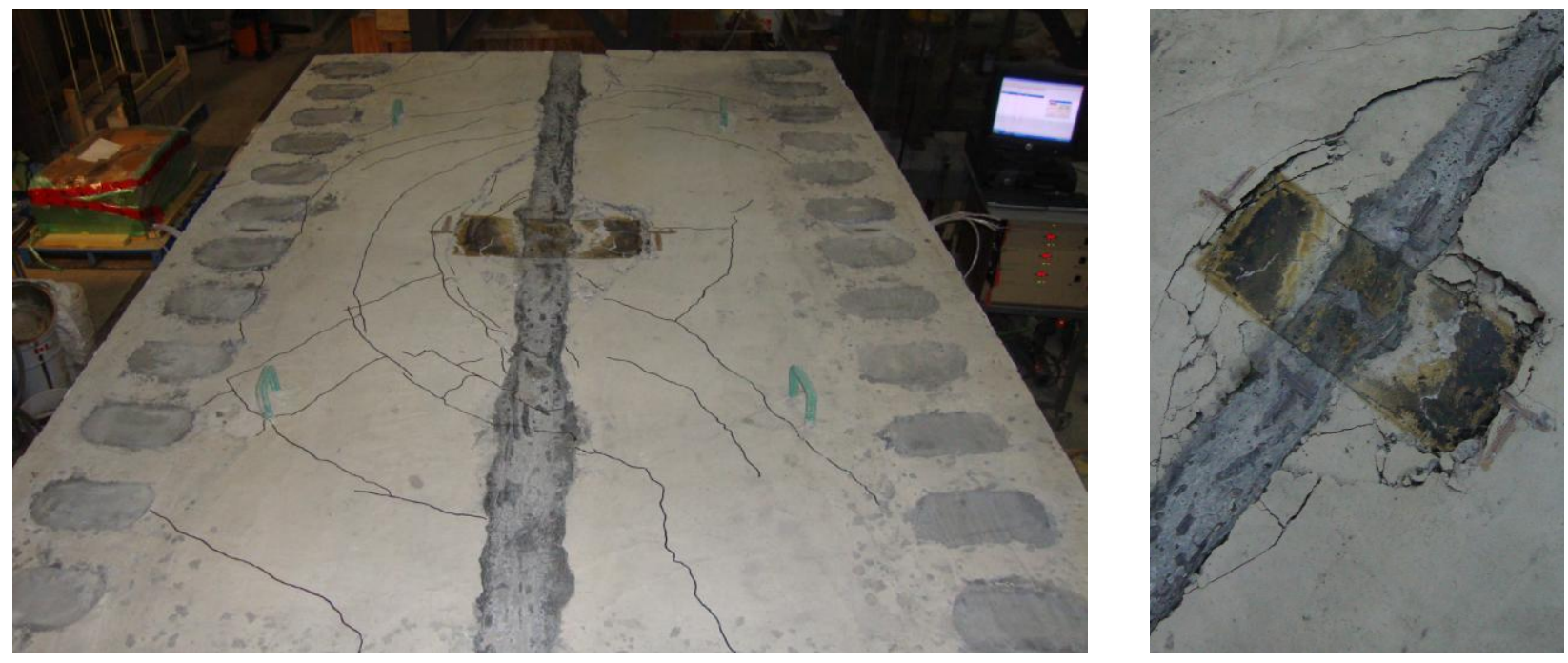

(a) Top surface

(b) Top surface close-up
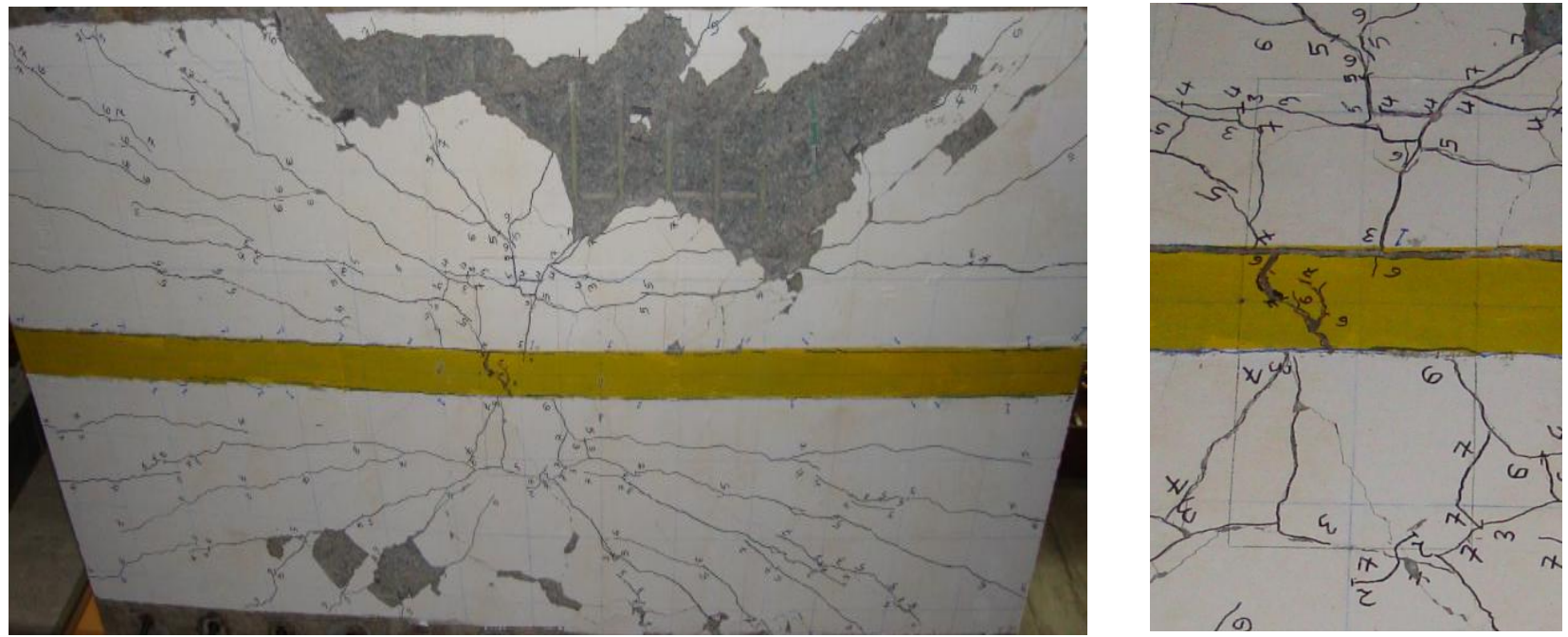

(c) Bottom surface

(d) Bottom surface close-up

Figure 4.30 Views of punching shear crack pattern and failure of precast jointed slab S7 


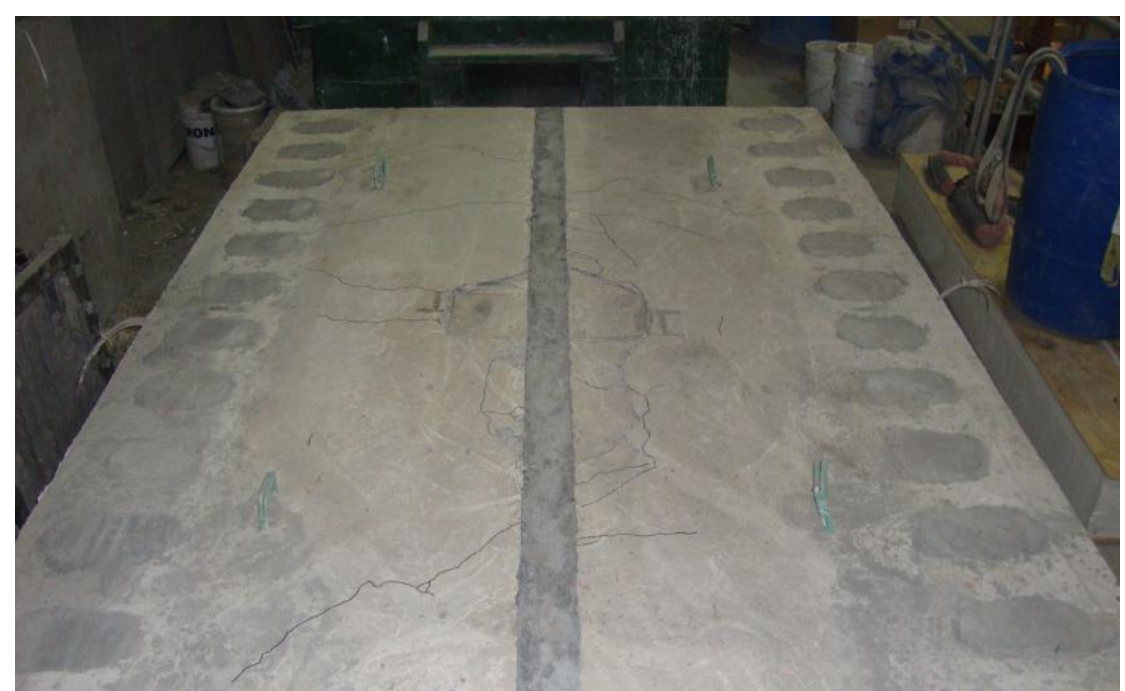

(a) Top surface

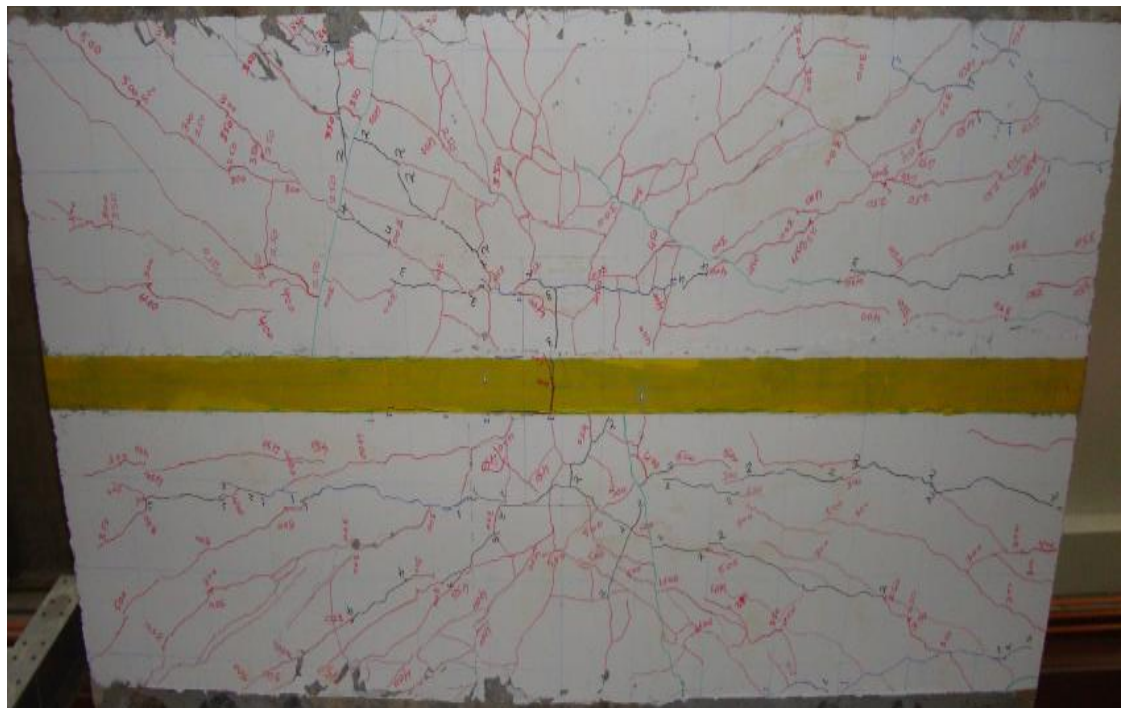

(c) Bottom surface

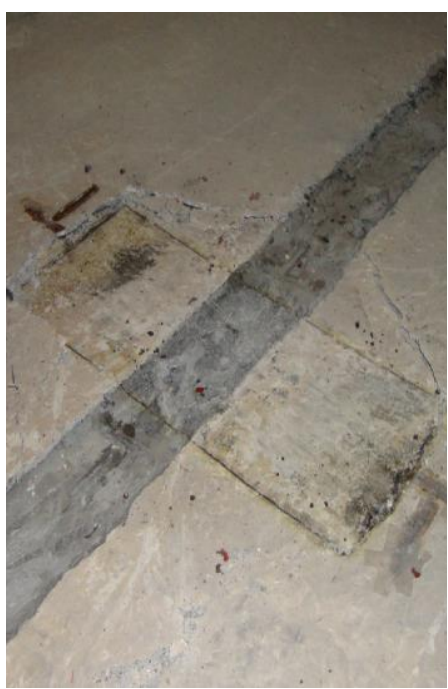

(b) Top surface close-up

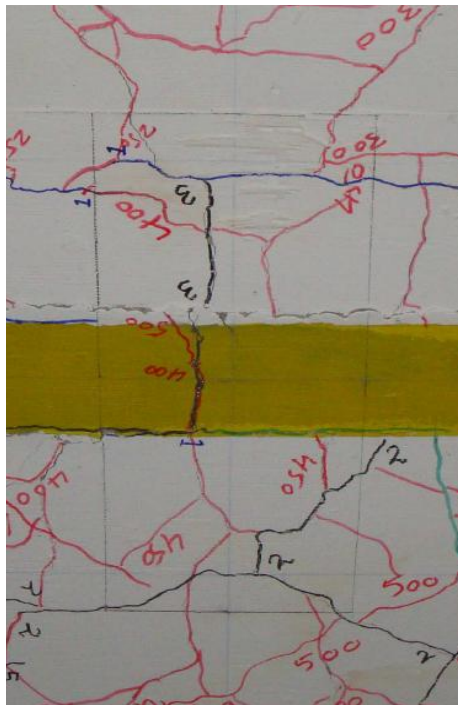

(d) Bottom surface close-up

Figure 4.31 Views of punching shear crack pattern and failure of precast jointed slab S8

To compare the performance of the tested deck slabs, Fig. 4.33 shows load-maximum deflection relationships obtained at mid-span of slabs S1, S3, S4, S6 and S8. All these slabs were tested under static loading to failure, while only slabs S3, S4 and S8 were tested under CAF loading 
prior to loading them under static loading to failure. It can be observed that all deck slabs exhibited similar deflection behaviour, linear up to approximately $240 \mathrm{kN}$. This load exceeds CHBDC factored design load of $208.25 \mathrm{kN}$ by about $16 \%$ before undergoing a change in slope as the flexural stiffness gradually decreased. After this load, all slabs exhibited a bit linear behaviour up to failure. Given the linear nature of the load-deflection relationships from the cracking load to failure, the recorded punching shear failures of the tested deck slabs were sudden. The test results indicated that deck slabs S3, S4 and S8 subjected to 4,000,000 load cycles prior to static load testing, exhibited similar deflection behavior compared to slabs S1 and S6 subjected to a static load only. Also, it can be noticed for both cast-in-place and precast deck slabs tested under a static load, the maximum measured vertical deflection at service load of $110.25 \mathrm{kN}$ was $1.1 \mathrm{~mm}$, which is less than the allowable limit specified by AASHTO-LRFD specifications, $(L / 800=2.5 \mathrm{~mm}$, where $\mathrm{L}$ is the slab span of $2000 \mathrm{~mm})$.

Figure 4.34 shows the static load-deflection relationships of slabs, S3, S4 and S8, after different constant amplitude fatigue (CAF) loading steps. It should be noted that the term "S" in Fig. 4.34 refers to the static loading following the completion of each fatigue loading step, while the number following "S-" refers to the number of completed load cycles. For example, S-250,000 refers to static loading and unloading cycle after completing 250,000 cycles. It is obvious that the three slabs exhibited linear behavior with almost similar slopes of the load-deflection relationships after being subjected to 4,000,000 load cycles at a fatigue load range of $122.5 \mathrm{kN}$. This indicates that there was no reduction in the slabs flexural stiffness during the CAF tests. One can conclude that GFRP-reinforced slab showed high fatigue performance and there was no observed fatigue damage when subjected to 4,000,000 load cycles under FLS load range of $122.5 \mathrm{kN}$ specified in the CHBDC. 


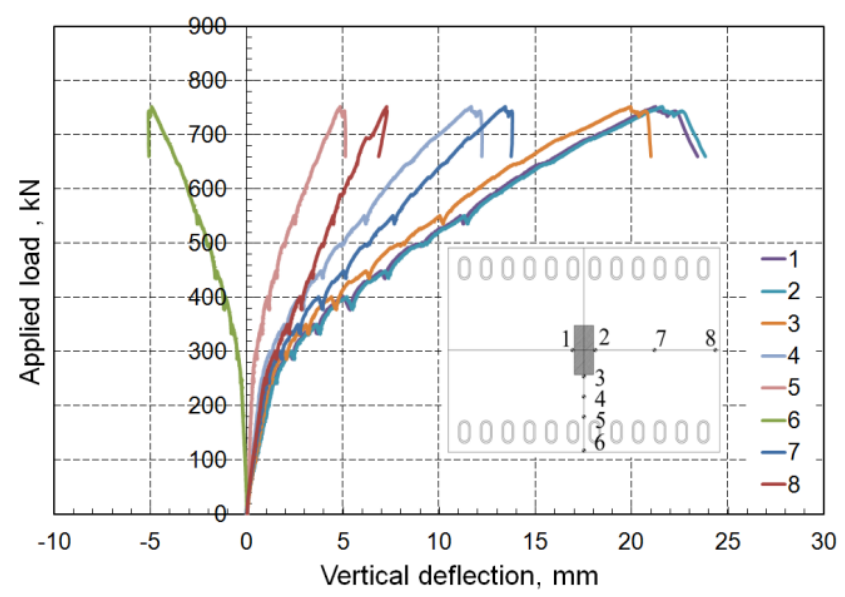

(a) Slab S1

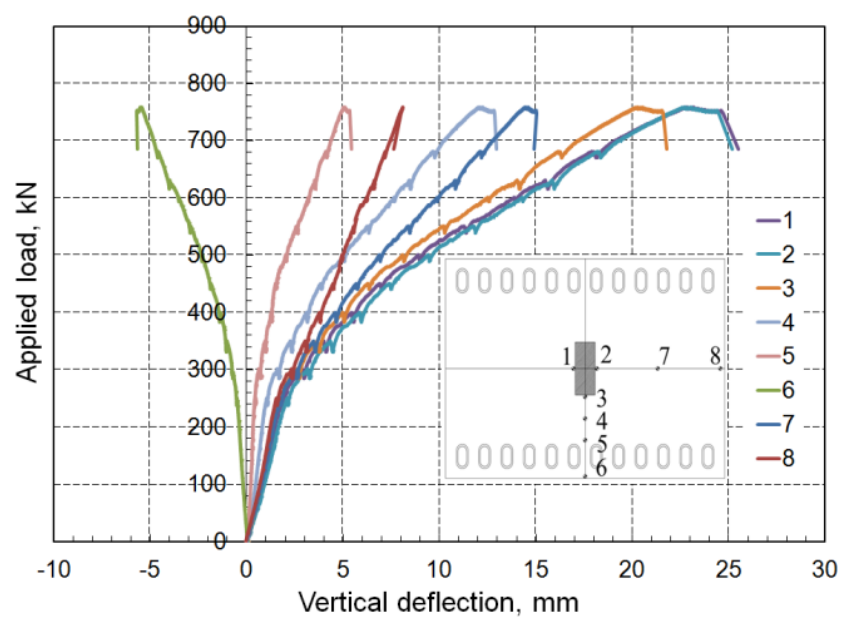

(c) Slab S4

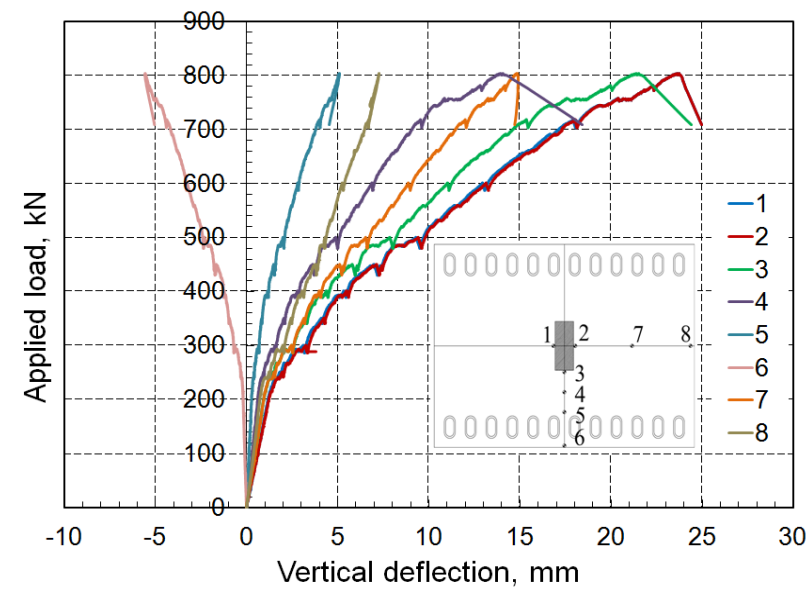

(b) Slab S3

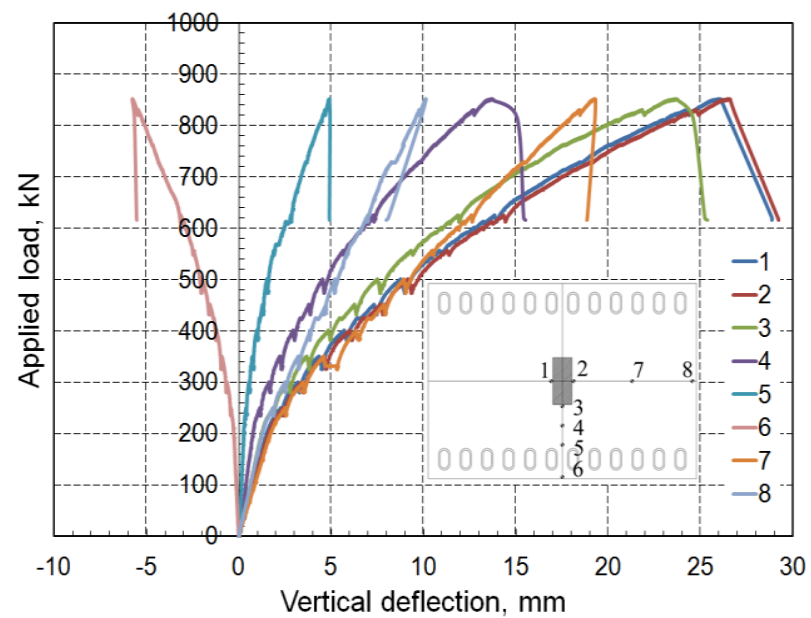

(d) Slab S6

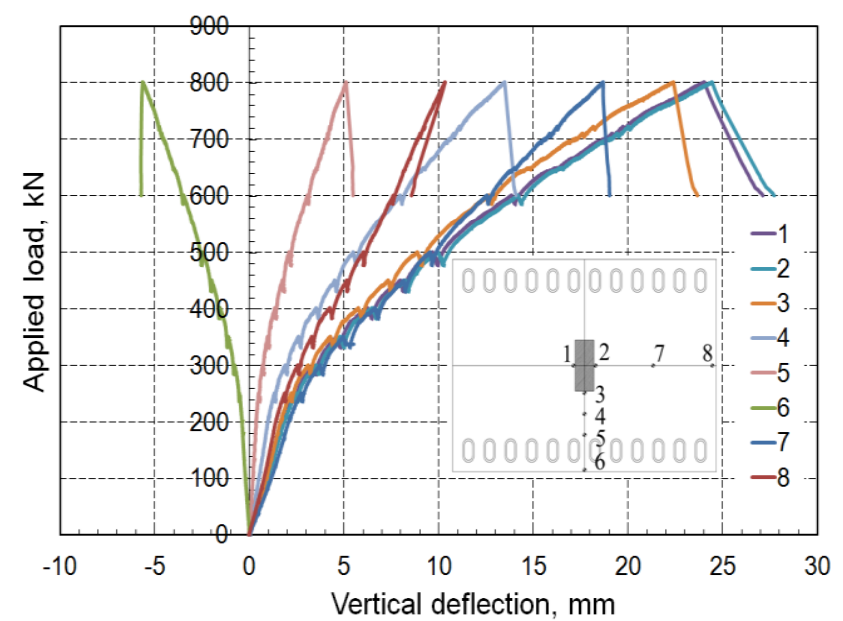

(e) Slab S8

Figure 4.32 Load-deflection relationships for slabs S1, S3, S4, S6 and S8 


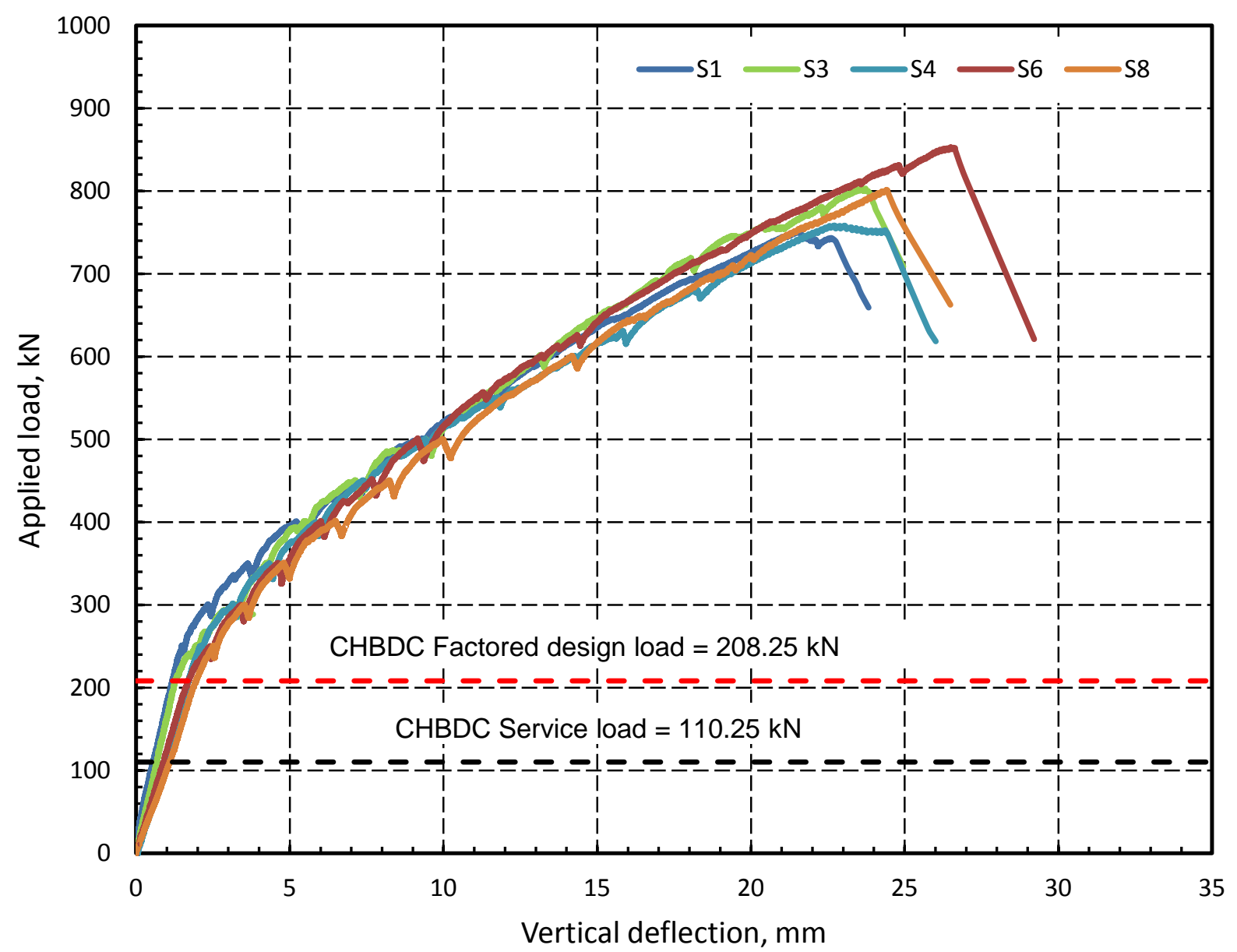

Figure 4.33 Load-maximum deflection relationships obtained at mid-span of slabs S1, S3, S4, S6 and $\mathrm{S} 8$

Figure 4.35 shows the static load-deflection relationships of slabs, S2, S5 and S7, after different variable amplitude fatigue (VAF) loading steps. It should be noted that the term "S" in Fig. 4.35 refers to the static loading following the completion of each fatigue loading step, while the number following "S-" refers to the peak load at which the slab completed 100,000 load cycles. For example, S-122.5 $\mathrm{kN}$ refers to the static loading and unloading cycle after completing 100,000 cycles at a fatigue load range of $122.5 \mathrm{kN}$. It can be observed that with the increase in the peak load and number of cycles, a progressive loss of flexural stiffness and increase in both vertical and residual deflection occurred in the three deck slabs. Figure 4.35 also indicates that 
the cast-in-place deck slab, S2, and the precast deck slabs, S5 and S7, exhibited linear loaddeflection relationships up to a peak load of $428.75 \mathrm{kN}$ and 600,000 load cycles. Also, one can notice that the fatigue damage accumulated by slab S7 was less than the that accumulated by slabs S2 and S5. This may be attributed to the high bond characteristic of sand-coated GFRPbars used to reinforce slab S7 compared to the less bond characteristic of ribbed-surface GFRPbars used to reinforce slabs S2 and S5 in addition to the higher concrete strength recorded for slab S7, compared to those for slabs S2 and S5 as depicted in Table 4.3. Given the linear nature of the load-deflection relationships from the cracking load to failure, the recorded punching shear failure of the tested deck slabs were sudden.

Figure 4.36 illustrates the deflection versus number of load cycles of CAF loading for the tested slabs, S3, S4 and S8, at a fatigue load range of $122.5 \mathrm{kN}$. Test results indicated that all the three deck slabs completed 4,000,000 load cycles without significant damage. Two fatigue damage accumulation phases were observed in the slab responses. The first phase, that can be called crack initiation phase, involved sudden increase in the deflections up to approximately 250,000 load cycles, followed by the stable cracking phase, in which slight increases in the vertical deflections were observed. In this phase, fatigue damage accumulated at low rate and the maximum measured vertical deflections at the end of this phase for the three slabs S3, S4 and S8 were $1.02,1.47$ and $1.74 \mathrm{~mm}$, respectively. One can conclude that precast deck slabs, S4 and S8, fatigued approximately $44 \%$ and $70 \%$, times as fast as the cast-in-place deck slab, S3.

Figure 4.37 illustrates the deflection versus number of load cycles of VAF loading for the tested deck slabs, S2, S5 and S7, at different peak loads. Two fatigue damage accumulation phases were observed in the slabs response. In the first phase, it can be observed that the three deck 
slabs exhibited slight increase in the vertical deflections up to approximately 100,000 load cycles (stable cracking phase). In this phase, fatigue damage accumulated at low rate. After 100,000 load cycles, the second phase (crack propagation phase) started. This phase was characterized by rapid increase in vertical deflection until failure. Test results indicated that the three deck slabs S2, S5 and S7 failed at 808,651, 616,145 and 886,346 cycles, respectively, while the maximum measured vertical deflections at failure were $27.6,26.01$ and $27.23 \mathrm{~mm}$, respectively.

\subsubsection{Strain in Concrete and Reinforcement}

Figure 4.38 illustrates the maximum measured concrete strains versus the number of load cycles of CAF loading for the tested slabs, S3, S4 and S8, at a fatigue load range of $122.5 \mathrm{kN}$. It should be noted that the location of the maximum concrete strain was at the edge of the loaded area as depicted in Fig. 3.28. Two fatigue damage accumulation phases were observed in the slabs response. The first phase, that can be called crack initiation phase, characterized by increases in the concrete strains up to approximately 250,000 load cycles, followed by the stable cracking phase, in which slight increases in the concrete strains were observed. In this phase, fatigue damage accumulated at low rate and the maximum measured strains at the end of this phase for the three deck slabs S3, S4 and S8 were $-415 \mu \varepsilon,-116 \mu \varepsilon$ and $-202 \mu \varepsilon$, respectively. It can be observed that the maximum measured concrete strain in cast-in-place deck slab, S3, was more than two times the concrete strain in precast deck slab, S4. After completed 4,000,000 load cycles without significant damage, the three deck slabs, S3, S4 and S8 were monotonically loaded until failure, and the maximum measured concrete strains at failure were -2391 $\mu \varepsilon,-1043$ $\mu \varepsilon$ and $-1499 \mu \varepsilon$, respectively. 
The maximum measured concrete strains in the cast-in-place deck slab S1 and the precast deck slab S6, tested under static load without pre-fatigue loading to failure were $-2410 \mu \varepsilon$ and -1316 $\mu \varepsilon$, respectively. In comparing the recorded maximum concrete strains at failure in the prefatigued slabs to the identical slabs tested under static load only, one can notice that the prefatigued deck slab, S3, exhibited similar maximum strain as slab, S1, subjected to a static load only. This result indicated that there was no observed fatigue damage accumulation after slab, $\mathrm{S} 3$, completed 4,000,000 cycles at a fatigue load range of $122.5 \mathrm{kN}$. Also, the results showed that the maximum measured concrete strain at failure in the pre-fatigued slab, S8 was about 14 $\%$ higher than the similar deck slab, S6 that was tested under static load only. Since these maximum strains were recorded on the top surface of the precast panels not on the UHPC, one can conclude that this is mainly due to the variation in concrete compressive strength of slab S8 $\left(\mathrm{f}_{\mathrm{c}}^{\prime}=44 \mathrm{MPa}\right)$ and slab S6 $\left(\mathrm{f}_{\mathrm{c}}^{\prime}=58.75 \mathrm{MPa}\right)$.

Figure 4.39 illustrates the maximum measured concrete strains on top of slab surfaces versus number of load cycles of VAF loading of the tested deck slabs, S2, S5 and S7, at different peak loads. The results showed that the maximum measured concrete strains at failure for the three deck slabs, S2, S5 and S7 were $-4135 \mu \varepsilon,-1249 \mu \varepsilon$ and $-920 \mu \varepsilon$, respectively. 


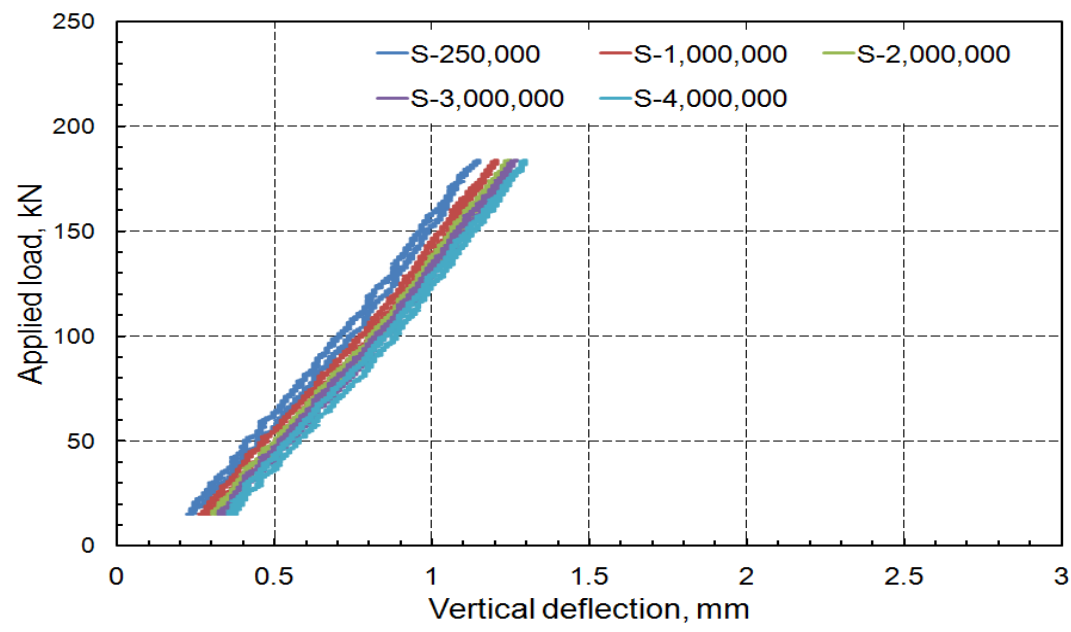

(a) Slab S3

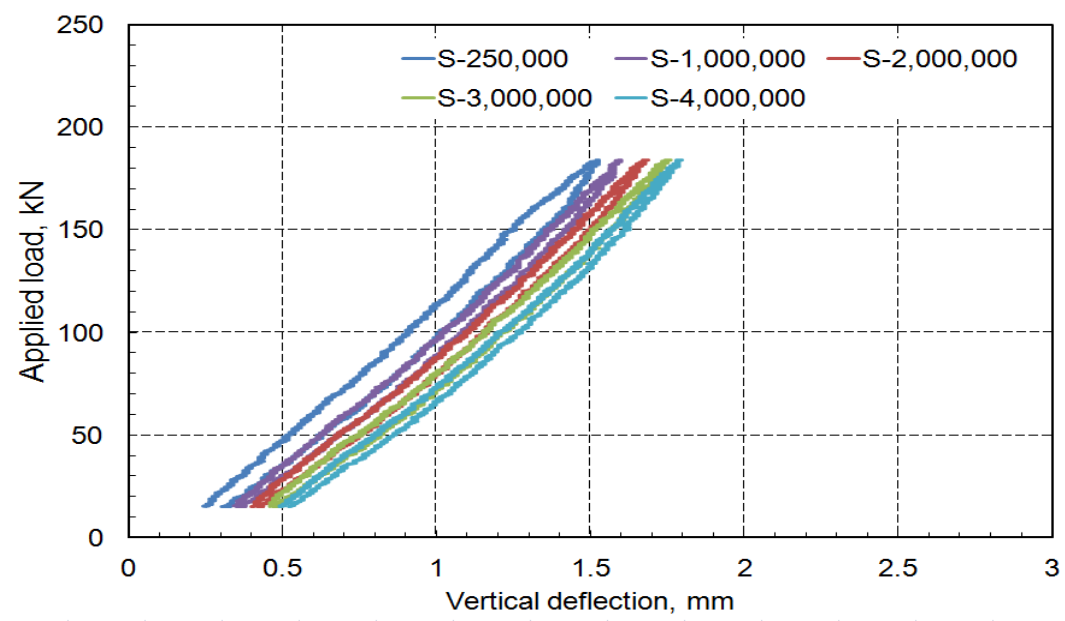

(b) Slab S4

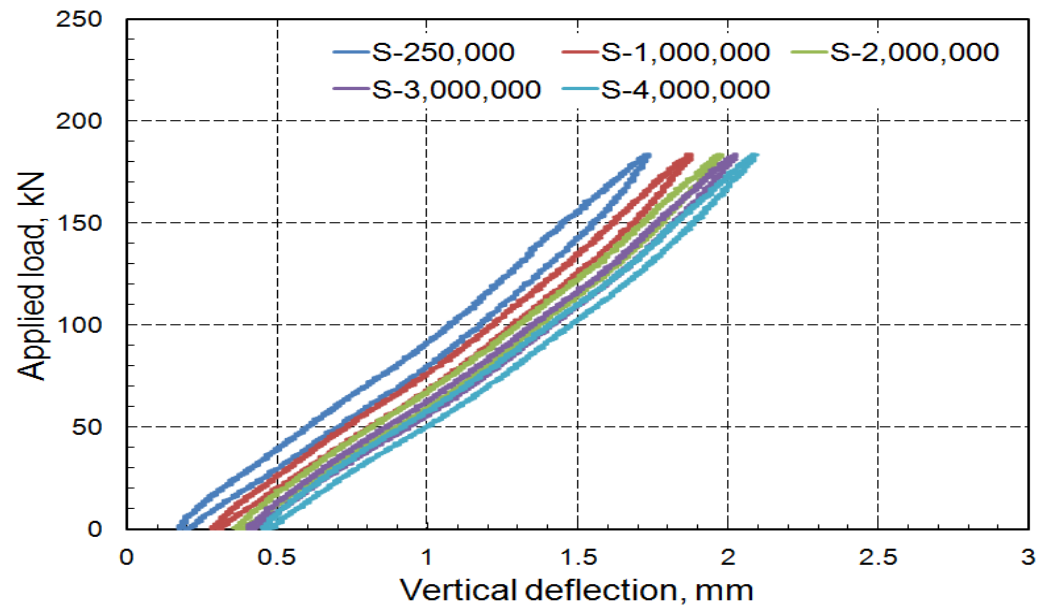

(c) Slab S8

Figure 4.34 Static load-deflection relationships of slabs S3, S4 and S8 after different constant-amplitude fatigue loading cycles 


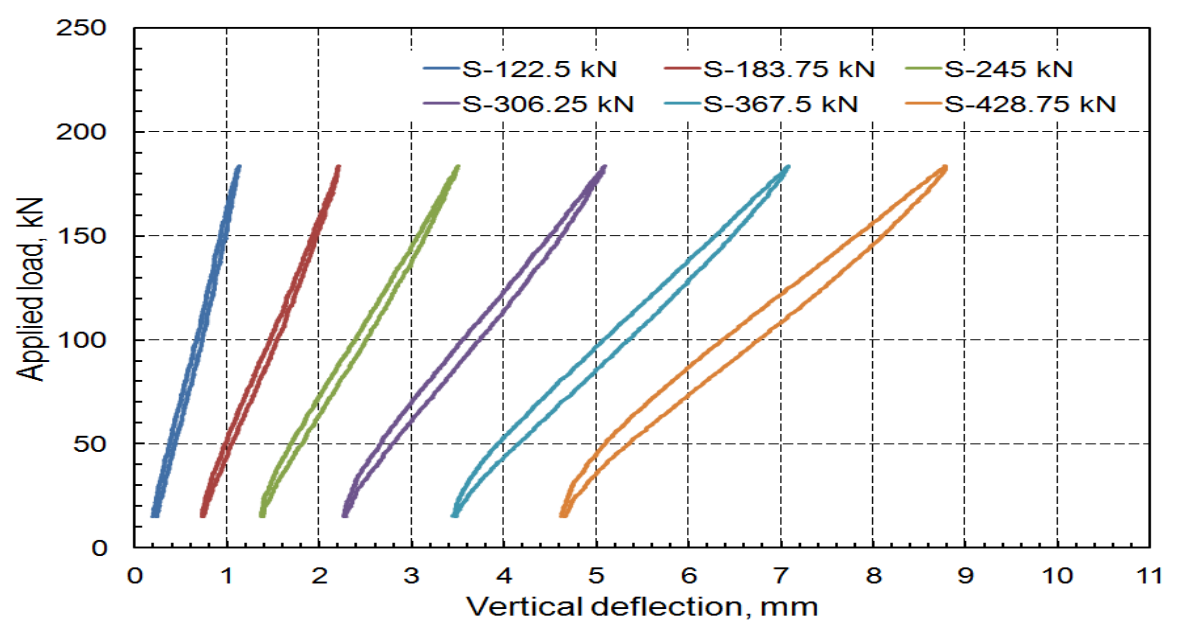

(a) Slab S2

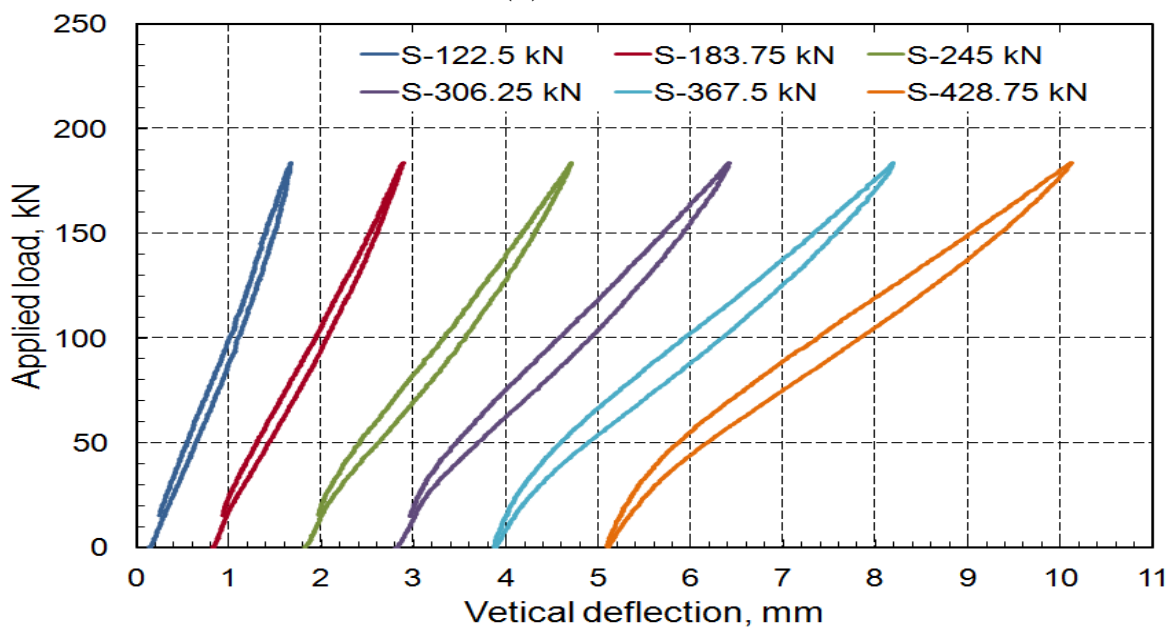

(b) Slab S5

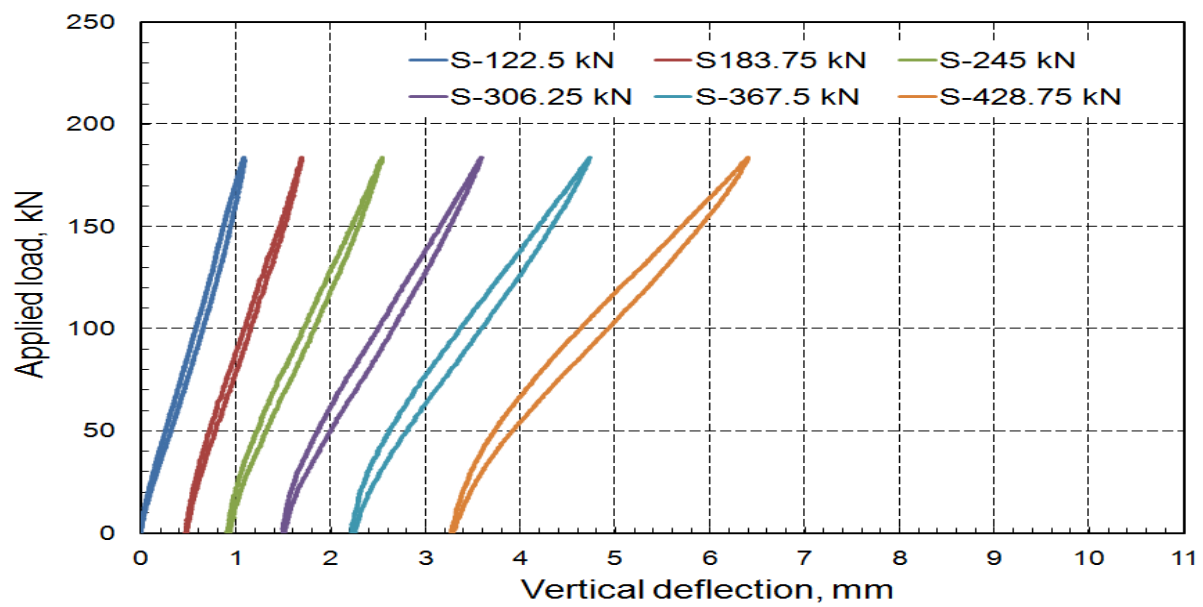

(c) Slab S7

Figure 4.35 Static load-deflection relationships of S2, S5 and S7 after different variable-amplitude fatigue loading steps 


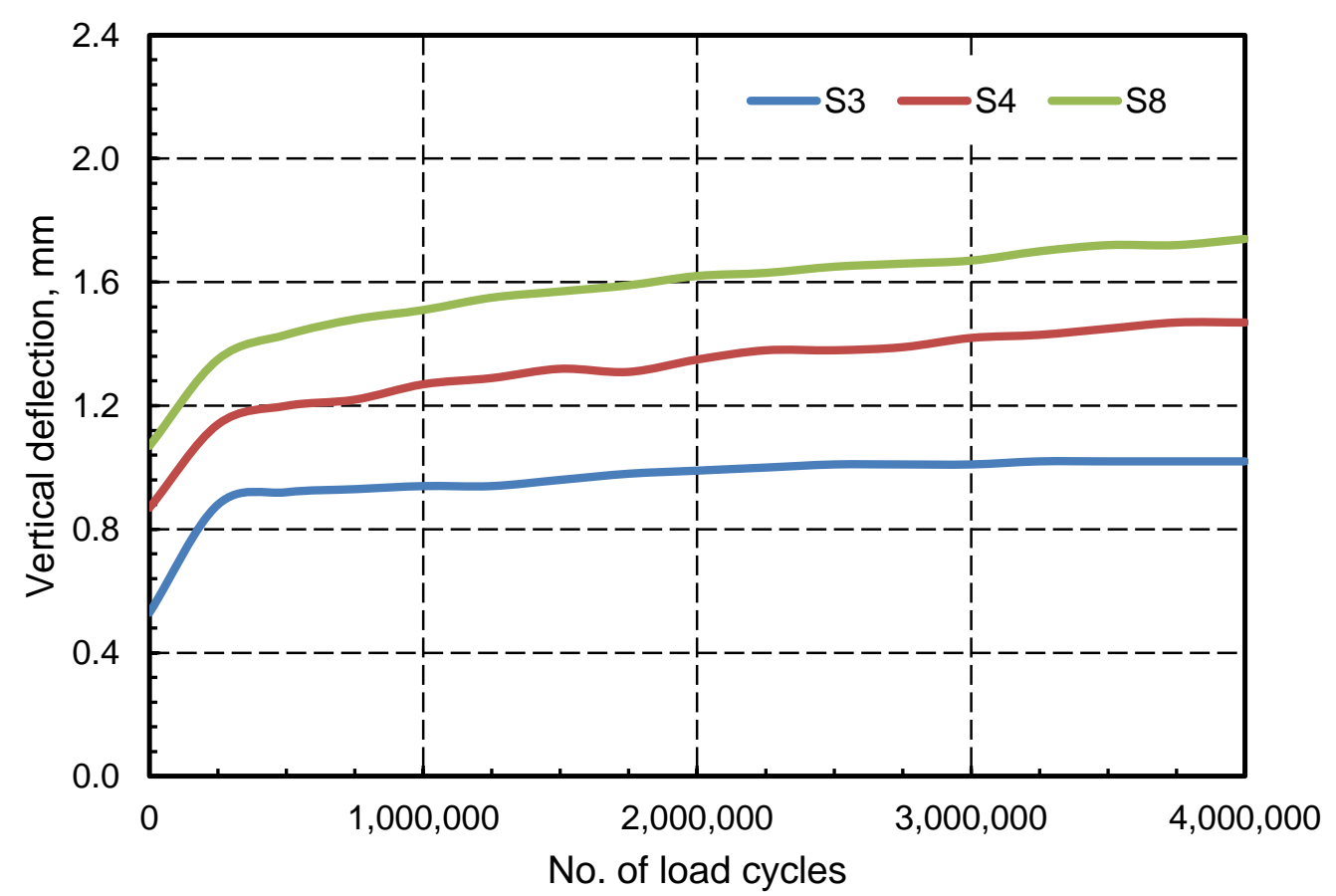

Figure 4.36 Deflection versus number of load cycles for CAF tested slabs S3, S4 and S8

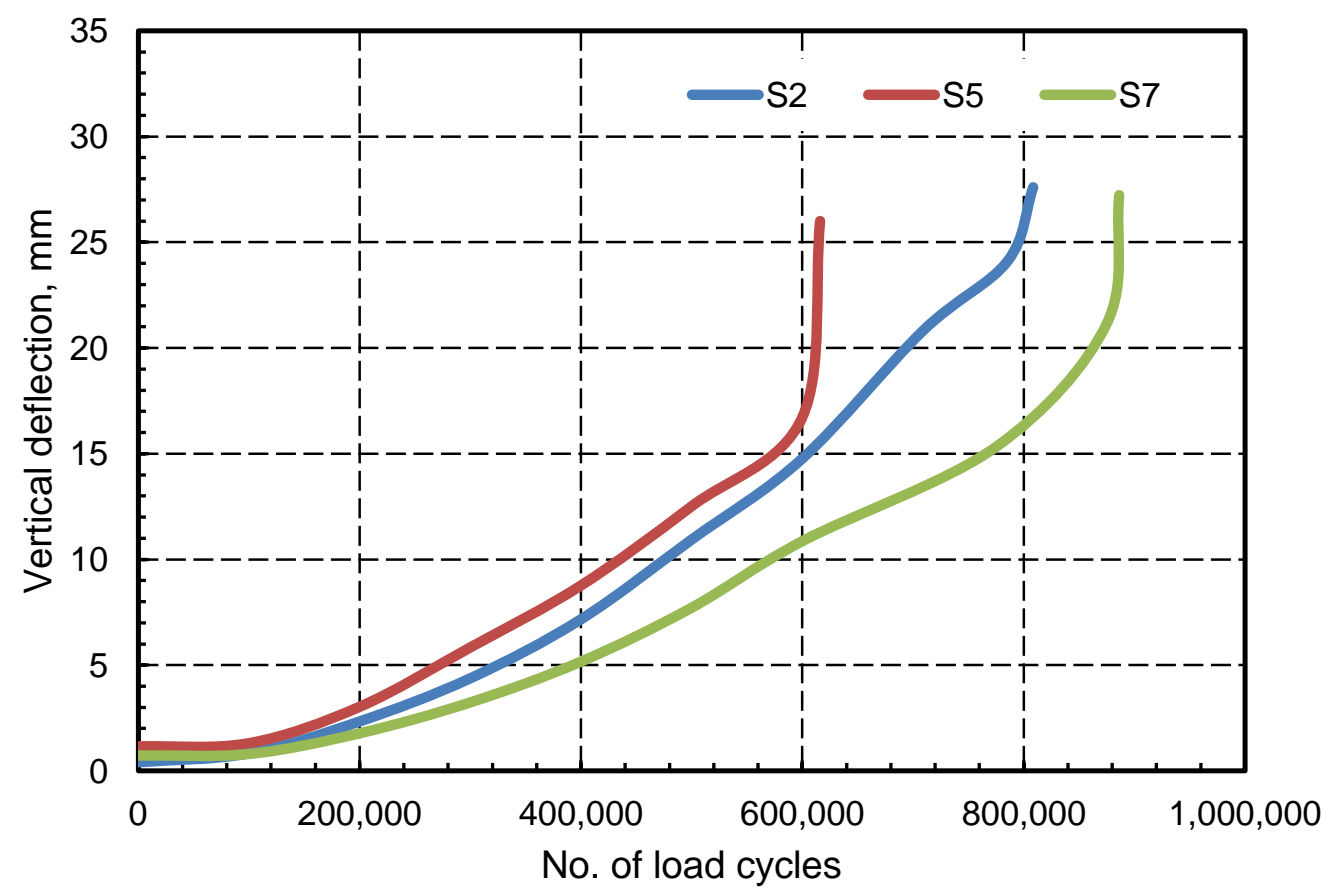

Figure 4.37 Deflection versus number of load cycles for VAF tested slabs 


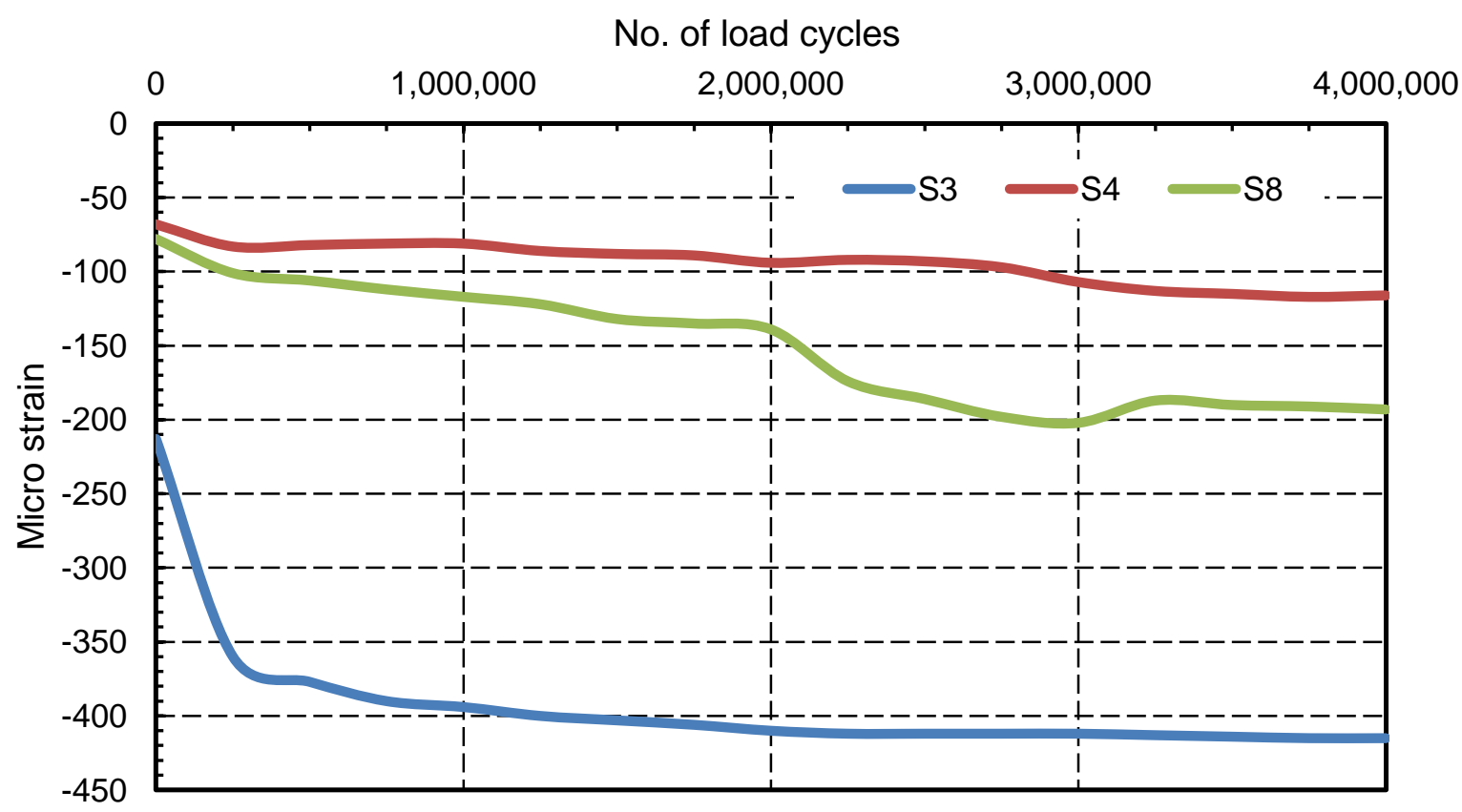

Figure 4.38 Concrete strain versus number of load cycles for CAF loading of the tested slabs $\mathrm{S} 3, \mathrm{~S} 4$ and S8

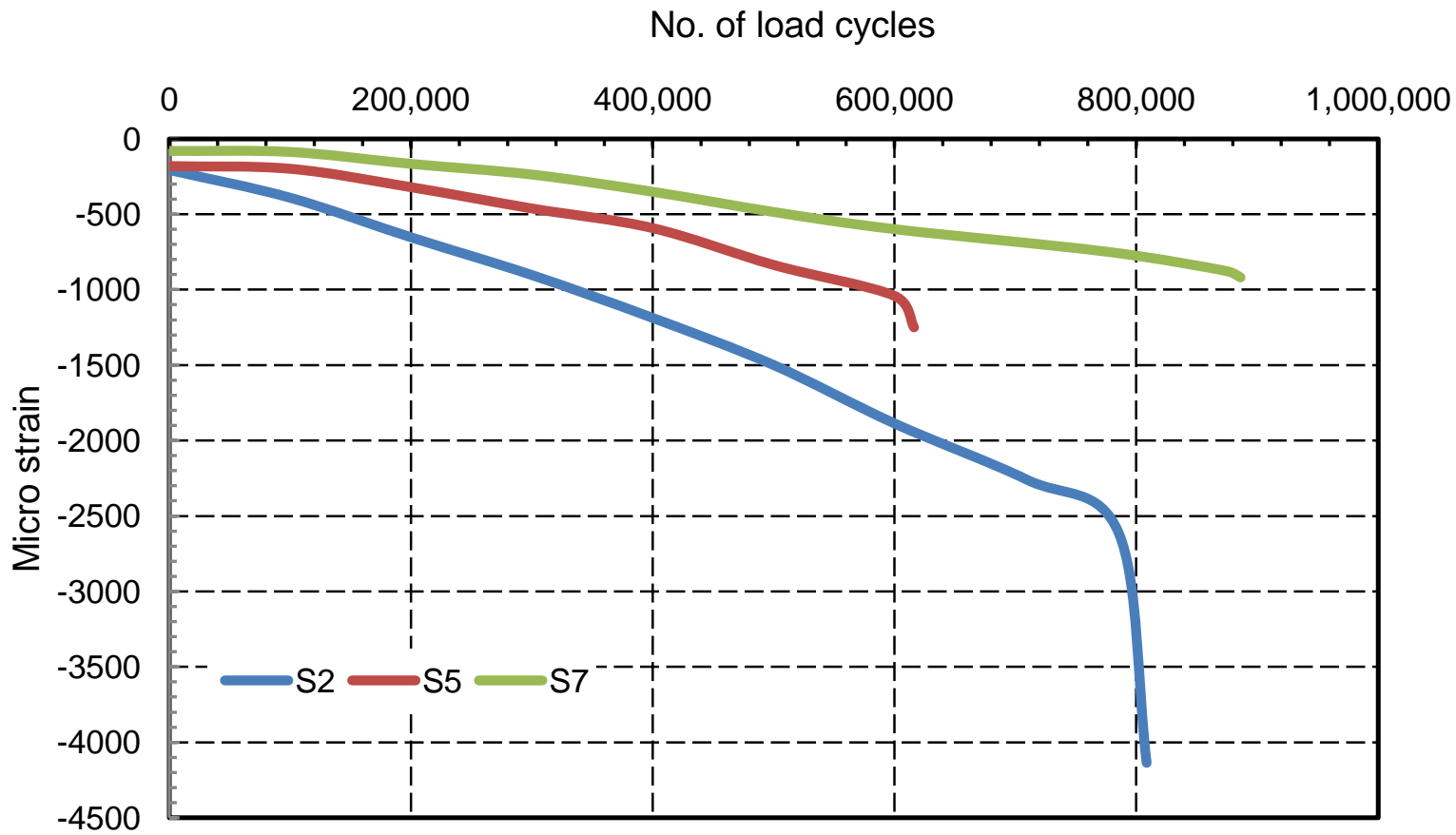

Figure 4.39 Concrete strain versus number of load cycles for VAF loading of the tested slabs S2, S5 and S7 
Figure 4.40 show the maximum measured strains in the bottom transverse GFRP reinforcement versus number of load cycles of CAF tested slabs, S3, S4 and S8, at a fatigue load range of $122.5 \mathrm{kN}$. Similar behaviour as in concrete strain was observed. Sharp increase in the GFRP reinforcement strain up to approximately 250,000 load cycles, followed by the stable cracking phase, in which slight increases in the reinforcement strains were observed. In this phase, fatigue damage accumulated at low rate and the maximum measured strains at the end of this phase for the three deck slabs S3, S4 and S8 were $1141 \mu \varepsilon, 1066 \mu \varepsilon$ and $1329 \mu \varepsilon$, respectively. After completed 4,000,000 load cycles without significant damage, the three deck slabs, S3, S4 and S8 were monotonically loaded to-failure, and the maximum measured reinforcement strains were $11123 \mu \varepsilon, 9560 \mu \varepsilon$ and $7532 \mu \varepsilon$, respectively.

The maximum measured strains in the bottom transverse GFRP reinforcement of cast-in-place deck slab, S1, and precast deck slab, S6, tested under a static load only to failure, were $9242 \mu \varepsilon$ and $6796 \mu \varepsilon$, respectively. In comparing the recorded maximum bottom transverse reinforcement strains at failure in the pre-fatigued slabs to the identical slabs tested under a static load only, the results showed that the maximum measured strain in the GFRP reinforcement at failure in the pre-fatigued slabs, S3 and S8 were about $20 \%$ and $11 \%$ higher than those for similar deck slabs S1 and S6, respectively. For the VAF-tested deck slabs, S2, S5 and S7, after the stage of a fatigue load range of $122.5 \mathrm{kN}$, most of the strain gauges installed on the bottom transverse GFRP reinforcement were damaged due to the internal friction between the concrete and the GFRP bars. Accordingly, no strain data was collected. 


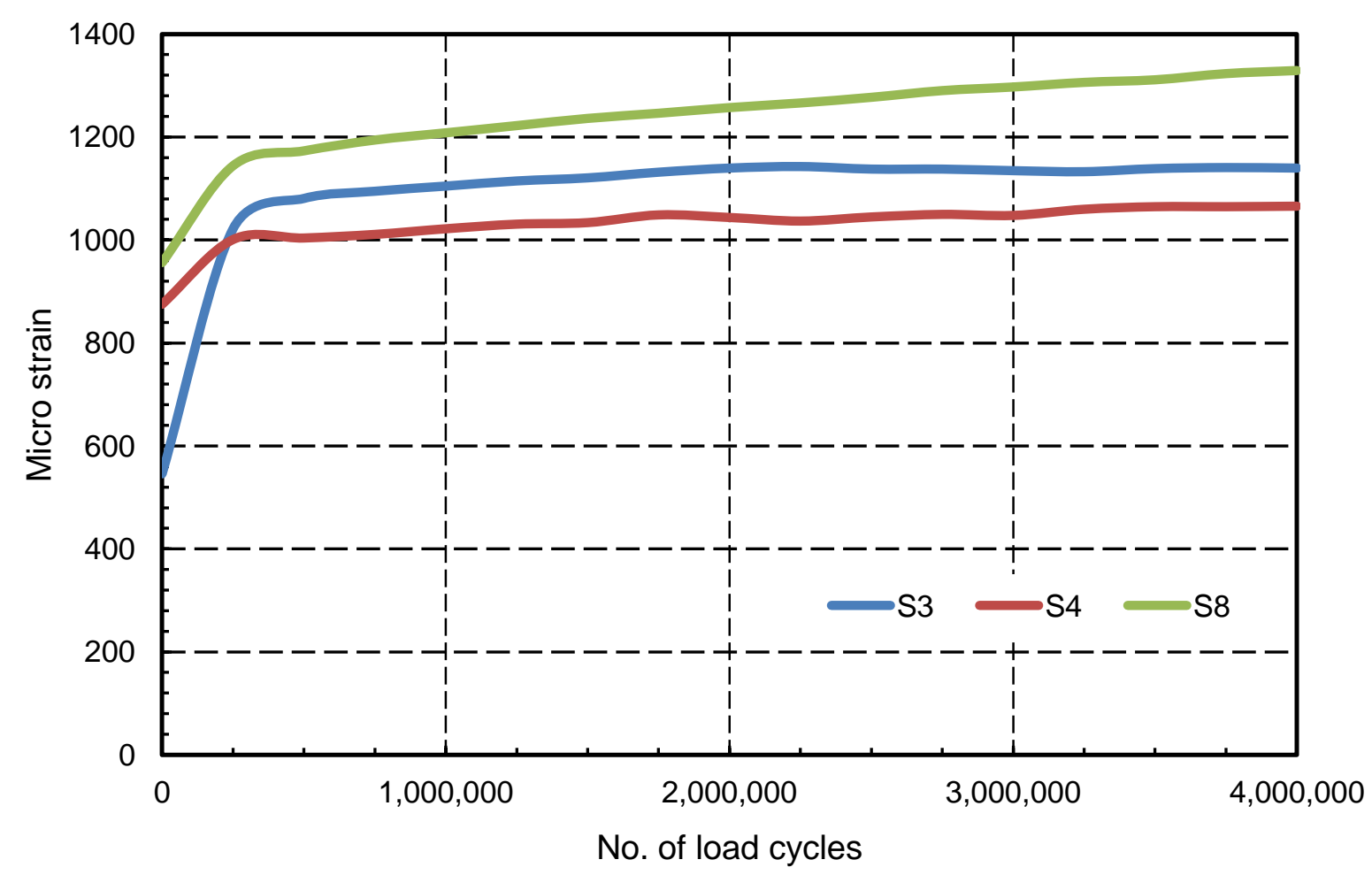

Figure 4.40 Bottom GFRP reinforcement strain versus number of load cycles for CAF loading of the tested slabs S3, S4 and S8

\subsubsection{Ultimate Capacity and Failure Type}

All the deck slabs failed in a punching shear mode at extremely high load capacities ranging from $751 \mathrm{kN}$ to $853 \mathrm{kN}$. Figure 4.41 compares the failure shapes at the undersides of the three cast-in-place deck slabs, S1, S2 and S3. It should be noted that deck slab S1 was tested under monotonic load to failure, deck slab S2 was tested under VAF loading until failure, while deck slab S3 was pre-fatigued up to 4 million load cycles followed by monotonic load to-failure. It is clear from Fig. 4.41 that all cast-in-place slabs failed in the classical punching shear mode. The perimeter of punching shear cracks at the underside of the three deck slabs formed a circle of diameter approximately equal to the clear distance between the top flanges of the steel girders. 


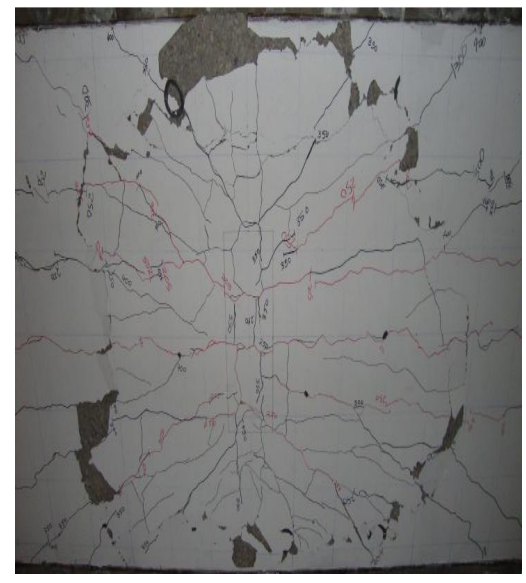

(a) $\mathrm{S} 1$

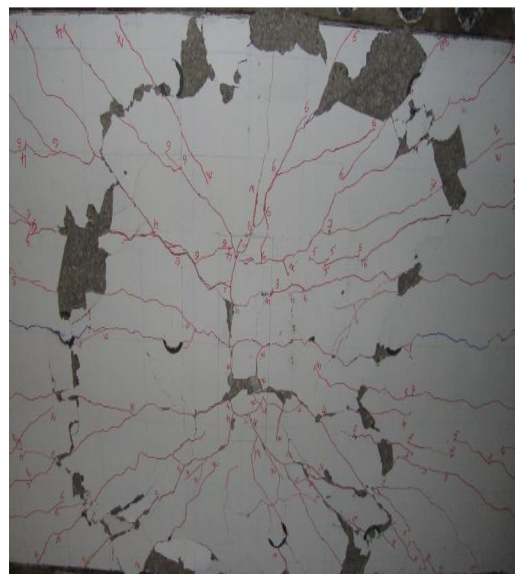

(b) S2

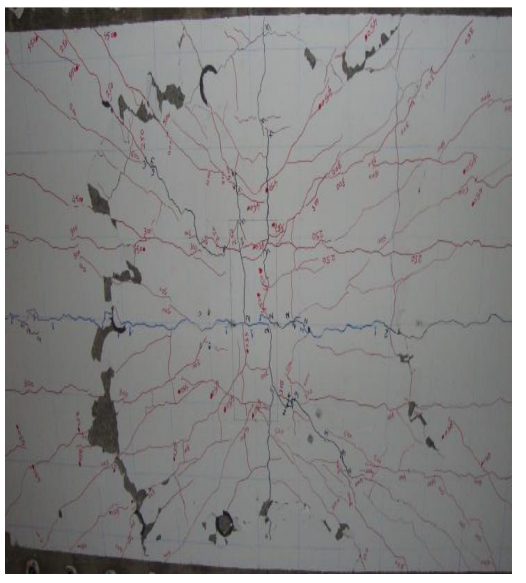

(c) S3

Figure 4.41 Comparison of failure shapes at the underside of the cast-in-place deck slabs

Figures 4.42 and 4.43 compare the failure shapes at the top surface and underside of the precast deck slabs, S4, S5, S6, S7 and S8, respectively. It is clear that the perimeter of punching shear failure did not follow the traditional pattern of being along the perimeter of the $250 \times 600 \mathrm{~mm}$ loaded area and a large circle at the underside of the deck slab. Due to the presence of the stiff UHPC in the closure strip, the punching shear cracks at the top surface deviated to the longitudinal direction of the joint rather than crossing the joint. This made the punching shear perimeter at the bottom of the slab to appear close to the supporting steel girders without being connected across the UHPC-filled joint. Also, it can be observed that in case of variable amplitude fatigue (VAF) loading until failure, more cracks were developed on the top surface of the slab in addition to the falling of concrete from the bottom surface of the slabs compared to the pre-fatigued and monotonically loaded slabs. 

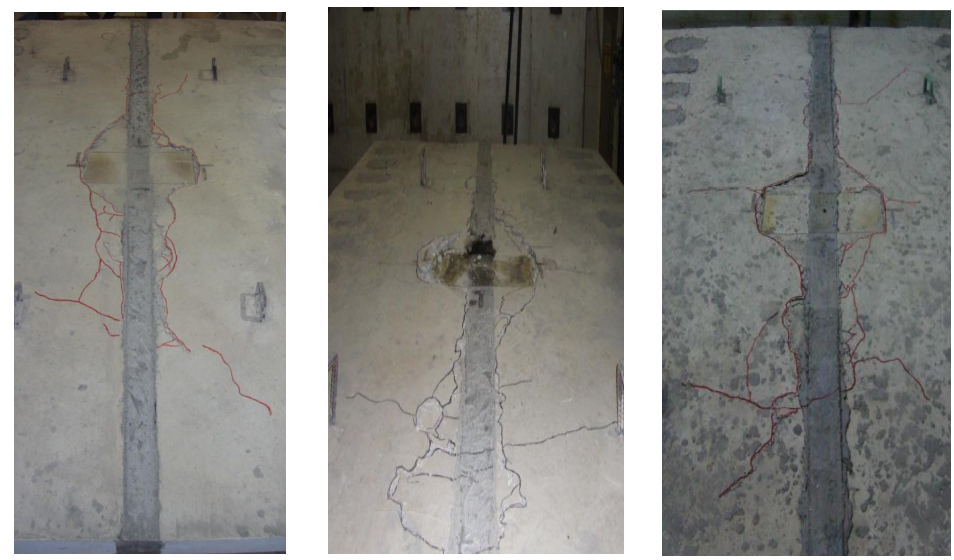

(a) S4

(b) S5

(c) S6
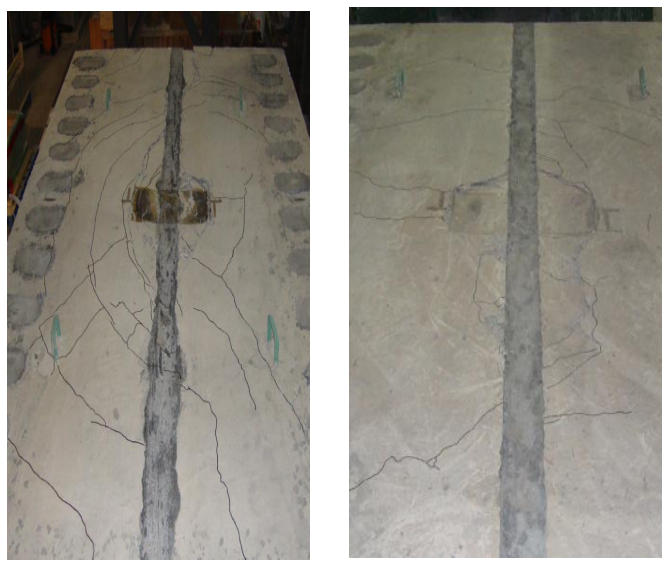

Figure 4.42 Comparison of failure shapes at the top surface of the precast slabs S4 through S8

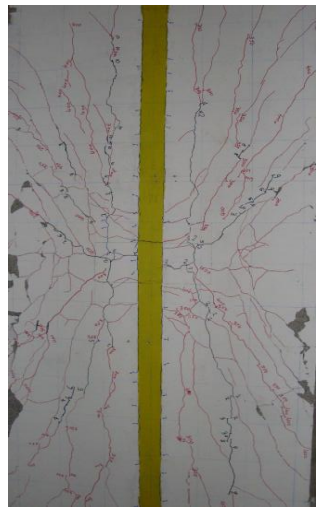

(a) S4

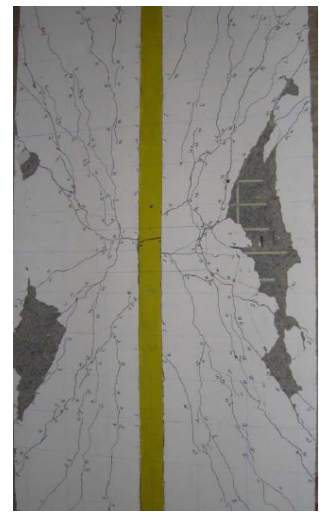

(b) S5

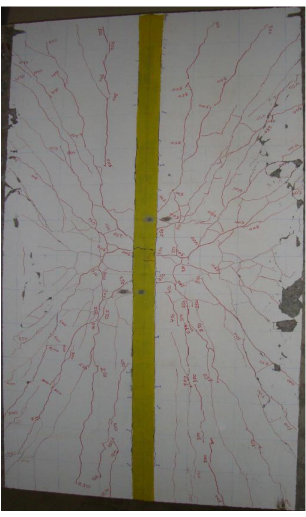

(c) S6

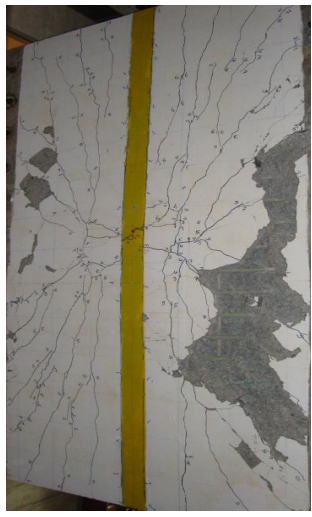

(d) S7

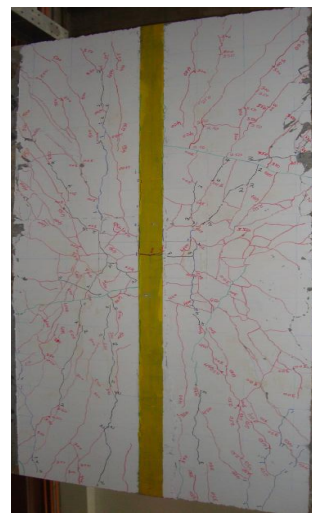

(e) $\mathrm{S} 8$

Figure 4.43 Comparison of failure shapes at the underside of the precast slabs S4 through S8

To determine the punching shear perimeter of the tested deck slabs, all deck slabs were cut into half along the transverse direction, as shown in Fig. 4.44, and then one of the halves was cut into half again along the longitudinal direction as shown in Fig. 4.45. From the saw-cut slabs, the widths of the punched sections at the mid-depth of the slabs were measured and the punching shear perimeter was calculated. The average observed mid-depth punching perimeters for the cast-in-place deck slabs and the precast jointed deck slabs were measured to be $1.25 \mathrm{~d}$ and $1.33 \mathrm{~d}$ 
away from the sides of the loaded area, respectively, which are more than twice the corresponding distance specified in ACI 440.1R-06 and CSA S806-12 for calculating theoretical punching shear perimeter.

\subsubsection{Punching Shear Design Formulas}

The punching shear strengths of the slabs, S1, S3, S4, S6 and S8 were predicted using the punching shear strength equations available in the CSA S806-12 (2012, eq. 2.13b), ACI 440.1R06 (2006), JSCE (1997), Matthy and Taerwe (2000) and El-Gamal et al. (2005). It should be noted that CSA S806-12 standard specifies 3 equations for punching shear of slabs as shown in equations $2.13 \mathrm{a}$ through $2.13 \mathrm{c}$. However, equation $2.13 \mathrm{~b}$ was considered in this study. These equations were discussed in details in chapter II. Table 4.5 presents ratios of experimental to predicted punching shear strength for each of the tested slabs. It should be noted that ratios of 1.0 perfectly predict the test punching shear strength, ratios greater than 1.0 indicate some level of conservativeness (i.e., overdesign), while ratios less than 1.0 indicate that the prediction model underestimates the punching shear strength of the deck slab (i.e., unsafe design). From Table 4.5, it can be observed that all the prediction models are safe to predict the punching shear strength, but with varying degrees of conservativeness and goodness. For example, the equation specified by ACI 440.1R-06 is significantly conservative with an average ratio for $V_{\text {exp }} / V_{\text {pred }}$ of 2.25, while the equation specified by the JSCE (1997) and Matthy and Taerwe equations yielded good, yet conservative, prediction with average $V_{\text {exp }} / V_{\text {pred }}$ of 1.37 and 1.5 , respectively. Furthermore, the equation available in CSA S806-12 (2012) and El-Gamal et al. (2005) showed very good agreement with the experimental results with average ratio $\mathrm{V}_{\text {exp }} / \mathrm{V}_{\text {pred }}$ of 1.05 and 1.16, respectively. As a conclusion, the equation available in CSA S806-12 (2012) and El-Gamal 
et al. (2005) can accurately predict the punching shear strength of the cast-in-place slabs as well as precast jointed bridge deck slabs reinforced with GFRP bars.
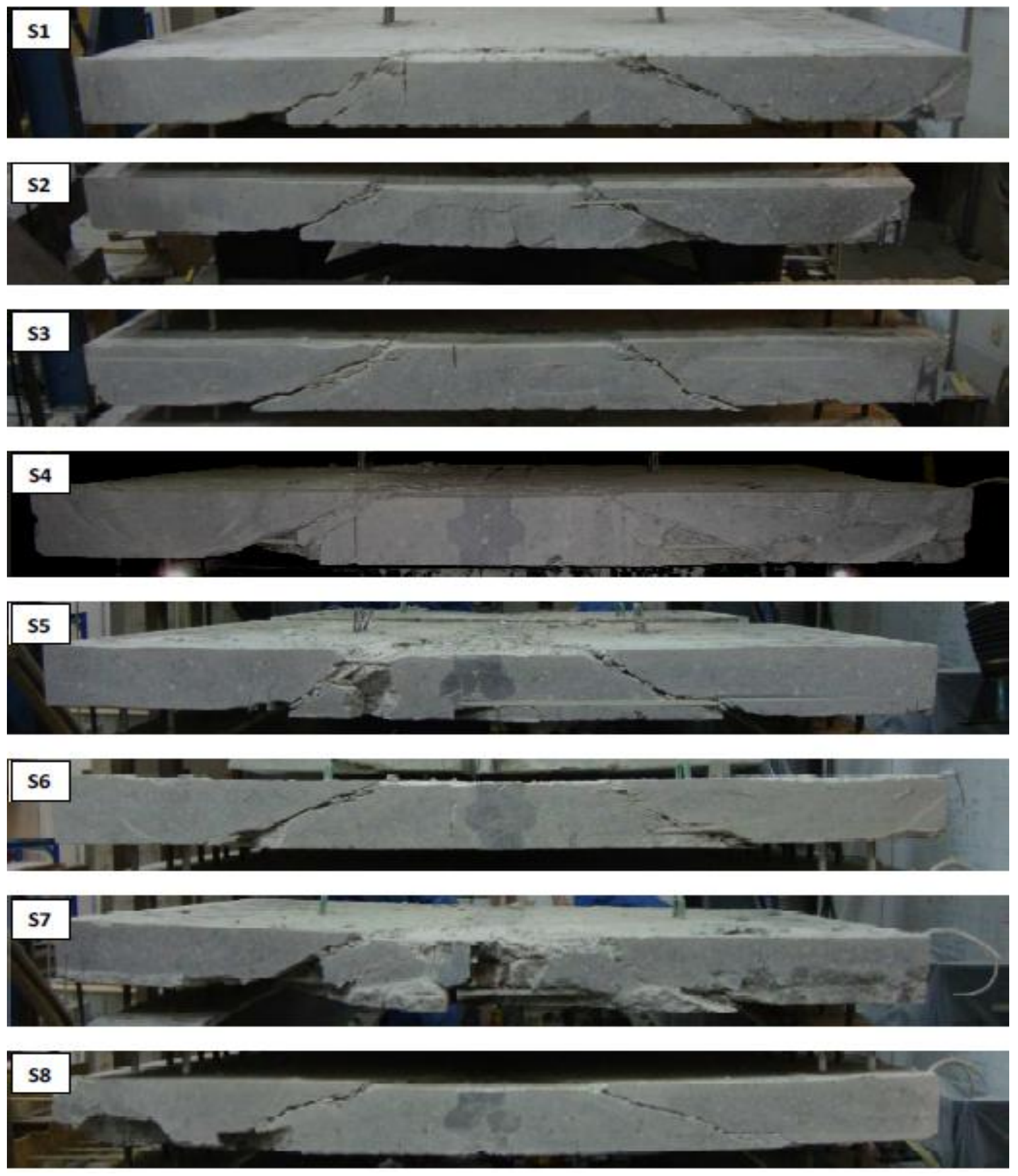

Figure 4.44 Views of saw-cut slab segments after punching shear failure for all deck slabs S1 through S8 (transverse direction) 


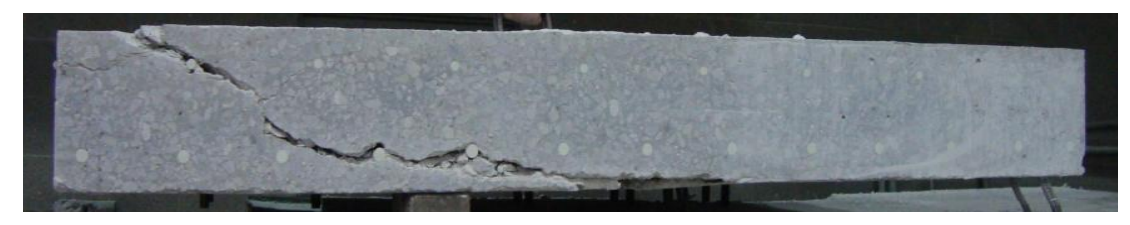

(a) $\mathrm{S} 1$

(b) S2

Figure 4.45 Views of saw-cut slab segments after punching shear failure for deck slabs, S1 and S2 (longitudinal direction)

Table 4.5 Correlation between the punching shear strength of the tested slabs obtained experimentally and from available equations

in the literature

\begin{tabular}{|c|c|c|c|c|c|c|c|c|c|c|c|c|}
\hline \multirow[b]{2}{*}{ Slab } & \multirow[b]{2}{*}{ Slab type } & \multirow[b]{2}{*}{$\begin{array}{c}\text { Loaded } \\
\text { area } \\
(\mathrm{mm})\end{array}$} & \multirow[b]{2}{*}{$\begin{array}{c}d \\
(\mathrm{~mm})\end{array}$} & \multirow[b]{2}{*}{$\begin{array}{c}f_{c}^{\prime} \\
(\mathrm{MPa})\end{array}$} & \multirow[b]{2}{*}{$\begin{array}{c}\rho_{f} \\
(\%)\end{array}$} & \multirow[b]{2}{*}{$\begin{array}{c}E_{f} \\
(\mathrm{GPa})\end{array}$} & \multirow[b]{2}{*}{$\begin{array}{l}V_{\text {exp }} \\
(\mathrm{kN})\end{array}$} & \multicolumn{5}{|c|}{$V_{\text {exp }} / V_{\text {pred }}$} \\
\hline & & & & & & & & $\begin{array}{c}\text { CSA } \\
\text { S806-12 }\end{array}$ & $\begin{array}{c}\text { ACI } \\
440.1 \mathrm{R}-06\end{array}$ & $\begin{array}{c}\text { JSCE } \\
(1997)\end{array}$ & $\begin{array}{c}\text { Matthy \& } \\
\text { Taerwe } \\
(2000)\end{array}$ & $\begin{array}{c}\text { El-Gamal } \\
\text { et al. } \\
(2005)\end{array}$ \\
\hline $\mathrm{S} 1$ & \multirow{2}{*}{$\begin{array}{l}\text { Cast-in- } \\
\text { place }\end{array}$} & \multirow{5}{*}{$250 \times 600$} & \multirow{5}{*}{154} & 55.48 & \multirow{5}{*}{0.93} & 64 & 751.40 & 0.98 & 2.10 & 1.29 & 1.40 & 1.07 \\
\hline S3 & & & & 56.19 & & 64 & 803.39 & 1.04 & 2.22 & 1.38 & 1.49 & 1.14 \\
\hline S4 & \multirow{3}{*}{$\begin{array}{l}\text { Precast with } \\
125 \mathrm{~mm} \\
\text { closure strip } \\
\text { filled with } \\
\text { UHPC }^{*}\end{array}$} & & & 53.78 & & 64 & 758.51 & 1.00 & 2.13 & 1.30 & 1.43 & 1.10 \\
\hline S6 & & & & 58.75 & & 62.5 & 853.26 & 1.10 & 2.36 & 1.48 & 1.57 & 1.19 \\
\hline S8 & & & & 44.02 & & 62.5 & 801.58 & 1.14 & 2.44 & 1.39 & 1.62 & 1.29 \\
\hline Aver: & & & & & & & & 1.05 & 2.25 & 1.37 & 1.50 & 1.16 \\
\hline
\end{tabular}

UHPC $^{*}=$ ultra-high-performance concrete 


\subsubsection{Life Estimation of Fatigue of GFRP-Reinforced Concrete Deck Slabs}

As bridge deck slabs are the part of bridge most prone to repeated moving wheel loads, the design of concrete deck slabs is governed by long-term fatigue endurance and durability of constituent materials. A few researchers conducted experiments on bridge deck slabs to examine their fatigue and ultimate load carrying capacity under wheel loads (among them: Sonoda and Horikawa, 1982; Pardikaris and Beim, 1988; Mufti et al, 1993; Matsui et al., 2001; Graddy et al, 2002; Mufti et al., 2002). Most of the studies on the fatigue of concrete deck slabs have been directed to correlate the applied fatigue stress and the fatigue life of concrete. This relationship is shown by the so-called S-N curves (stress, $\mathrm{S}$, versus number of cycles, $\mathrm{N}$ ) or Wohler curves. The S-N curves enable the designer to predict the mean fatigue life of concrete under given constantamplitude cyclic stress (Oh 1986). S-N curves could be used for constant amplitude stress histories only. However in reality, bridge decks are seldom subjected to constant amplitude loading during their service life, rather, they are subjected to random loading. To take into account the different loading amplitudes, an equivalent constant amplitude load range and a damage accumulation rule may be used (Sonoda and Horikawa, 1982; Matsui et al., 2001; Mufti et al., 2002; El-Ragaby et al., 2007).

Different mathematical models were proposed specifically for estimating the fatigue life of concrete deck slabs. These equations are summarized as follows:

Batchelor and Hewitt (1974): $\left(P / P_{u}\right)=1.0-0.102 \log (N)+0.006(\log (N))^{2}$

Youn and Chang (1998): $\log \left(P / P_{u}\right)=-0.0066 \log (N)+\log (1.4461)$

Matsui et al. (2001): $\log \left(P / P_{u}\right)=\log (1.52)-0.7835 \log (N)$

Mufti et al. (2002): $\left(P / P_{u}\right)=1.0-\frac{\ln (N)}{30}$ 
Memon (2005): $\log (N)=5.737 \sqrt{\left(\frac{1-R}{R}\right)}$

El-Ragaby et al (2007): $\left(P / P_{u}\right)=0.0034(\log (N))^{2}-0.1187 \log (N)+1.0752$

where $P$ is the applied load, $P_{u}$ is the ultimate static load, $R=P / P_{u}$ and $N$ is the load cycles until failure.

Fatigue damage cumulative rules can be classified as linear damage cumulative rule if the damage evaluation rule is the same for all stress level and loading histories, and as nonlinear damage cumulative rule if the damage evaluation rule is variable according to the stress levels or loading histories. One of the most widely used methods in analyzing cumulative fatigue damage is the linear damage rule developed by Miner (1945), also called Palmgren-Miner rule or (Miner's rule). Miner's rule is probably the simplest cumulative damage model. It states that if a structure experiences damages $D_{i}(i=1, \ldots, k)$ from $\mathrm{k}$ different fatigue load levels, then failure might be expected to occur if:

$$
\sum_{i=1}^{k} \frac{D_{i}}{D}=1
$$

where $\frac{D_{i}}{D}$ is the fractional damage accumulated received from the $i$ th fatigue load level and D is the total damage. This rule can be used to estimate fatigue life damage for bridge deck slab subjected to variable amplitude fatigue loading. In this case one may consider a bridge deck slab subjected to $n_{1}$ cycles at stress level $\sigma_{1}, n_{2}$ cycles at stress level $\sigma_{2}, \ldots, n_{k}$ cycles at $\sigma_{k}$, and the expected number of cycles to failure, $N_{1}$, at $\sigma_{1}, N_{2}$, at $\sigma_{2}, \ldots, N_{k}$, at $\sigma_{k}$. According to PalmgrenMiner rule, the fractional damage at stress level $\sigma_{i}$ will be $n_{i} / N_{i}$, and failure occurs when:

$$
D=\sum_{i=1}^{k} \frac{n_{i}}{N_{i}}=1
$$


According to Mufti et al. (2002), for two different wheel loads $P_{1}$ and $P_{2} ; n_{1}$ and $n_{2}$ are the corresponding number of passes of $P_{1}$ and $P_{2}$, respectively, so that the two loads have the same damaging effect; $N_{1}$ and $N_{2}$ are the limiting number of passes corresponding to $P_{1}$ and $P_{2}$, respectively. Then, the following relation was found to be valid:

$$
\frac{n_{1}}{n_{2}}=\frac{N_{1}}{N_{2}}
$$

Based on this concept, Mufti et al. (2002), Eq. (4.4) can be rewritten as:

$\frac{N_{2}}{N_{1}}=\frac{n_{2}}{n_{1}}=\frac{e^{30\left(1.0-R_{2}\right)}}{e^{30\left(1.0-R_{1}\right)}}$

where $R_{1}=P_{1} / P_{u}, R_{2}=P_{2} / P_{u}$ and the equivalent number of cycles at two different load levels $P_{1}$ and $P_{2}$ to produce same fatigue damage, is given by:

$$
n_{2}=n_{1} \times e^{30\left(R_{1}-R_{2}\right)}
$$

\subsubsection{Prediction of Fatigue Life of the Tested GFRP-Reinforced Deck Slabs}

The intent of this research was to develop P-N curves that can predict the fatigue life of cast-inplace bridge deck slabs as well as precast bridge deck slabs reinforced with GFRP bars. Three of the previously-mentioned fatigue life models were selected to predict the fatigue life of the GFRP-reinforced cast-in-place and precast bridge deck slabs tested in this research. The three selected fatigue life models were Matsui et al. model, Mufti et al. model and Memon model. It should be noted that the three models were based on the results of testing full-scale bridge deck slabs similar to those tested in this study. In addition, Matsui et al. were the only researchers who have provided a P-N relationship based on rolling wheel tests on full-scale models of both 
reinforced concrete and reinforcement-free deck slabs (Mufti et al. 2002). Similar to equation (4.11), the equivalent number of cycles at two different loads $P_{1}$ and $P_{2}$ to produce same fatigue damage, using Matsui et al. and Memon fatigue life models can be given as follows:

Matsui et al. model:

$$
n_{2}=n_{1} \times 10^{12.7632 \log P_{1} / P_{2}}
$$

Memon model:

$$
n_{2}=n_{1} \times 10^{5.737}\left[\sqrt{\frac{1-R_{2}}{R_{2}}}-\sqrt{\frac{1-R_{1}}{R_{1}}}\right]
$$

The cast-in-place deck slab S2 was tested under variable amplitude fatigue (VAF) loading to failure and the total number of cycles until failure was 808,651 cycles. Using Matsui et al. model equation (4.12), this number of load cycles was converted to an equivalent number of cycles to failure at constant amplitude single peak load. For example, at VAF loading steps, the total number of cycles until failure for slab S2, that was 808,651 cycles, is equivalent to 165,122 load cycles at constant amplitude fatigue (CAF) loading of $490 \mathrm{kN}$ peak load. Table 4.6 shows the equivalent number of cycles to failure at constant amplitude fatigue loading of deck slab S2, based on Matsui et al. model (2001). Similarly, the equivalent number of cycles to failure at constant amplitude fatigue loading for deck slabs S5 and S7 were calculated.

Figure 4.46 shows graphical representation of the equivalent number of load cycles to failure at constant amplitude peak load for slabs S2, S5 and S7, based on Eqs. (4.3) and (4.12). From Fig. 4.46, it can be seen that Matsui et al. model accurately predicts the fatigue life of precast concrete bridge deck slabs, S5 and S7 reinforced with GFRP bars, but slightly underestimate the 
fatigue life of cast-in-place deck slab, S2. Also, Matsui et al. prediction model yields $P / P_{u}$ greater than 1.0 for $\mathrm{N}$ smaller than about 1000 cycles, for example, for $\mathrm{N}=1$ (static failure), Matsui et al. model gives $P / P_{u}=1.52$ with $52 \%$ error. Matsui confirmed that his model is valid only for $\mathrm{N}$ greater than 10,000 .

Mufti et al. and Memon models were also used to predict the fatigue life of the concrete bridge deck slabs reinforced with GFRP bars investigated in this study. Table 4.7 shows the equivalent number of cycles to failure at constant amplitude fatigue loading of deck slab S2, based on Mufti et al. model, while Figure 4.47 shows graphical representation of the equivalent number of load cycles to failure at constant amplitude peak load for slabs S2, S5 and S7, based on Eqs. (4.4) and (4.11). Results show that Mufti et al. model well predicts the fatigue life of the precast concrete bridge deck slabs, S5 and S7 reinforced with GFRP bars, but slightly underestimates the fatigue life of the cast-in-place deck slab, S2. In addition, for static failure $N=1$, Mufti et al. model yields $P / P_{u}=1.0$.

Table 4.8 shows the equivalent number of cycles to-failure at constant amplitude fatigue loading of deck slab S2, according to Memon model, while Figure 4.48 shows graphical representation of the equivalent number of load cycles to failure at constant amplitude peak load for slabs S2, S5 and S7, based on Eqs. (4.5) and (4.13). As can be noticed in Fig. 4.48, Memon model underestimates the fatigue life for both GFRP-reinforced cast-in-place deck slab, S2 and precast deck slabs, S5 and S7. 
Table 4.6 Equivalent number of cycles to failure at constant amplitude fatigue loading for deck slab S2 according to Matsui et al. (2001)

\begin{tabular}{ccccccccc}
\hline \hline \multirow{2}{*}{$\begin{array}{c}\text { Test } \\
\text { loads } \\
(\mathrm{kN})\end{array}$} & $\begin{array}{c}\text { No of } \\
\text { test } \\
\text { cycles }\end{array}$ & 122.5 & 183.75 & 245 & 306.25 & 367.5 & 428.75 & 490 \\
\cline { 3 - 9 } & & & & \multicolumn{7}{c}{ Equivalent number of cycles } \\
\hline \hline 122.5 & 100,000 & $1.00 \mathrm{E}+05$ & $5.66 \mathrm{E}+02$ & $1.44 \mathrm{E}+01$ & $1.00 \mathrm{E}+00$ & - & - & - \\
\hline 183.75 & 100,000 & $1.77 \mathrm{E}+07$ & $1.00 \mathrm{E}+05$ & $2.54 \mathrm{E}+03$ & $1.47 \mathrm{E}+02$ & $1.44 \mathrm{E}+01$ & $2.01 \mathrm{E}+00$ & - \\
\hline 245 & 100,000 & $6.95 \mathrm{E}+08$ & $3.93 \mathrm{E}+06$ & $1.00 \mathrm{E}+05$ & $5.80 \mathrm{E}+03$ & $5.66 \mathrm{E}+02$ & $7.91 \mathrm{E}+01$ & $1.44 \mathrm{E}+01$ \\
\hline 306.25 & 100,000 & $1.20 \mathrm{E}+10$ & $6.78 \mathrm{E}+07$ & $1.73 \mathrm{E}+06$ & $1.00 \mathrm{E}+05$ & $9.76 \mathrm{E}+03$ & $1.36 \mathrm{E}+03$ & $2.48 \mathrm{E}+02$ \\
\hline 367.5 & 100,000 & $1.23 \mathrm{E}+11$ & $6.95 \mathrm{E}+08$ & $1.77 \mathrm{E}+07$ & $1.02 \mathrm{E}+06$ & $1.00 \mathrm{E}+05$ & $1.40 \mathrm{E}+04$ & $2.54 \mathrm{E}+03$ \\
\hline 428.75 & 100,000 & $8.79 \mathrm{E}+11$ & $4.97 \mathrm{E}+09$ & $1.26 \mathrm{E}+08$ & $7.33 \mathrm{E}+06$ & $7.15 \mathrm{E}+05$ & $1.00 \mathrm{E}+05$ & $1.82 \mathrm{E}+04$ \\
\hline 476 & 208,651 & $6.97 \mathrm{E}+12$ & $3.94 \mathrm{E}+10$ & $1.00 \mathrm{E}+09$ & $5.81 \mathrm{E}+07$ & $5.67 \mathrm{E}+06$ & $7.92 \mathrm{E}+05$ & $1.44 \mathrm{E}+05$ \\
\hline Total & 808,651 & $7.98 \mathrm{E}+12$ & $4.51 \mathrm{E}+10$ & $1.15 \mathrm{E}+09$ & $6.65 \mathrm{E}+07$ & $6.49 \mathrm{E}+06$ & $9.08 \mathrm{E}+05$ & $1.65 \mathrm{E}+05$ \\
\hline \hline
\end{tabular}

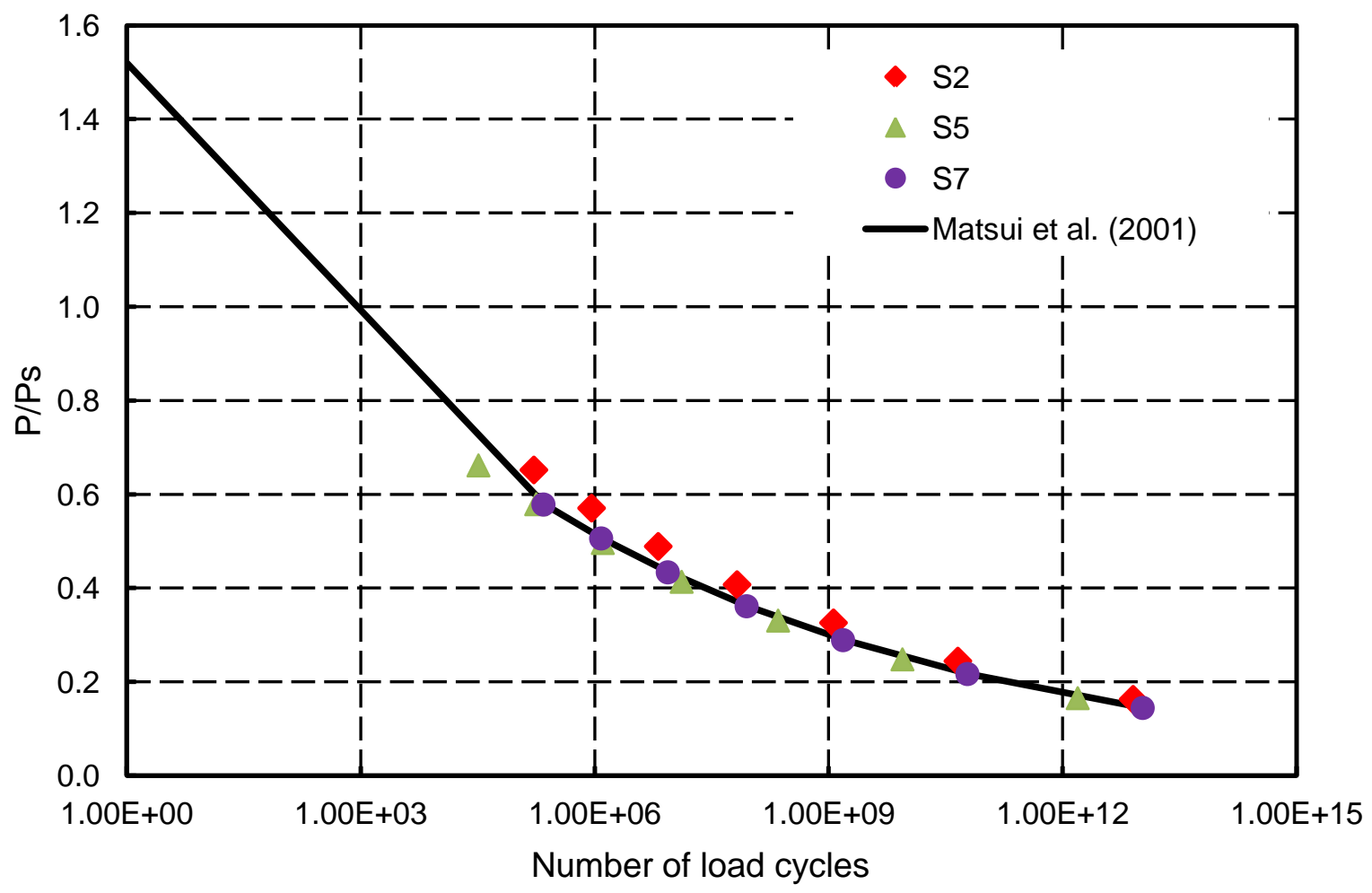

Figure 4.46 Equivalent number of load cycles to failure at constant amplitude fatigue loading based on the fatigue prediction model by Matsui et al. (2001) 
Table 4.7 Equivalent number of cycles to failure at constant amplitude fatigue loading for deck slab S2 according to Mufti et al. (2002)

\begin{tabular}{ccccccccc}
\hline \hline \multirow{2}{*}{$\begin{array}{c}\text { Test } \\
\text { loads } \\
(\mathrm{kN})\end{array}$} & $\begin{array}{c}\text { No of } \\
\text { test } \\
\text { cycles }\end{array}$ & 122.5 & 183.75 & 245 & 306.25 & 367.5 & 428.75 & 490 \\
\cline { 3 - 9 } & & \multicolumn{7}{c}{ Constant amplitude peak loads $(\mathrm{kN})$} \\
\hline \hline 122.5 & 100,000 & $1.00 \mathrm{E}+05$ & $8.67 \mathrm{E}+03$ & $7.51 \mathrm{E}+02$ & $6.51 \mathrm{E}+01$ & $5.65 \mathrm{E}+00$ & - & - \\
\hline 183.75 & 100,000 & $1.15 \mathrm{E}+06$ & $1.00 \mathrm{E}+05$ & $8.67 \mathrm{E}+03$ & $7.51 \mathrm{E}+02$ & $6.51 \mathrm{E}+01$ & $5.65 \mathrm{E}+00$ & - \\
\hline 245 & 100,000 & $1.33 \mathrm{E}+07$ & $1.15 \mathrm{E}+06$ & $1.00 \mathrm{E}+05$ & $8.67 \mathrm{E}+03$ & $7.51 \mathrm{E}+02$ & $6.51 \mathrm{E}+01$ & $5.65 \mathrm{E}+00$ \\
\hline 306.25 & 100,000 & $1.54 \mathrm{E}+08$ & $1.33 \mathrm{E}+07$ & $1.15 \mathrm{E}+06$ & $1.00 \mathrm{E}+05$ & $8.67 \mathrm{E}+03$ & $7.51 \mathrm{E}+02$ & $6.51 \mathrm{E}+01$ \\
\hline 367.5 & 100,000 & $1.77 \mathrm{E}+09$ & $1.54 \mathrm{E}+08$ & $1.33 \mathrm{E}+07$ & $1.15 \mathrm{E}+06$ & $1.00 \mathrm{E}+05$ & $8.67 \mathrm{E}+03$ & $7.51 \mathrm{E}+02$ \\
\hline 428.75 & 100,000 & $2.04 \mathrm{E}+10$ & $1.77 \mathrm{E}+09$ & $1.54 \mathrm{E}+08$ & $1.33 \mathrm{E}+07$ & $1.15 \mathrm{E}+06$ & $1.00 \mathrm{E}+05$ & $8.67 \mathrm{E}+03$ \\
\hline 476 & 208,651 & $2.81 \mathrm{E}+11$ & $2.44 \mathrm{E}+10$ & $2.11 \mathrm{E}+09$ & $1.83 \mathrm{E}+08$ & $1.59 \mathrm{E}+07$ & $1.38 \mathrm{E}+06$ & $1.19 \mathrm{E}+05$ \\
\hline Total & 808,651 & $3.03 \mathrm{E}+11$ & $2.63 \mathrm{E}+10$ & $2.28 \mathrm{E}+09$ & $1.98 \mathrm{E}+08$ & $1.71 \mathrm{E}+07$ & $1.49 \mathrm{E}+06$ & $1.29 \mathrm{E}+05$ \\
\hline \hline
\end{tabular}

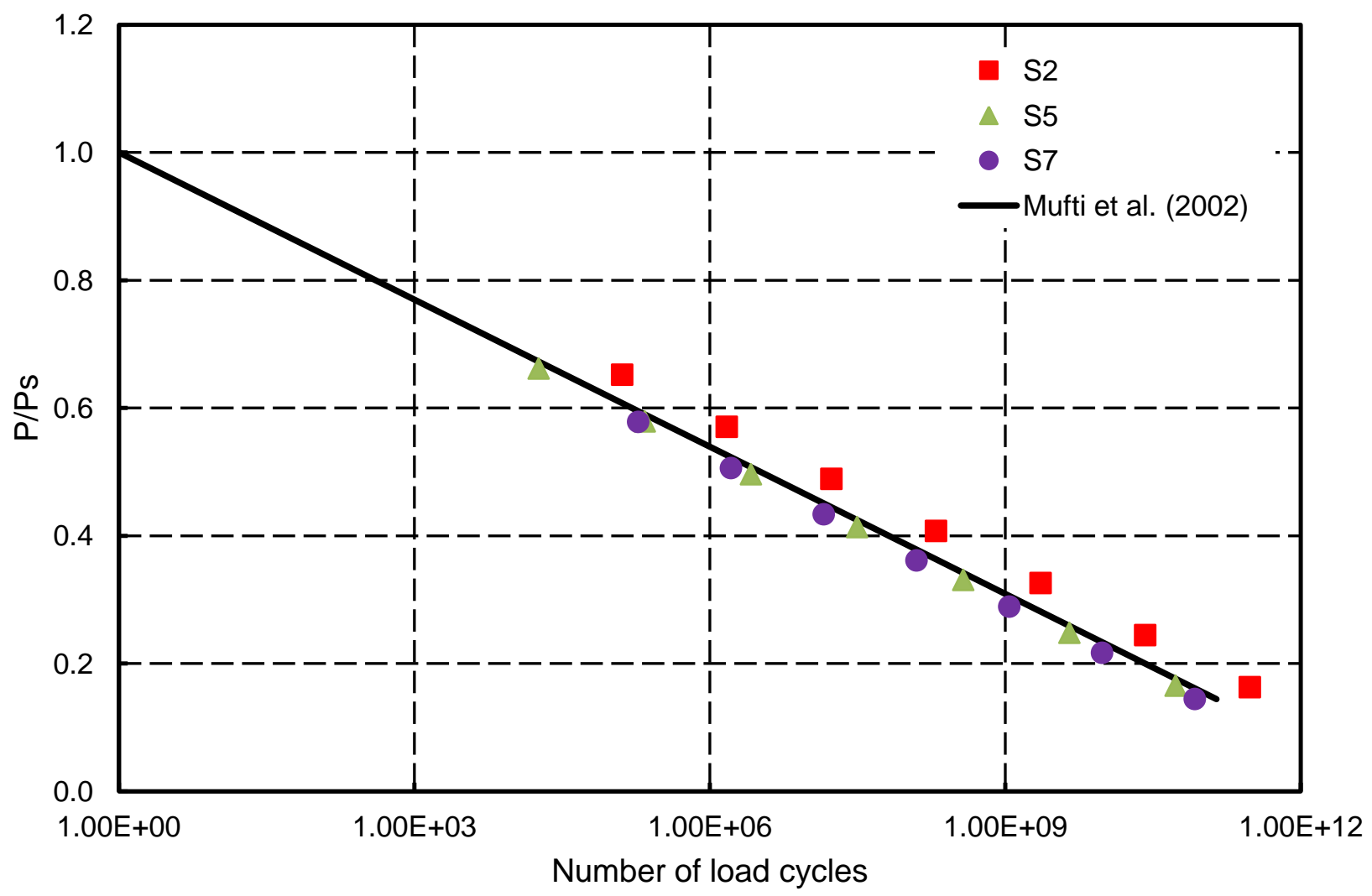

Figure 4.47 Equivalent number of load cycles to failure at constant amplitude fatigue loading based on the fatigue prediction model by Mufti et al. (2002) 
Table 4.8 Equivalent number of cycles to failure at constant amplitude fatigue loading for deck slab S2 according to Memon (2005)

\begin{tabular}{|c|c|c|c|c|c|c|c|c|}
\hline \multirow{3}{*}{$\begin{array}{c}\text { Test } \\
\text { loads } \\
(\mathrm{kN})\end{array}$} & \multirow{3}{*}{$\begin{array}{c}\text { No of } \\
\text { test } \\
\text { cycles }\end{array}$} & \multicolumn{7}{|c|}{ Constant amplitude peak loads $(\mathrm{kN})$} \\
\hline & & 122.5 & 183.75 & 245 & 306.25 & 367.5 & 428.75 & 490 \\
\hline & & \multicolumn{7}{|c|}{ Equivalent number of cycles } \\
\hline 122.5 & 100,000 & $1.00 \mathrm{E}+05$ & $1.21 \mathrm{E}+02$ & $1.77 \mathrm{E}+00$ & - & - & - & - \\
\hline 183.75 & 100,000 & $8.23 \mathrm{E}+07$ & $1.00 \mathrm{E}+05$ & $1.46 \mathrm{E}+03$ & $6.81 \mathrm{E}+01$ & $6.03 \mathrm{E}+00$ & $1.00 \mathrm{E}+00$ & - \\
\hline 245 & 100,000 & $5.64 \mathrm{E}+09$ & $6.85 \mathrm{E}+06$ & $1.00 \mathrm{E}+05$ & $4.66 \mathrm{E}+03$ & $4.13 \mathrm{E}+02$ & $5.36 \mathrm{E}+01$ & $8.75 \mathrm{E}+00$ \\
\hline 306.25 & 100,000 & $1.21 \mathrm{E}+11$ & $1.47 \mathrm{E}+08$ & $2.14 \mathrm{E}+06$ & $1.00 \mathrm{E}+05$ & $8.85 \mathrm{E}+03$ & $1.15 \mathrm{E}+03$ & $1.88 \mathrm{E}+02$ \\
\hline 367.5 & 100,000 & $1.37 \mathrm{E}+12$ & $1.66 \mathrm{E}+09$ & $2.42 \mathrm{E}+07$ & $1.13 \mathrm{E}+06$ & $1.00 \mathrm{E}+05$ & $1.30 \mathrm{E}+04$ & $2.12 \mathrm{E}+03$ \\
\hline 428.75 & 100,000 & $1.05 \mathrm{E}+13$ & $1.28 \mathrm{E}+10$ & $1.87 \mathrm{E}+08$ & $8.71 \mathrm{E}+06$ & $7.71 \mathrm{E}+05$ & $1.00 \mathrm{E}+05$ & $1.63 \mathrm{E}+04$ \\
\hline 476 & 208,651 & $9.01 \mathrm{E}+13$ & $1.09 \mathrm{E}+11$ & $1.60 \mathrm{E}+09$ & $7.45 \mathrm{E}+07$ & $6.60 \mathrm{E}+06$ & $8.56 \mathrm{E}+05$ & $1.40 \mathrm{E}+05$ \\
\hline Total & 808,651 & $1.02 \mathrm{E}+14$ & $1.24 \mathrm{E}+11$ & $1.81 \mathrm{E}+09$ & $8.45 \mathrm{E}+07$ & $7.48 \mathrm{E}+06$ & $9.70 \mathrm{E}+05$ & $1.59 \mathrm{E}+05$ \\
\hline
\end{tabular}

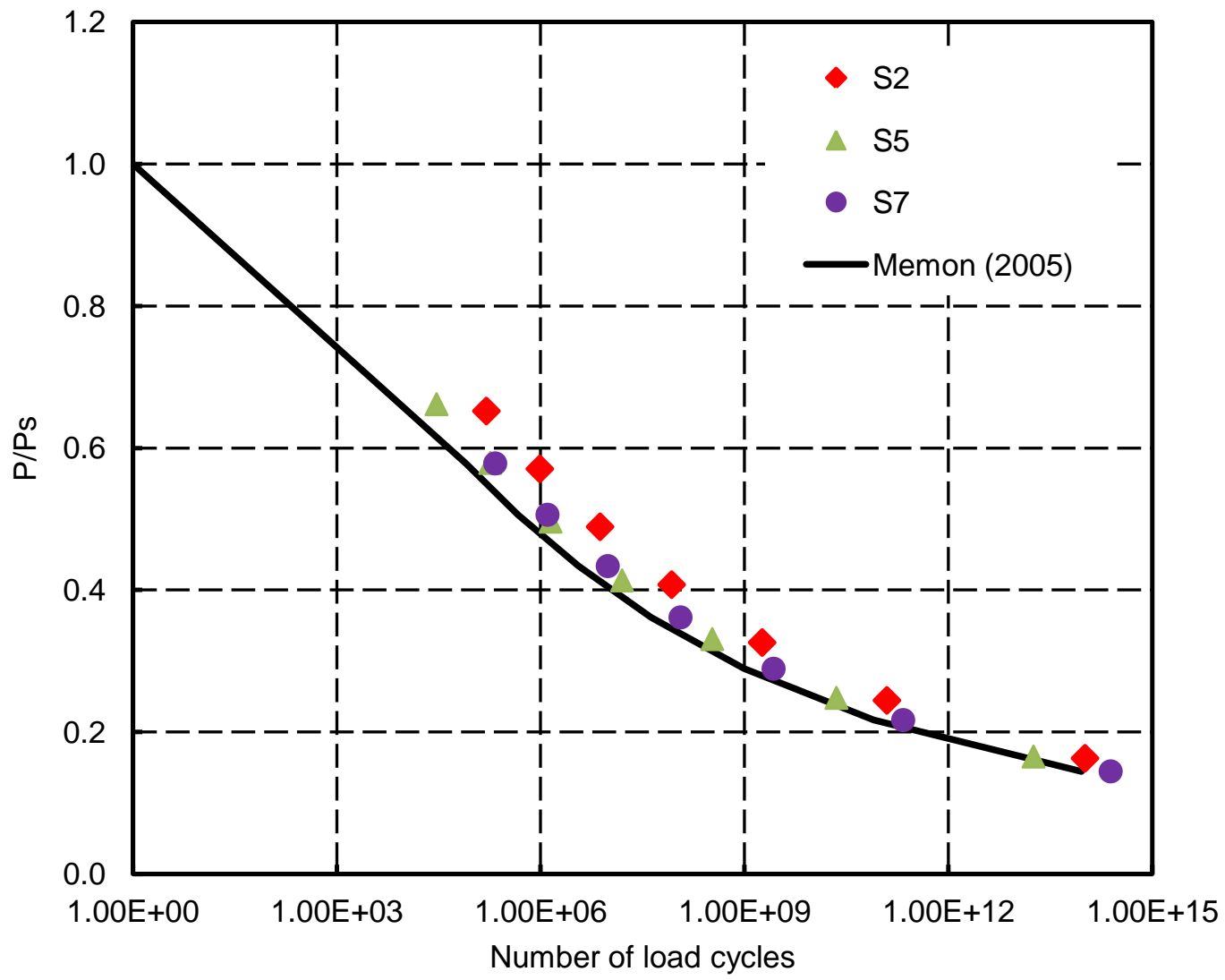

Figure 4.48 Equivalent number of load cycles to failure at constant amplitude fatigue loading based on the fatigue prediction model by Memon (2005) 
The fatigue life model is considered accurately predicting the number of cycles at failure for GFRP-reinforced bridge deck slab if the points representing the equivalent number of cycles were plotted directly on the curve of the model used in the analysis. It is obvious from Figs. 4.46, 4.47 and 4.48 that none of the investigated models accurately predicted the fatigue life of GFRPreinforced bridge deck slabs. However, Matsui et al. and Mufti et al. models fairly predicted the fatigue life for the precast deck slabs, S5 and S7, but slightly underestimated the fatigue life for the cast-in-place deck slab, S2. Mufti et al. model represents a refinement for Matsui et al. model and this model yields the correct results for $\mathrm{N}=1$ ( static failure). In addition, for $\mathrm{N}$ greater than 10,000, Mufti et al. model gives nearly the same results as Matsui et al. model. Accordingly, it was decided to modify Mufti et al. model to match test results. To achieve this task, the experimental results from the current study and by using a statistical package for curve fit, the following modification to Eq. (4.4) was developed to accurately predict the fatigue life of the cast-in-place and the precast jointed GFRP-reinforced bridge deck slabs :

$$
P / P_{u}=1.0-\ln (N) / K
$$

where:

$K=33.6$ for cast-in-place GFRP-reinforced bridge deck slabs;

$K=29$ for precast jointed GFRP-reinforced bridge deck slabs.

Figures 4.49 and 4.50 illustrate the equivalent number of load cycles to failure at constant amplitude fatigue load based on the modified fatigue prediction model for cast-in-place and precast jointed GFRP-reinforced bridge deck slabs, respectively. It can be observed that the proposed model is in a good agreement with the experimental results. Similar to equations 
(4.11), (4.12) and (4.13), the equivalent number of cycles at two different loads $\mathrm{P}_{1}$ and $\mathrm{P}_{2}$ to produce same fatigue damage, using the proposed fatigue life models, can be given as follows: For cast-in-place GFRP-reinforced bridge deck slabs:

$$
\mathrm{n}_{2}=\mathrm{n}_{1} \times \mathrm{e}^{33.6\left(\mathrm{R}_{1}-\mathrm{R}_{2}\right)}
$$

For precast jointed GFRP-reinforced bridge deck slabs:

$$
\mathrm{n}_{2}=\mathrm{n}_{1} \times \mathrm{e}^{29\left(\mathrm{R}_{1}-\mathrm{R}_{2}\right)}
$$

As a conclusion, the fatigue strength of the cast-in-place and precast jointed GFRP-reinforced bridge deck slabs can be predicted using equation (4.14) or the P-N curves shown in Fig. 4.51.

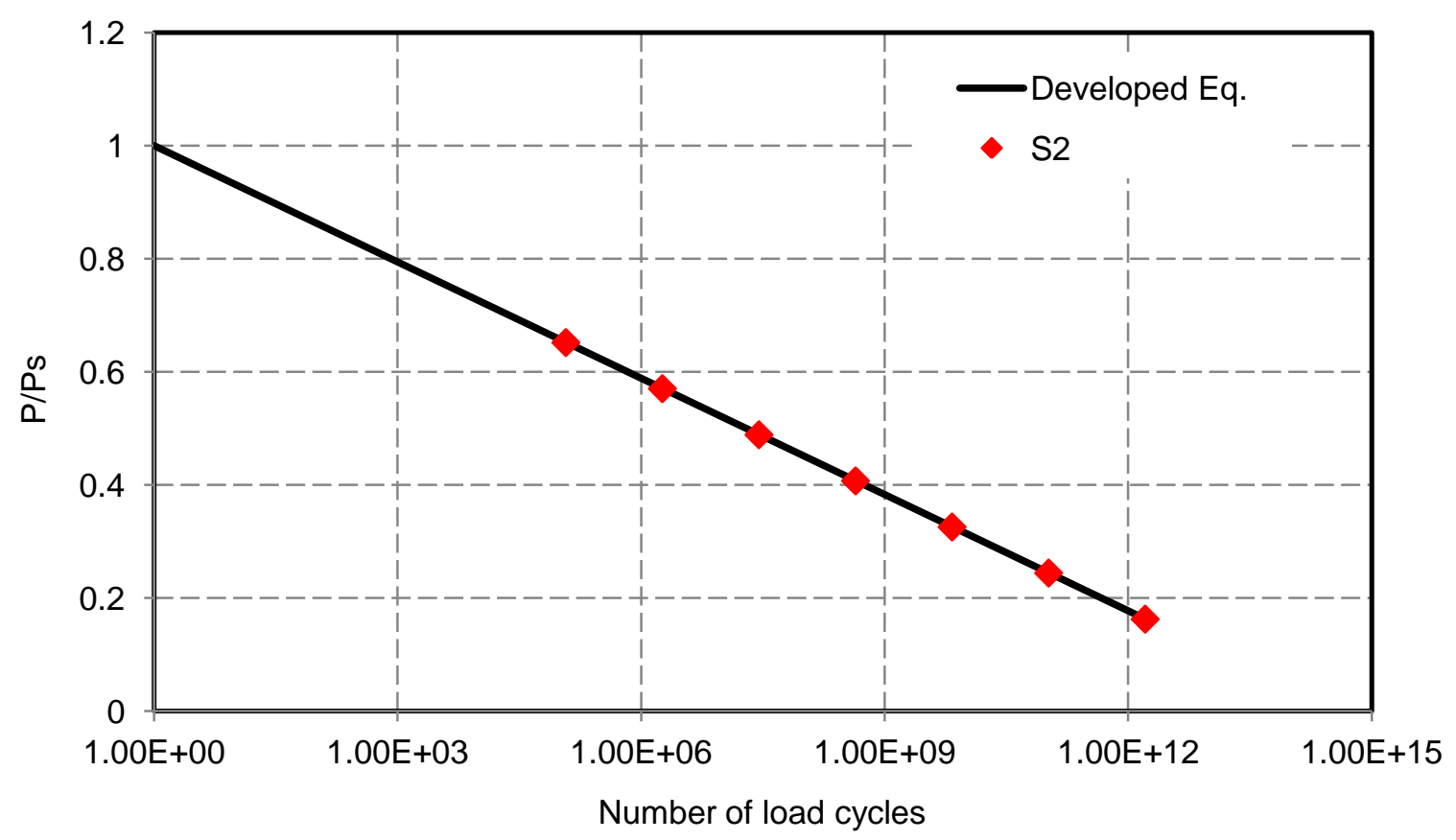

Figure 4.49 Equivalent number of load cycles to failure at constant amplitude fatigue load based on the developed equation for cast-in-place bridge deck slabs 


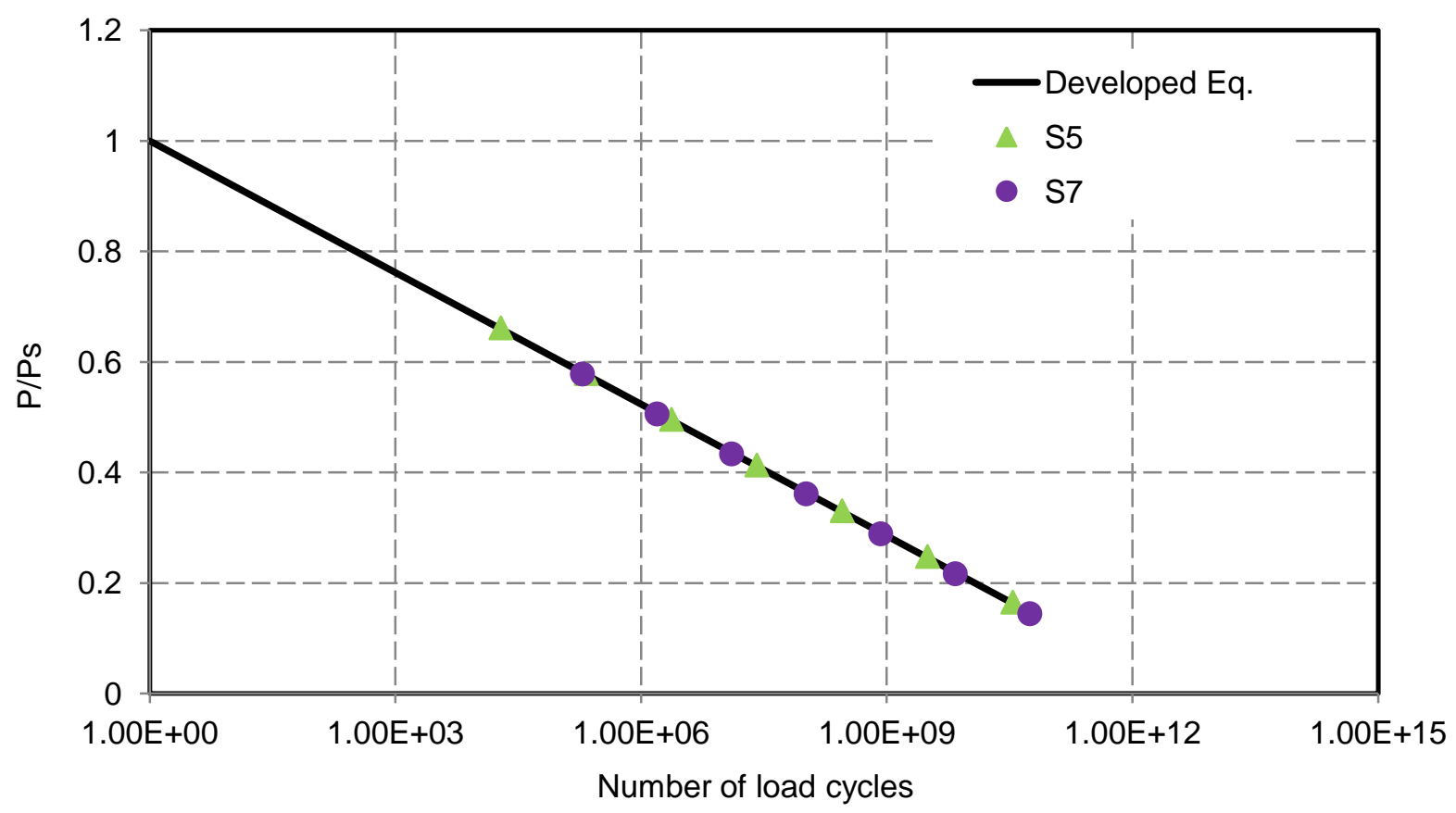

Figure 4.50 Equivalent number of load cycles to failure at constant amplitude fatigue load based on the developed equation for precast jointed bridge deck slabs

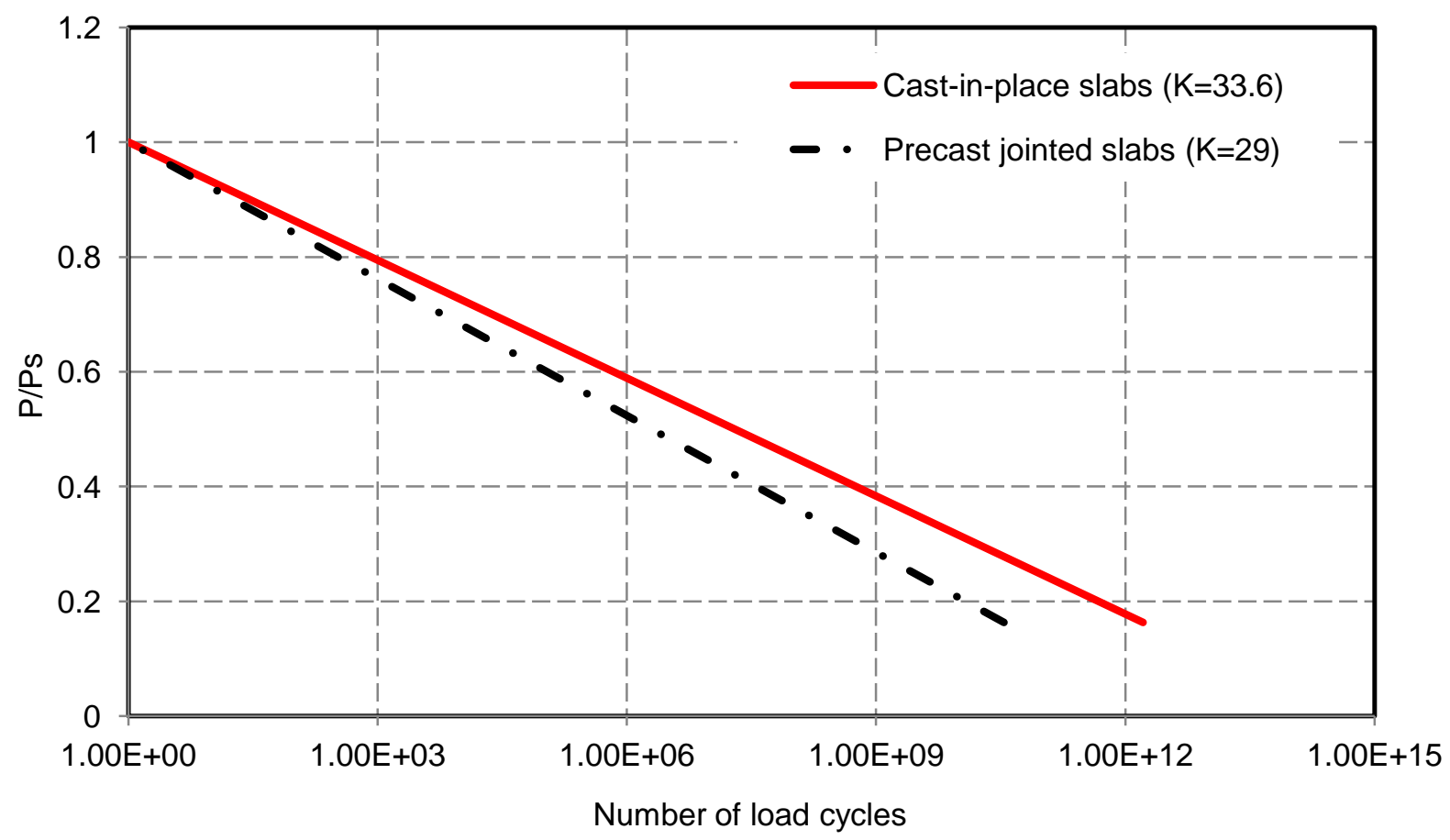

Figure 4.51 P-N curves for GFRP-reinforced cast-in-place and precast jointed deck slabs 


\section{CHAPTER V \\ CONCLUSIONS AND RECOMMENDATIONS FOR FUTURE RESEARCH}

\subsection{Summary}

The use of glass fiber reinforced polymer (GFRP) bars to reinforce bridge deck slabs as well as jointed precast bridge deck slab in prefabricated bridge bulb-tee pre-tensioned girders was investigated experimentally. Two types of GFRP bars were used in this study, namely: (i) ribbedsurface GFRP bars and (ii) sand-coated GFRP bars. The studied GFRP-reinforced precast deck slabs incorporated three proposed joints between girder flanges using headed stud connectors embedded in a closure strip filled with non-shrink ordinary-cement grout and ultra-highperformance concrete (UHPC), respectively. To verify whether the structural performance of those proposed joints is superior and more cost-effective as compared to L-shaped (90ํำ hooks) and straight bars, other three joint details, incorporating GFRP bars with L-shaped and straight bars were also tested. Fatigue behavior and fatigue life of the successful control joint were further investigated using different schemes of fatigue loading, namely: accelerated variable amplitude fatigue (VAF) loading and constant amplitude fatigue (CAF) loading. Also, experimental crack width and ultimate load carrying capacity of the tested GFRP-reinforced slabs were correlated with similar steel-reinforced deck slabs.

\subsubsection{Phase I: Static Tests on Simply-Supported Deck Slab Strips}

In phase I, six precast slab joint details between flanges of precast bulb-tee girders were developed incorporating GFRP bars embedded in a closure strip filled with non-shrink cement 
grout or ultra-high-performance concrete (UHPC). A total of 11 actual-size specimens representing the proposed joint details, in addition to 5 cast-in-place control specimens, were built and tested until failure to examine the structural adequacy of the proposed connection details between precast slab segments incorporating GFRP bars. Each slab had 2500 mm length, $200 \mathrm{~mm}$ thick and $600 \mathrm{~mm}$ width in the direction of traffic. Further tests were conducted in phase II to examine the fatigue life of the successful control joint under simulated vehicular wheel loading.

\subsubsection{Phase II: Static and Fatigue Tests on Internally-Restrained Deck Slabs}

In phase II, a total of 8 actual-size, GFRP-reinforced, concrete deck slabs were designed according to CHBDC specifications to perform static and fatigue tests to determine their behavior under CHBDC truck wheel loading. Each slab had $200 \mathrm{~mm}$ thickness, $2500 \mathrm{~mm}$ width normal to traffic and $3500 \mathrm{~mm}$ length in the direction of traffic. Ultimate strength, fatigue behavior and fatigue life of the GFRP-reinforced deck slabs were investigated using different schemes of cyclic loadings (accelerated variable amplitude cyclic loading as well as constant amplitude cyclic loading followed by loading the slab monotonically to failure). Overall, the experimental results indicated that the GFRP-reinforced deck slabs showed high fatigue performance and a new model for predicting the fatigue life for GFRP-reinforced deck slabs was developed.

\subsection{Conclusions}

Based on the experimental results in phase I and II, the following conclusions can be drawn: 
1- The ultimate load capacity of GFRP-reinforced cast-in-place deck slab reinforced with the reinforcement ratio specified in CHBDC, is about $75 \%$ greater than that of a similar slab reinforced with steel bars.

2- The 125-mm wide closure strip with projecting headed-end or L-shaped GFRP bars filled with UHPC and the 200-mm wide closure strip with projecting L-shaped GFRP bars and filled with non-shrink grout had a load carrying capacity about $27 \%$ greater than that of a similar slab reinforced with steel bars.

3- The GFRP bars with headed ends can provide a continuous force transfer in the longitudinal joint for deck bulb-tee bridge systems while reducing the closure strip width to accelerate bridge construction.

4- The cracking loads at the underside of the GFRP-reinforced cast-in-place deck slabs, S1, S2 and S3 were 167, 119 and $153 \mathrm{kN}$, respectively, which are more than the service design load of $110.25 \mathrm{kN}$ specified in CHBDC.

5- The GFRP-reinforced cast-in-place deck slab and precast deck slab with a 125-mm wide closure strip and projecting headed-end bars filled with UHPC showed high fatigue performance since there was insignificant fatigue damage when subjected to 4,000,000 cycles under FLS load range of $122.5 \mathrm{kN}$ specified in CHBDC.

6- The ultimate load capacities of pre-fatigued GFRP-reinforced cast-in-place deck slab and precast deck slab with a 125 -mm wide closure strip and projecting headed-end bars filled with UHPC are more than three times the design factored load of $208.25 \mathrm{kN}$ specified by CHBDC.

7- Under static and fatigue loadings, punching shear is the mode of failure for all tested GFRPreinforced restrained deck slabs, as expected. 
8- For cast-in-place and the precast jointed deck slabs tested under a static load, the maximum measured vertical deflection at service load of $110.25 \mathrm{kN}$ was $1.1 \mathrm{~mm}$, which is less than the allowable limit specified by AASHTO-LRFD specifications $(\mathrm{L} / 800=2.5 \mathrm{~mm})$.

9- GFRP reinforcement ratio specified by CHBDC is adequate to meet the ultimate limit state and fatigue limit state requirements for concrete bridge deck slabs.

10- After completed 4,000,000 load cycles, the maximum measured vertical deflections for the three slabs S3, S4 and S8 were 1.02, 1.47 and 1.74, respectively. This indicates that the precast jointed deck slabs, S4 and S8, fatigued approximately $44 \%$ and $70 \%$, times as fast as the cast-in-place deck slab, S3.

11- The maximum measured strain in the bottom transverse GFRP reinforcement at failure in the pre-fatigued slabs, S3 and S8 were about $20 \%$ and $11 \%$ higher than those of similar reinforced deck slabs, S1 and S6, respectively.

12- The average observed mid-depth punching perimeters for the cast-in-place deck slabs and the precast jointed deck slabs were measured to be $1.25 \mathrm{~d}$ and $1.33 \mathrm{~d}$ away from the sides of the loaded area, respectively, which are more than twice the corresponding distance specified in ACI 440.1R-06 and CSA S806-12 for calculating theoretical punching shear perimeter.

13- The available equation in CSA S806-12 (2012) and El-Gamal et al. (2005) can predict the punching shear strength of the cast-in-place as well as precast jointed bridge deck slabs reinforced with GFRP-bars with good accuracy.

14- A fatigue formula and P-N curves for fatigue life of the tested cast-in-place and precast jointed GFRP-reinforced bridge deck slabs were developed using Miner's rule and the results obtained from variable amplitude fatigue (VAF) loading tests. 
15- Based on the ultimate load capacity, fatigue strength, cracking, deflection, and GFRP strain comparisons, the developed 125-mm wide UHPC-filled precast deck joint with projecting headed-end GFRP bars is recommended to join the precast slabs of the bulb-tee girders to provide sustainable and accelerated bridge construction, thus optimizing the use of tax payers money in transportation infrastructure.

16- The conclusions reached in this research are limited to the slab thickness of $200 \mathrm{~mm}$, girder spacing of $2000 \mathrm{~mm}$ and the amount of reinforcement specified in CHBDC for deck slabs. Other configurations can be considered for design using manual calculations for strength and the reported experimental findings.

\subsection{Recommendations for Future Research}

Based on the outcome of this research, the following recommendations for future research can be made:

1- Develop connection details for the transverse joints between precast slab systems in full depth, full-width deck panels, incorporating GFRP bars for sustainable construction.

2- Study the strength of GFRP-reinforced deck slabs incorporating high performance concrete (HPC) at the negative moment region and Engineering Cementitious Composite (ECC) in case of link slabs.

3- Study the ultimate and fatigue strength of shear connectors embedded in shear pockets filled with high-strength grout or ultra-high-performance concrete.

4- Study the strength of deck slabs subjected to wheel loads at the negative moment region where tensile forces from global negative moment in composite girders exist. 


\section{APPENDIX A}




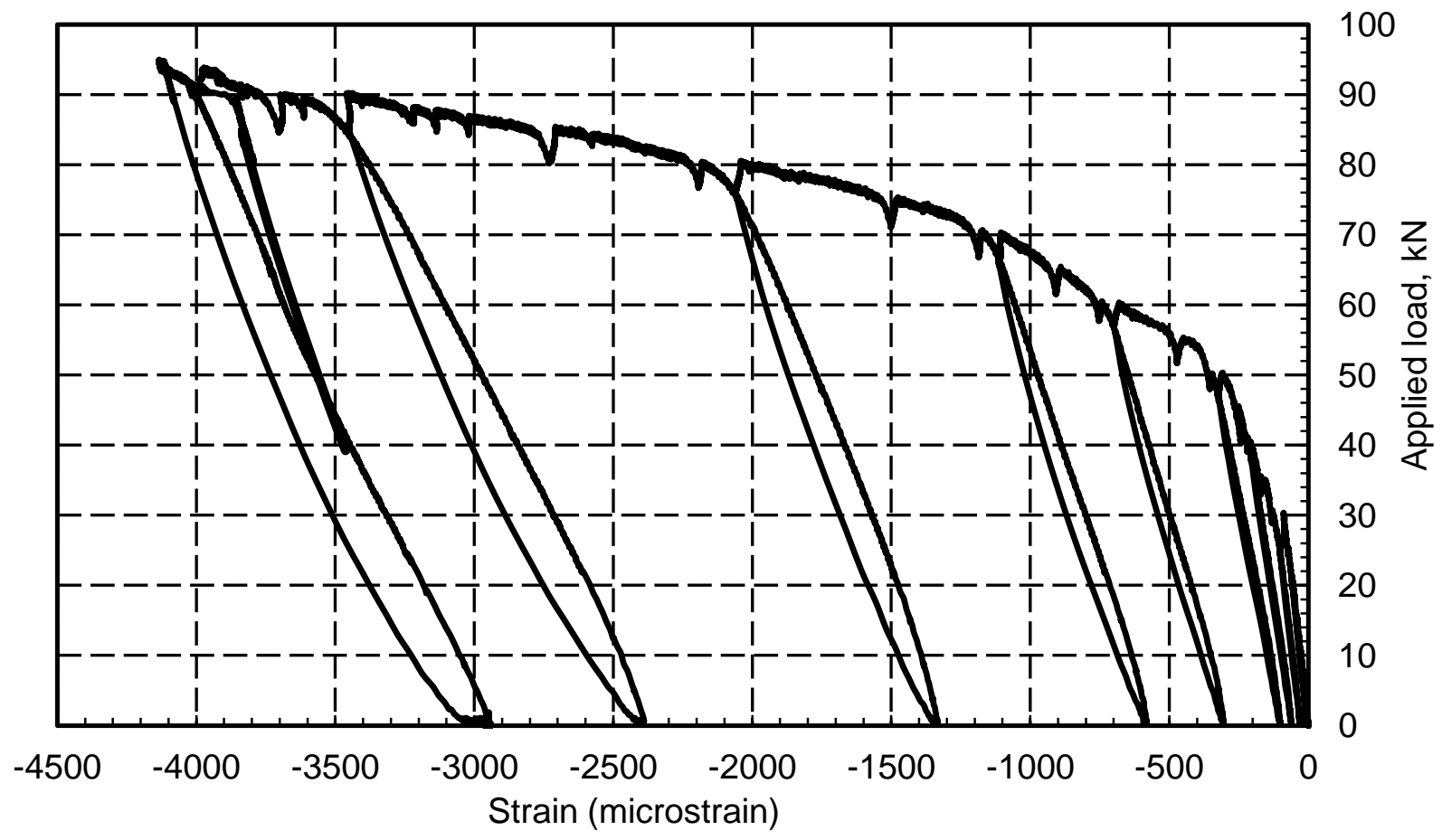

Figure A.1 Load versus concrete strain of slab SS1 subjected to incremental loading to failure

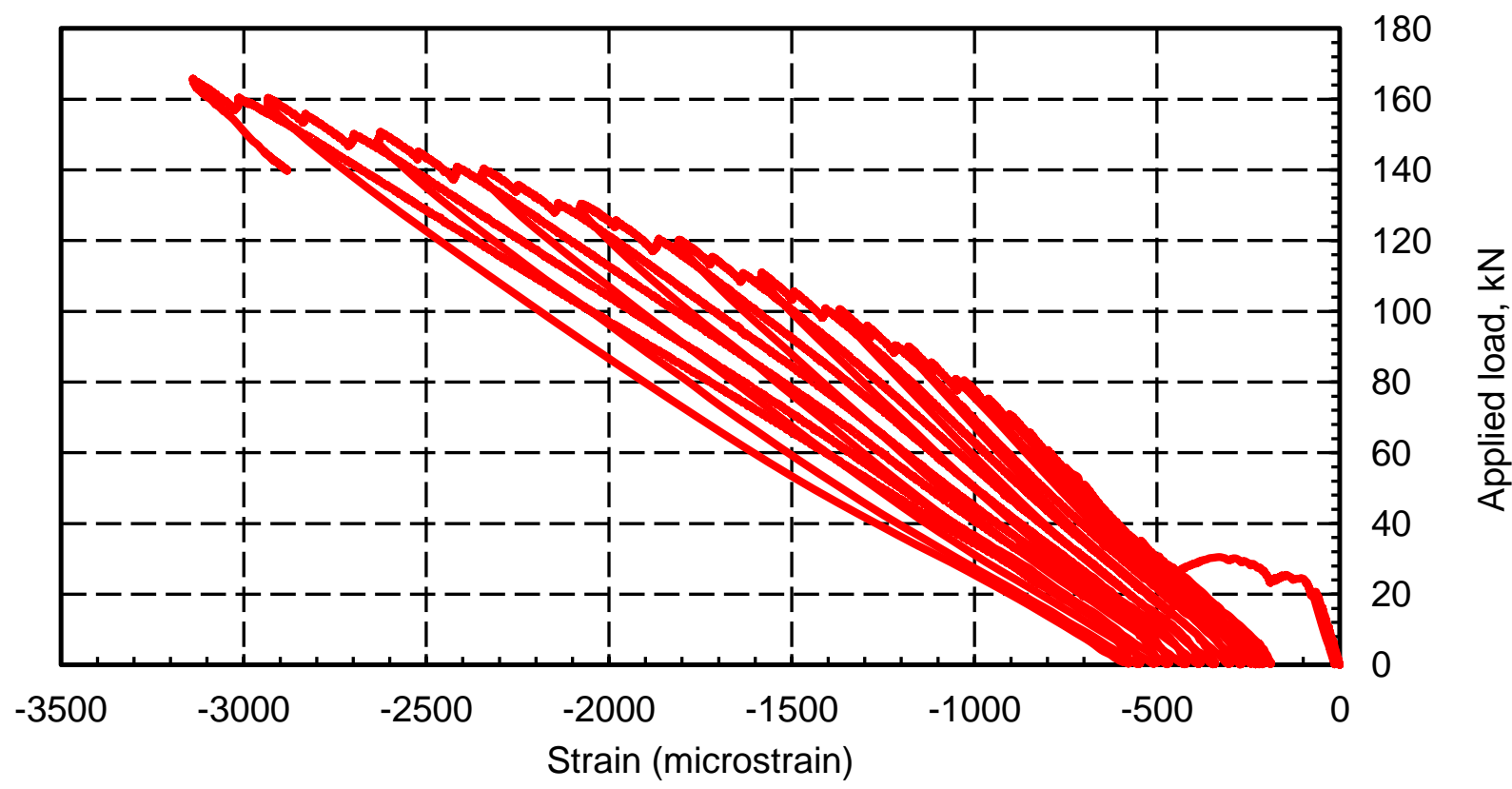

Figure A.2 Load versus concrete strain of slab SS2 subjected to incremental loading to failure 


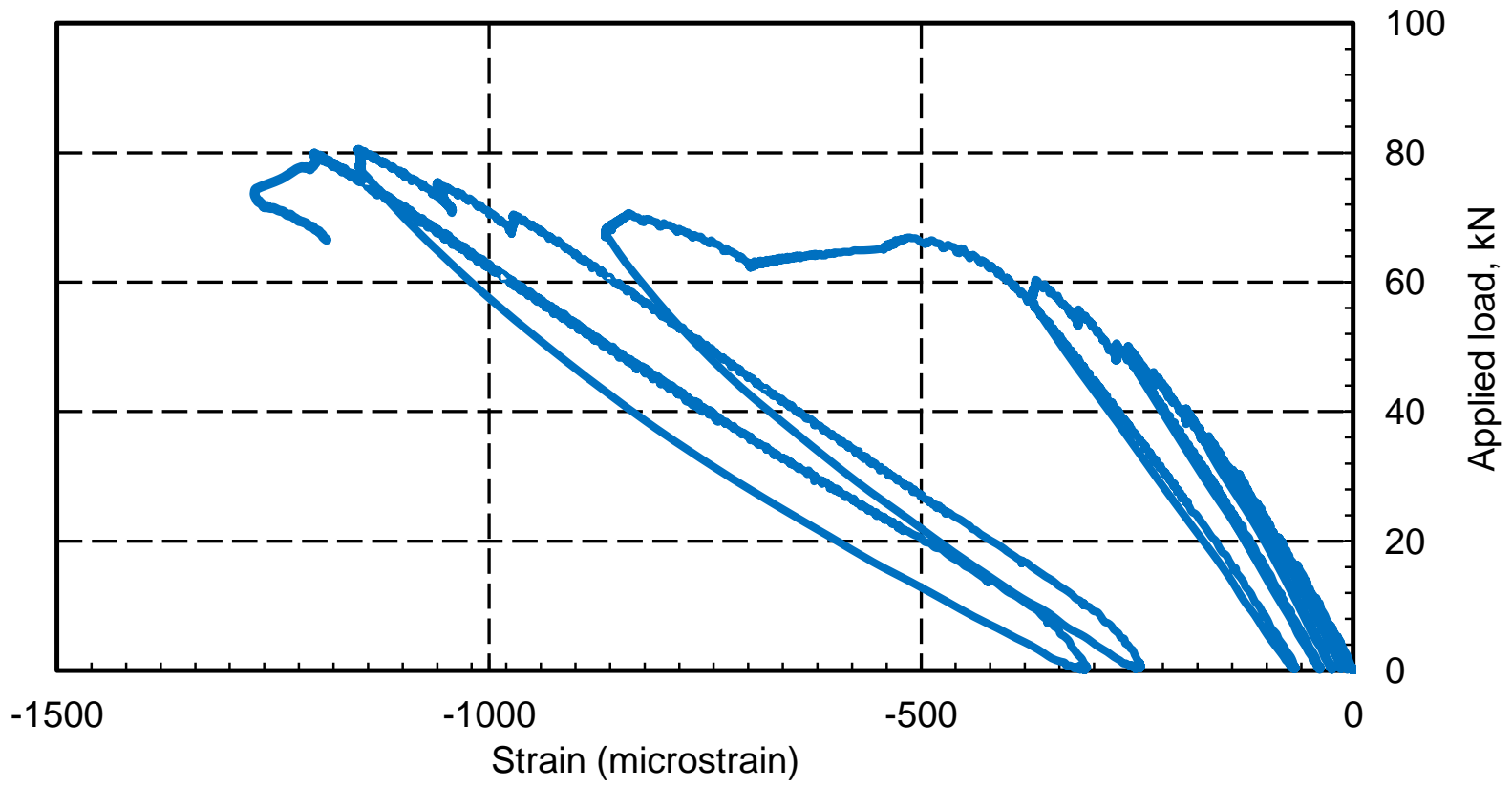

Figure A.3 Load versus concrete strain of slab SS3 subjected to incremental loading to failure

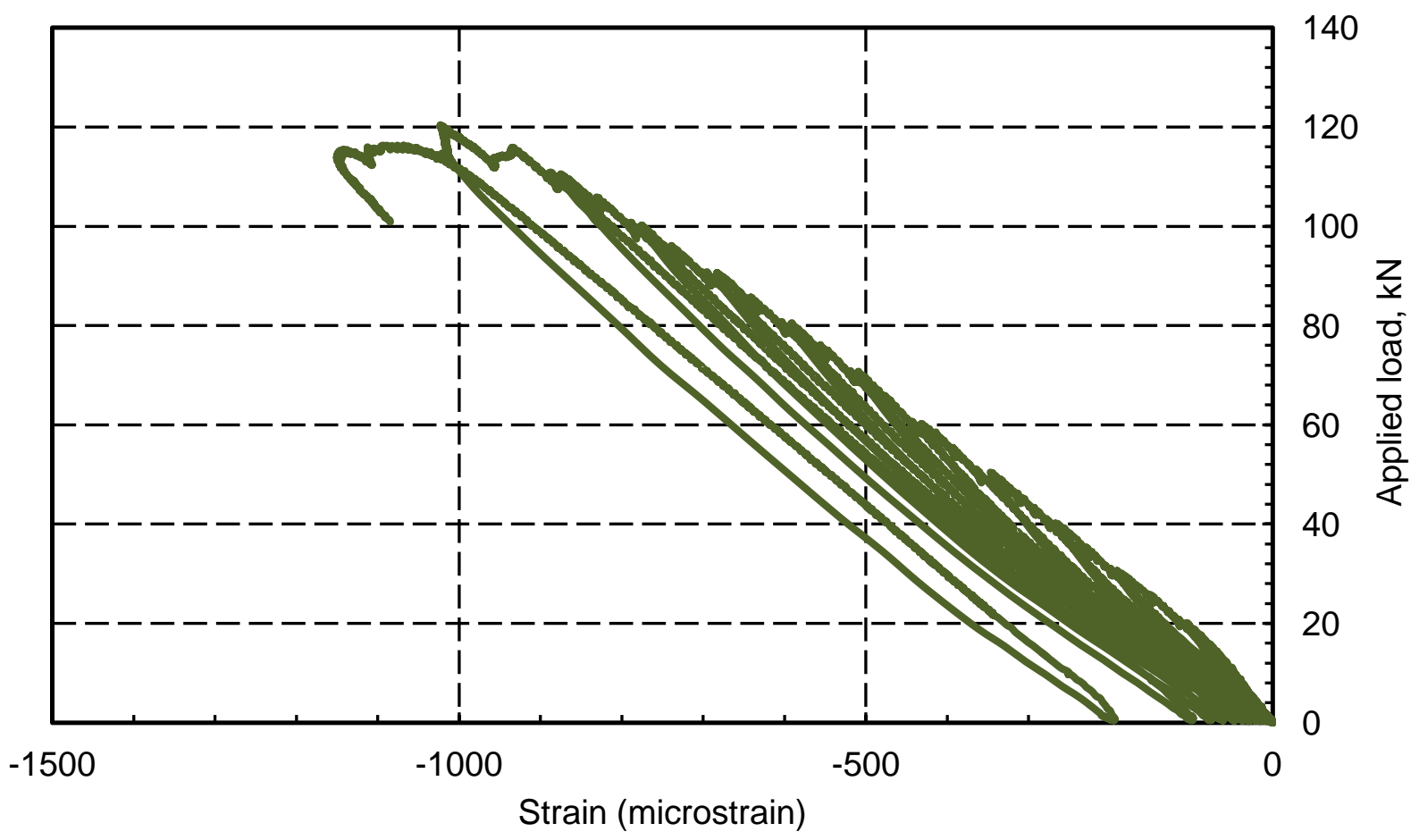

Figure A.4 Load versus concrete strain of slab SS4 subjected to incremental loading to failure 


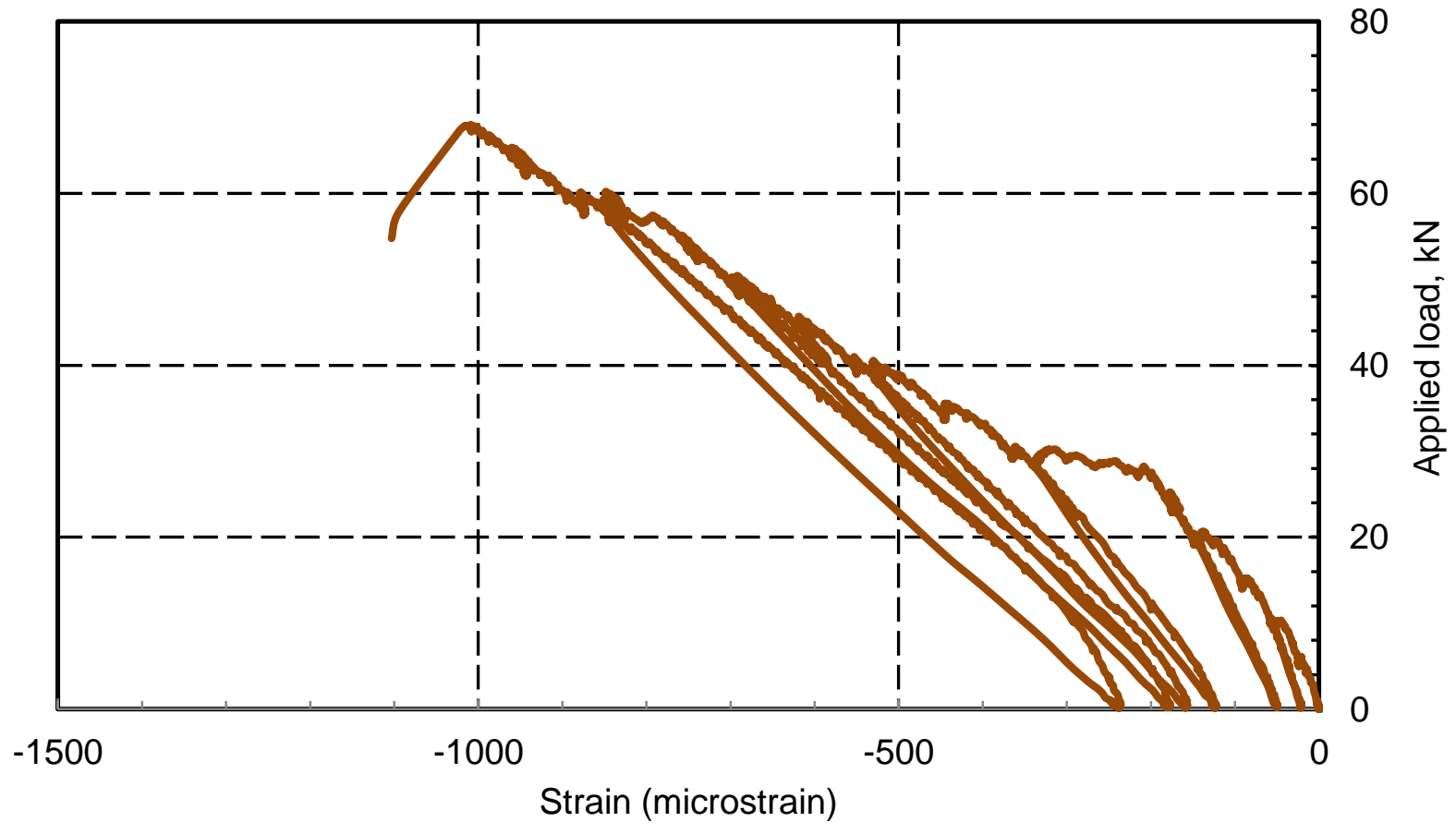

Figure A.5 Load versus concrete strain of slab SS5 subjected to incremental loading to failure

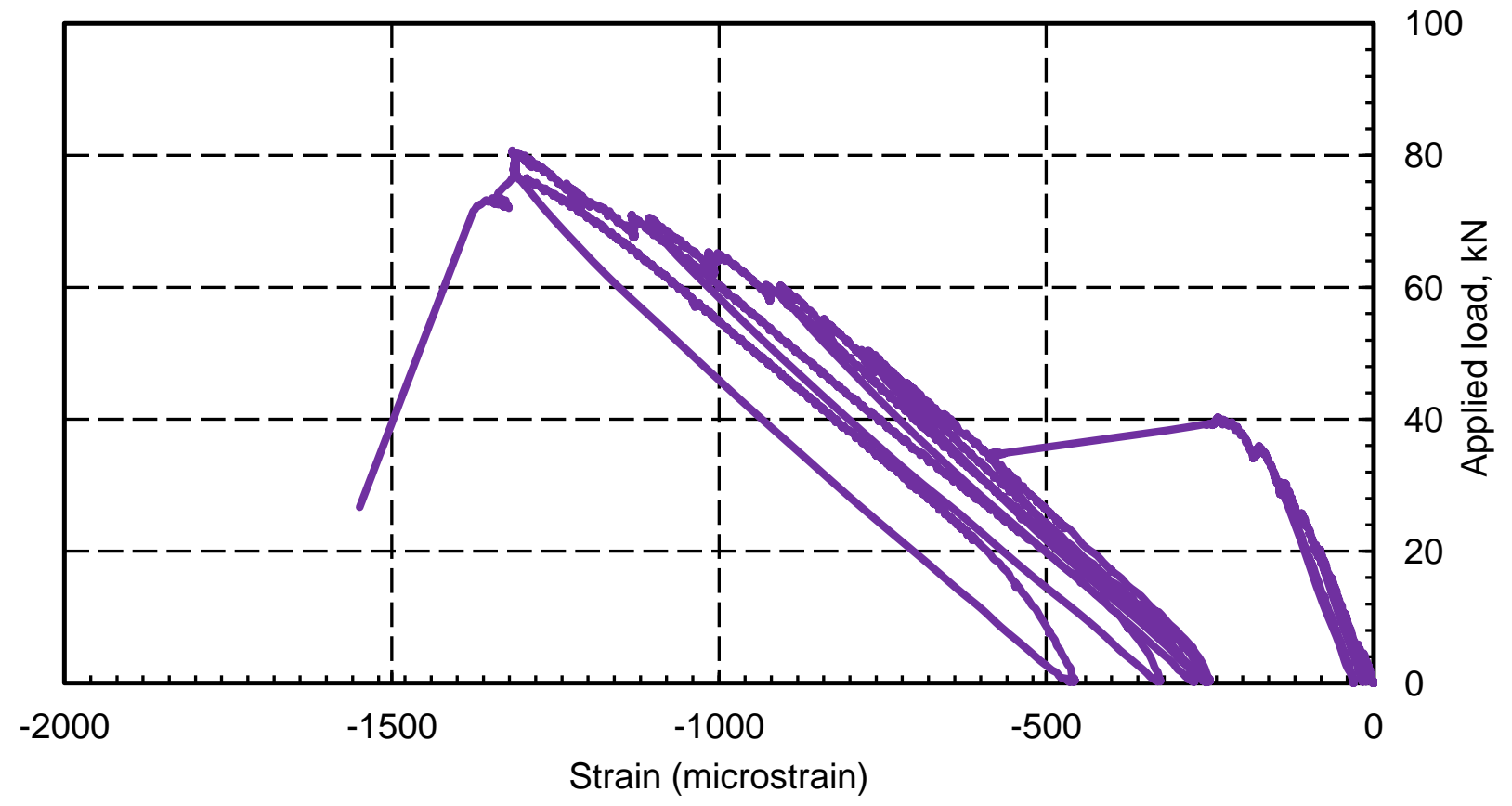

Figure A.6 Load versus concrete strain of slab SS6 subjected to incremental loading to failure 


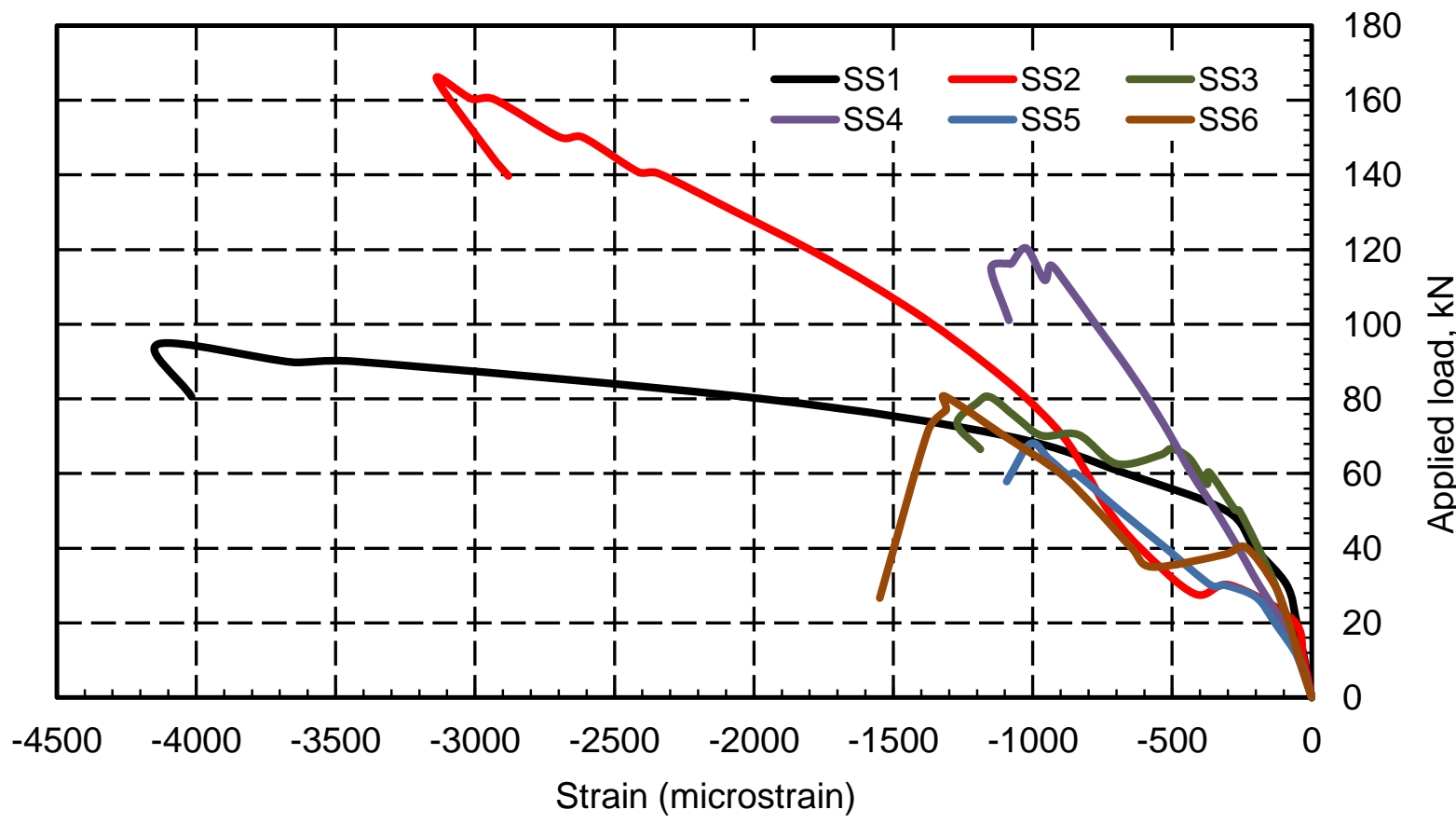

Figure A.7 Envelopes of the Load versus concrete strain of slabs SS1 through SS6 subjected to incremental loading to failure

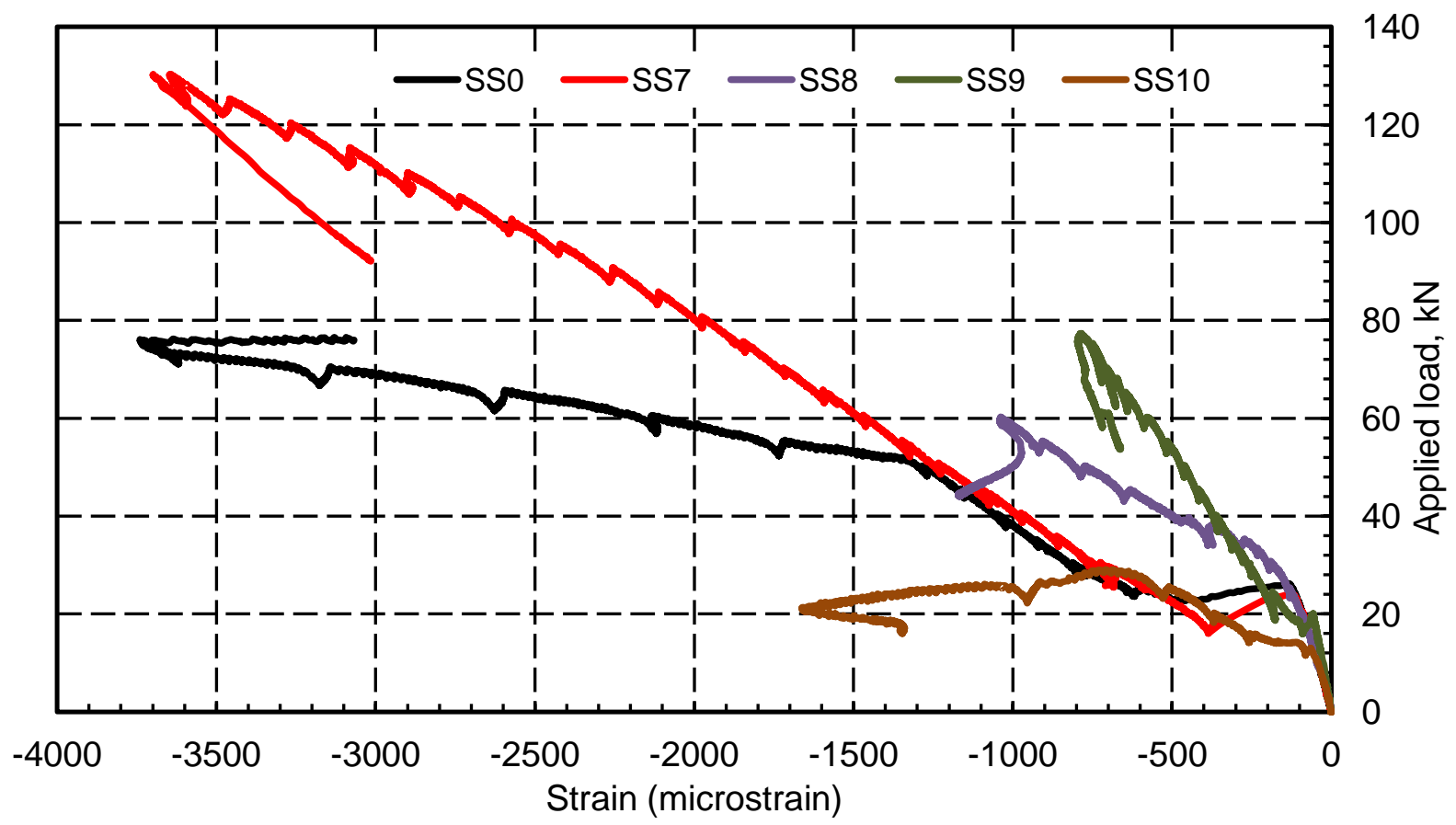

Figure A.8 Load versus concrete strain of slabs SS0, SS7, SS8, SS9 and SS10 subjected to increasing load to failure 


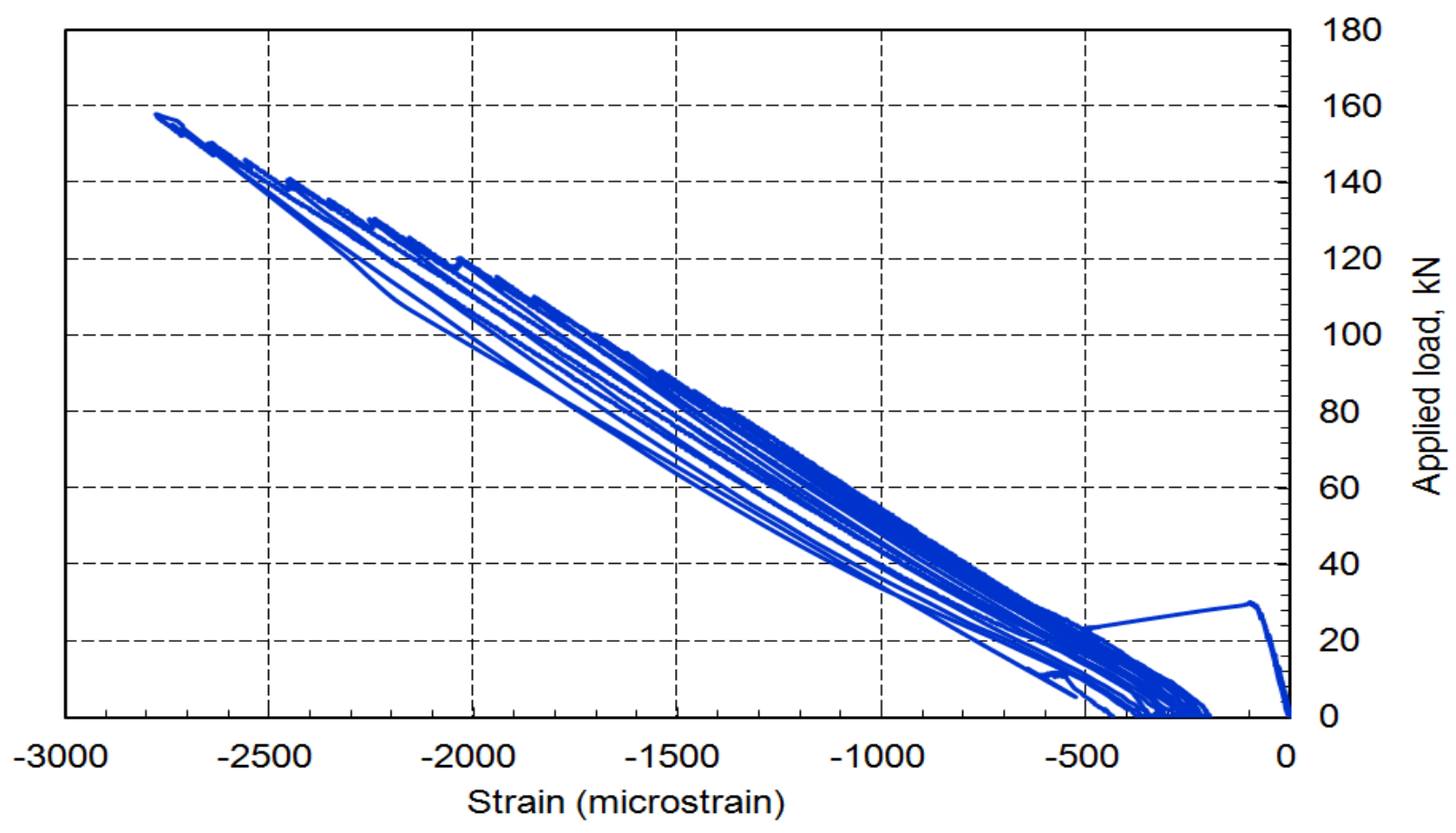

Figure A.9 Load versus concrete strain of slab PS1 subjected to incremental loading to failure

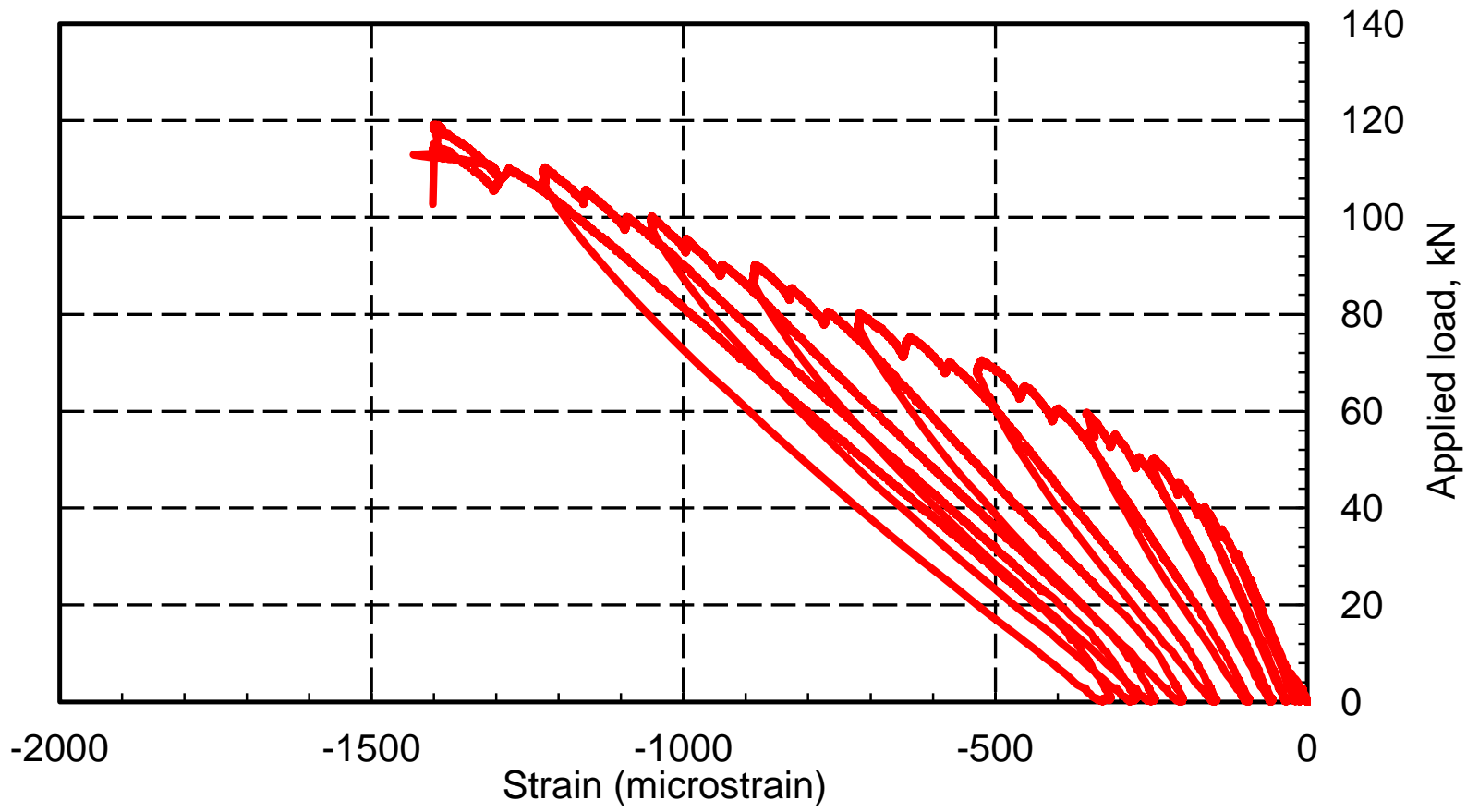

Figure A.10 Load versus concrete strain of slab PS2 subjected to incremental loading to failure 


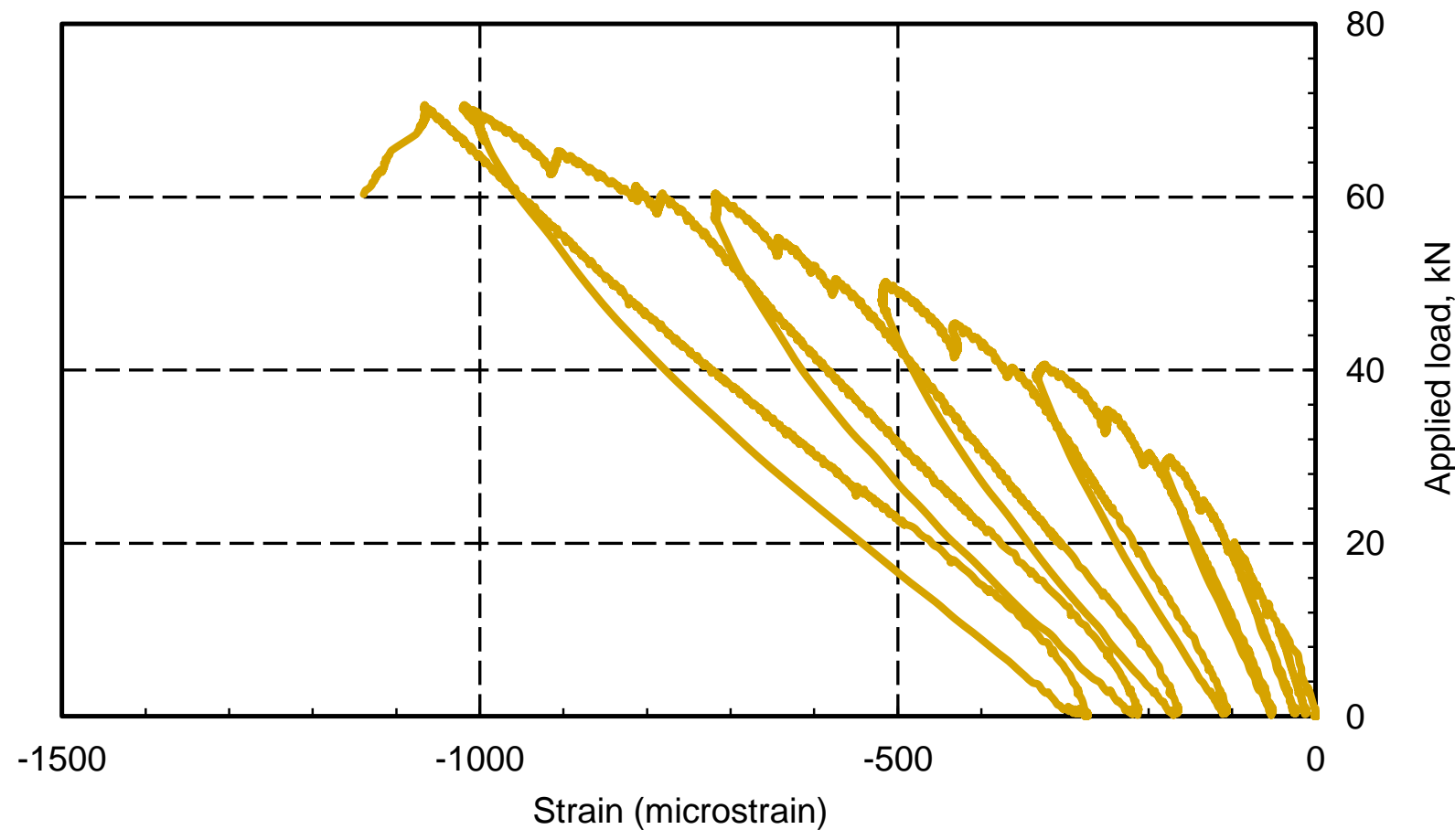

Figure A.11 Load versus concrete strain of slab PS3 subjected to incremental loading to failure

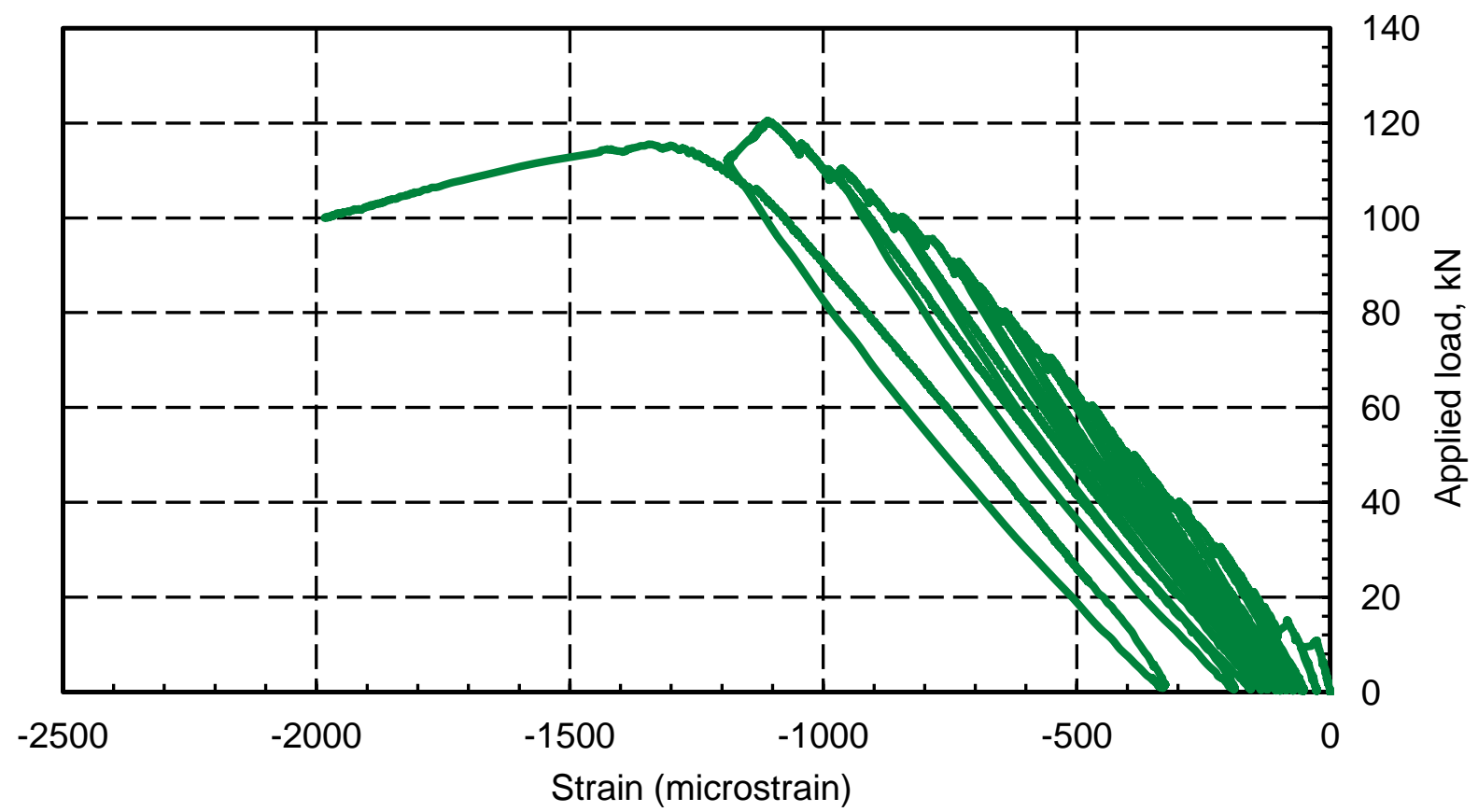

Figure A.12 Load versus concrete strain of slab PS4 subjected to incremental loading to failure 


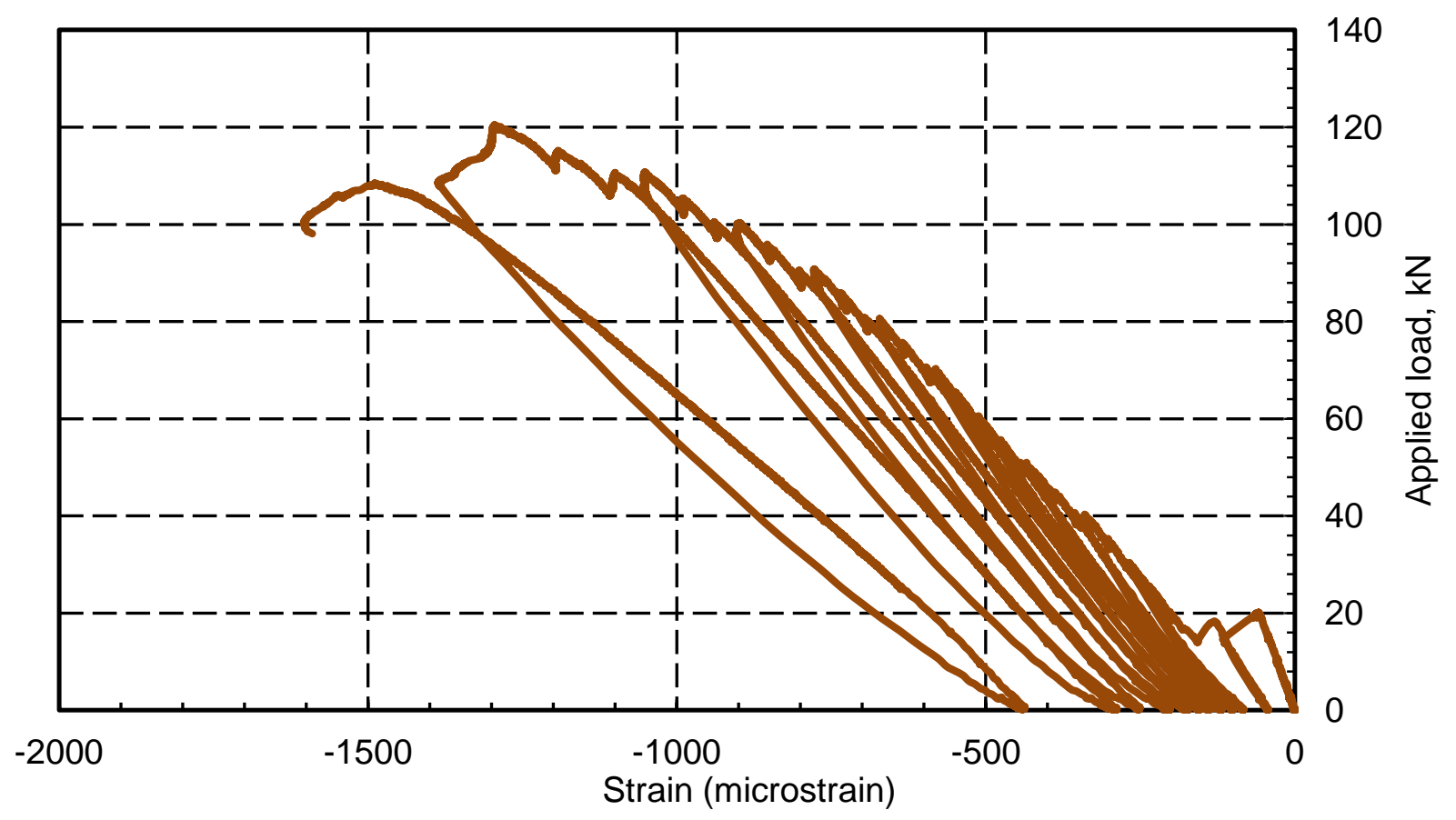

Figure A.13 Load versus concrete strain of slab PS5 subjected to incremental loading to failure

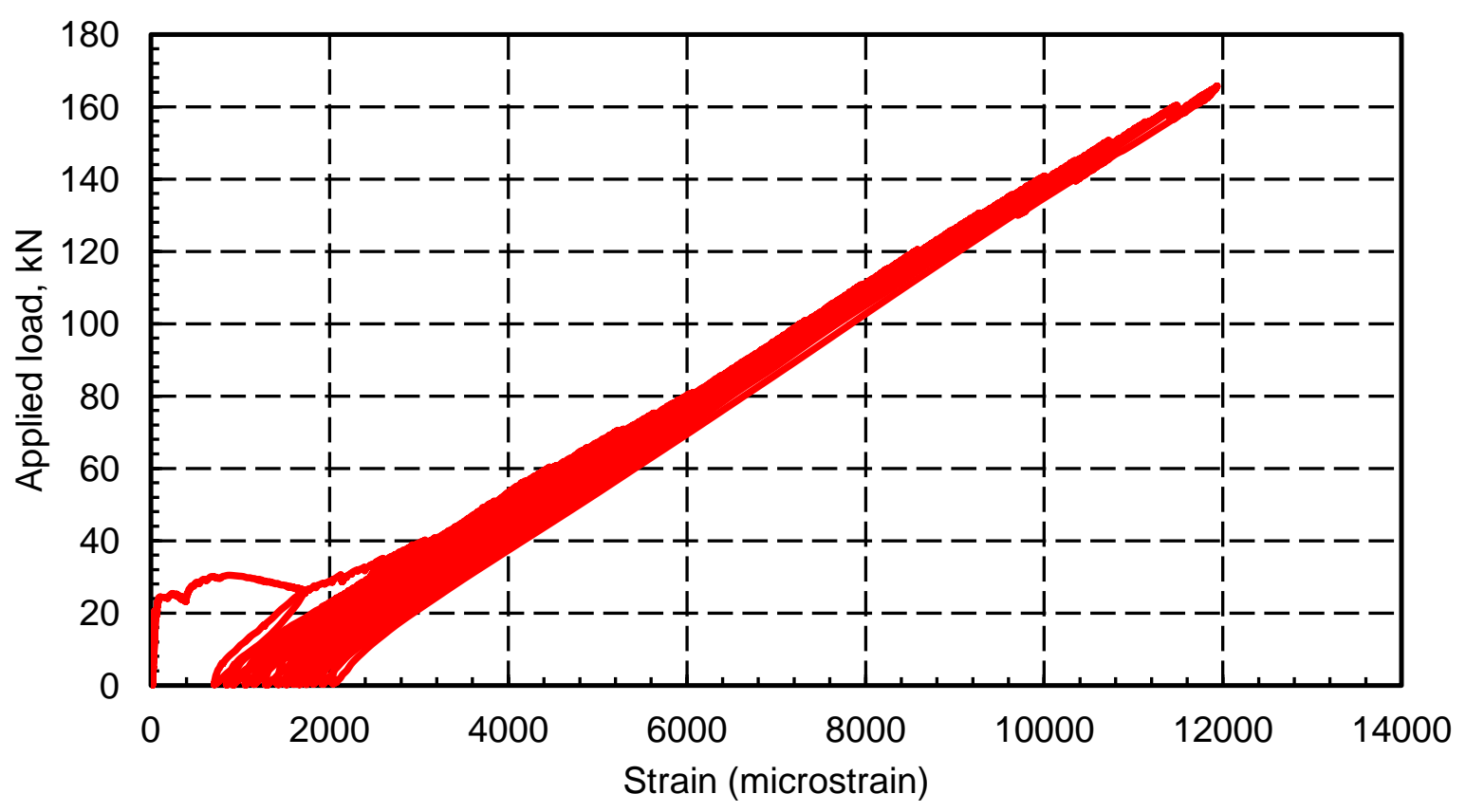

Figure A.14 Load versus reinforcement strain of slab SS2 subjected to incremental loading to failure 


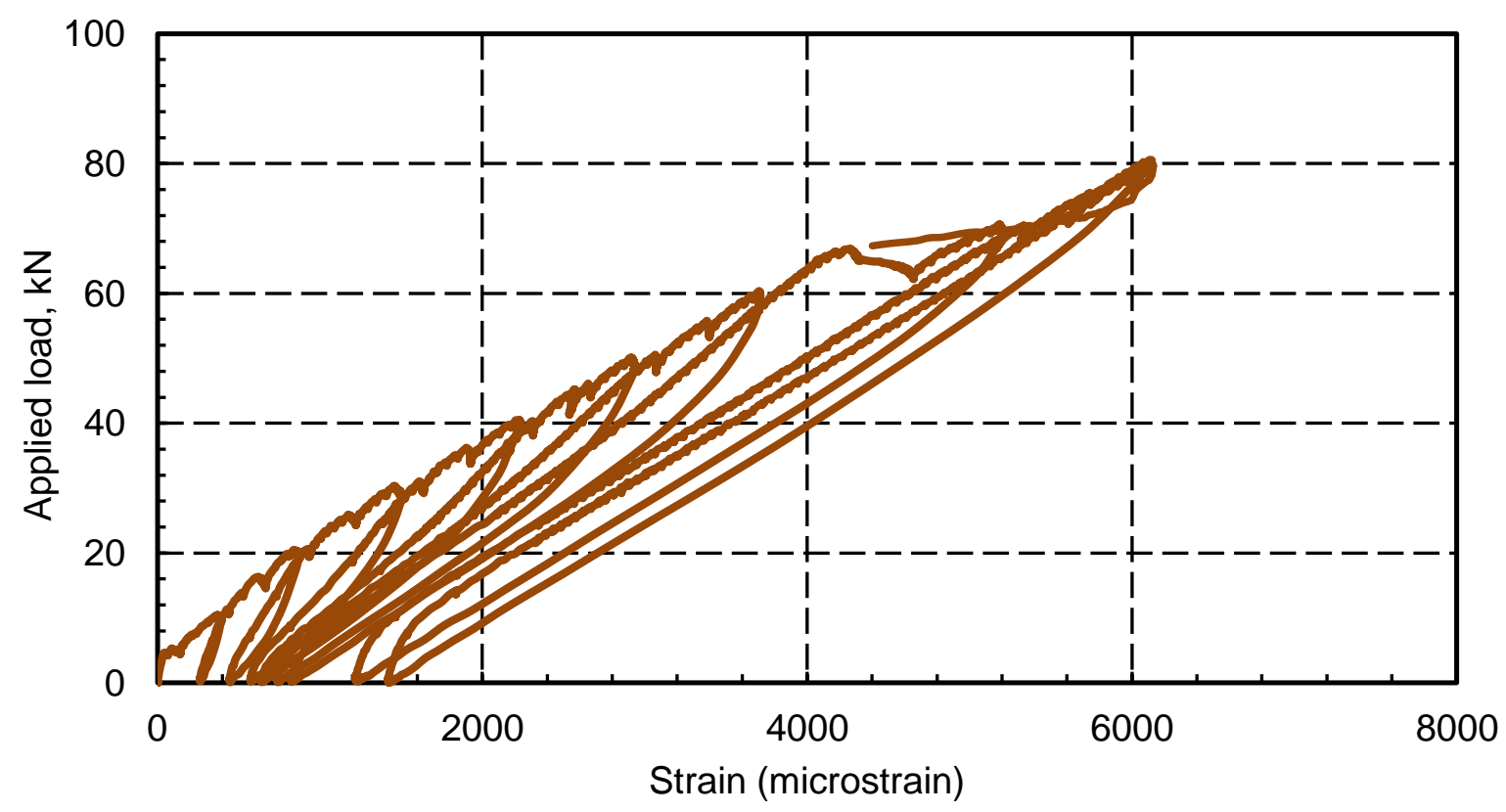

Figure A.15 Load versus reinforcement strain of slab SS3 subjected to incremental loading to failure

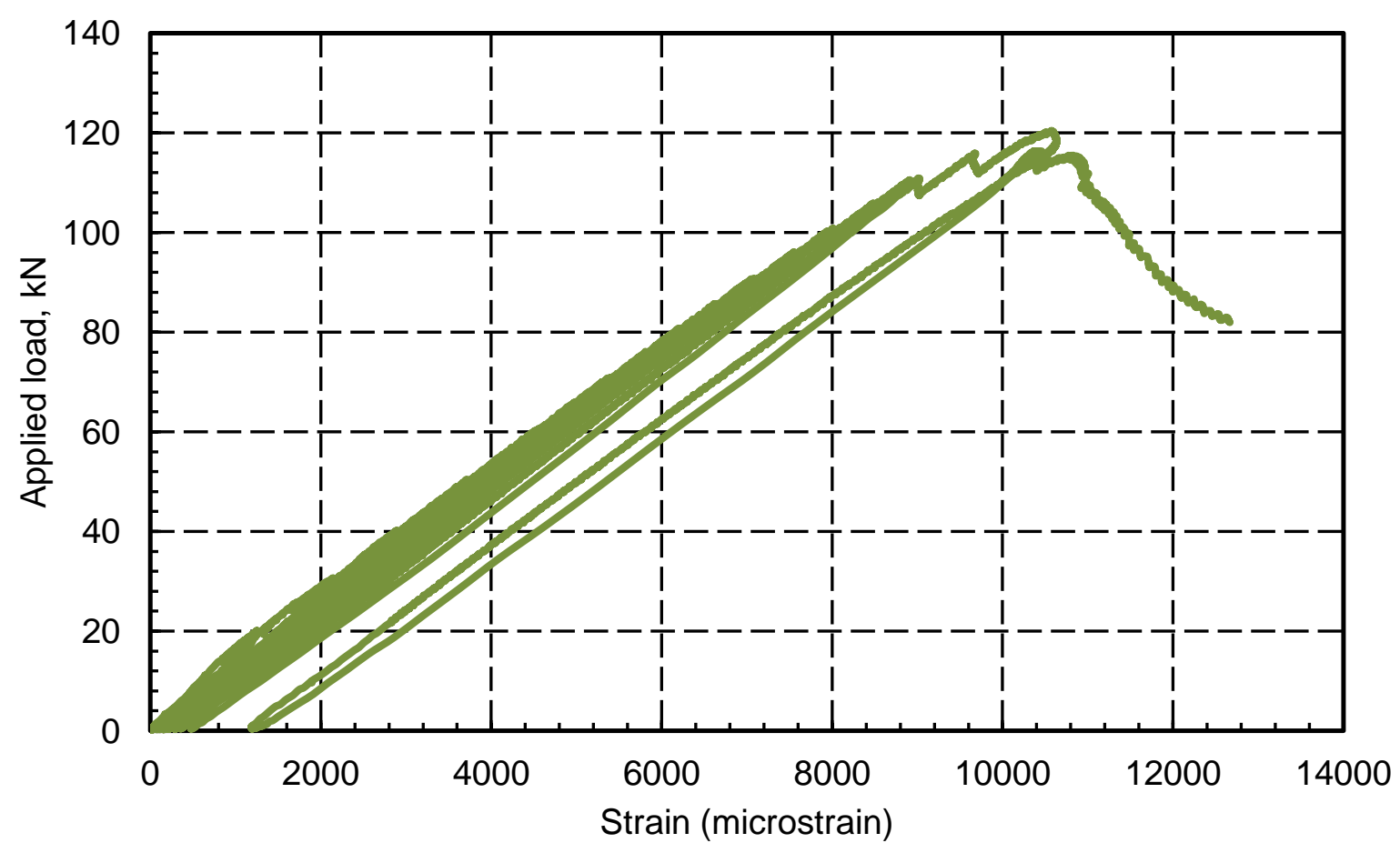

Figure A.16 Load versus reinforcement strain of slab SS4 subjected to incremental loading to failure 


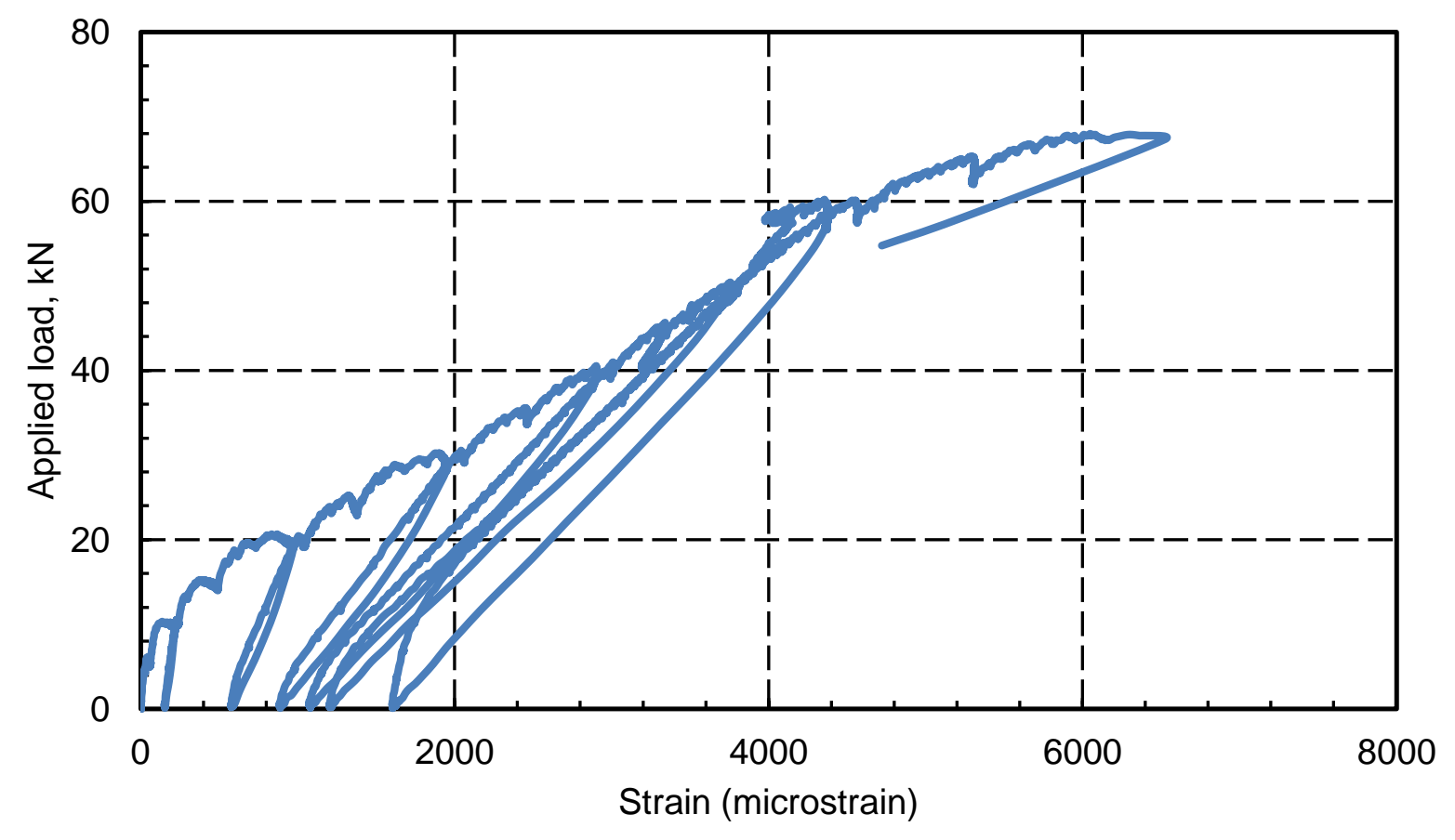

Figure A.17 Load versus reinforcement strain of slab SS5 subjected to incremental loading to failure

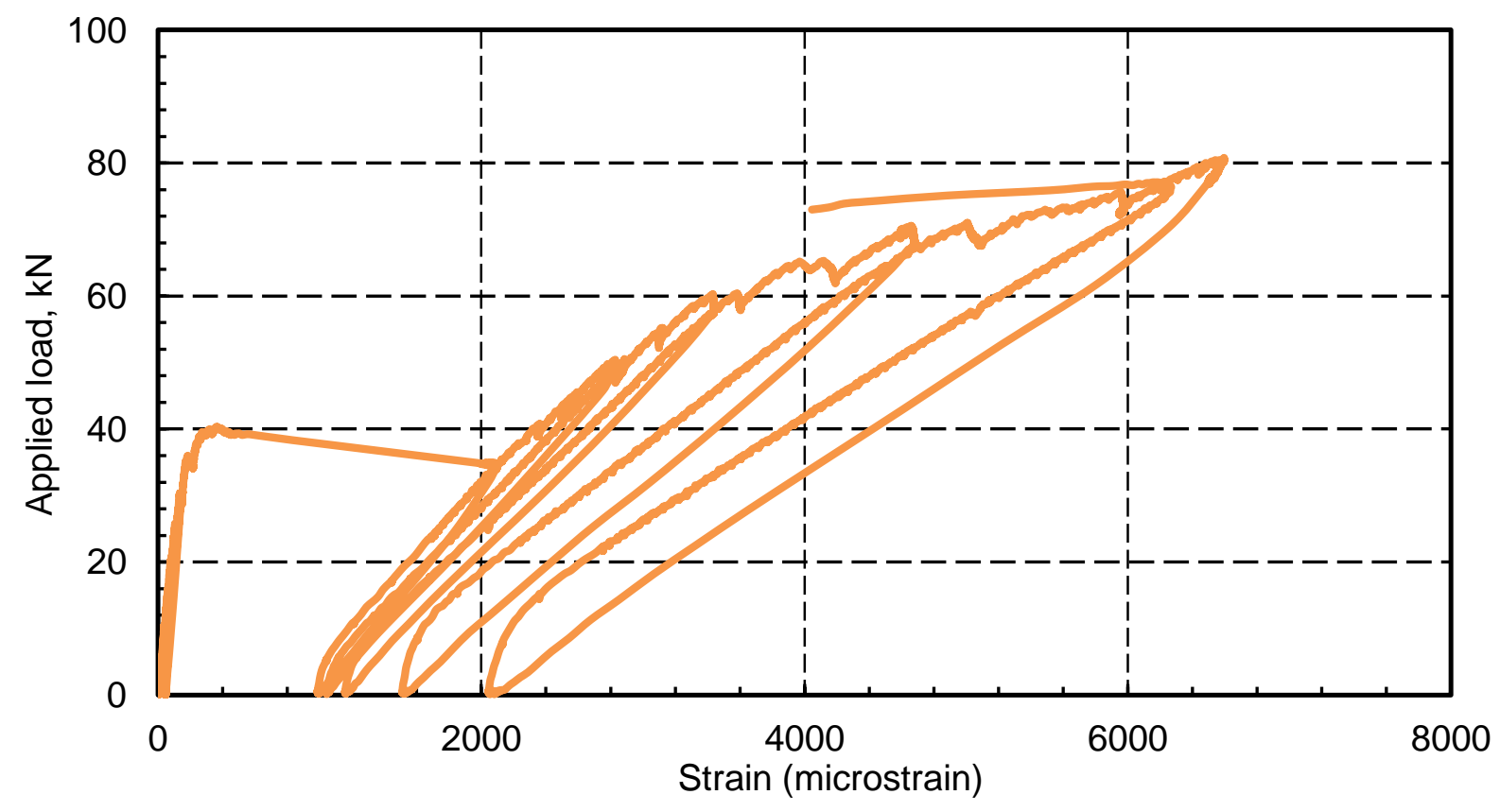

Figure A.18 Load versus reinforcement strain of slab SS6 subjected to incremental loading to failure 


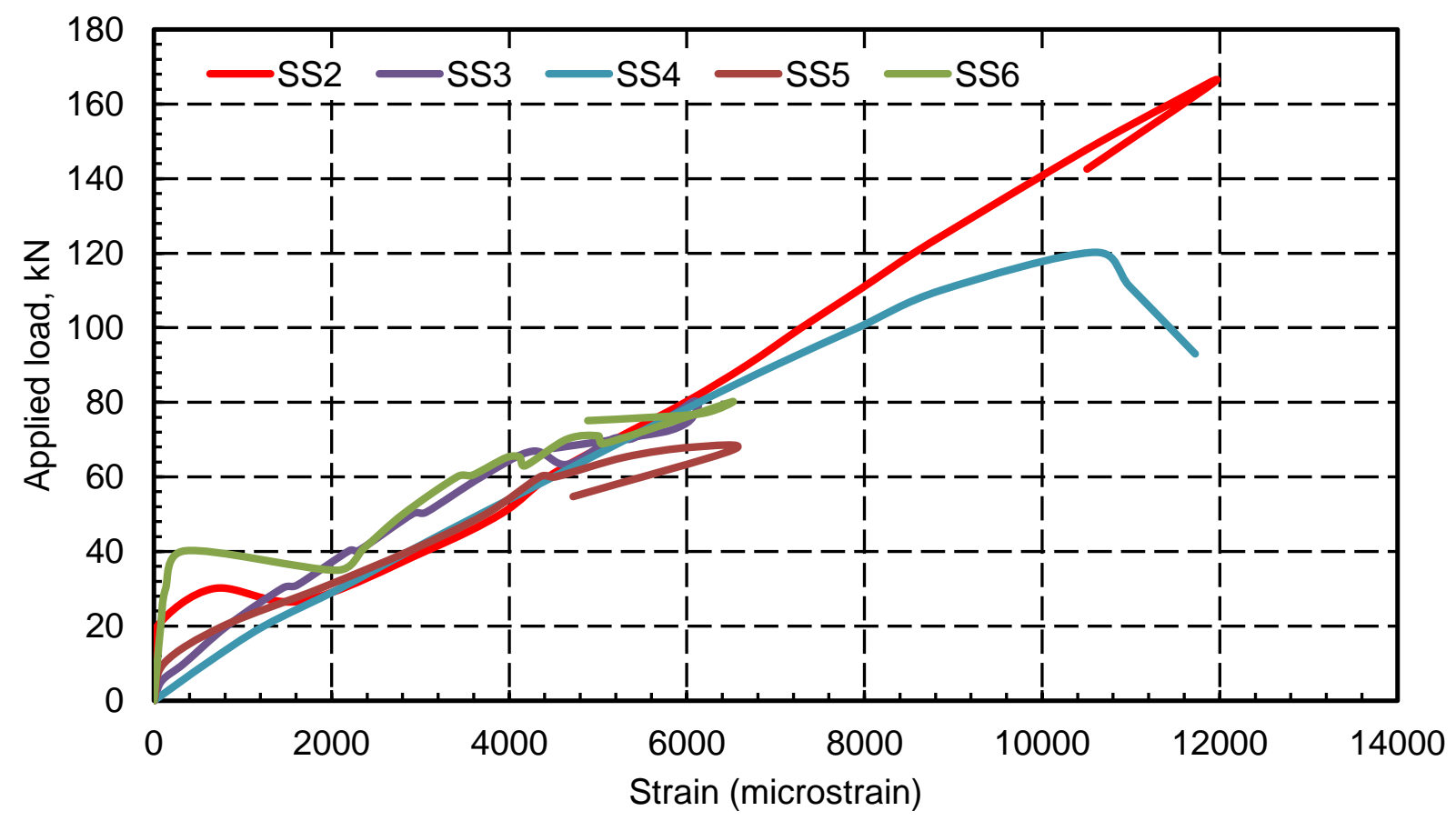

Figure A.19 Envelopes of the Load versus reinforcement strain of slabs SS2 through SS6 subjected to incremental loading to failure

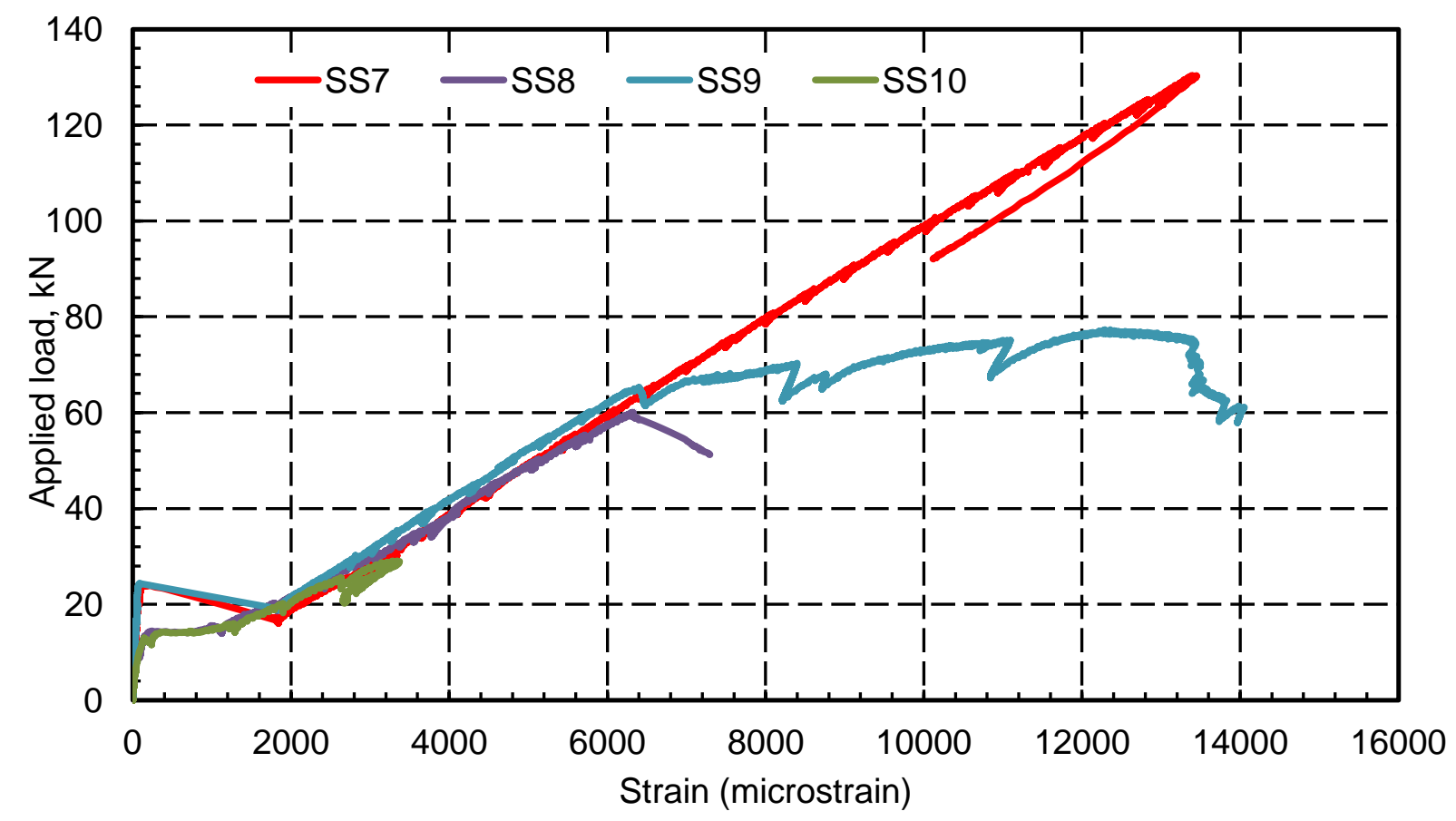

Figure A.20 Load versus reinforcement strain of slabs SS7 through SS10 subjected to increasing load to failure 


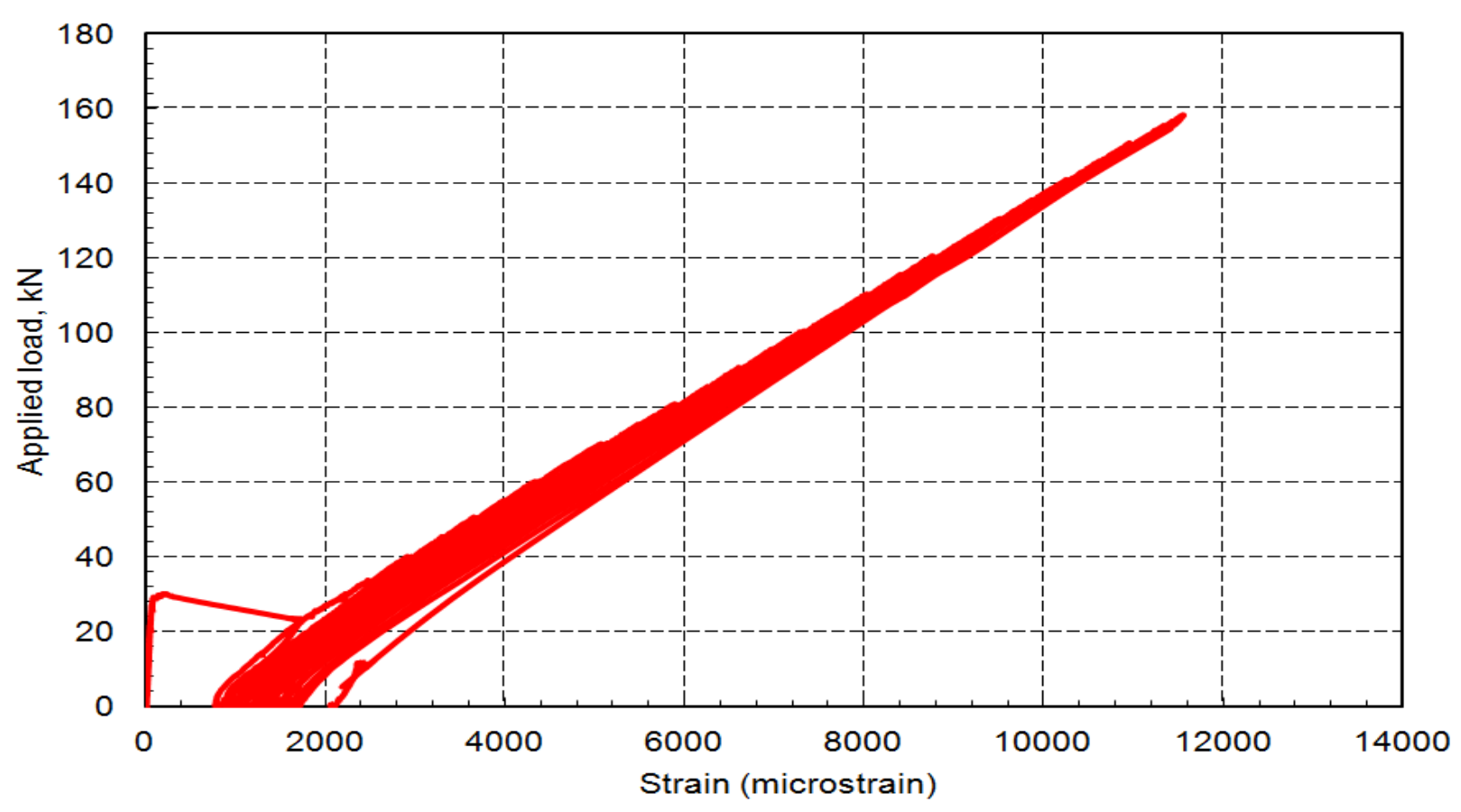

Figure A.21 Load versus reinforcement strain of slab PS1 subjected to incremental loading to failure

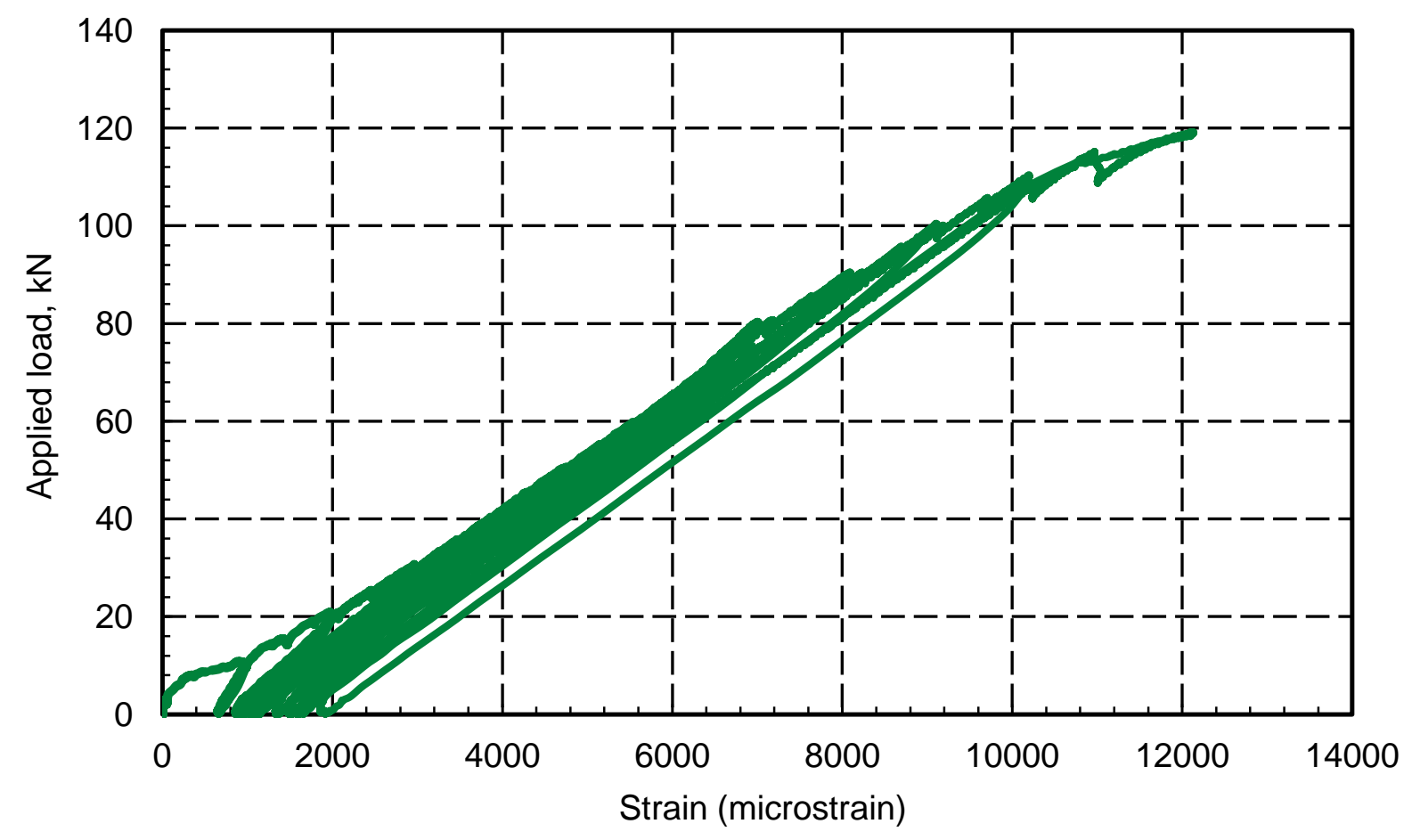

Figure A.22 Load versus reinforcement strain of slab PS2 subjected to incremental loading to failure 


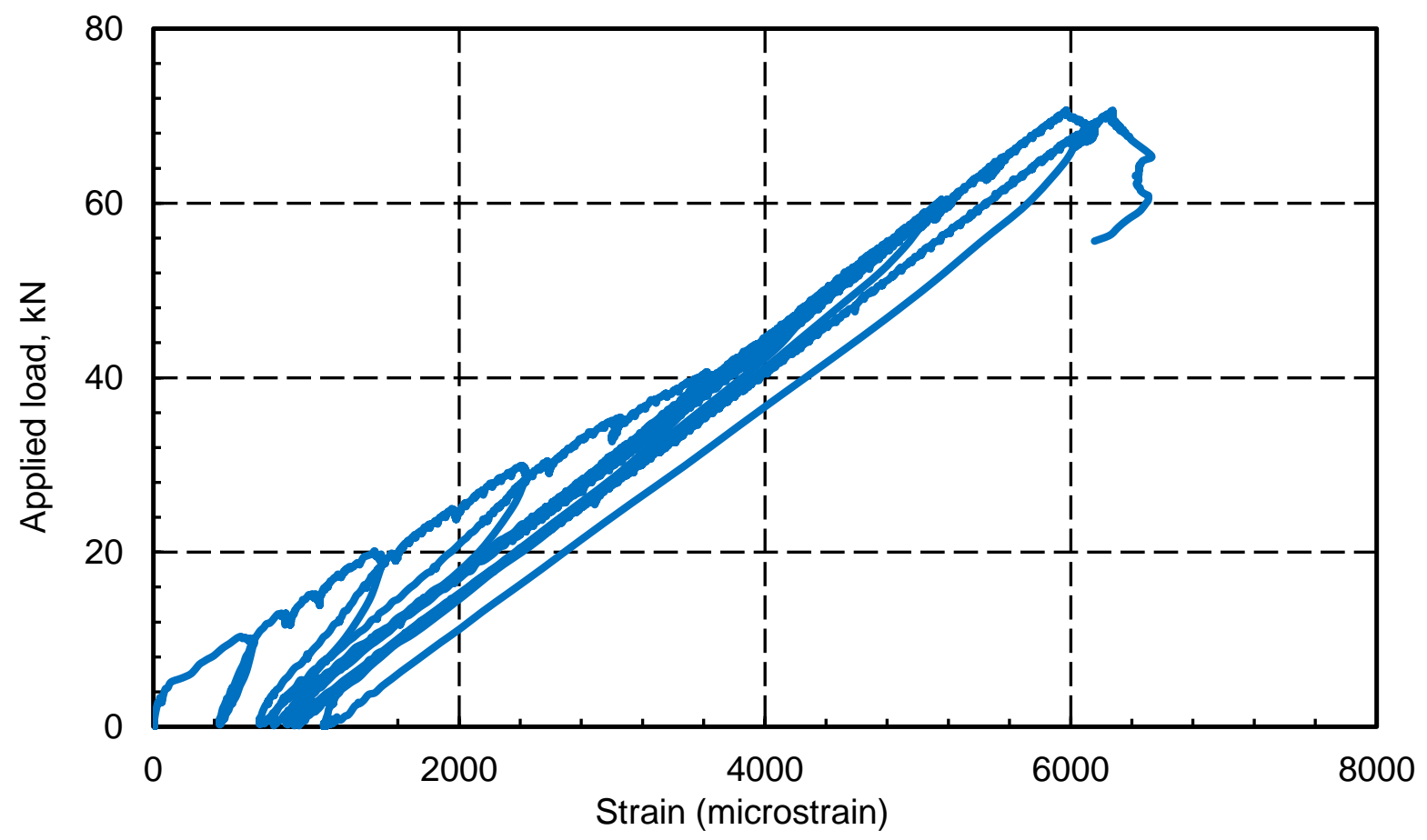

Figure A.23 Load versus reinforcement strain of slab PS3 subjected to incremental loading to failure

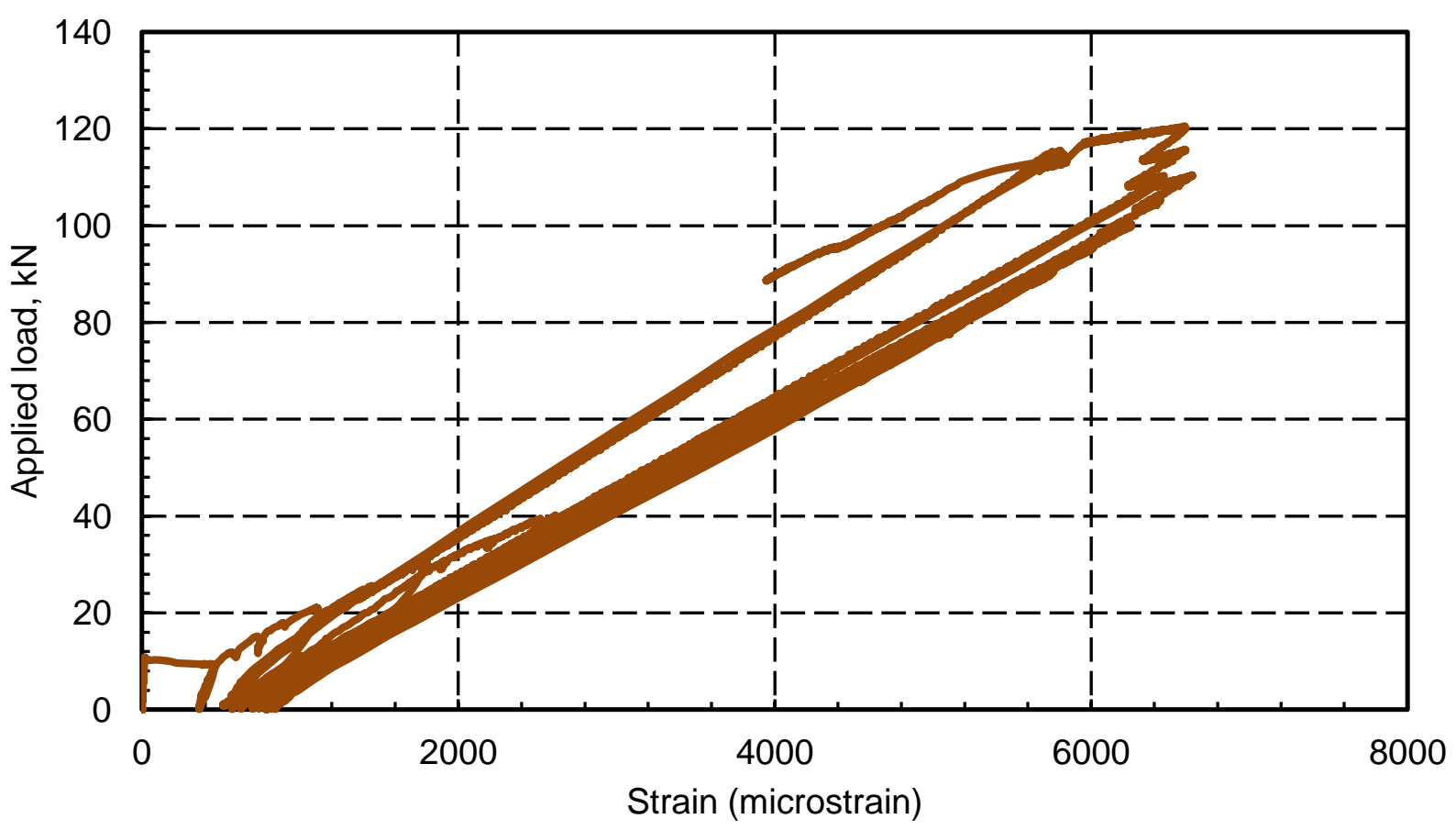

Figure A.24 Load versus reinforcement strain of slab PS4 subjected to incremental loading to failure 


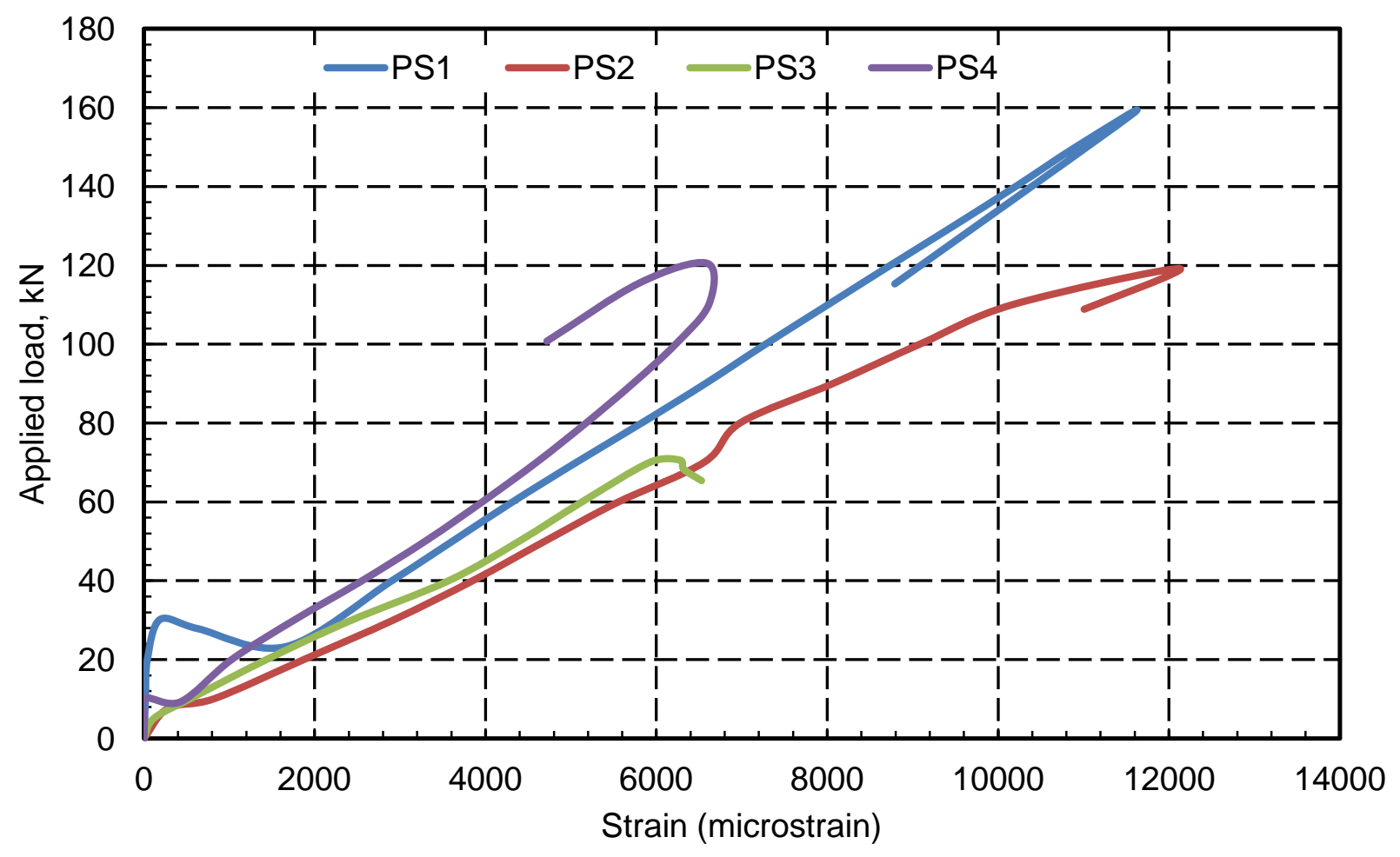

Figure A.25 Envelopes of the Load versus reinforcement strain of slabs PS1 through PS4 subjected to incremental loading to failure 


\section{APPENDIX B}




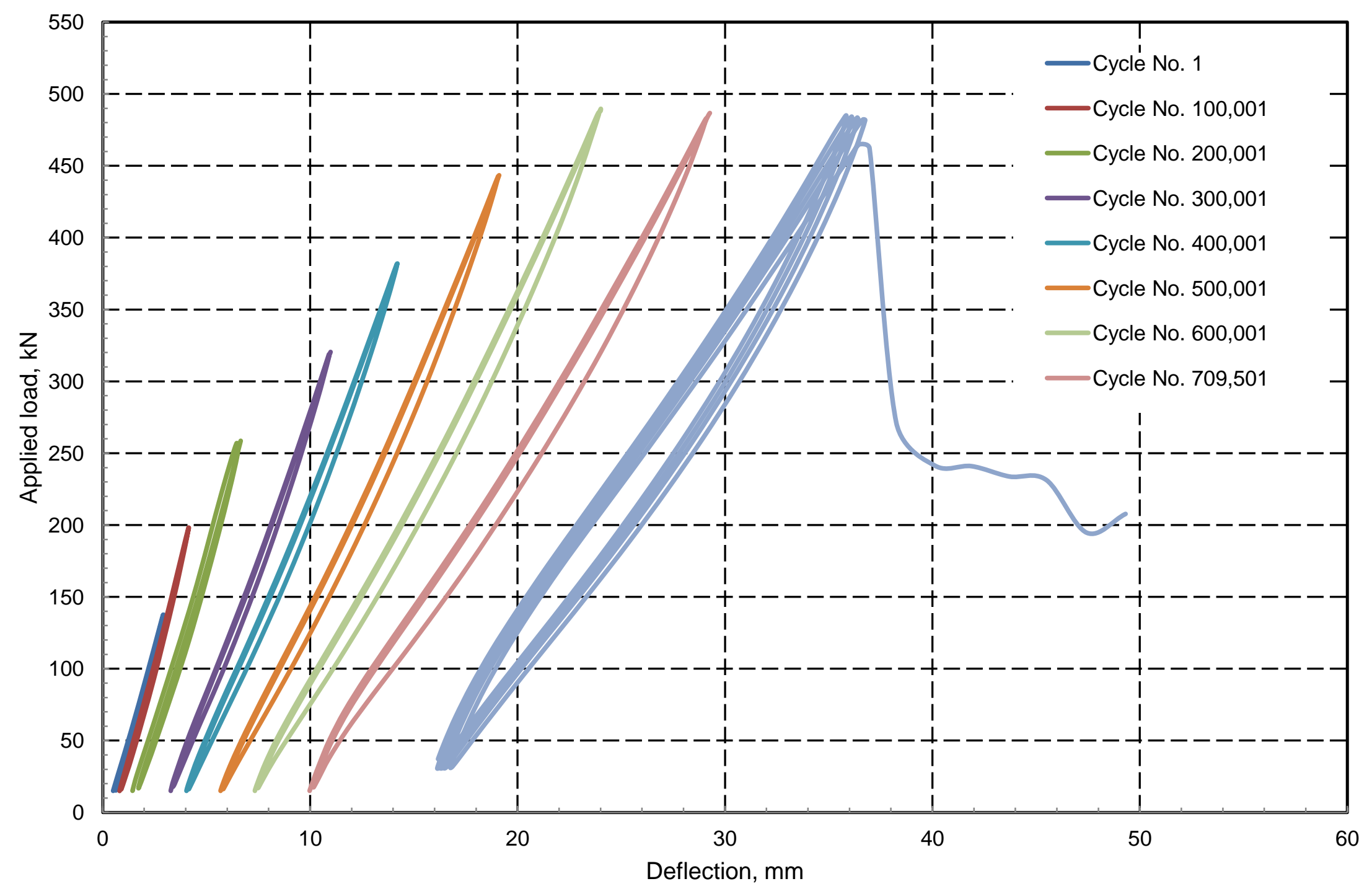

Figure B.1 Typical hysteresis curves of cast-in-place deck slab S2 under VAF loading 


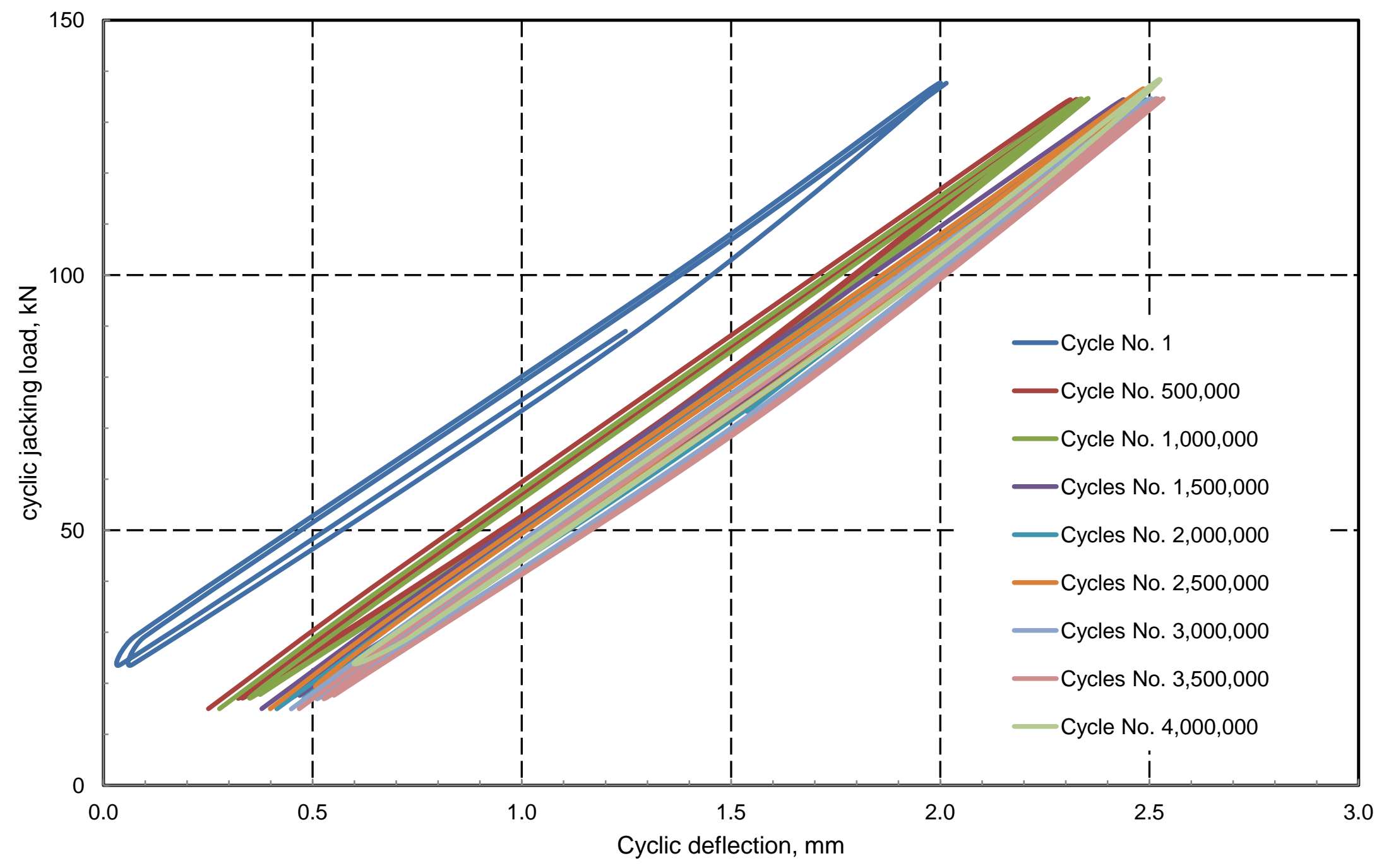

Figure B.2 Typical hysteresis curves of cast-in-place deck slab S3 under CAF loading 


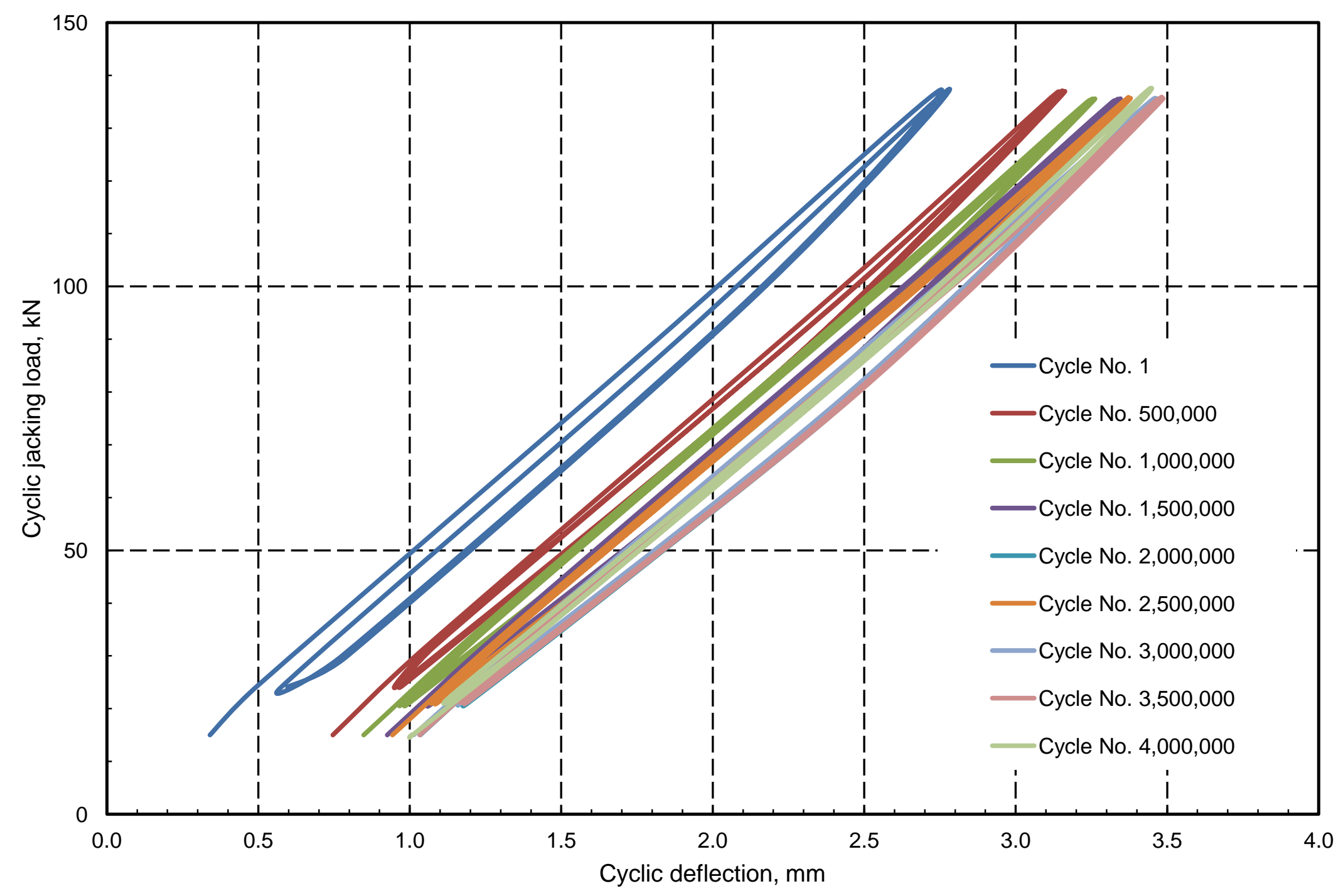

Figure B.3 Typical hysteresis curves of precast deck slab S4 under CAF loading 


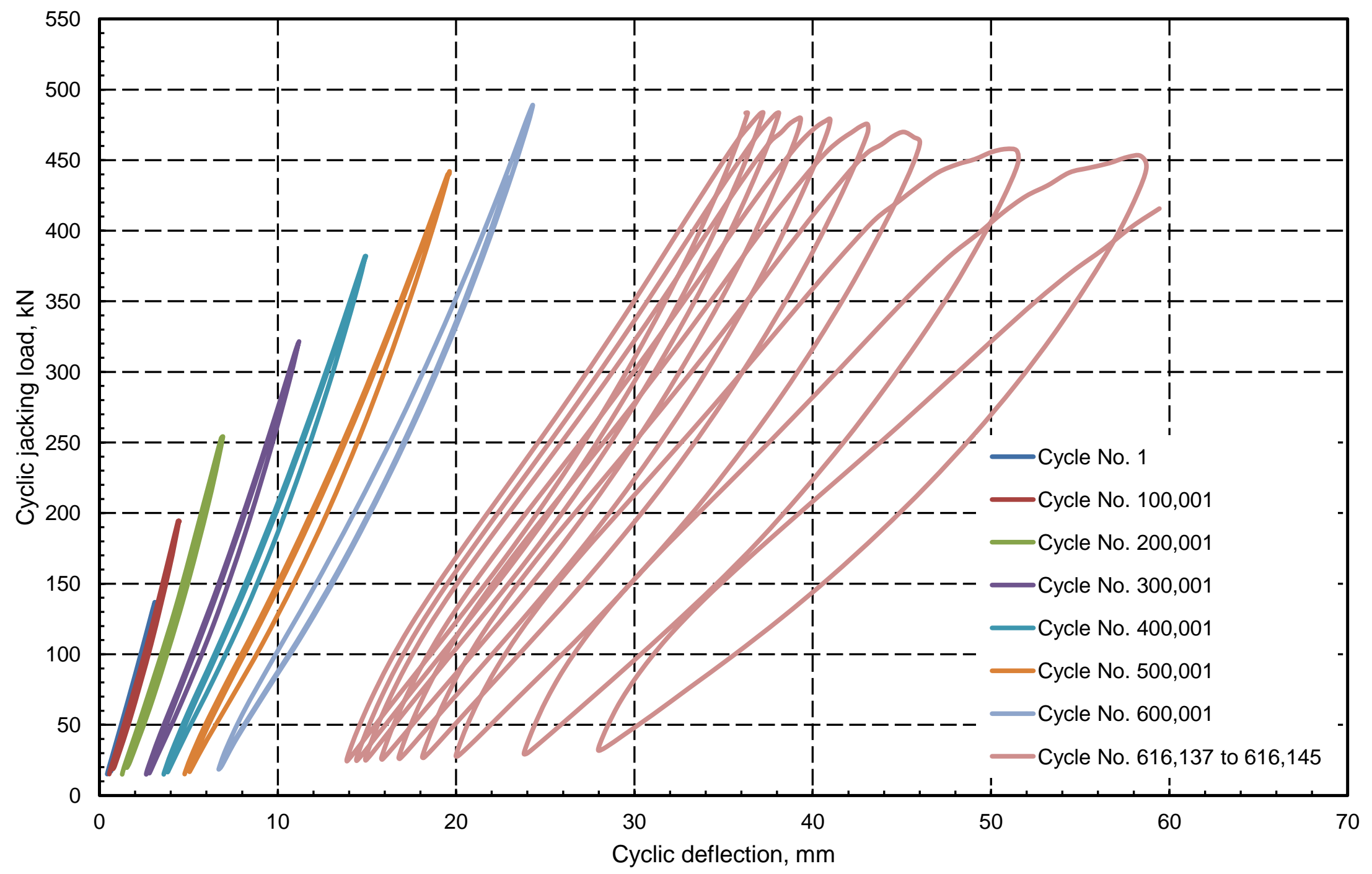

Figure B.4 Typical hysteresis curves of precast deck slab S5 under VAF loading 


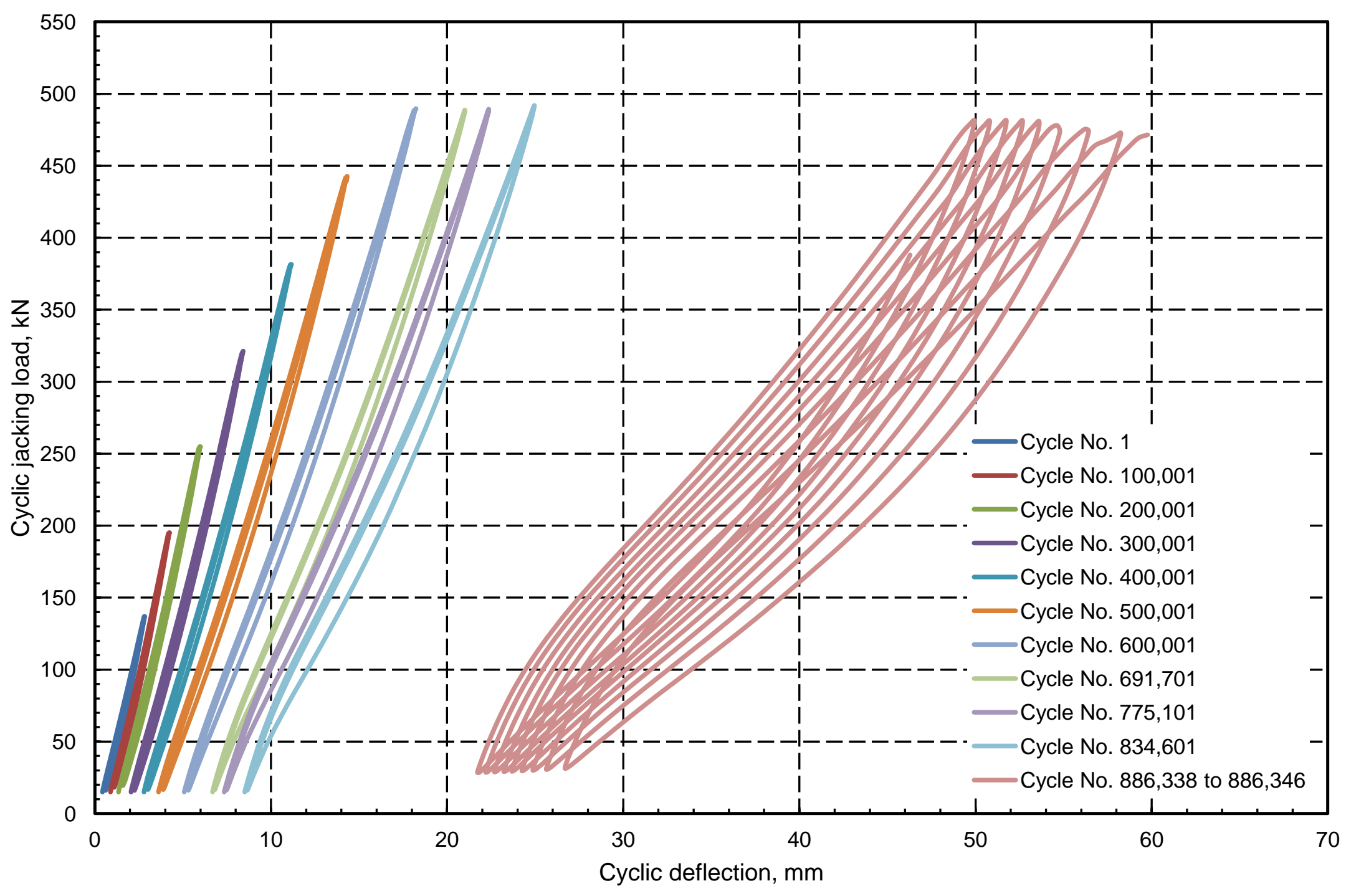

Figure B.5 Typical hysteresis curves of precast deck slab S7 under VAF loading 


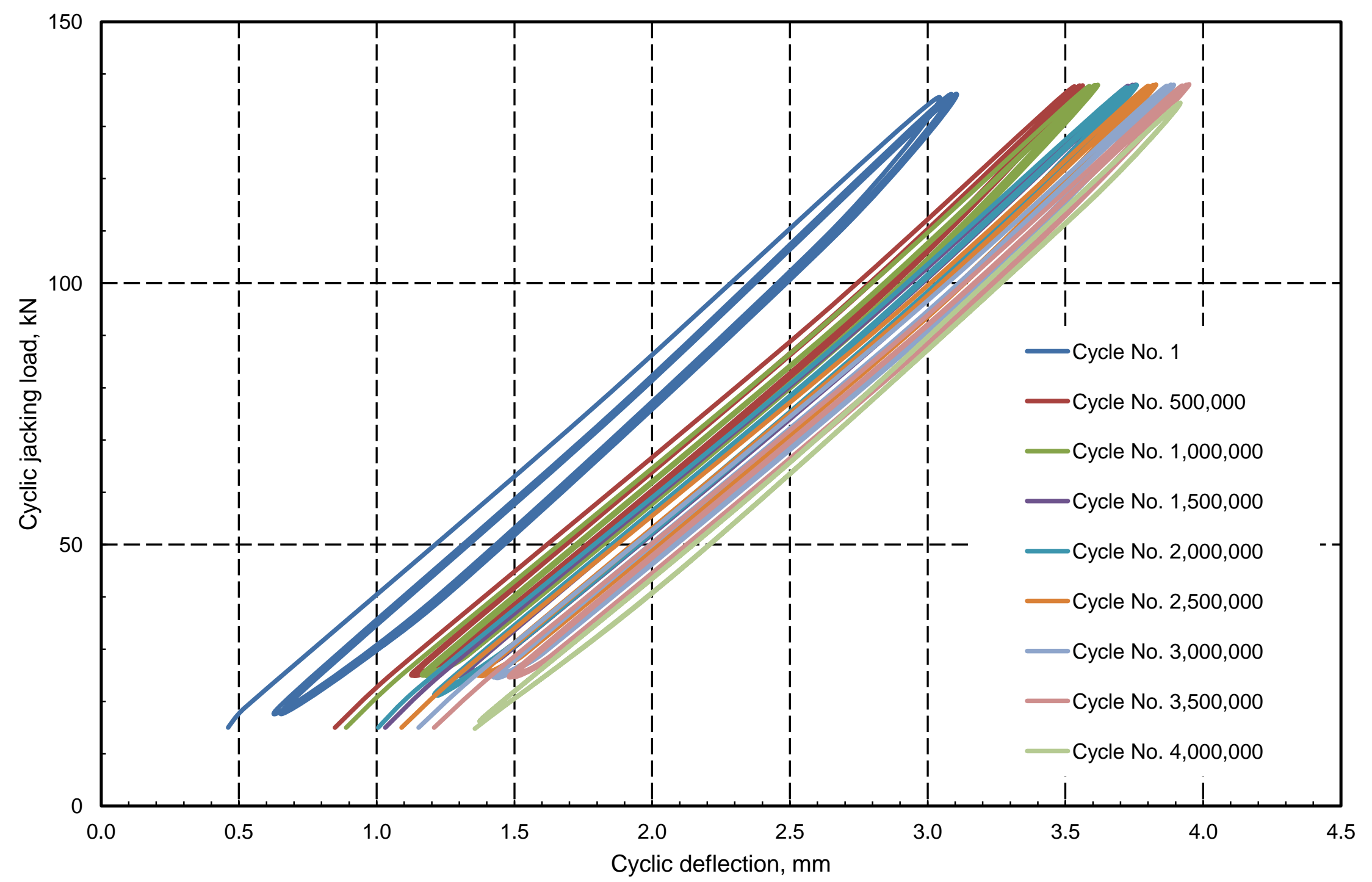

Figure B.6 Typical hysteresis curves of precast deck slab S8 under CAF loading 


\section{APPENDIX C}




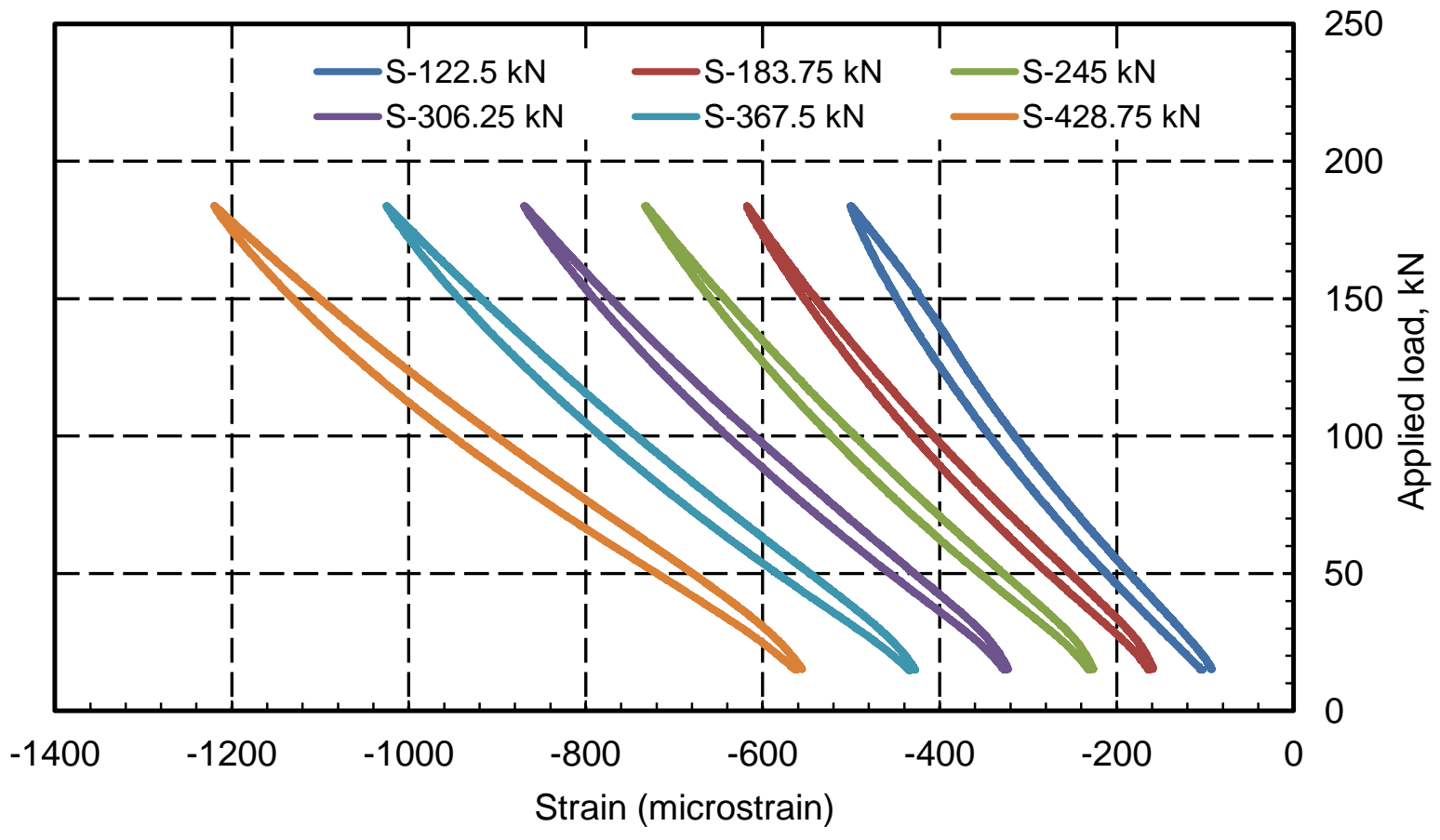

Figure C.1 Static load versus maximum concrete strain measured on top surface of slab S2 after different variable-amplitude fatigue loading steps

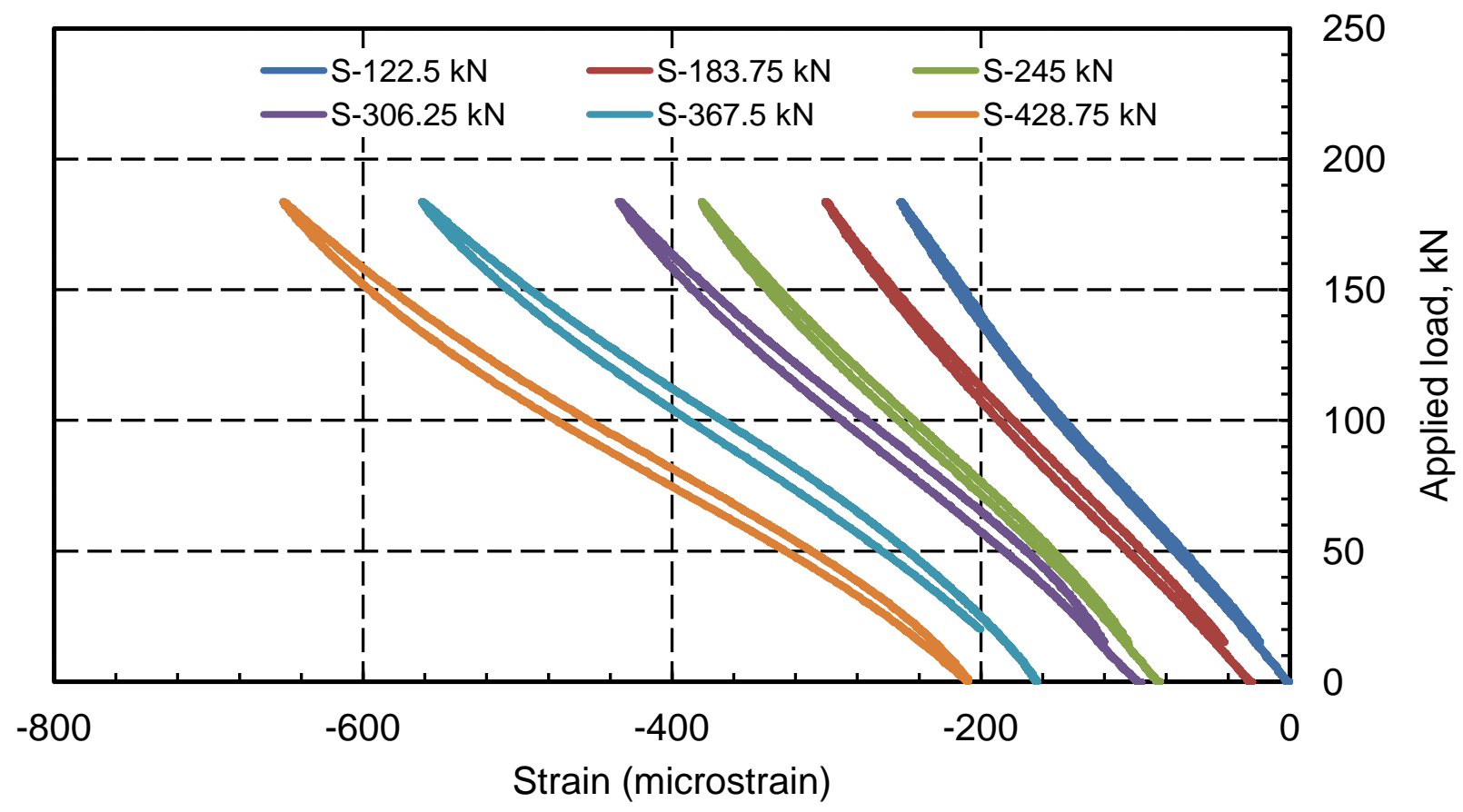

Figure C.2 Static load versus maximum concrete strain measured on top surface of slab S5 after different variable-amplitude fatigue loading steps 


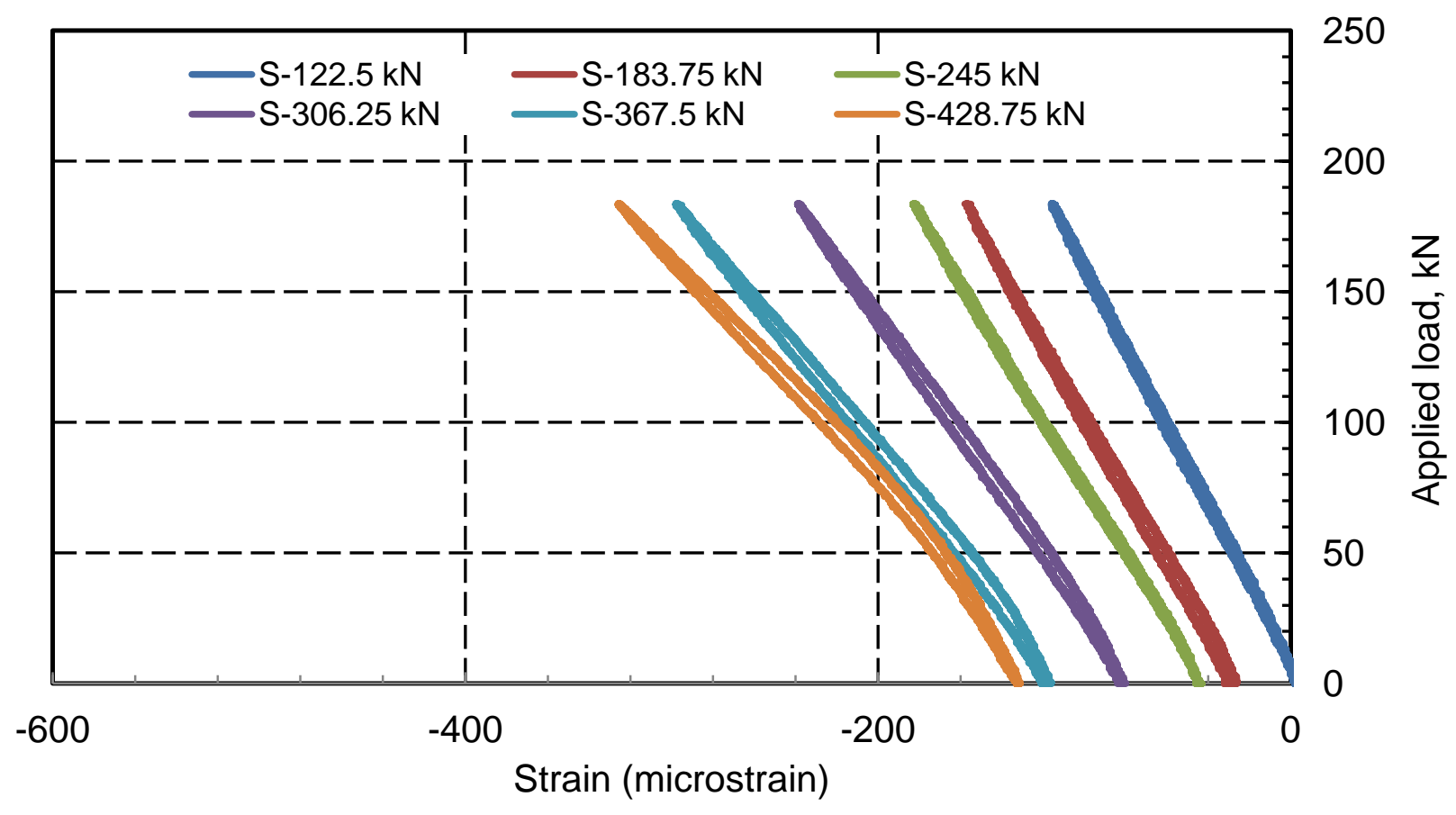

Figure C.3 Static load versus maximum concrete strain measured on top surface of slab S7 after different variable-amplitude fatigue loading steps

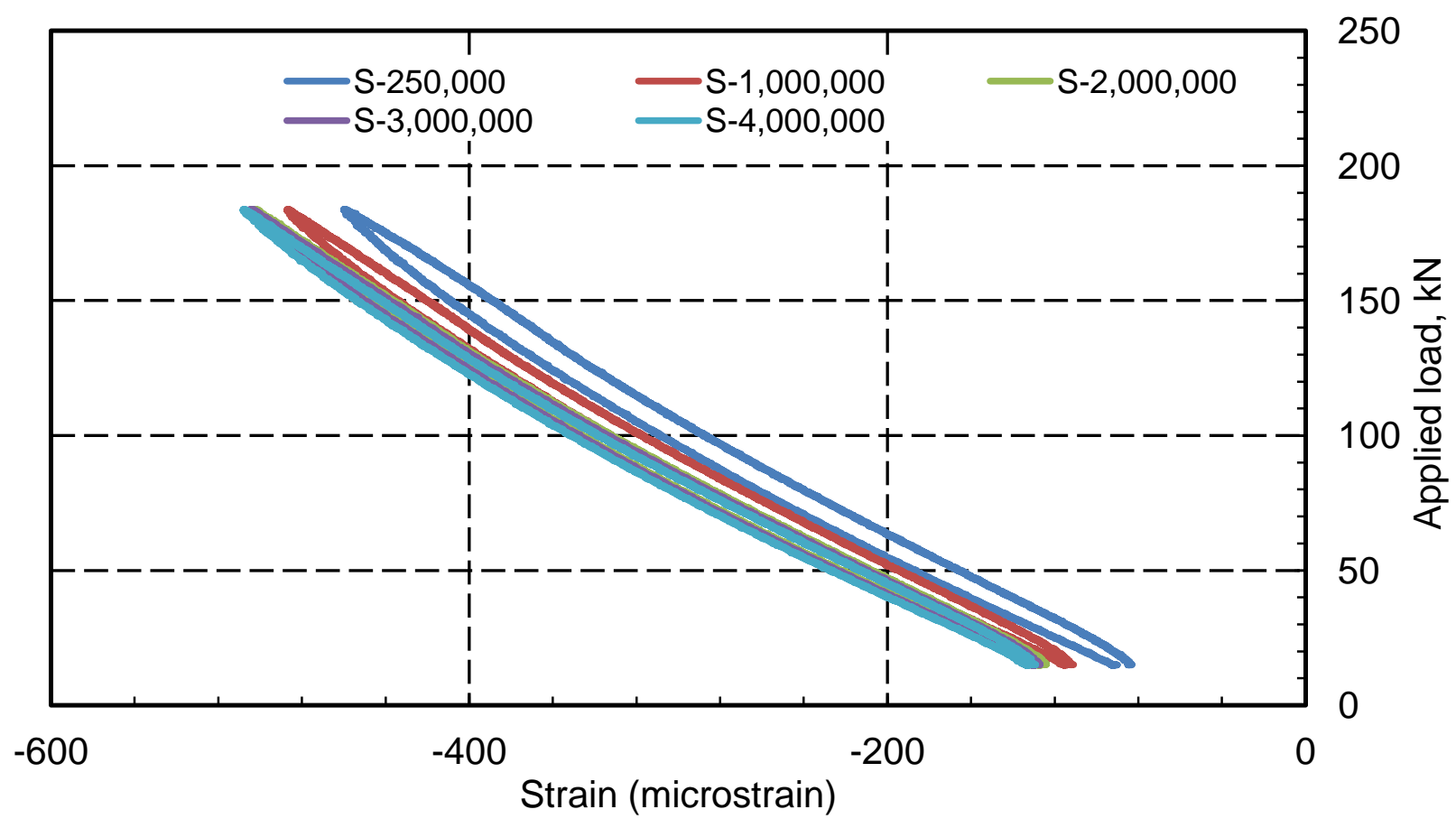

Figure C.4 Static load versus maximum concrete strain measured on top surface of slab S3 after different constant-amplitude fatigue loading cycles 


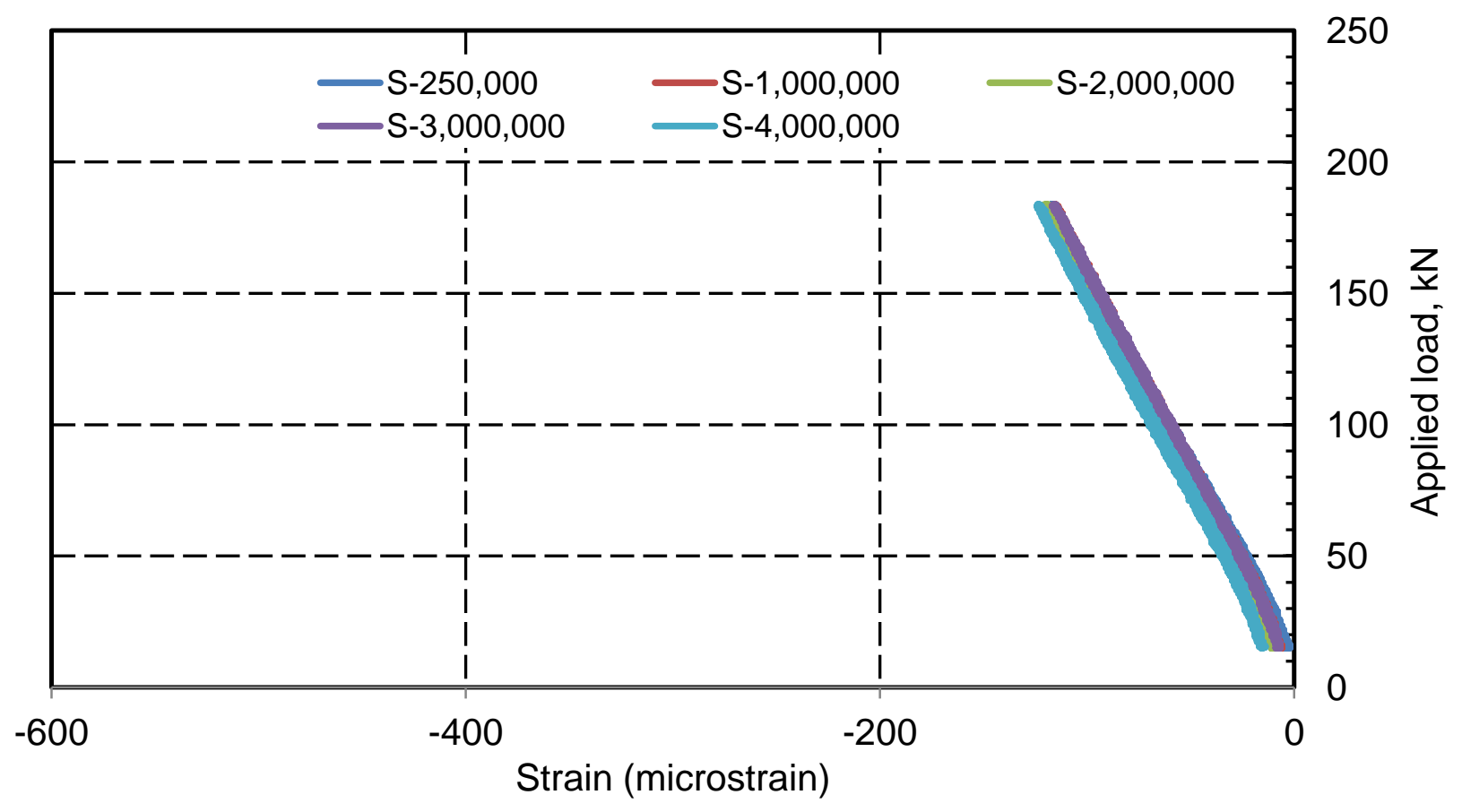

Figure C.5 Static load versus maximum concrete strain measured on top surface of slab S4 after different constant-amplitude fatigue loading cycles

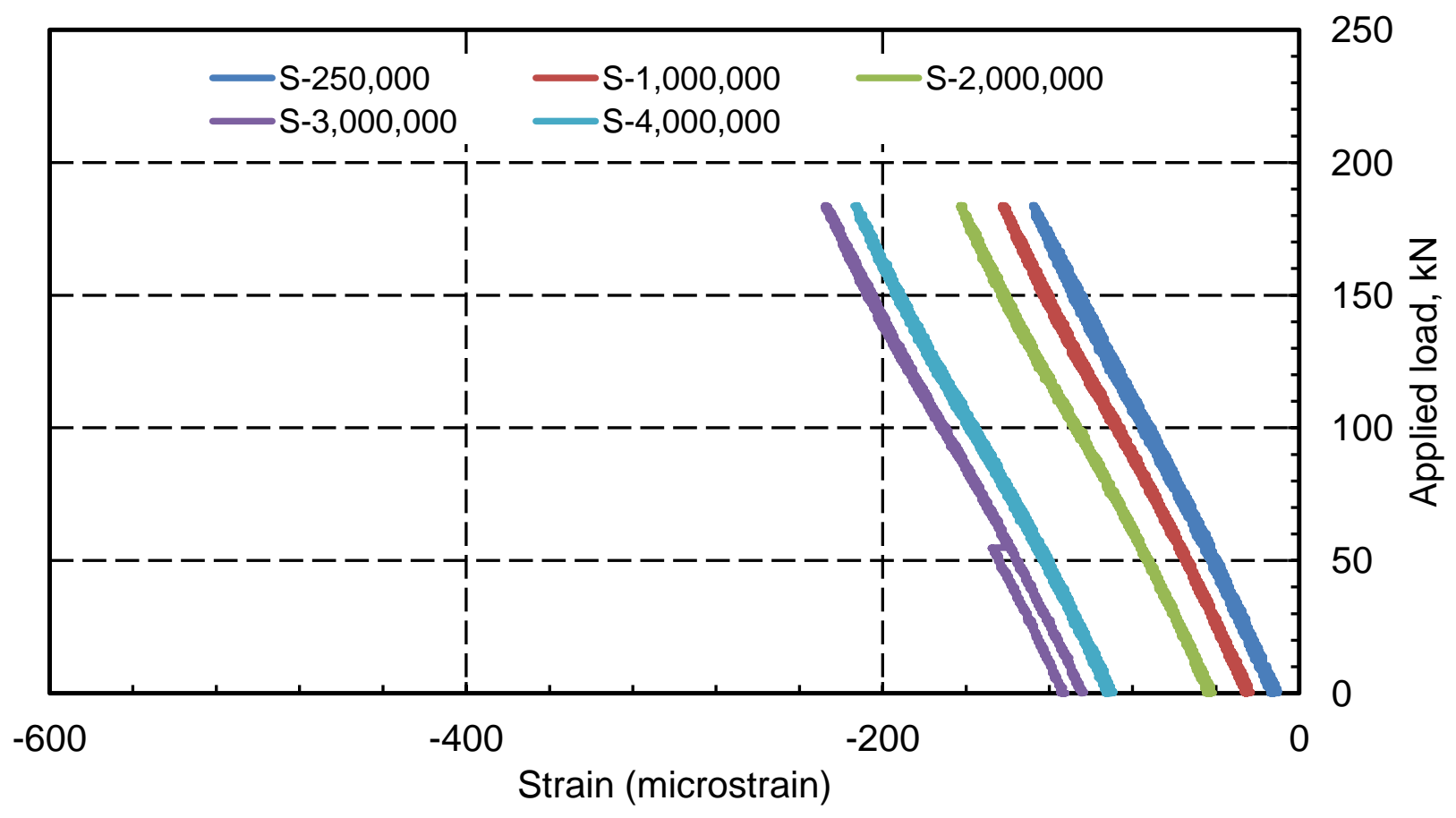

Figure C.6 Static load versus maximum concrete strain measured on top surface of slab S8 after different constant-amplitude fatigue loading cycles 


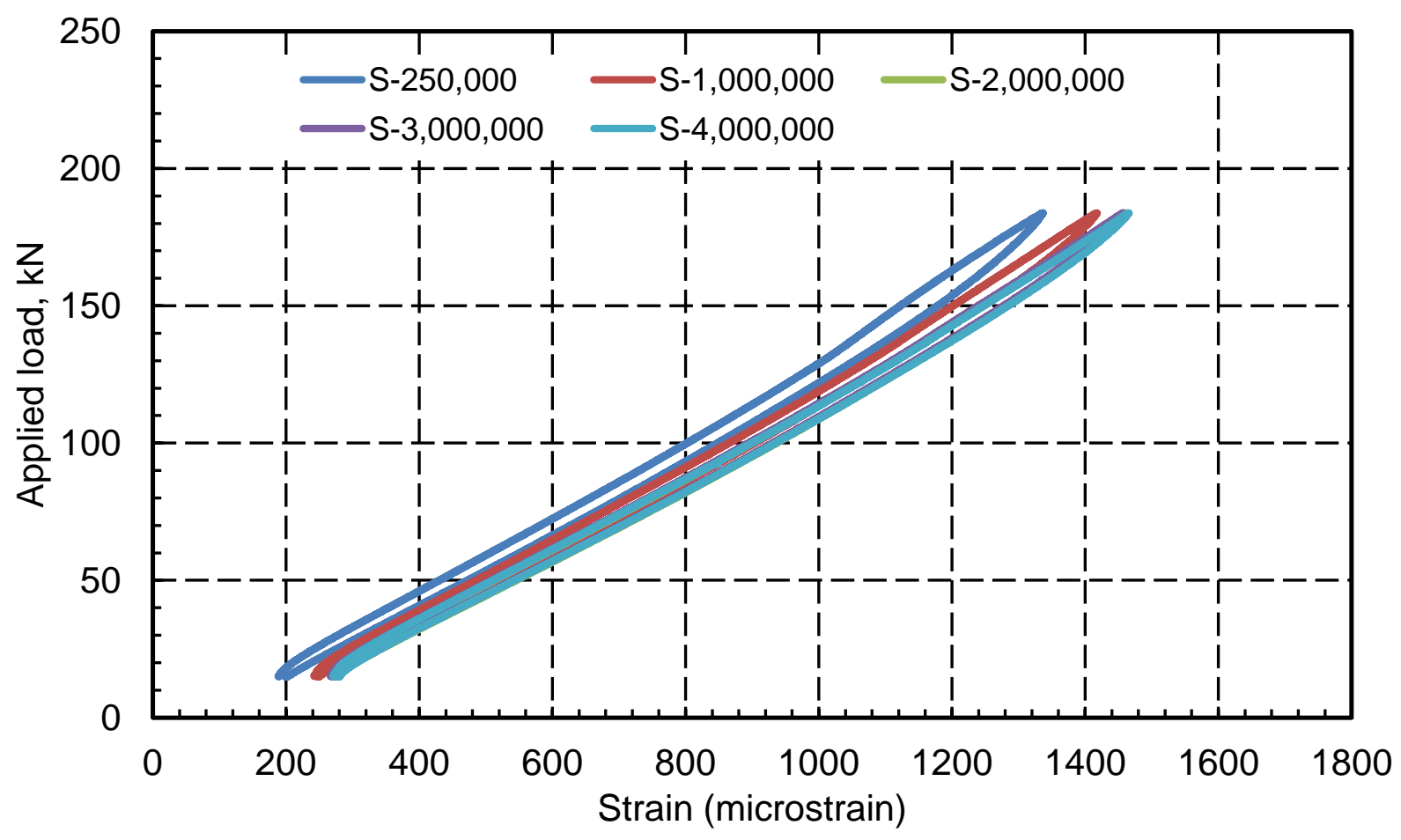

Figure C.7 Static load versus maximum reinforcement strain of slab S3 after different constant-amplitude fatigue loading cycles

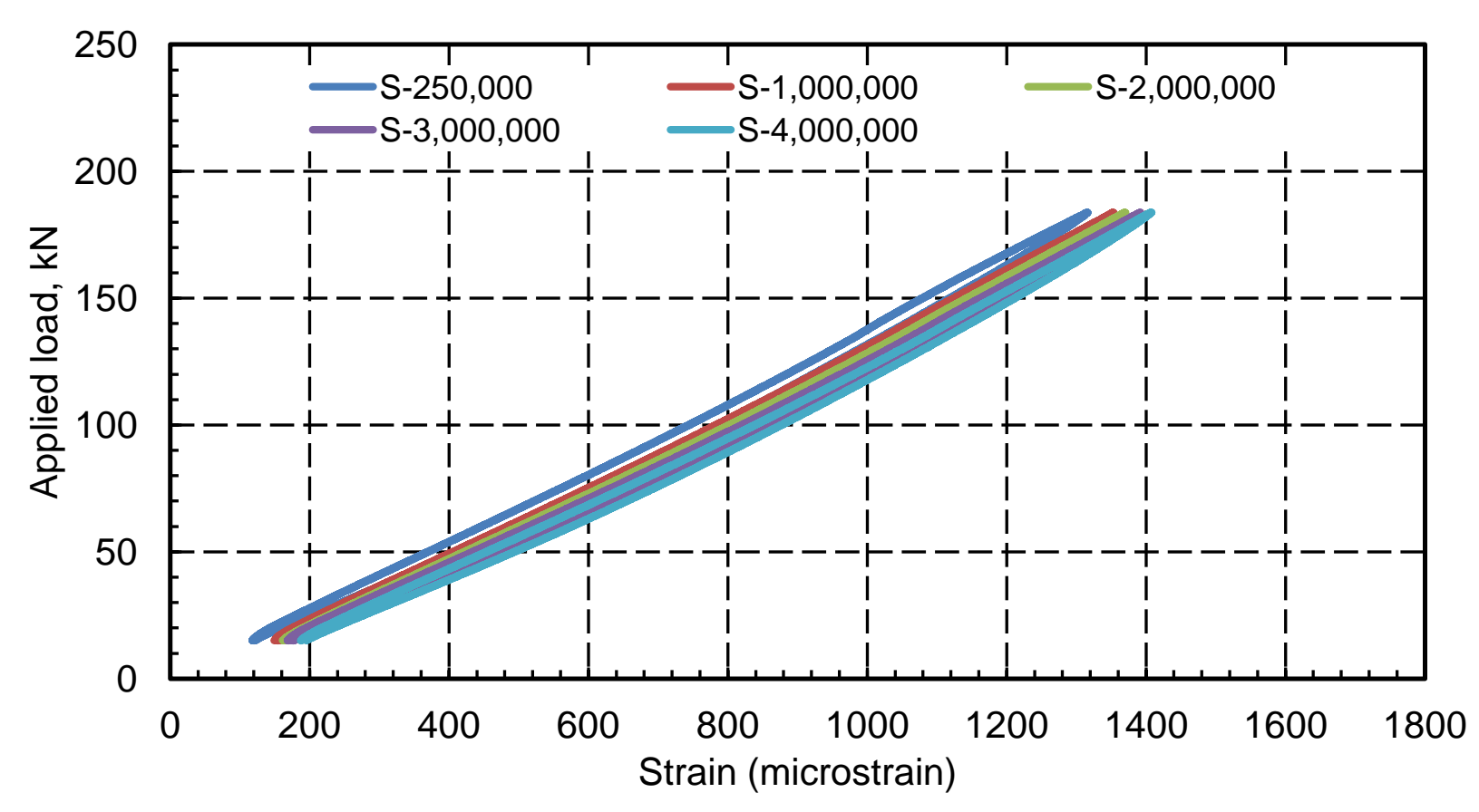

Figure C.8 Static load versus maximum reinforcement strain of slab S4 after different constant-amplitude fatigue loading cycles 


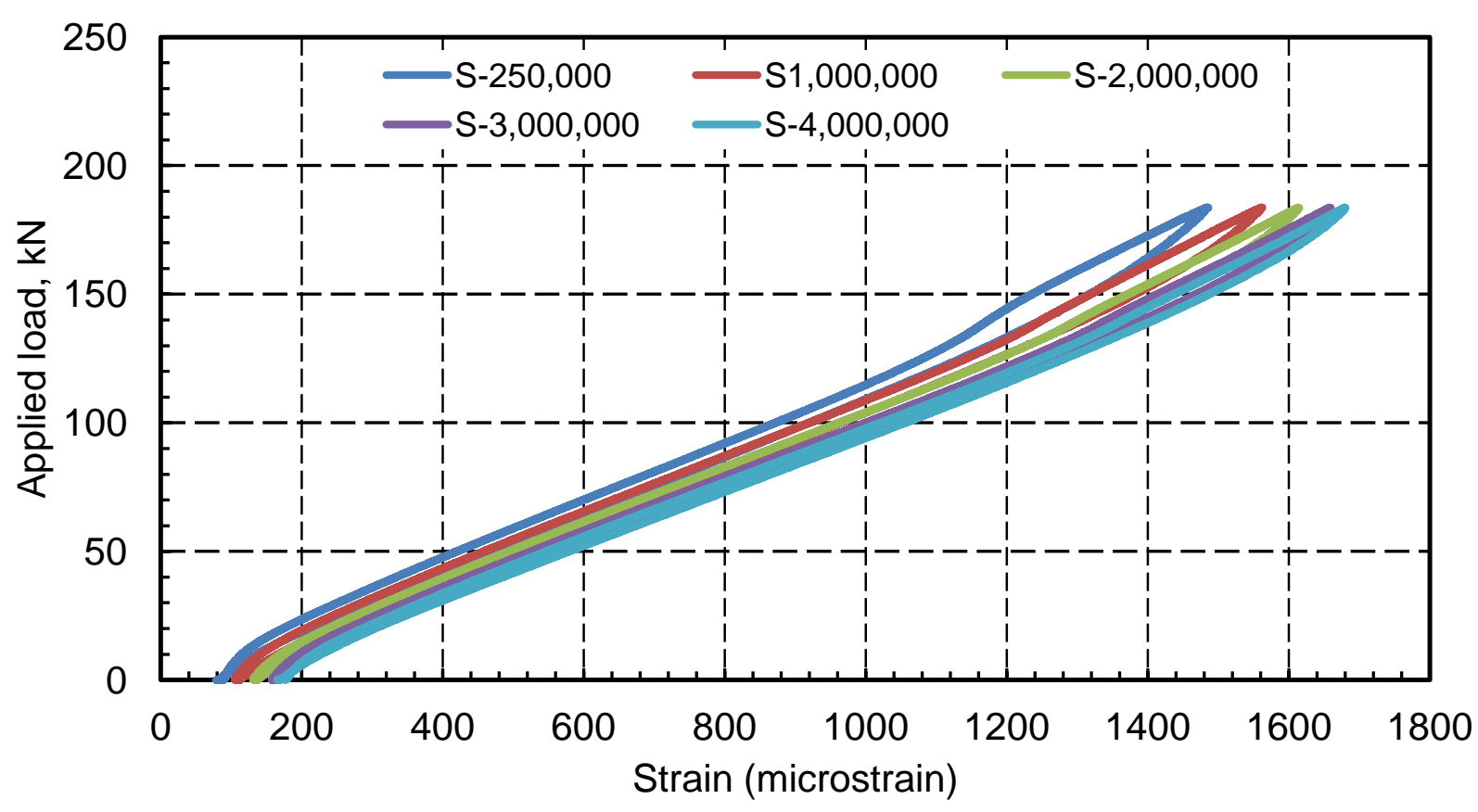

Figure C.9 Static load versus maximum reinforcement strain of slab S8 after different constant-amplitude fatigue loading cycles

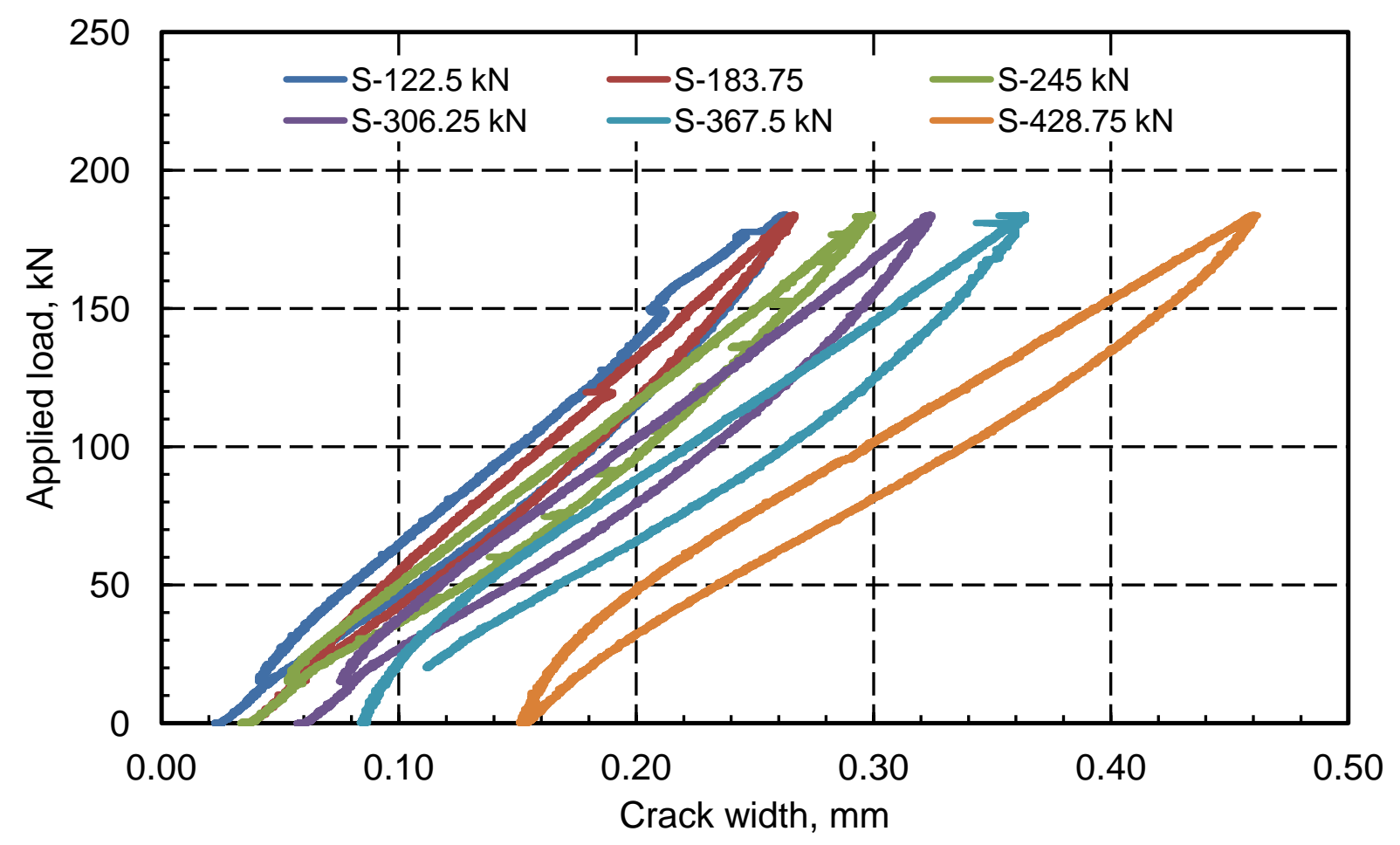

Figure C.10 Static load versus crack width of slab S5 after different variable-amplitude fatigue loading steps 


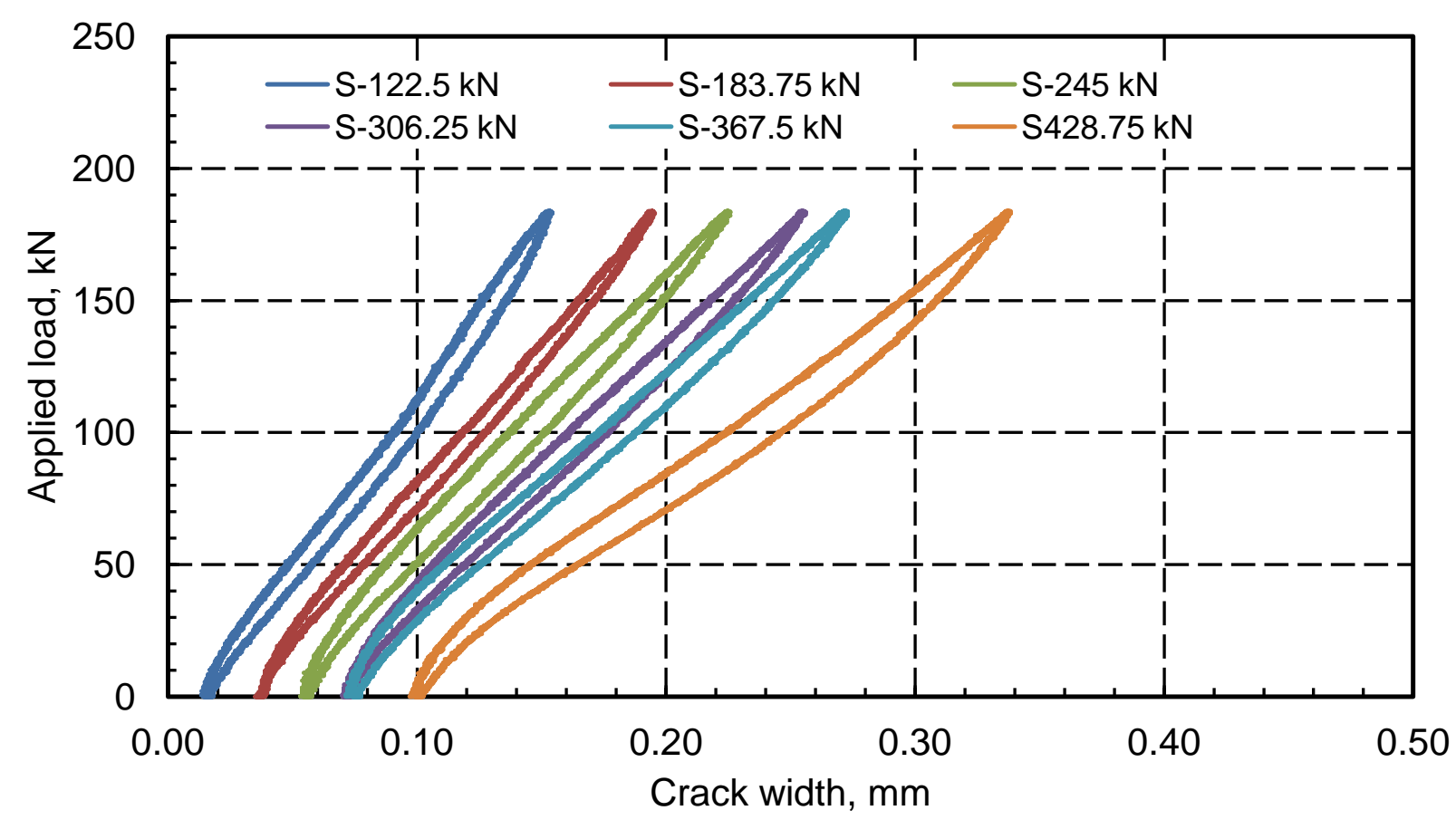

Figure C.11 Static load versus crack width of slab S7 after different variable-amplitude fatigue loading steps

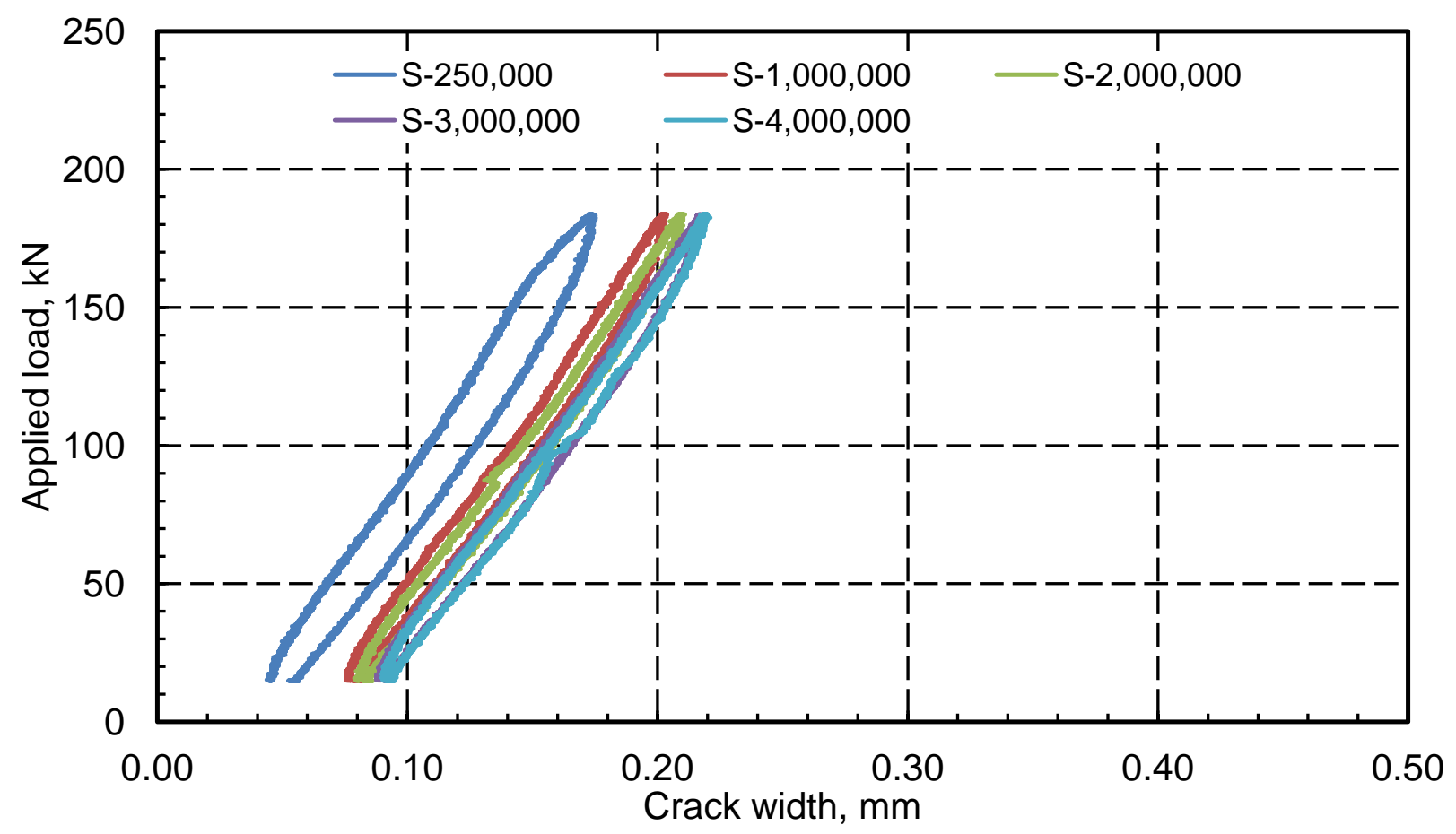

Figure C.12 Static load versus crack width of slab S3 after different constant-amplitude fatigue loading cycles 


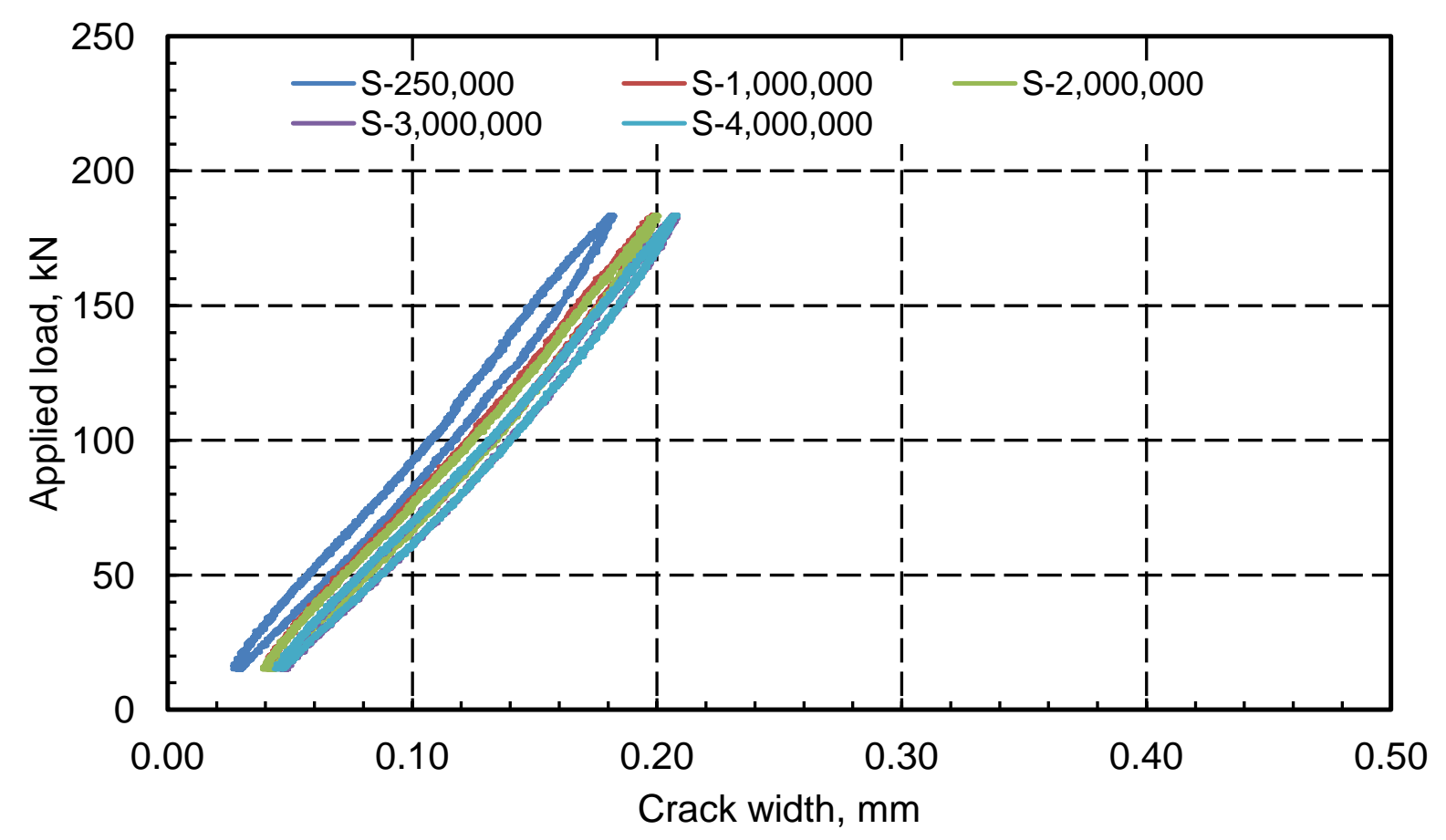

Figure C.13 Static load versus crack width of slab S4 after different constant-amplitude fatigue loading cycles

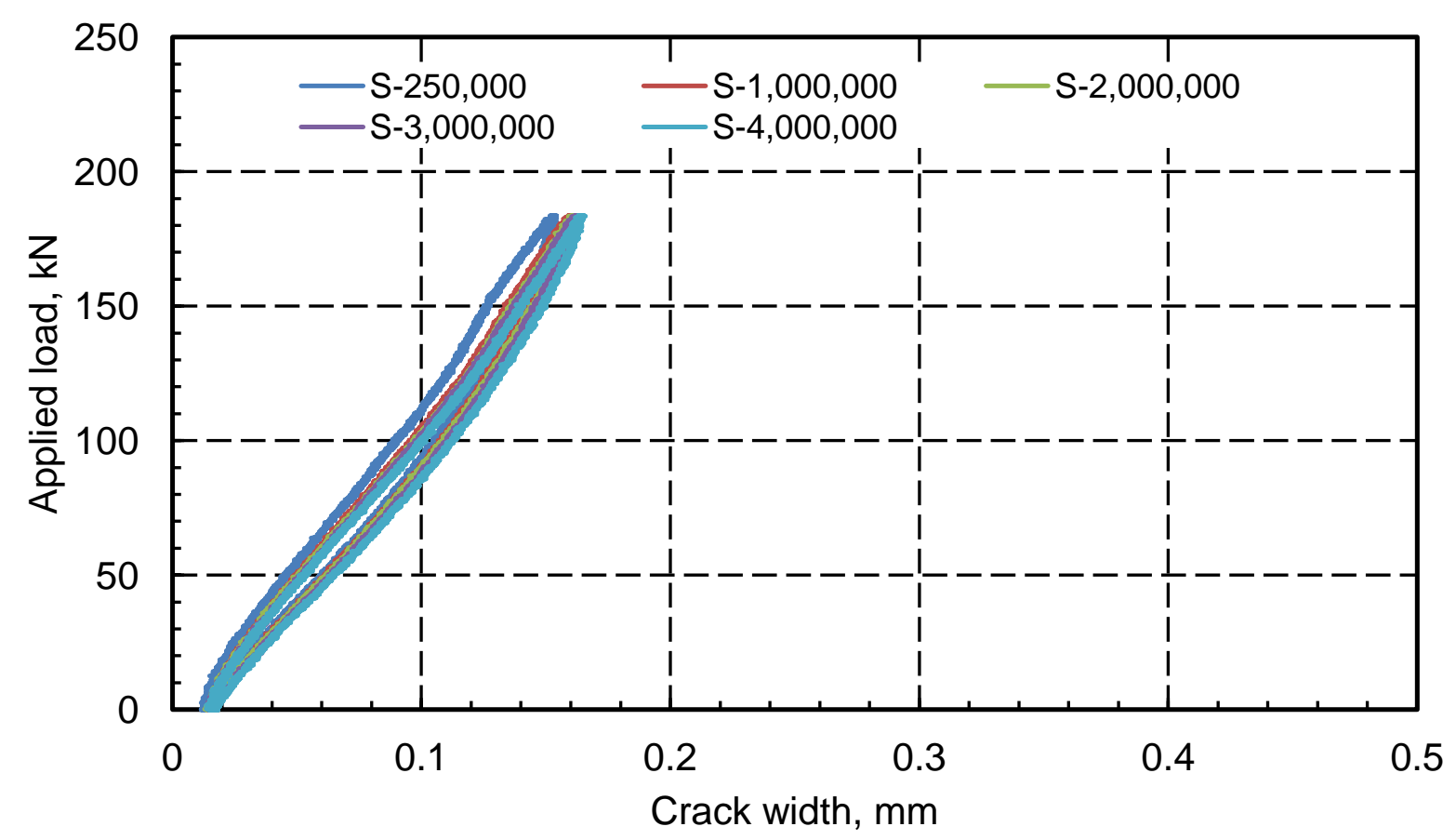

Figure C.14 Static load versus crack width of slab S8 after different constant-amplitude fatigue loading cycles 


\section{REFERENCES}

AASHTO. 2010. AASHTO-LRFD Bridge Design Specifications. American Association of State Highway and Transportation Officials. Washington, D.C.

AASHTO. 2009. AASHTO-LRFD Bridge Design Guide Specifications for GFRP-Reinforced

Concrete Bridge Decks and Traffic Railings. American Association of State Highway and Transportation Officials, Washington, D.C.

Abendroth, R. E. 1995. Nominal Strength of Composite Prestressed Concrete Bridge Deck Panels, Journal of Structural Engineering, 121 (2): 307-318.

ACI Committee 440. 2006. Guide for the Design and Construction of Structural Concrete Reinforced with FRP Bars, ACI 440.1R-06. American Concrete Institute, Farmington Hills, MI, USA.

ACI Committee 318. 2008. Building code requirements for structural concrete (ACI 318-08) and commentary, ACI 318R-08. American Concrete Institute, Farmington Hills, MI, USA.

ACI 318-05. 2005. Building Code Requirements for Structural Concrete and Commentary. American Concrete Institute, Farmington Hills, MI, USA.

ACI. 1998. Provisional Design Recommendations for Concrete Reinforced with FRP Bars, ACI 440R-98. American Concrete Institute, Farmington Hills, MI, USA, September, Sec. 6.5.

Adimi, M., Rahman, A., and Benmokrane, B. 2000. New Method for Testing Fibre-Reinforced Polymer Rods Under Fatigue. Journal of Composites for Construction, 4(4): 206-213.

Ahmed, E. and Benmokrane, B. 2009. Development and Strength Evaluation of the Headed GFRP Bars. Report submitted to Pultrall Inc., Department of Civil Engineering, Université de Sherbrooke, Sherbrooke, Québec, Canada. 
Alexander S. and Simmonds S. 1987. Ultimate Strength of Slab-Column Connections. ACI Structural Journal, 84(3): 255-61.

Arockiasamy, M., Badve, A. P., Rao, B. V. and Reddy, D. V. 1991. Fatigue Strength of Joints in a Precast Prestressed Concrete Double Tee Bridge. PCI Journal, 36(1): 84-97.

Au, A., Lam, C., and Tharmabala, B. 2008. Investigation of Prefabricated Bridge Systems using Reduced-Scale Models. PCI Journal, 53(6): 67-95.

Au, A., Lam, C., and Tharmabala, B. 2011. Investigation of Closure Strip Details for Connecting Prefabricated Deck Systems. PCI Journal, 56(3): 75-93.

Badie, S. and. Tadros, M. 2008. Full-Depth Precast Concrete Bridge Deck Panel Systems. Technical Report submitted to NCHRP, National Cooperative Highway Research Program, report 584, Washington, D.C.

Bank, L.C. and Gentry, R.T. 1995. Accelerated Test Methods to Determine the Long-Term Behaviour of FRP Composite Structures: Environmental Effects. Journal of Reinforced Plastics and Composites, 14: 559-587.

Bank, L.C. and Gentry, R.T., Barakatt, A., Prian, L., Wang, F. and Mangla, S.R. 1998. Accelerated Aging of Pultruded Glass/Vinylester Rods. Proceedings of $2^{\text {nd }}$ International Conference on Fiber Composites in Infrastructure (ICCI), 2:423-437.

Batchelor, B.D. and Hewitt, B.E. 1974. Are Composite Bridge Slabs too Conservatively Designed? Fatigue Studies. Fatigue of Concrete. ACI Special Publication (AP4-15): 331-346.

Bažant Z.P., Cao Z. 1987. Size Effect in Punching Shear Failure of Slabs. ACI Structural Journal, 84(1): 44-53.

Benmokrane, B., and Rahman, H. 1998. Durability of Fiber Reinforced Polymer (FRP) Composites for Construction. Proceedings of the First International Conference, (CDCC '98), Sherbroke, 
Québec, Canada, 692 pp.

Benmokrane, B., Wang, P., Ton-That, T.M., Rahman, H. and Jean-Francois Robert, J.F. 2002.

Durability of Glass Fiber-Reinforced Polymer Reinforcing Bars in Concrete Environment. Journal of Composites for Construction, 6(3): 143-153.

Benmokrane, B., El-Salakawy, E., El-Ragaby, A., and Lackey, T. 2006. Designing and Testing of Concrete Bridge Decks Reinforced with Glass FRP Bars. Journal of Bridge Engineering, ASCE, 11(2): 217-229.

BS 8110. 1997. Structural Use of Concrete, Part 1, Code of Practice for Design and Construction. British Standards Institution, London.

Burgoyne, C. 2001. Non-Metallic Reinforcement for Concrete Structures. Proceedings of the $5^{\text {th }}$ International Conference on Fibre Reinforced Plastics for Reinforced Concrete Structures (FRPRCS-5), Cambridge, UK.

Campbell, F.C. 2010. Structural Composite Materials. ASM International, Materials Park, Ohio.

CHBDC. 2006. Canadian Highway Bridge Design Code, CSA-S6-06. Canadian Standard Association (CSA), Toronto, Ontario, Canada, 734 pp.

CAN/CSA-S806-02. 2002. Design and Construction of Building Components with FibreReinforced Polymers. Canadian Standard Association, Rexdale, Ontario, Canada, 177 pp.

CAN/CSA-S806-12. 2012. Design and Construction of Building Structures with FibreReinforced Polymers. Rexdale, Ontario, Canada, 37 pp.

CEB-FIP MC 90. 1993. Design of Concrete Structures, CEB-FIP-model-code 1990. Thomas Telford, $437 \mathrm{pp}$.

Choi K., Park H., and Wight J.K. 2007. Unified Strength Model for Reinforced Concrete BeamsPart I: Development. ACI Structural Journal, 104(1):142-152. 
Chun Sung-Chul, Oh Bohwan, Lee Sung-Ho, and Naito J. Clay. 2009. Anchorage Strength and Behavior of Headed Bars in Exterior Beam-Column Joints. ACI Structural Journal, 106(5): 579-590.

Clarke, J.L. and Sheard, P. 1998. Designing Durable FRP Reinforced Concrete Structures. Proceedings of $1^{\text {st }}$ International Conference on Durability of Fiber Reinforced Polymers (FRP) Composite for Construction (CDCC 1998), Sherbrooke, Quebec, Canada: 13-24.

Cosenza, E., Manfredi, G., and Nanni, A. 2001. Composites in Construction: A Reality. Proceedings of the International Workshop, Capri, Italy, ASCE, Reston, Va., 277 pp.

David Z.Y., and Orit L. 1999. Punching Shear in Concrete Slabs. International Journal of Mechanical Sciences, 41(1):1-15.

Nielsen, M.P. 1999. Limit Analysis and Concrete Plasticity, $2^{\text {nd }}$ edition. New York: CRC Press: 306-328.

Demers, C. 1998. Fatigue Strength Degradation of E-Glass FRP Composites and Carbon FRP Composites. Journal of Construction Building Materials, 12(5): 311-318.

Dolan, C. W., Rizkalla, S., and Nanni, A. 1999. Fourth International Symposium on Fiber Reinforced Polymer Reinforcement for Reinforced Concrete Structures, SP-188, American Concrete Institute, Farmington Hills, Mich., 1182 pp.

EC-02. 2002. Design of Concrete Structures Part I: General Rules and Rules for Buildings. European Committee for Standardization, Brussels.

Edalatmanesh, R., and Newhook, J.P. 2013. Investigation of Fatigue Damage in Steel-Free Bridge Decks with Application to Structural Monitoring. ACI Structural Journal, 110(4): 557564. 
Eder M.A., Vollum R.L., Elghazouli A.Y., and Abdel-Fattah T. 2010. Modelling and Experimental Assessment of Punching Shear in Flat Slabs with Shear Heads. Engineering Structure, 32(12): 3911-24.

El-Badry, M., Ed. 1996. Advanced Composite Materials in Bridges and Structures (ACMBS-II). Proceedings of the $2^{\text {nd }}$ International Conference, Montreal, Canada, $1027 \mathrm{pp}$.

El-Gamal, S., El-Salakawy, E., and Benmokrane, B. 2005. Behavior of Concrete Bridge Deck Slabs Reinforced with Fiber-Reinforced Polymer Bars under Concentrated Loads. ACI Structural Journal, 102(5): 727-735.

El-Ghandour, A.W., Pilakoutas K., and Waldron, P. 1999. New Approach for Punching Shear Capacity Prediction of Fiber Reinforced Polymer Reinforced Concrete Flat Slabs. Proceedings of the $4^{\text {th }}$ International Symposium on Fiber Reinforced Polymer Reinforcement for Reinforced Concrete Structures, SP-188, American Concrete Institute, Farmington Hills, MI: 135-144.

El-Ghandour, A.W., Pilakoutas. K., and Waldron, P. 2003. Punching Shear Behavior of Fiber Reinforced Polymers Reinforced Concrete Flat Slabs: Experimental Study. Journal of Composites for Construction, ASCE, 7(3): 258-265.

El-Ghandour, A.W., Pilakoutas, K., and Waldron, P. 2000. Punching Shear Behavior and Design of FRP RC Flat Slabs. In: Silfwerbrand J., Hassanzadeh G. editors. Proceedings of The International Workshop on Punching Shear Capacity of RC Slabs, Dedicated to Professor Sven Kinnunen. Stockholm, TRITA-BKN Bulletin 57: 359-366.

El-Ragaby, A., El-Salakawy, E., and Benmokrane, B. 2007. Fatigue Life Evaluation of Concrete Bridge Deck Slabs Reinforced with Glass FRP Composite Bars. Journal of Composites for Construction, 11(3): 258-268. 
El-Salakawy, E., Benmokrane, B., El-Ragaby, A., and Nadeau, D. 2005. Field Investigation on the First Bridge Deck Slab Reinforced with Glass FRP Bars Constructed in Canada. Journal of Composites for Construction, 9(6): 470-479.

Erberik, M.A., and Elnashai, A.S. 2004. Fragility Analysis of Flat-Slab Structures. Journal of Engineering Structures, 26(7): 937-948.

Fang, I., Lee, J., and Chen, C. 1994. Behavior of Partially Restrained Slabs under Concentrated Load. ACI Structural Journal, 91(2): 133-139.

Figueiras, J., Juvandes, L., and Furia, R., eds. 2001. Composites in Construction. Proceedings of the $2^{\text {nd }}$ International conference on Composites in Construction (CCC), Porto, Portugal.

Gayed, R.B., and Ghali, A. 2002. Double-Head Studs as Shear Reinforcement in Beams. Proceeding of the $4^{\text {th }}$ Structural Specialty Conference of the Canadian Society for Civil Engineering, Montréal, Québec, Canada: pp 1-10.

Gergely, J., Boyajian, D.M., Young, D.T., Frank, C.R., and Szabo, I.F. 2007. Analysis and Testing of a Bridge Deck Reinforced with GFRP Rebars. Technical Report Submitted to North Carolina Department of Transportation Research, Report No. FHWA/NC/2006-35.

Graddy, J., Kim, J., Whitt, J., Burns, N. and Klingner, R. 2002. Punching Shear Behavior of Bridge Decks under Fatigue Loading. ACI Structural Journal, 90(3): 257-266.

Hariatmadar, H. 1997. Seismic Response of Connections in Precast Concrete Double Tees. Ph.D. Dissertation, Department of Civil Engineering, McGill University, Canada.

Hegger, J., Ricker, M., Ulke, B., and Ziegler, M. 2007. Investigations on The Punching Behavior of Reinforced Concrete Footings. Engineering Structures, 29(9): 2233-2241.

Holman, J. 1982. Fatigue of Concrete By Constant and Variable-Amplitude Loading. Fatigue of Concrete Structures, SP-75, American Concrete Institute, Detroit. 
Hong, S., Chun, S., Lee, S., and Oh, B. 2007. Strut-and-Tie Model for Development of Headed Bars in Exterior Beam-Column Joint. ACI Structural Journal, 104(5): 590-600.

Hwan, H. 1986. Fatigue Analysis of Plain Concrete in Flexure. Journal of Structural Engineering, 112(2): 273-268.

Humar, J., and Razaqpur, G., Eeditors. 2000. Proceedings of the $3^{\text {rd }}$ International Conference on Advanced Composite Materials in Bridges and Structures, Canadian Society for Civil Engineering, Montreal, Canada.

Issa, M.A., Anderson, R., Domagalski, T., Asfour, S. and Islam, M.S. 2007. Full-Scale Testing of Prefabricated Full-Depth Precast Concrete Bridge Deck Panel System. ACI Structural Journal, 104(3): 324-332.

Iyer, S. L., and Sen, R. 1991. Advanced Composite Materials in Civil Engineering Structures. Proceedings of the Specialty Conference, American Society of Civil Engineers, New York, $443 \mathrm{pp}$.

Japan Society of Civil Engineers (JSCE), 1997a. Proceedings of the Third International Symposium on Non-Metallic (FRP) Reinforcement for Concrete Structures (FRPRCS-3), Japan Concrete Institute, Tokyo, Japan, 2: 511-518.

Japan Society of Civil Engineers (JSCE). 1997b. Recommendations for Design and Construction of Concrete Structures Using Continuous Fiber Reinforcing Materials. Concrete Engineering, Series 23, A. Machida, Ed., Tokyo, Japan, 167 pp.

Japan Society of Civil Engineers (JSCE). 1992. Subcommittee on Continuous Fiber

Reinforcement. Proceedings of the Utilization of FRP-Rods for Concrete Reinforcement, Japan Society of Civil Engineers, Tokyo, Japan, 314 pp.

Johansen, K.W. 1962. Yield-line theory. Cement and Concrete Association, London. 
Joint ACI-ASCE Committee 421. 2008. Guide to Shear Reinforcement for Slabs (ACI 421.1R08). American Concrete Institute, Farmington Hills, MI, 23 pp.

Joint ACI-ASCE Committee 352. 2002. Recommendations for Design of Beam-Column Connections in Monolithic Reinforced Concrete Structures (ACI 352R-02). American Concrete Institute, Farmington Hills, MI, 37 pp.

Kang, T.H.-K., Shin, M., Mitra, N. and Bonacci, J.F. 2009. Seismic Design of Reinforced Concrete Beam-Column Joints with Headed Bars. ACI Structural Journal, 106(6): 868-877.

Kang, T.H.-K., Ha, S. and Choi, D. 2010. Bar Pullout Tests and Seismic Tests of Small-Headed Bars in Beam-Column Joints. ACI Structural Journal, 107(1): 32-42.

Katz, A. 2000. Bond to Concrete of FRP Rebars After Cyclic Loading. Journal of Composites for Construction, 4(3): 137-144.

Khanna, O.S., Mufti, A.A. and Bakht, B. 2000. Experimental Investigation of The Role of Reinforcement on The Strength of Concrete Deck Slabs. Canadian Journal of Civil Engineering, 27: 475-480.

Klowak, C., Memon, A. and Mufti, A.A. 2007. Static and Fatigue Investigation of Innovative Second-Generation Steel-Free Bridge Decks. Canadian Journal of Civil Engineering, 34: 331339.

Kuang, J. and Morly, C. 1992. Punching Shear Behavior of Restrained Reinforced Concrete Slabs. ACI Journal, 89(1): 13-19.

Kumar, S. and GangaRao, H. 1998. Fatigue Response of Concrete Decks Reinforced with FRP Rebars. Journal of Structural Engineering, 124(1): 11-16.

Lee, J., Yoon, Y., Cook, W.D. and Mitchell, D. 2009. Improving Punching Shear Behavior of Glass Fiber-Reinforced Polymer Reinforced Slabs. ACI Structural Journal, 106(4): 427-434. 
Li, L., Ma, Z., Griffey M.E. and Oesterle, R.G. 2010a. Improved Longitudinal Joint Details in Decked Bulb Tees for Accelerated Bridge Construction: Concept Development, Journal of Bridge Engineering, ASCE, 15(3): 327-336.

Li, L., Ma, Z., Griffey M.E. and Oesterle R.G. 2010b. Improved Longitudinal Joint Details in Decked Bulb Tees for Accelerated Bridge Construction: Fatigue Evaluation, Journal of Bridge Engineering, ASCE , 15(5): 511-522.

Li, R., Cho, Y.S. and Zhang, S. 2007. Punching Shear Behavior of Concrete Flat Plate Slab Reinforced with Carbon Fiber Reinforced Polymer Rods. Composites: Part B 38: 712-719.

Liu, R. and Pantelides, C.P. 2012. Shear Capacity of Concrete Slabs Reinforced with GlassFiber-Reinforced Polymer Bars Using the Modified Compression Field Theory. PCI Journal, 57(3): 83-99.

Malvar, L. J. 1995. Tensile and Bond Properties of GFRP Reinforcing Bars. ACI Materials Journal, 92(3): 276-285.

Mander,T.J., Henley, M.D., Scott, M.R., Head, M.H., Mander, J.B. and Trejo, D. 2010. Experimental Performance of Full-Depth Precast, Prestressed Concrete Overhang, Bridge Deck Panels. Journal of Bridge Engineering, 15(5): 503-510.

Mander, T.J., Mander, J.B. and Head, M.H. 2011. Modified Yield Line Theory for Full-Depth Precast Concrete Bridge Deck Overhang Panels. Journal of Bridge Engineering, ASCE, 16(1): $12-20$.

Marinković S.B., and Aldendar V.H. 2008. Punching Failure Mechanism at Edge Columns of Post-Tensioned Lift Slabs. Engineering Structures, 30(10): 2752-2761.

Matthys S., and Taerwe L. 2000. Concrete Slabs Reinforced with FRP Grids. II: Punching Resistance. Journal of Composites for Construction, ASCE,4(3): 154-161. 
Matsui, S., Tokai, D., Higashiyama, H. and Mizukoshi, M. 2001. Fatigue Durability of FibreReinforced Concrete Decks Under Running Wheel Load. Proceedings of the $3^{\text {rd }}$ International Conference on Concrete Under Severe Conditions, University of British Columbia, Vancouver, Canada, pp 982-991.

Memon, A.H. 2005. Compressive Fatigue Performance of Steel Reinforced and Steel-Free Bridge Deck Slabs . PhD Thesis, Department of Civil Engineering, University of Manitoba, Wennipg, Canada, $125 \mathrm{p}$.

Miner, M. 1945. Cumulative Damage in Fatigue. ASME Trans. Journal of Applied. Mechanics, 67(9): 159-164.

Mufti, A., Jaeger, L., Bakht, B., and Wegner, L. 1993. Experimental Investigation of FRC Slabs without Internal Steel Reinforcement. Canadian Journal of Civil Engineering, 20(3): 398-406.

Mufti, A., Memon, A., Bakht, B., and Banthia, N. 2002. Fatigue Investigation of the Steel-Free Bridge Deck Slab. ACI International SP-206, American Concrete Institute, Farmington, Hills, Michigan, USA: 61-70.

Mufti, A.A., Onofrei, M., Benmokrane, B., Banthia, N., Boulfiza, M., Newhook, J.P., Bakht, B., Tadros, G., and Brett, P. 2005. Report on the Studies of GFRP Durability in Concrete from Field Demonstration Structures. Proceedings of Composites in Construction Conference (CCC 2005). Lyon, France

Mufti, A.A., and Newhook, J.P. 1998. Punching Shear Strength of Restrained Concrete Bridge Deck Slabs. ACI Structural Journal, 95(4): 375-381.

Muruts, M., and Nad, L. 1998. Laminated Glass Fiber Reinforced Plastic (GFRP) Bars in Concrete Structures. proceeding of the $2^{\text {nd }}$ International Ph.D. Symposium in Civil Engineering, Budapest, Slovakia. 
Nanni, A. 1993. Fiber-Reinforced-Plastic (FRP) Reinforcement for Concrete Structures: Properties and Applications. Developments in Civil Engineering, Elsevier, V. 42, 450 pp.

Nanni, A., and Dolan, C. W. 1993. Fiber-Reinforced-Plastic Reinforcement for Concrete Structures-International Symposium, SP-138, American Concrete Institute, Farmington Hills, Mich., 977 pp.

Neale, K.W., and Labossiere, P. 1992. Advanced Composite Materials in Bridges and Structures. Proceedings of the First International Conference (ACMBS-I), Sherbrooke, Canada, 705 pp.

Nielsen M.P. 1999. Limit Analysis and Concrete Plasticity. 2th ed. New York, CRC Press: 306328.

OAGO. 2009. Annual Report of the Office of the Auditor General of Ontario (OAGO). Chapter 3, section 3.02, Toronto, Ontario: $491 \mathrm{pp}$.

Oh, B.H. 1986. Fatigue Analysis of Plain Concrete in Flexure. Journal of Structural Engineering, 112(2): 273-288.

Ospina C.E, Alexander S.D.B., and Cheng J.J.R. 2003. Punching of Two-Way Concrete Slabs with Fiber-Reinforced Polymer Reinforcing Bars or Grids. ACI Structural Journal, 100(5): 589-598.

Ospina C.E. 2005. Alternative Model for Concentric Punching Capacity Evaluation of Reinforced Concrete Two-way Slabs. ACI Concrete International, 27(9): 53-57.

Pahn, M. 2008. Monitoring of Bond Tests and Pull-out Tests for ComBAR $\phi 16$ Provided with Headed Stud Connectors. Technical Report for SchÖck Bauteile GmbH, Technische Universität Kaiserslautern, Germany, 17 pp.

Park, H., Choi, K., and Chung, L. 2011. Strain-Based Strength Model for Direct Punching Shear of Interior Slab-Column Connections. Engineering Structures, 33(3): 1062-1073. 
Park H., Choi K., and Wight J.K. 2006. Strain-Based Shear Strength Model for Slender Beams without Web Reinforcement. ACI Structural Journal, 103(6): 783-793.

Perdikaris, P., and Beim, S. 1988. RC Bridge Decks under Pulsating and Moving Load. Journal of Structural Engineering, 114(3): 591-607.

Pincheira, J. A., Oliva, M. G. and Kusumo-Rahardjo, F. I., 1998. Tests on Double Tee Flange Connectors Subjected to Monotonic and Cyclic Loading. PCI Journal, 43(3): 82-96.

Rahman, A., Kingsly, C., and Kobayashi, K. 2000. Service and Ultimate Load Behavior of Bridge Deck Reinforced with Carbon FRP Grid. Journal of Composites for Construction, 4(1): 16-23.

Rankin, G.I.B. and Long, A.E. 1997. Arching Action Strength Enhancement in Laterally Restrained Slabs. Proceedings of the Institution of Civil Engineers, Structures and Buildings, 122: 461-467.

Rankin, G.I.B. and Long, A.E. 1987. Predicting the Punching Strength of Conventional SlabColumn Specimens. Proceedings of Institution of Civil Engineers, Part I, 82: 327-346.

RCCAO. 2007. Ontario's Bridges Bridging the Gap. Report Prepared by MMM Group for Infrastructure Investment Coalition (IIC) and Residential and Civil Construction Alliance of Ontario (RCCAO).

Ruiz M.F., and Muttoni A. 2009. Applications of Critical Shear Crack Theory to Punching of Reinforced Concrete Slabs with Transverse Reinforcement. ACI Structural Journal, 106(4): 485-94.

Saadatmanesh, H., and Ehsani, M. R., 1998. Fiber Composites in Infrastructure. Proceedings of the Second International Conference on Composites in Infrastructure (ICCI-98), Tucson, Arizona. 
Sen, R., Marsical, D., Issa, M., and Shahawy, M. 1993. Durability and Ductility of Advanced Composites. In Structural Engineering in Natural Hazards Mitigation, Proceedings of the 1993 Structures Congress, Irvine, Calif., Edited by A.H-S. Ang and R. Villaverde. American Society of Civil Engineers, New York, 2: 1373-1378.

Sen, R., Mullim, G. and Sale, T. 2002. Durability of E-Glass/Vinylester Reinforcement in Alkaline Solution. ASI Structural Journal, 99:369-375.

Sennah, K., Kianoush, R., Shah, B., Tu, S. and Al-Hashimy, M. 2004. Innovative Precast/Prestressed Concrete Bridge Systems and Connection Technology: Experimental Study. Report submitted to MTO Highway Infrastructure Innovation Funding Program, Ministry of Transportation of Ontario, $232 \mathrm{pp}$.

Shah, B., Sennah, K., Kianoush, R., Tu, S. and Lam, C. 2006. Flange-to-Flange Moment Connections for Precast Concrete Deck Bulb-Tee Bridge Girders. Journal of Prestressed Concrete Institute, PCI, 51(6): 86-107.

Shah, B., Sennah, K., Kianoush, R., Tu, S. and Lam, C. 2007. Experimental Study on Prefabricated Concrete Bridge Girder-to-Girder Intermittent-Bolted Connection Systems. ASCE journal of Bridge Engineering, 12(5): 570-584.

Silva, R.J.C., Regan, P.E., Melo G.S.S.A. 2007. Punching of Post-Tensioned Slabs-Tests and Codes. ACI Structural Journal, 104(1):123-32.

Sonoda, K., and Horikawa, T. 1982. Fatigue Strength of Reinforced Concrete Slabs under Moving Loads. Proceedings of the IABSE Colloquium on Fatigue of Steel and Concrete Structures, International Association for Bridges and Structural Engineering, Zurich, Switzerland: 455-462. 
Taerwe, L. 1995. Non-Metallic (FRP) Reinforcement for Concrete Structures. Proceedings of the

Second International RILEM Symposium on Non-Metallic (FRP) Reinforcement for Concrete Structures (FRPRCS-2), Ghent, Belgium, 714 pp.

Taylor, S. E., Rankin, B., Cleland, J. and Kirkpatrick, J. 2007. Serviceability of Bridge Deck Slabs with Arching Action. ACI Structural Journal, 104(1): 39-48.

Taylor, S. E., Rankin, G.I.B., and Cleland, D.J. 2001. Arching Action in High Strength Concrete Slabs. Proceedings of the Institution of Civil Engineers, Structures and Buildings, 146(4):353-362.

Teng, J.-G. 2001. FRP Composites in Civil Engineering. Proceedings CICE 2001, Hong Kong, China, V. 1 and 2.

Theodorakopoulos, D.D. and Swamy, R.N. 2008. A Design Model for Punching Shear of FRPReinforced Slab-Column Connections. Cement \& Concrete Composites, 30: 544-555.

Thompson, M.K., Ledesma, A., Jirsa, J.O., and Breen, J.E. 2006. Lap Splices Anchored by Headed Bars, ACI Structural Journal, 103(2): 271-279.

Thompson, M.K., Jirsa, J.O. and Breen, J.E. 2006. Behavior and Capacity of Headed Reinforcement, ACI Structural Journal, 103(4): 522-530.

Tilly, G., and Moss, D. 1982. Long Endurance Fatigue of Steel Reinforcement. Proceedings of IABSE Colloquium on Fatigue of Steel and Concrete Structures, International Association for Bridges and Structural Engineering, Zurich, Switzerland: 229-238.

Tomosawa F., and Nakatsuji T. 1997. Evaluation of ACM Reinforcement Durability by Exposure Test. Proceedings of $3^{\text {rd }}$ International Symposium on Non-Metallic (FRP) Reinforcement for Concrete Structures, Sapporo, 2: 139-146. 
Tureyen, A.K. and Frosch, R.J. 2003. Concrete Shear Strength: Another Perspective. ACI Structural Journal, 100(5): 609-615.

Uomoto, T. 2000. Durability of FRP as Reinforcement for Concrete Structures. Advanced Composite Materials in Bridges and Structures, $3^{\text {rd }}$ International Conference, Ottawa, Ontario, Canada: 3-17.

Vijay, P. V. 1999. Aging and Design of Concrete Members Reinforced with GFRP Bars. Ph.D. Dissertation, Department of Civil Engineering at West Virginia, West Virginia.

White, T.D. 1992. Composite Materials and Structural Plastics in Civil Engineering Construction. Proceedings of the Materials Engineering Congress, American Society of Civil Engineers, New York: 532-718.

Yamane, T., Tadros, M. K., Badie, S. S. and Baishya, M. C. 1998. Full Depth Precast, Prestressed Concrete Bridge Deck System. PCI Journal, 43(3): 50-66.

Youn, S.G. and Chang, S.P. 1998. Behaviour of Composite Bridge Decks Subjected to Static and Fatigue Loading. ACI Structural Journal, 95(3): 249-258.

Zhu, P. and Ma, Z.J. 2010. Selection of Durable Closure Pour Materials for Accelerated Bridge Construction. Journal of Bridge Engineering, 15(6): 695-704. 